\title{
TOWARDS THE SYNTHESIS OF HYBRID PELORUSIDE A AND LAULIMALIDE ANALOGUES
}

By

Febly Tho

\author{
A thesis \\ Submitted to Victoria University of Wellington \\ In partial fulfilment of the requirements for the degree of \\ Masters \\ in Biomedical Sciences
}

Victoria University of Wellington

2010 


\section{Abstract}

(+)-Peloruside A is a novel cytotoxic marine natural product isolated from the New Zealand sponge Mycale hentscheli. ${ }^{42}$ Peloruside A is a potential anticancer agent that has a similar mode of action to that of the successful drug paclitaxel. Biological analysis indicated that (+)-peloruside A promotes tubulin hyperassembly and cellular microtubule stabilisation which lead to mitosis blockage in the $\mathrm{G}_{2} / \mathrm{M}$ phase of the cell cycle and consequent cell apoptosis. ${ }^{43,47}$ (-)-Laulimalide is also a cytotoxic natural product with microtubule stabilising bioactivity, and is a potential anticancer agent. ${ }^{47}$ Biological analysis showed that (+)-peloruside A and (-)-laulimalide are competitive, suggesting that they bind to the same active site. ${ }^{47}$ (+)-Peloruside $\mathrm{A}$ and (-)laulimalide also display synergy with taxoids. ${ }^{47}$

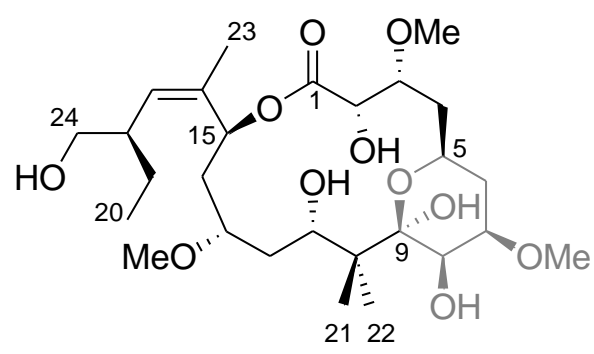

(+)-Peloruside A

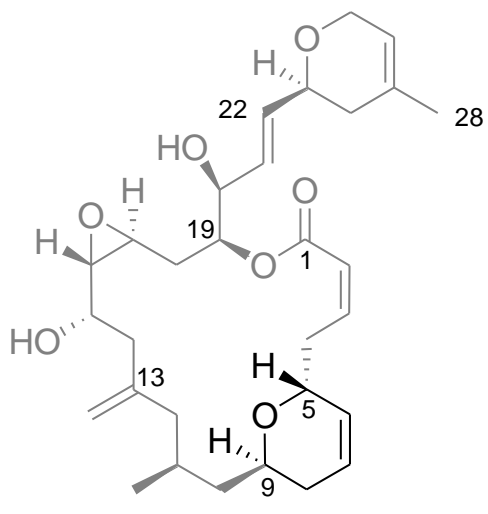

(-)-Laulimalide

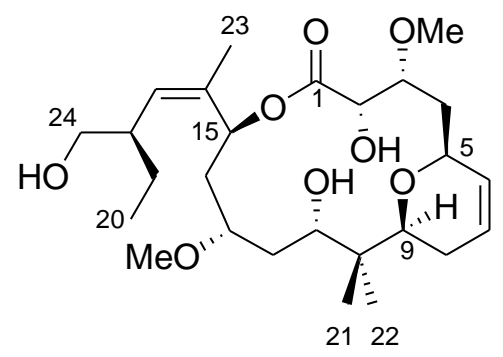

Analogue 151

Due to the structural complexity of peloruside A, our research has focused on developing an analogue 151 for ease of synthesis. Thus, the simplified $C_{5}-C_{9}$ dihydropyran moiety of (-)-laulimalide, with fewer stereocentres than that of (+)peloruside $\mathrm{A}$, has been incorporated into analogue 151 whilst retaining the 16- 
membered ring backbone of (+)-peloruside A. The proposed synthesis of 151 involves a Yamaguchi macrolactonization, a 1,5-anti-aldol coupling, and a ring closing metathesis as key reactions. This thesis reports on the synthesis of key fragments of analogue 151 and the crucial 1,5-anti-aldol coupling reaction for the assembly of the carbon backbone. 


\section{Acknowledgement}

I would like to thank all of those without whom this thesis will never be written. First and foremost, I want to thank my supervisors Dr. Joanne Harvey and Assoc. Prof. Paul Teesdale-Spittle for generously sharing their knowledge to guide me through this process. They have been a source of inspiration. They have provided me with support, encouragement, understanding, and advice for which I am very grateful. I also wish to thank Dr. Peter Northcote for his assistance in interpretation of the spectral data and Prof. John Miller for the provision of confocal images.

I would also like to thank my family, especially my mother and father for their unfailing support, encouragement, and love. They have been my pillar of strength, a source of comfort, and a safe heaven throughout this time. I also want to thank my sister and best friend for always eagerly lending me her time and ears whenever I need a shoulder to cry on and someone to rant at.

I would like to express my gratitude towards all my fellow lab-mates for the time spent and the knowledge shared in discussion on chemistry, for making chemistry that much more fun than it already is, and most importantly for being good friends and understanding lab-fellows. I also want to thank my fellow fumehood-mates for putting up with my selfishness and allowing me to have free reign of the space most of the time.

I would like to thank Dr. Russell Hewitt for generously giving his time to proofread and providing me with advice for this thesis and for the countless daily assistance in the lab. I would also like to thank everyone that had offered their assistance to proofread this thesis, some of which I was regretfully unable to take advantage of because of time constraint.

I also wish to thanks all my friends, especially Sotinea and Stephanie for always looking out for me. They have been a source of fun distraction when studying became too overwhelming. 
Finally, I would like to thank Victoria University of Wellington, especially everyone at the School of Physical and Chemical Sciences and the School of Biological Sciences for making this time an enjoyable and memorable experience. I wish to express my deepest and sincerest gratitude to all of these people. 


\section{Table of contents}

Abstract 2

Acknowledgement 4

Table of contents $\quad 6$

$\begin{array}{lr}\text { List of figures, schemes and tables } & 8\end{array}$

$\begin{array}{ll}\text { Abbreviations } & 11\end{array}$

1 Introduction 12

1.1 The impact of cancer in modern society 12

1.2 Treatments for cancer 16

$\begin{array}{lll}1.3 & \text { The cell cycle } & 20\end{array}$

1.4 Microtubules as targets in cancer treatment 22

1.5 Anticancer agents targeting microtubules 24

1.5.1 Microtubule stabilising agents 24

$\begin{array}{ll}\text { 1.5.2 Microtubule destabilising agents } & 27\end{array}$

1.6 Anticancer agents from marine sources 29

1.7 Peloruside A 33

1.7.1 Biological activity of peloruside A 34

1.7.2 Synthesis of peloruside A 35

1.7.2.1 Synthesis of (-)-peloruside A by De Brabander 37

1.7.2.2 Synthesis of (+)-peloruside A by Jin and Taylor $\quad 40$

1.7.2.3 Synthesis of (+)-peloruside A by Ghosh 42

1.7.2.4 Synthesis of (+)-peloruside A by Evans 45

1.7.3 Peloruside A analogues 48

1.7.3.1 (-)-2-epi-peloruside A 49

1.7.3.2 Monocyclic peloruside A analogue 52

$\begin{array}{lll}\text { 1.7.3.3 Peloruside B } & 54\end{array}$

$\begin{array}{lll}1.8 & \text { Laulimalide } & 57\end{array}$

1.8.1 Biological activity of laulimalide $\quad 58$

1.8.2 Synthesis of laulimalide $\quad 58$

2 Objectives and strategies $\quad 66$

2.1 The research aim 66

$\begin{array}{lll}2.2 & \text { Retrosynthetic strategy } & 68\end{array}$ 
2.3 Research precedence

$\begin{array}{lll}2.4 & \text { The research objectives } & 71\end{array}$

3 Results and discussion $\quad 72$

3.1 Synthesis of $\mathrm{C}_{1}-\mathrm{C}_{11}$

3.1.1 Synthesis of the $\mathrm{C}_{1}-\mathrm{C}_{2}$ synthon $\quad 72$

3.1.2 Synthesis of the $\mathrm{C}_{3}-\mathrm{C}_{11}$ synthon 73

3.1.3 Aldol coupling of the $\mathrm{C}_{1}-\mathrm{C}_{2}$ and $\mathrm{C}_{3}-\mathrm{C}_{11}$ fragments 75

$\begin{array}{lll}3.2 & \text { Synthesis of } \mathrm{C}_{12}-\mathrm{C}_{24} & 78\end{array}$

3.2.1 Synthesis of the $\mathrm{C}_{12}-\mathrm{C}_{16}$ synthon $\quad 78$

3.2.2 Synthesis of the $\mathrm{C}_{17}-\mathrm{C}_{24}$ synthon $\quad 79$

3.2.3 Double-silylation reaction to form silyl bis-ether $\mathbf{1 7 9} 80$

3.2.4 Ring closing metathesis reaction $\quad 81$

3.3 Attempts to synthesise $\mathrm{C}_{1}-\mathrm{C}_{24}$ by aldol reaction 89

$\begin{array}{lll}3.4 & \text { Synthesis of other analogues } & 100\end{array}$

$\begin{array}{lll}3.5 & \text { Evaluation of the synthesis strategy } & 104\end{array}$

$\begin{array}{ll}3.6 \text { Conclusion } & 105\end{array}$

4 Future work 107

5 Experimental methods 109

$\begin{array}{ll}\text { References } & 134\end{array}$ 


\section{List of figures, schemes, and tables}

Figure

Figure 1.1 Topoisomerase inhibitors.

Figure 1.2 Vorinostat, an inhibitor of histone deacetylases.

Figure 1.3 Ansamysin and tanespimycin, inhibitors of Hsp90.

Figure 1.4 Proteasome inhibitors.

Figure 1.5 The basis of cancer immunotherapy.

Figure 1.6 The cell cycle.

Figure 1.7 Structure of a microtubule.

Figure $1.8 \quad$ Microtubule treadmilling.

Figure 1.9 Taxanes.

Figure 1.10 Epothilones and synthetic analogues.

Figure 1.11 Vinca alkaloids 28

Figure 1.12 Colchicine. 28

Figure 1.13 Combretastatins and derivatives.

Figure 1.14 Discodermolide.

Figure 1.15 Dolastatin 10 and its derivatives.

Figure 1.16 Halichondrin B and analogues. 32

Figure 1.17 Zampanolide.

Figure 1.18 The naturally occurring members of the peloruside family.

Figure $1.19 \alpha$-Tubulin antibody staining of microtubules in 1A9 ovarian cancer cells.

Figure 1.20 Synthetic and semisynthetic variants of (+)-peloruside A. 36

$\begin{array}{lll}\text { Figure 1.21 Laulimalide family. } & 57\end{array}$

Figure 1.22 Several analogues of laulimalide. 65

$\begin{array}{lll}\text { Figure 2.1 The proposed hybrid peloruside-laulimalide analogue. } & 66\end{array}$

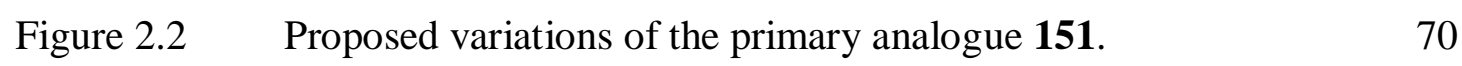

\section{Scheme}

Scheme 1.1 The semisynthetic route to paclitaxel from 10deacetylbaccatin III and protected $\beta$-lactam. 
Scheme 1.2 Synthetic route to (-)-peloruside A by De Brabander.

Scheme 1.3 Synthetic route to (+)-peloruside A by Jin and Taylor.

Scheme 1.4 Synthetic route to (+)-peloruside A by Ghosh.

Scheme 1.5 Synthetic route to (+)-peloruside A by Evans.

Scheme 1.6 Synthetic route to (-)-2-epi-peloruside A by Smith.

Scheme 1.7 Synthetic route to monocyclic peloruside A analogue by Wullschleger.

Scheme 1.8 Synthetic route to peloruside B by Ghosh.

Scheme 1.9 Synthetic route to (-)-laulimalide by Ghosh.

Scheme 2.1 Proposed retrosynthesis for the hybrid peloruside-laulimalide analogue 151.

Scheme 3.1 Retrosynthesis of $\mathrm{C}_{1}-\mathrm{C}_{11}$ segment 172.

$\begin{array}{lll}\text { Scheme } 3.2 & \text { Synthesis of } \mathrm{C}_{1}-\mathrm{C}_{2} \text { synthon. } & 73\end{array}$

$\begin{array}{lll}\text { Scheme } 3.3 & \text { Synthesis of } \mathrm{C}_{3}-\mathrm{C}_{11} \text { synthon. } & 74\end{array}$

Scheme 3.4 Completion of $\mathrm{C}_{1}-\mathrm{C}_{11}$ synthon. 76

$\begin{array}{lll}\text { Scheme 3.5 Retrosynthesis of } \mathrm{C}_{12}-\mathrm{C}_{24} \text { synthon. } & 78\end{array}$

$\begin{array}{lll}\text { Scheme 3.6 Synthesis of } \mathrm{C}_{12}-\mathrm{C}_{16} \text { synthon. } & 79\end{array}$

Scheme 3.7 Synthesis of $\mathrm{C}_{17}-\mathrm{C}_{24}$ synthon. 80

Scheme 3.8 Hydrolysis of dichlorodiphenylsilane to chlorodiphenylsilanol and diphenylsilanediol. $\quad 80$

Scheme 3.9 Formation of bis-homoallylic alcohol 203. 81

Scheme 3.10 The cross-metathesis products of diene 179.

Scheme 3.11 Proposed mechanism of formation for the observed RCM $\begin{array}{ll}\text { products. } & 88\end{array}$

Scheme 3.12 Attempted aldol reaction of the ketone $\mathbf{1 8 0}$ and aldehyde $\mathbf{1 7 2 .} 89$

Scheme 3.13 Synthesis of the aldehyde 175. 90

Scheme 3.14 Attempted aldol reaction of the ketone $\mathbf{1 8 0}$ and aldehyde 175.91

Scheme 3.15 Evans' aldol reaction between $\mathrm{C}_{1}-\mathrm{C}_{11}$ with $\mathrm{C}_{12}-\mathrm{C}_{24}$ using 9-BBNOTf. 91

Scheme 3.16 Attempted aldol reaction of the ketone $\mathbf{1 8 0}$ and aldehyde $\mathbf{1 7 5 .} 91$

Scheme 3.17 Synthesis of the aldehyde 182. 92

Scheme 3.18 Aldol coupling of the aldehyde 182 and the ketone 180 using DIPEA as base. 
Scheme 3.19 Proposed mechanism for the formation of the alcohol $\mathbf{1 8 1}$ by Cannizzaro reaction.

Scheme 3.20 Proposed mechanism to cyclic lactone 220.

Scheme 3.21 Study of the aldehyde $\mathbf{1 8 2}$ with two equivalents of TEA and $\mathrm{Bu}_{2}$ BOTf.

Scheme 3.22 The synthesis of precursor to analogue 152.

Scheme 3.23 Substitution of $\alpha, \beta$-unsaturated pyran ring.

Scheme 3.24 Proposed mechanism for the formation of 4,4-dimethyl-2,9dioxa-bicyclo[3.3.1] nonane 226.

Scheme 3.25 Interception of an oxonium intermediate by an internal silyloxy nucleophile by Batchelor.

Scheme 3.26 The attempted synthesis of precursor to analogue 154. 102

Scheme 3.27 The synthesis of precursor to analogue $\mathbf{1 5 5 .} 103$

Scheme 4.1 Alternative retrosynthesis for analogue 151.

Scheme 4.2 Alternative route for installation of the $\mathrm{C}_{10}$ gem-dimethyl group.

Table

Table 3.1 Methylation of $\mathrm{C}_{3}$ hydroxyl.

Table 3.2 Spectroscopic evidence for the cross-metathesised diene product 210.

Table 3.3 Spectroscopic evidence for the side-product 212.

Table $3.4 \quad$ Spectroscopic evidence for the side-product 215.

Table 3.5 Spectroscopic evidence for the bicyclic lactone 220. 94

Table 3.6 Determination of compound 221. 97

Table 3.7 Determination of compound 222. 99 


\section{Abbreviations}

Ac

$\mathrm{AcOH}$

BAIB

9-BBNOTf

BINOL

$\mathrm{Bn}$

Boc-ON

BOM

BPS

$\mathrm{Bu}_{2} \mathrm{BOTf}$

BuLi

CBS

COSY

CSA

Cy

DCM

DDQ

(+)-DET

DIBAL-H

DIPEA

DMAP

DMF

DMP

DMSO

$\mathrm{dr}$

EBTHI

ee

Et

$\mathrm{Et}_{2} \mathrm{BuOTf}$

$\mathrm{Et}_{2} \mathrm{O}$

EtOAc
Acetyl

Acetic acid

(Bisacetoxyiodo)benzene

9-Borabicyclo[3.3.1]nonyl trifluoromethanesulfonate

1,1-Binaphthol

Benzyl

2-(tert-Butoxycarbonyloxyimino)-2-phenylacetonitrile

Benzyloxymethyl

tert-Butyldiphenylsilyl

Dibutylboryl trifluoromethanesulfonate

Butyllithium

Corey-Bakshi-Shibata

Correlation spectroscopy

(1S)-(+)-10-Camphorsulfonic acid

Cyclopentadienyl

Dichloromethane

2,3-Dichloro-5,6-dicyanobenzoquinone

(+)-Diethyl tartrate

Diisobutylaluminium hydride

$N, N$-Diisopropylethylamine

$N, N$-Dimethyl-4-aminopyridine

$N, N$-Dimethylformamide

2,2-Dimethoxypropane

Dimethylsulfoxide

diastereomeric ratio

ethylenebis(4,5,6,7-tetrahydro-1-indenyl)

enantiomeric excess

Ethyl

Diethylboryl trifluoromethanesulfonate

Diethyl ether

Ethyl acetate 


\begin{tabular}{|c|c|}
\hline EtOH & Ethanol \\
\hline GC-MS & Gas chromatography-mass spectrometry \\
\hline HBTU & $\begin{array}{l}N, N, N^{\prime}, N^{\prime} \text {-Tetramethyl- } O \text { - }(1 H \text {-benzotriazol-1-yl)uronium } \\
\text { hexafluorophosphate }\end{array}$ \\
\hline HMBC & Heteronuclear Multiple Bond Coherence \\
\hline HMPA & Hexamethylphosphoramide \\
\hline HOTf & Trifluoromethanesulfonic acid \\
\hline HRMS & High resolution mass spectrometry \\
\hline HSQC & Heteronuclear Single Quantum Coherence \\
\hline HWE & Horner-Wadsworth-Emmons \\
\hline $\mathrm{IC}_{50}$ & Half maximal inhibitory concentration \\
\hline Ipc & Isopinocamphenyl \\
\hline IR & Infrared Spectroscopy \\
\hline KHMDS & Potassium hexamethyldisilazide \\
\hline LAH & Lithium aluminium hydride \\
\hline LDA & Lithium diisopropylamide \\
\hline LiHMDS & Lithium hexamethyldisilazide \\
\hline$m \mathrm{CPBA}$ & $m$-Chloroperbenzoic acid \\
\hline $\mathrm{Me}$ & Methyl \\
\hline $\mathrm{MeCN}$ & Acetonitrile \\
\hline $\mathrm{MeOH}$ & Methanol \\
\hline $\min$ & Minute(s) \\
\hline MOM & Methoxymethyl \\
\hline $\mathrm{MsCl}$ & Methanesulfonyl chloride \\
\hline NIS & $N$-Iodosuccinimide \\
\hline NMO & $N$-oxide-4-methylmorpholine \\
\hline NMP & $N$-Methyl-2-pyrrolidone \\
\hline NMR & Nuclear Magnetic Resonance \\
\hline nOe & nuclear Overhauser effect \\
\hline PADA & 4-(Phenylazo)diphenylamine \\
\hline $\mathrm{Ph}$ & Phenyl \\
\hline PMB & $p$-Methoxybenzyl \\
\hline $\mathrm{PPh}_{3}$ & Triphenylphosphine \\
\hline PPTS & Pyridinium $p$-toluenesulfonate \\
\hline
\end{tabular}


PTSA $\quad p$-Toluenesulfonic acid

RCM Ring closing metathesis

RT Room Temperature

SEM [2-(Trimethylsilyl)ethoxy]methyl

TBAF Tetra- $N$-butylammonium fluoride

TBAI Tetra- $N$-butylammonium iodide

TBS tert-Butyldimethylsilyl

TBSOTf tert-Butyldimethylsilyl trifluoromethanesulfonate

$t \mathrm{Bu} \quad$ tert-Butyl

TEA Triethylamine

TEMPO 2,2,6,6-Tetramethylpiperidine-1-oxyl

TES Triethyl silyl

TESOTf Triethyl silyl trifluoromethanesulfonate

TFA Trifluoroacetic acid

THF Tetrahydrofuran

THP Tetrahydropyranyl

TIPS Triisopropylsilyl

TLC Thin layer chromatography

TMS Trimethylsilyl

TPAP Tetra- $N$-propylammoniun perruthenate

Ts $\quad p$-Toluenesulfonyl 


\section{Chapter 1 - Introduction}

\subsection{The impact of cancer in modern society}

Cancer is an ailment that has afflicted humans throughout history. Evidence of the existence of cancerous growth was found in fossils, mummies, and ancient manuscripts. ${ }^{1}$ In today's medically advanced society, cancer has become one of the leading causes of death. Cancer accounted for $12 \%$ of all deaths worldwide in 2000 with fatality reported at 6.2 million. $^{2}$ Furthermore, the total number of cancer cases worldwide and cancer related the mortality rate is expected to increase. ${ }^{3}$

Cancer imposes a huge burden of individual suffering on the patients and their families. Furthermore, the "epidemic" of cancer is also an enormous financial drain on economic resources. The estimated overall cost of the cancer in the United States for 2002 only, was approximately $\$ 171.6$ billion. ${ }^{1}$ The scale of this cancer "epidemic" causes a large strain on healthcare systems. Of the estimated 2002 cost, $\$ 60.9$ billion was for direct medical costs. ${ }^{1}$ Governments and private agencies alike are putting large amounts of resources into helping cancer patients, as well as developing more effective treatments for the disease.

Human knowledge regarding cancer has advanced tremendously in the past decades. However, despite the effort, dedication and resources poured into understanding the nature of cancer, the magic bullet remains elusive. The search for a single effective treatment of cancer might not be forthcoming in any foreseeable future because of the diversity of the disease. Cancer is caused by uncontrolled proliferation of abnormal cells, leading to fatal results. ${ }^{4}$ There are more than one hundred known types of cancer. Cancerous cells can affect any organ and bodily component at any location. However, the lung, intestine, pancreas, liver, breast, prostate, bladder, bone and blood cells are the most common areas inflicted by cancerous cells. ${ }^{4}$

Most cancers arise from changes in cellular DNA (deoxyribonucleic acid). Such changes might be the results of exposure to ultraviolet radiation, production of abnormal diseased cells, or damage to the immune system. Reactive chemicals can 
cause inflammation and abnormal metabolism that lead to DNA damage. Changes in DNA as the result of errors in the reading, translation, or replication processes can also lead to the production of damaged DNA.

Generally, the causes of cancer have been blamed on factors such as lifestyle, carcinogens, hormones, viral infection, and genetic predisposition. Lifestyle, including diet, is believed to have a great impact on a person's predisposition towards developing certain types of cancer. A diet that is high in fat content but low in fibre intake is known to induce liver, stomach, endometrium and bowel cancers. ${ }^{4}$ Similarly, a diet that contain mostly grilled and fried food can also promote the development of liver, stomach, endometrium and bowel cancers. ${ }^{4}$ Studies have found that the intake of processed meat and meat cooked at high temperature increases the risk of colon cancer. $^{5}$

Smoking and alcohol consumption have long been established as leading causes of cancer. It is widely known that heavy smokers tend to develop lung, mouth, oesophagus, and stomach cancers. ${ }^{6}$ Excessive alcohol intake has also been associated with the development of mouth, oesophagus, stomach, and liver cancers. ${ }^{4,7}$ Prolonged exposure to ultraviolet radiation from the sun on unprotected skin is attributed to the development of skin melanoma. ${ }^{8}$

Exposure to carcinogenic and toxic chemicals such as polycyclic aromatics, asbestos, azo dyes, and pesticides has been proven to increase the chance of cancer development. ${ }^{4,7}$ Breast cancer and prostate cancer have been associated with exposure to high levels of hormones. Repeated exposure to high concentrations of oestrogen from hormone replacement therapy and fertility drugs may increase the likelihood of ovarian and breast cancer development in females. ${ }^{4,} 7$ In men, repeated exposure to high concentration of testosterone from hormone replacement therapy can cause prostate cancer. $^{4}$

Studies have also shown that certain types of cancer are caused by viral infection. Hepatitis B virus has the potential to induce hepatocellular carcinoma. ${ }^{9}$ Human papilloma virus is known to be the cause of cervical cancer. ${ }^{7}$ Burkitt's lymphoma is cancer caused by untreated infection of Epstein-Barr virus. ${ }^{4}$ Furthermore, some 
individuals might also have genetic predispositions towards developing certain types of cancers. ${ }^{10}$

\subsection{Treatments for cancer}

The main goal of a successful cancer treatment is the total eradication of cancer cells. The reason that total eradication is essential is because cancerous cells replicate in an uncontrolled fashion. If a gram of cancerous tissue contains ten thousand cells and only a hundred cells survive the treatment, these remaining cells will still be able to reform the cancerous tissue. ${ }^{4}$ Furthermore, there is also the possibility that the cells that developed from the surviving cancer cells will be resistant to, and therefore unaffected by, the previously applied cancer therapy.

Most cancerous cells form benign tumours, which are relatively harmless if treatment is applied early. However, an untreated tumour can became unconstrained and progress into a malignant, invasive cancer. Aside from the difficulty of treating a large tumour effectively, unconstrained cancer cells can also spread throughout the body, producing a secondary metastatic cancer in organs other than the original cancer site. Metastasis is estimated to be the cause of more than $90 \%$ of all cancer related deaths. ${ }^{11}$ Invasive cancer cells can spread by invading the tissues surrounding the original cancerous site or by travelling through blood vessels and lymphatic systems to a remote metastasis site. ${ }^{4,11}$

The cancer therapies that are currently used to manage tumours usually involve combination of two or more different treatments. Most patients will have surgery to remove the majority of the cancerous tissue, with chemotherapy and radiation therapy used to kill the remaining cancer cells. ${ }^{8}$ Chemotherapeutic drugs that are currently used for clinical treatment can be categorised based on their mode of action. These anticancer agents target a wide number of cell survival mechanisms. Chemotherapeutic drugs include tubulin interactive agents, actin active agents, inhibitors of topoisomerases, inhibitors of histone deacetylases, inhibitors of Hsp90 (heat shock protein 90), proteasome inhibitors, protein kinase inhibitors, inhibitors of hypoxia inducible factor, caspase activating and apoptosis inducing agents, inhibitors 
of DNA polymerase, actin interactive agents, and telomerase inhibitors. ${ }^{11,12}$ Most of the clinical drugs used for cancer chemotherapy target the cell cycle, resulting in the prevention of cell proliferation and therefore the death of the cancerous cells.

Tubulin interactive agents promote polymerisation or depolymerisation of tubulin heterodimers. The consequent disruption of microtubule dynamics leads to mitotic arrest and eventual cell death. Tubulin interactive agents such as the taxanes and epothilones are clinically used as promoter of tubulin polymerisation, while discodermolide, peloruside, and laulimalide are currently under development as potential anticancer drugs. Tubulin interactive agents that inhibit tubulin polymerisation include the vinca alkaloids, dolastatins, and halichondrins.

Actin is another cytoskeletal component with important roles in the maintainance of the cellular cytoskeleton and interacts with the microtubule network during cell division. Therefore, disruption of actin filaments by actin active agents such as latrunculins can lead to cell death. ${ }^{11}$

Inhibitors of topoisomerases can be divided into inhibitors of topoisomerase I, inhibitors of topoisomerase II, and dual topoisomerase inhibitors. Topoisomerases are enzymes that release torsional constraints on the DNA double helix during transcription, replication, or repair processes. Topoisomerases create a restorable local strand break through formation of a complex with the DNA strand. ${ }^{13}$ Topoisomerase I inhibitors such as camptothecin (Figure 1.1) and its derivatives stabilise the DNAtopoisomerase I complexes and prevent re-ligation of strand breaks leading to cell death. $^{12,13}$ Anthracyclines (Figure 1.1) and their derivatives are inhibitors of topoisomerise II. ${ }^{12}$ Derivatives of the protein kinase inhibitor staurosporine (Figure 1.1) are examples of dual topoisomerise inhibitors. ${ }^{12}$ 
Figure 1.1 Topoisomerase inhibitors.<smiles>CC[C@@]1(O)C(=O)OCc2c1cc1n(c2=O)Cc2cc3ccccc3nc2-1</smiles>

Camptothecin<smiles>[R2]C(=O)[C@]1(O)Cc2c(O)c3c(c(O)c2[C@@H](O[C@H]2C[C@H](N)[C@@H](O)[C@H](C)O2)[C@H]1[3H])C(=O)c1c([R2])cccc1C3=O</smiles><smiles>CN[C@H]1C[C@H](OC)[C@]2(C)O[C@]1(C)n1c3ccccc3c3c4c(c5c6ccccc6n2c5c31)C(=O)NC4</smiles>

Staurosporine

\begin{tabular}{ccc} 
Anthracyclines & $\mathbf{R}_{\mathbf{1}}$ & $\mathbf{R}_{\mathbf{2}}$ \\
\hline Doxorubicin & $\mathrm{CH}_{2} \mathrm{OH}$ & $\mathrm{OCH}_{3}$ \\
Daunorubucin & $\mathrm{CH}_{3}$ & $\mathrm{OCH}_{3}$ \\
Idarubicin & $\mathrm{H}$ & $\mathrm{H}$
\end{tabular}

Histone deacetylases are a group of proteins that remove acetyl groups from the Nterminus of acetylated histones during gene expression. ${ }^{14}$ Inhibitors of histone deacetylases are designed to interfere with the catalytic domain of histone deacetylase. ${ }^{14}$ Inhibitors of histone deacetylases block substrate recognition that leads to induction of gene expression resulting in apoptosis. Vorinostat (Figure 1.2) is a histone deacetylase inhibitor that has been approved by the FDA (Food and Drug Administration) for treatment of cutaneous T-cell lymphoma. ${ }^{14}$

Figure 1.2 Vorinostat, an inhibitor of histone deacetylases.<smiles>O=C(CCCCCCC(=O)Nc1ccccc1)NO</smiles> 
Hsp90 is a chaperone protein that maintains the proper functioning of many cell signalling proteins. ${ }^{12}$ Therefore, Hsp90 is very important for the survival of cancerous, as well as normal, cells. Inhibiton of Hsp90 will eventually leads to cellular destruction. Ansamysin (Figure 1.3) and its derivative, tanespimycin, are examples of anticancer agents that act as inhibitors of Hsp90. ${ }^{12}$

Figure 1.3 Ansamysin and tanespimycin, inhibitors of Hsp90.

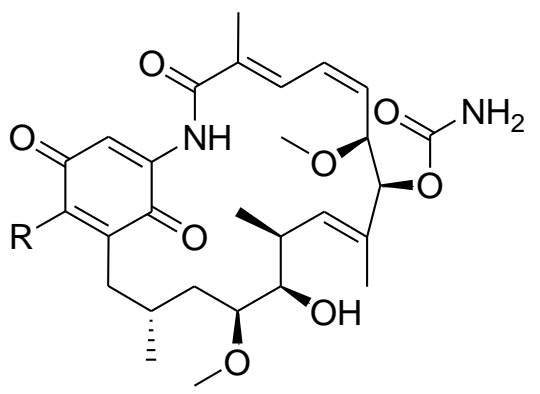

Ansamycin $\mathrm{R}=\mathrm{OCH}_{3}$

Tanespimycin $\mathrm{R}=\mathrm{NHCH}=\mathrm{CH}_{2}$

The proteasome is a multi-enzyme complex that controls the progression of the cell cycle and signal transduction cascade termination. ${ }^{12}$ The proteasome is also responsible for the removal of damaged, mutated, and misfolded proteins. Salinosporamide A, epoxomicin, and eponemycin (Figure 1.4) are examples of natural microbacterial metabolites that exhibit cytotoxic activities through inhibition of the proteasome. ${ }^{12}$

Figure 1.4 Proteasome inhibitors.<smiles>C[C@@]12NC(=O)[C@H](CCCl)[C@@H]1C(=O)O2</smiles>

Salinosporamide A<smiles>CC[C@H](C)[C@H](NC(C)=O)C(=O)N[C@H](C(=O)N[C@H](C(=O)N[C@@H](CC(C)C)C(=O)CC1CO1)[C@H](C)O)[C@@H](C)CC</smiles>

Epoxomicin<smiles>CC(C)CCCCC(=O)N[C@@H](CO)C(=O)N[C@@H](CC(C)C)C(=O)C[C@@]1(CO)CO1</smiles>

Eponemycin 
Recently, immunotherapy has been developed as an alternative option for cancer management and treatment. This utilises antigen specific T-cell responses to combat the cancer cells (Figure 1.5). Cancer vaccines containing antigens specific to the cancerous cells enhance the number of immune T-cells in the body. ${ }^{15}$ The antigens present in cancer vaccines trigger a recognition response by $\mathrm{T}$-cells. The T-cells will then proliferate, infiltrate and kill the tumour tissues that carry the specific antigens. ${ }^{15}$ The advantage of immunotherapy for cancer management is that it can be tailored to give the most effective results for an individual. ${ }^{15}$

Figure 1.5 The basis of cancer immunotherapy.

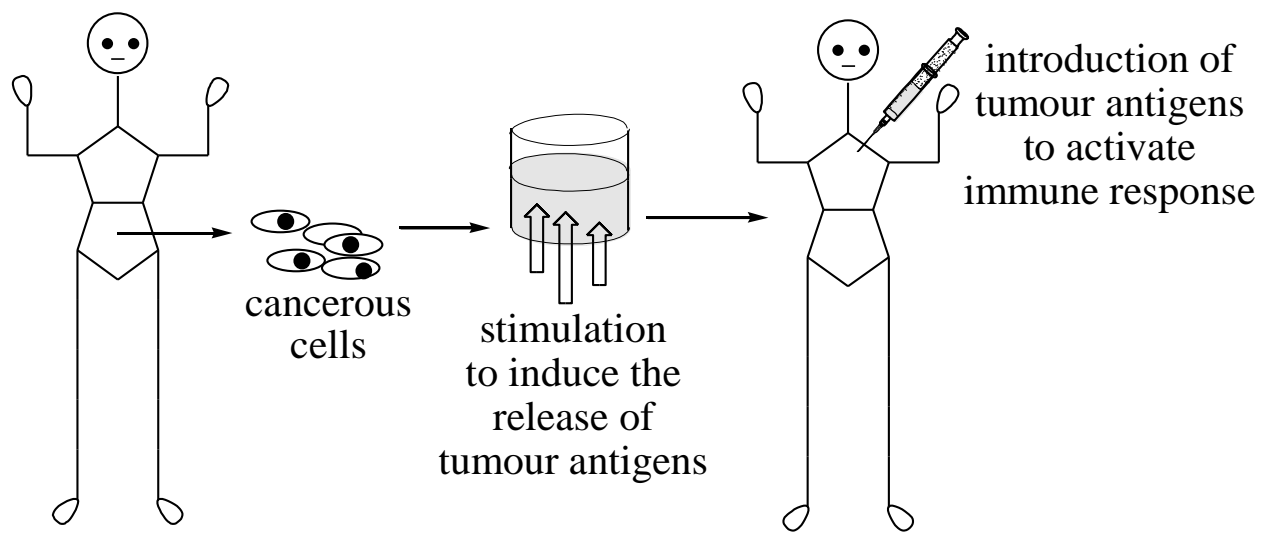

\subsection{The cell cycle}

The cell cycle (Figure 1.6) is a process by which cells ensure self-renewal. ${ }^{1}$ Production of undifferentiated cells is essential to provide a pool of precursor cells for differentiation into cells with specific functions. The undifferentiated precursor cells can mature into a range of cell types, such as germ cells to enable genetic transfer to the next generation, blood cells that need constant replenishing, and specific cell types to replace damaged cells. ${ }^{1}$ 
Figure 1.6 The cell cycle.

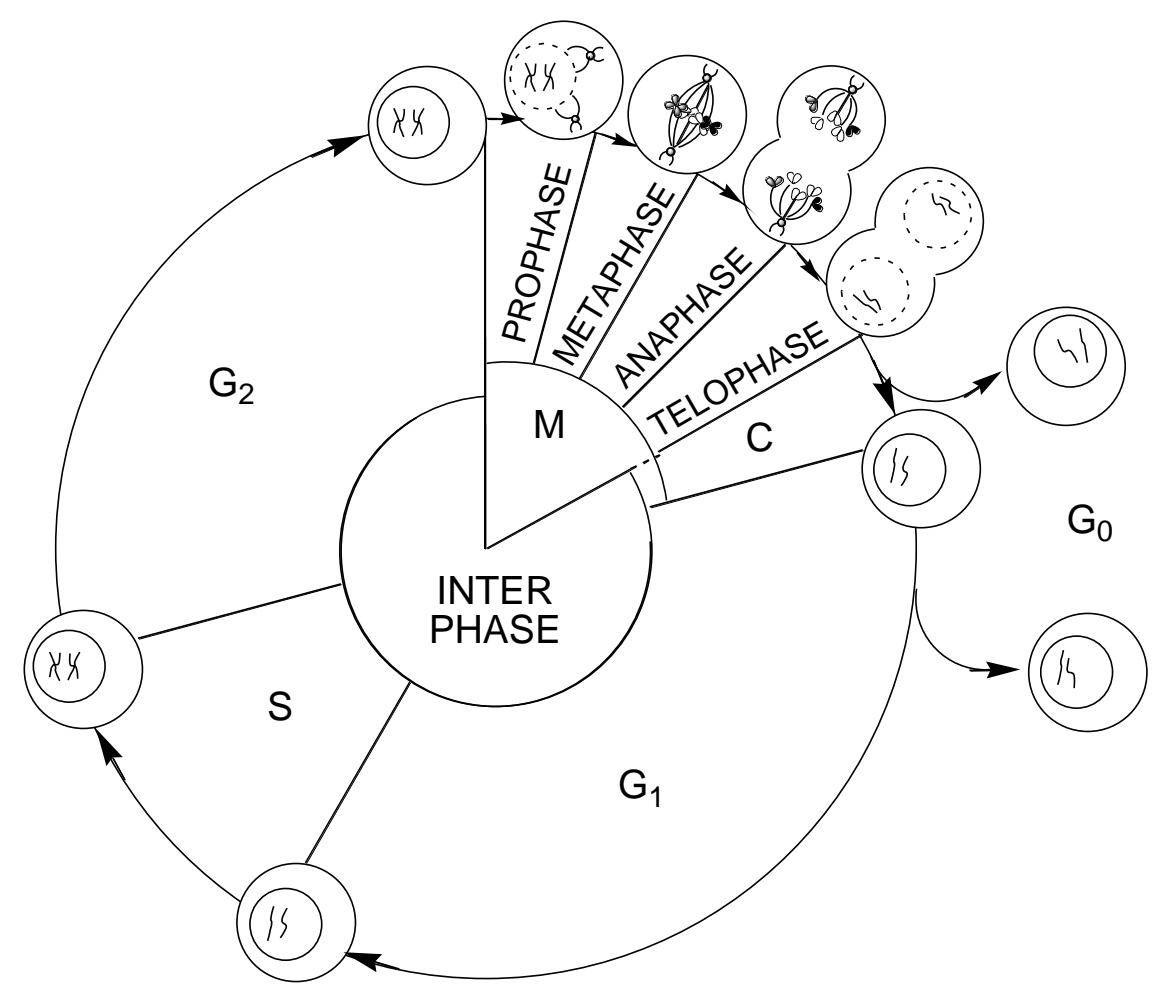

The cell cycle consists of five stages. ${ }^{16}$ Prior to entering the cell cycle, a cell exists in a quiescent state called $\mathrm{G}_{0}$. When the correct external stimuli are received, the cell will move out of the $G_{0}$ and into the $G_{1}$ state. ${ }^{17} G_{1}$ or the primary growth state is the first stage in the cell cycle. $G_{1}$ is the state in which the cell spends most of its life span, gaining nutrients, growing, and preparing to undergo cell division. ${ }^{16,17}$ Upon fulfilling the requirements for cell division, the cell will enter the $S$ phase. During the $\mathrm{S}$ phase, the cell will synthesise a replica of its genome in the form of sister chromatids. The cell then moves into the $\mathrm{G}_{2}$ phase and prepares for genomic separation. During $\mathrm{G}_{2}$ phase, the cellular organelles replicate, the chromosomes condense, and microtubule spindles assemble. Collectively, the $G_{1}, S$, and $G_{2}$ phases of the cell cycle form the interphase. ${ }^{16}$

The next stage in the cell cycle is mitosis, also called the $\mathrm{M}$ state. The prophase, metaphase, anaphase, and telophase sub-stages constitute mitosis. ${ }^{16}$ During prophase, the nuclear membrane of the dividing cell disintegrates and the nucleolus, a site within the cell's nucleus for synthesis of rRNA (ribosomal ribonucleic acid), dissolves. Mitotic spindles will start to form and attach themselves to the maturing kinetochores. The kinetochore is a disc-shaped protein assembly that anchors a 
chromosome pair to microtubules within part of the mitotic spindles. ${ }^{17}$ In the metaphase, chromosomes will self-align at the equator of the cells. Upon entering anaphase, kinetochore-associated microtubules pull the sister chromatids apart towards opposite poles of the cells as they shorten. Simultaneously, the polar microtubules elongate in preparation for cellular division. Upon entering telophase, the separated chromosomes recondense, the kinetochores dissolve, the nuclear membrane reforms and the nucleolus reappears. ${ }^{16,17}$

The final stage of the cell cycle is the cytokinesis or the $\mathrm{C}$ phase. ${ }^{16}$ During this stage, actin filaments form a constricting belt. The constricting belt causes formation of a cleavage furrow around the circumference of the cell. The constricting belt will gradually tighten until the mother cell eventually splits into two separate daughter cells. ${ }^{16,17}$ Upon finishing the cell cycle, the daughter cells can either re-enter into another cell cycle for further proliferation, or withdraw into $G_{0}$ state. Interference at one or more stages of the cell cycle through disruption of DNA replication, microtubule assembly or formation of the other cellular components essential for the cell cycle will either suspend the cell cycle or drive the cell into activating a selfregulated suicide mechanism called apoptosis. ${ }^{1}$

\subsection{Microtubules as targets in cancer treatment}

Microtubules (Figure 1.7) play essential roles in cell division. Microtubules are hollow cylindrical tubes made of the protein tubulin. A microtubule's morphology is adjusted to the role it is performing, either as a kinetochore microtubule or a polar microtubule. Correct microtubule morphology is crucial to the completion of a successful cell cycle. Tubulin subunits polymerise and depolymerise to adjust the length of microtubules. 
Figure 1.7 Structure of a microtubule.

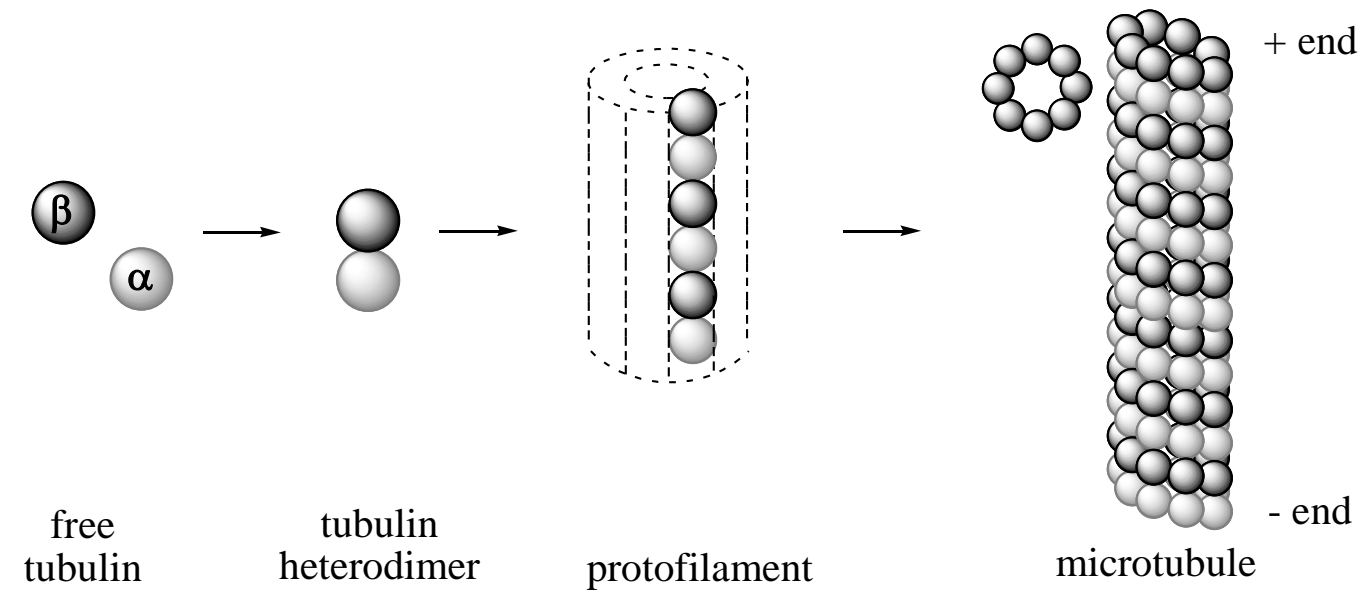

Microtubules are built of heterodimeric subunits made up of $\alpha$ - and $\beta$-monomers of tubulin. The heterodimers assemble in head-to-tail fashion ${ }^{18}$ (Figure 1.8) into threads of protofilaments with the $\beta$-monomers oriented to the plus end of the microtubule and the $\alpha$-monomers towards the minus end. ${ }^{19}$ During microtubule lengthening, the heterodimers polymerise at the plus end of the microtubule. ${ }^{20}$ When microtubules shorten, the heterodimers start to depolymerise from the minus end. ${ }^{20}$ The regulated changes in length through polymerisation and depolymerisation are called microtubule dynamics.

Whilst tubulin dynamics can lead to lengthening or shortening of microtubules, they can also lead to treadmilling (Figure 1.8). Treadmilling is a constant tubulin polymerisation at one end and depolymerisation at another end. The net result of treadmilling is a fixed tubular length but can lead to changes in its relative position in the cell. ${ }^{20}$ Treadmilling enables a microtubule to move around in the cellular matrix. This dynamic mechanism provides one means by which microtubules achieve cellular transportation and signalling. ${ }^{21}$ Thus, microtubule dynamics are very important for proper cellular functioning, and their disturbance can have fatal consequences for the affected cell. Therefore, disruption of microtubule dynamics during cellular division as well as $\mathrm{G}_{0}$ can be effective for inhibition of tumour and cancer progression. 
Figure 1.8 Microtubule treadmilling.

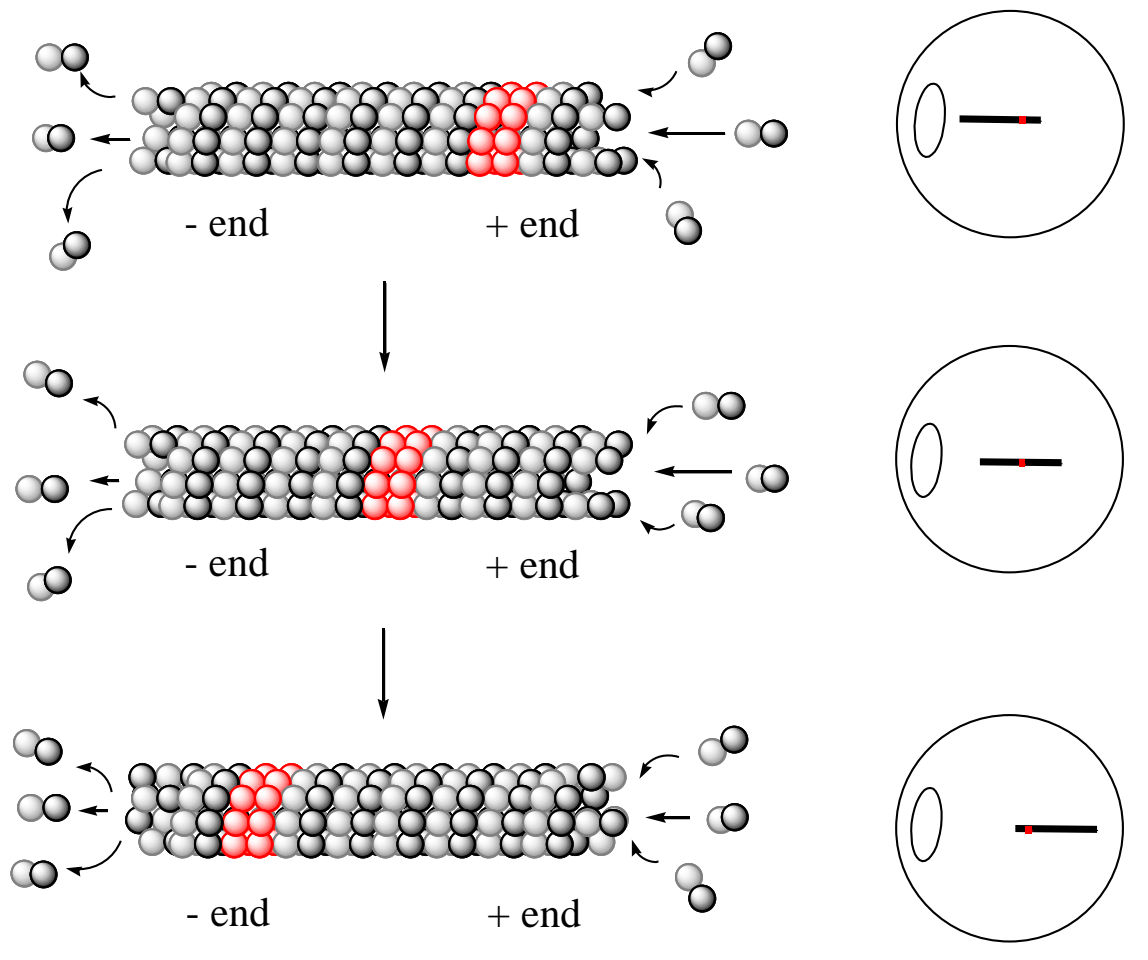

\subsection{Anticancer agents targeting microtubules}

A review of anticancer agents that entered into clinical trials in 2005 to 2007 showed that over $25 \%$ of the candidates operated by a mode of action that affected microtubule dynamics. ${ }^{22}$ Anticancer agents disturb microtubule dynamics by two main interaction mechanisms: stabilising and destabilising microtubules.

\subsubsection{Microtubule stabilising agents}

Microtubule stabilisers promote stabilisation of microtubule structure and prevent microtubule depolymerisation. Taxanes (Figure 1.9) are well known examples of microtubule stabilising agents whose mode of action involves binding to tubulin along the length of the microtubule. ${ }^{23}$

Taxanes bind to a site called the 'taxane binding site' on monomers $\beta$-tubulin. The taxane site is located on the inner surface of the microtubule with one taxane site per $\beta$-tubulin monomer. Taxanes gain entry into the taxane site by diffusion through small 
openings in the microtubule wall or during fluctuation of microtubule lattices. ${ }^{24}$ Binding of taxane molecules to their site promotes conformational changes that increase the affinity between neighbouring tubulin molecules and stabilise the microtubule structure.

The taxane family of anticancer agents include the natural compound paclitaxel (Figure 1.9), also known as Taxol ${ }^{\circledR}$, and several of its synthetic analogues, such as docetaxel, abraxane, larotaxel, cabazitaxel, taxoprexin, and milataxel just to mention a few. Most of these taxanes are still in clinical trials. Only paclitaxel, docetaxel and abraxane have been approved for use in cancer treatments. ${ }^{22}$

Figure 1.9 Taxanes.

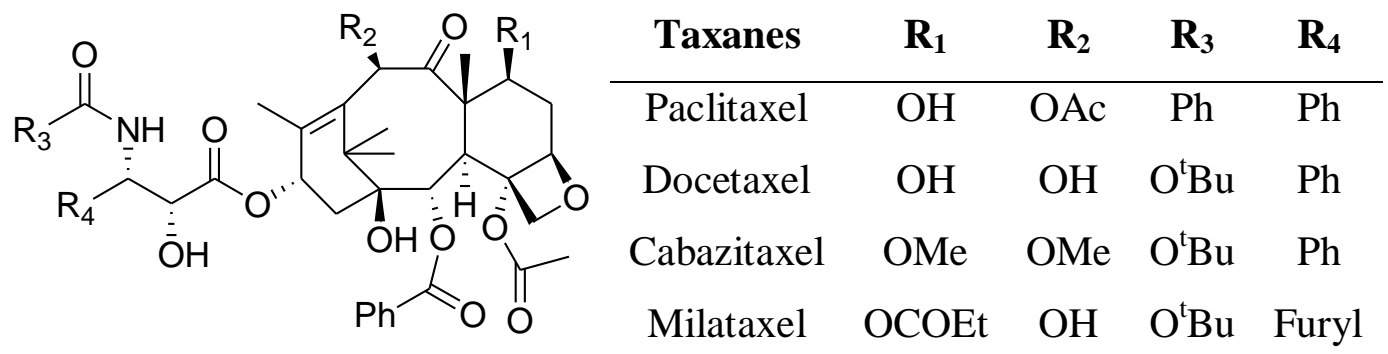

Paclitaxel was initially isolated by Wall and Wani in 1967 from the bark of the Pacific yew tree (Taxus brevifolia). ${ }^{25}$ The efficacy of paclitaxel as a microtubule stabilising anticancer agent was demonstrated by Schiff and Horwitz in their 1979 study. ${ }^{26}$ Paclitaxel was approved by the FDA in 1992 for use in cancer treatment. ${ }^{22}$ The increasing demand for paclitaxel led Holton and co-workers to devise a semisynthetic route for procuring paclitaxel from 10-deacetylbaccatin III (Scheme 1.1), a structurally related compound isolated from the needles and leaves the of the European yew (Taxus baccata). ${ }^{22,27,28}$ Docetaxel is a semisynthetic analogue of paclitaxel developed by the Potier group from France and was approved for use in cancer treatment by the FDA in $1995 .^{22,29}$ 
Scheme 1.1 The semisynthetic route to paclitaxel from 10-deacetylbaccatin III and protected $\beta$-lactam.

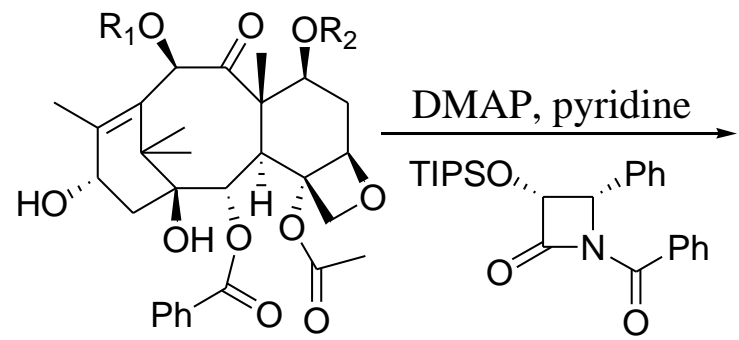

10-deacetylbaccatin III

1) $\mathrm{TESCl}$, pyridine $\mathrm{CH}_{3} \mathrm{COCl}$, pyridine $\longrightarrow \mathrm{R}_{1}=\mathrm{R}_{2}=\mathrm{H}$
$-\mathrm{R}_{1}=\mathrm{Ac}, \mathrm{R}_{2}=\mathrm{TES}$

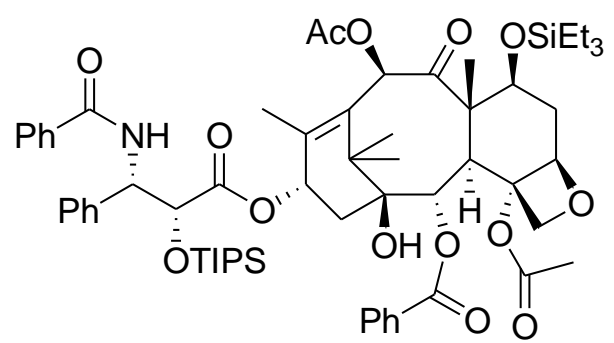

$0.5 \% \mathrm{HCl}$

Paclitaxel

Epothilones A and B (Figure 1.10) were discovered in soil myxobacteria called Sorangium cellulosum by Reinchenbach and co-workers in $1986 .^{22,30,31}$ Epothilones also promote microtubule stabilisation by binding to the taxane site on the $\beta$-subunit of tubulin. ${ }^{32}$ Several epothilones and epothilone-derived analogues have been in clinical trials. Ixabepilone (Figure 1.10) is a semisynthetic analogue of epothilone B that was approved by the FDA in 2007 for the treatment of breast cancer. ${ }^{22}$ Ixabepilone was prepared in a one-pot reaction from epothilone B by replacement of the ester moiety with an amide. ${ }^{22}$ Sagopilone and dehydelone (Figure 1.10) are synthetic analogues of epothilone that have gone into clinical trials for the treatment of advanced and recurrent metastatic cancers. ${ }^{22,31}$ 
Figure 1.10 Epothilones and synthetic analogues.

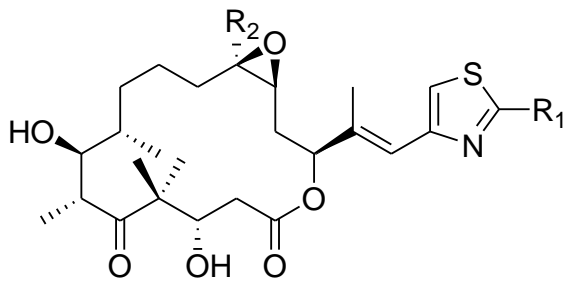

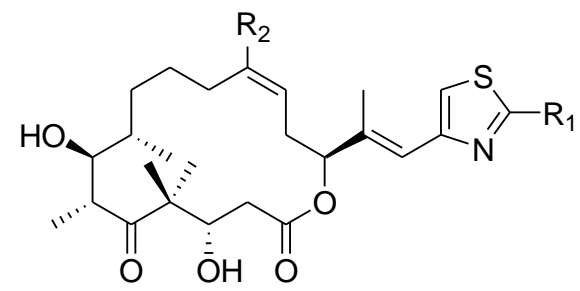

\begin{tabular}{ccc} 
Epothilone & $\mathbf{R}_{\mathbf{1}}$ & $\mathbf{R}_{\mathbf{2}}$ \\
\hline $\mathrm{A}$ & $\mathrm{Me}$ & $\mathrm{H}$ \\
$\mathrm{B}$ & $\mathrm{Me}$ & $\mathrm{Me}$ \\
$\mathrm{E}$ & $\mathrm{CH}_{2} \mathrm{OH}$ & $\mathrm{H}$
\end{tabular}

\begin{tabular}{ccc} 
Epothilone & $\mathbf{R}_{\mathbf{1}}$ & $\mathbf{R}_{\mathbf{2}}$ \\
\hline C & $\mathrm{Me}$ & $\mathrm{H}$ \\
D & $\mathrm{Me}$ & $\mathrm{Me}$ \\
F & $\mathrm{CH}_{2} \mathrm{OH}$ & $\mathrm{H}$
\end{tabular}

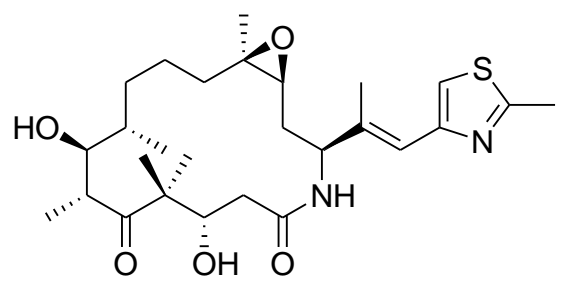

Ixabepilone

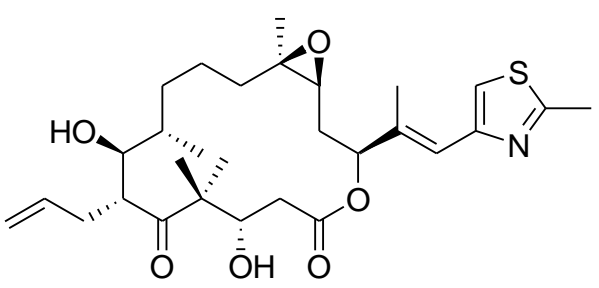

Sagopilone<smiles>CC/C=C\[C@H](C)[C@H](C)C(=O)/C(C)=C\CC(OC1(C)OC(=O)C[C@H](O)C1=O)/C(C)=C/c1csc(C)n1</smiles>

Dehydelone

\subsubsection{Microtubule destabilising agents}

Vinca alkaloids (Figure 1.11) were isolated from extracts of the Madagascan periwinkle (Catharanthus roseus). ${ }^{22}$ Two of the most widely used natural vinca alkaloids are vinblastine and vincristine. ${ }^{24}$ Vinca alkaloids are anticancer agents that disturb microtubule dynamics and their mode of action depends on the administered dosage. At relatively high concentrations of 10 to $100 \mathrm{nM}$ in HeLa cells, vinca alkaloids promote depolymerisation and dissolving of microtubule spindles. ${ }^{24}$ However, when administered at lower dosage, vinca alkaloids bind to the tips of microtubule filaments and suppress microtubule dynamics, thus preventing depolymerisation of the microtubule spindles. ${ }^{33}$ 
Figure 1.11 Vinca alkaloids

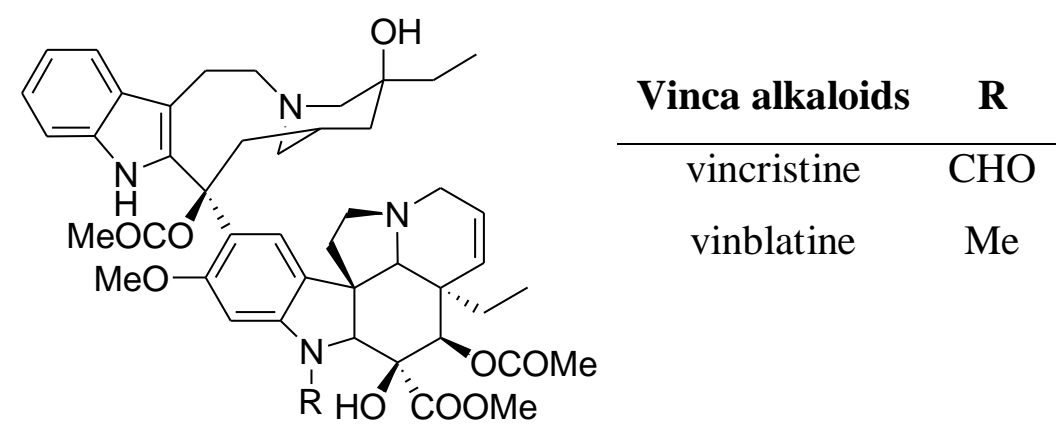

Vinca alkaloids have a distinct binding site at the $\beta$-subunit of tubulin called the 'vinca domain'. ${ }^{24}$ Binding of a vinca alkaloid molecule to a $\beta$-subunit causes conformational changes in the tubulin subunit. Subunits with associated vinca alkaloid molecules have increased affinity for self-association into discrete tubulin subunit pairs which lowers the concentration of polymerised tubulin. ${ }^{24}$

Colchicine (Figure 1.12) was extracted from Autumn crocus (Colchicum autumnale). ${ }^{34}$ Colchicine is an anticancer agent that has a similar mode of action to vinca alkaloids. Colchicine promotes microtubule depolymerisation at high concentration while arresting microtubule dynamics at low dosage resulting in the disruption of the correct orientation of microtubule protofilaments. ${ }^{24,}{ }^{33}$ Colchicine binds to a site called the 'colchicine domain' on the intradimer interface between the $\alpha$ - and the $\beta$-tubulin dimer. ${ }^{33}$ However, colchicine was deemed unsuitable for use in cancer treatment, due to its potent toxicity towards normal tissue. ${ }^{24}$

Figure 1.12 Colchicine.<smiles>COc1cc2c(c(OC)c1OC)-c1ccc(=O)c(OC)cc1CCC2NC(C)=O</smiles>

Although colchicine is not administered as an anticancer agent, the colchicine domain has proven valuable for other anticancer agents including the combretastatins (Figure 1.13), which are a family of natural anticancer agents isolated from Cape bushwillow (Combretum caffrum) by Pettit et al. ${ }^{22,34,35}$ The natural combretastatins and several 
synthetic analogues have gone into clinical trials as anti-mitotic agents for cancer therapy targeting microtubules. Combretastatins have been shown to inhibit the polymerisation of tubulin and the formation of microtubule spindles.

Figure 1.13 Combretastatins and derivatives.<smiles>[R]c1c(/C=C\c2cc(OC)c(OC)c(OC)c2)ccc(OC)c1[R]</smiles>

\begin{tabular}{ccc} 
Combretastatins & $\mathbf{R}_{\mathbf{1}}$ & $\mathbf{R}_{\mathbf{2}}$ \\
\hline Combretastatin A-4 & $\mathrm{H}$ & $\mathrm{OH}$ \\
Combretastatin A4 phosphate & $\mathrm{H}$ & $\mathrm{OPO}_{3} \mathrm{Na}_{2}$ \\
Combretastatin A-1 & $\mathrm{OH}$ & $\mathrm{OH}$ \\
OXi4503 & $\mathrm{OPO}_{3} \mathrm{Na}_{2}$ & $\mathrm{OPO}_{3} \mathrm{Na}_{2}$ \\
AVE8062A & $\mathrm{H}$ & $\mathrm{NHCOCH}\left(\mathrm{NH}_{2}\right) \mathrm{CH}_{2} \mathrm{OH}$ \\
AVE8063A & $\mathrm{H}$ & $\mathrm{NH}_{2}$
\end{tabular}

\subsection{Anticancer agents from marine sources}

The marine environment has been contributing an increasing list of natural anticancer agents in the recent decades. Antitumour marine natural products have been isolated from a variety of marine vertebrates and invertebrates. The anticancer agents have been derived mainly from marine sponges and molluscs. Several anticancer agents targeting microtubule dynamics as the mode of action are discussed below.

(+)-Discodermolide (Figure 1.14) was isolated from the deep-water sponge Discodermia dissoluta in 1990 by Gunasekera et al. ${ }^{36}(+)$-Discodermolide was originally studied as an immunosuppressant. However, further studies proved that (+)discodermolide is also an anti-mitotic suppressor of the cell cycle at 3 to $8 \mathrm{nM}$ concentration. ${ }^{37}$ A study on the mode of action of $(+)$-discodermolide has shown that the compound is a potent microtubule stabiliser that inhibits tumour cell growth by accelerating senescence. ${ }^{38}(+)$-Discodermolide binds to $\beta$-tubulin at the taxane site and is a competitive inhibitor to paclitaxel. ${ }^{37,}{ }^{38} \mathrm{~A}$ clinical trial using (+)- 
discodermolide was discontinued after phase I due to toxicity problems and lack of efficacy. $^{31,37}$

Figure 1.14 Discodermolide.

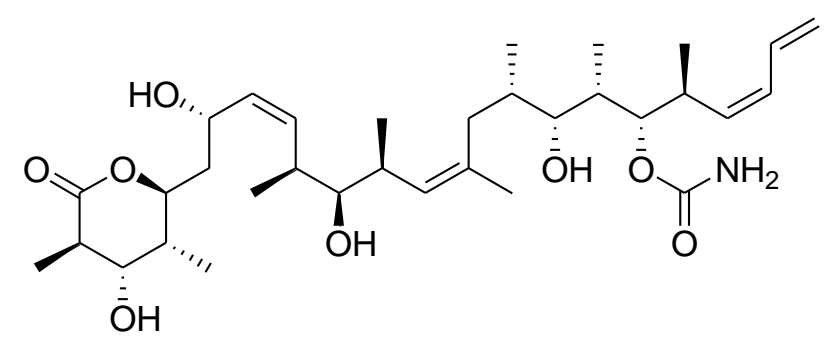

Dolastatin 10 (Figure 1.15) is a member of the dolastatin family. The dolastatins are a series of cytotoxic peptides first isolated from the sea hare Dolabella auricularis in $1972 .{ }^{37}$ Dolastatin 10 exhibits anti-mitotic activity with an $\mathrm{IC}_{50}$ of $1.2 \mu \mathrm{M} .{ }^{37}$ Studies showed that prolonged intracellular retention facilitates binding to tubulin, which leads to the inhibition of tubulin polymerisation, and thus prohibits microtubule assembly and promotes the subsequent depletion of the cellular microtubule network, resulting in cellular arrest at the mitotic stage. ${ }^{37}$ Dolastatin 10 binds to a distinct peptide site near the vinca domain on the $\beta$-subunit. ${ }^{11,22}$ However, dolastatin $10 \mathrm{did}$ not pass phase II clinical trials and has been withdrawn due to a lack of significant activity. $^{11,22,37}$ Several synthetic derivatives of dolastatins such as soblidotin, cematodin, and synthadotin (Figure 1.15) have entered clinical trials. ${ }^{11,38}$ 
Figure 1.15 Dolastatin 10 and its derivatives.<smiles>CCC(C)[C@H]([C@H](CC(=O)N1CCC[C@H]1[C@H](OC)[C@@H](C)C(=O)N[C@H](Cc1ccccc1)c1nccs1)OC)N(C)C(=O)[C@@H](NC(=O)[C@@H](C(C)C)N(C)C)C(C)C</smiles><smiles>CC[C@H](C)[C@H]([C@H](CC(=O)N1CCC[C@H]1[C@H](OC)[C@@H](C)C(=O)NCCc1ccccc1)OC)N(C)C(=O)[C@@H](NC(=O)[C@@H](C(C)C)N(C)C)C(C)C</smiles>

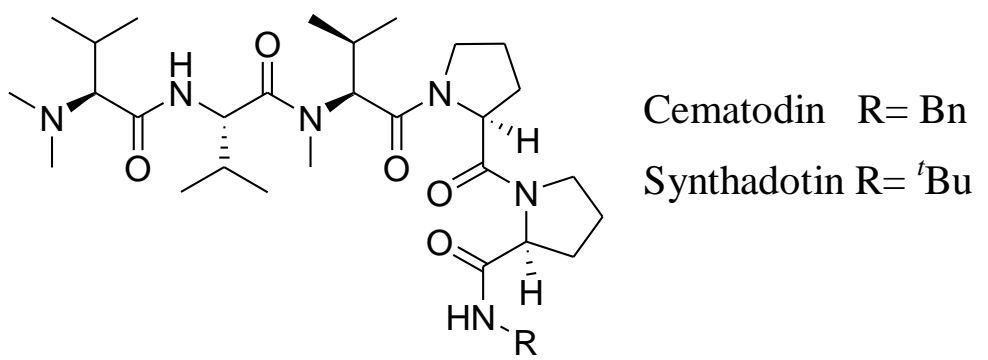

Halichondrin B (Figure 1.16) is a member of the halichondrin class of marine macrolide. Halichondrin B, homohalichondrin B, and norhalichondrin B were originally isolated from the sponge Halichondria okadai by Uemura and co-workers in 1985. ${ }^{11,39}$ Since its original discovery, Halichondrin B has also been found in several other sponges including Axinella sp., Lissodendory sp., and Phakellia carteri. ${ }^{11}$ An initial study determined that halichondrin $\mathrm{B}$ is a tubulin interactive agent that affects microtubule depolymerisation through binding to a distinct site near the vinca domain. ${ }^{11}$ Further studies have shown that halichondrin $\mathrm{B}$ is a non-competitive inhibitor of vinblastine. ${ }^{22}$ Halichondrin $\mathrm{B}$ is highly cytotoxic and a potent inhibitor of cell growth at subnanomolar concentrations towards the NCI-60-cell lines. ${ }^{22,} 37$ Eribulin mesylate (Figure 1.16), a less neurotoxic but more potent truncated analogue of halichondrin $\mathrm{B}$, has gone into crinical trials. ${ }^{11,22,37,38}$ 
Figure 1.16 Halichondrin B and analogues.<smiles>OCC(O)CC(O)C[C@@H]1CCO1</smiles>

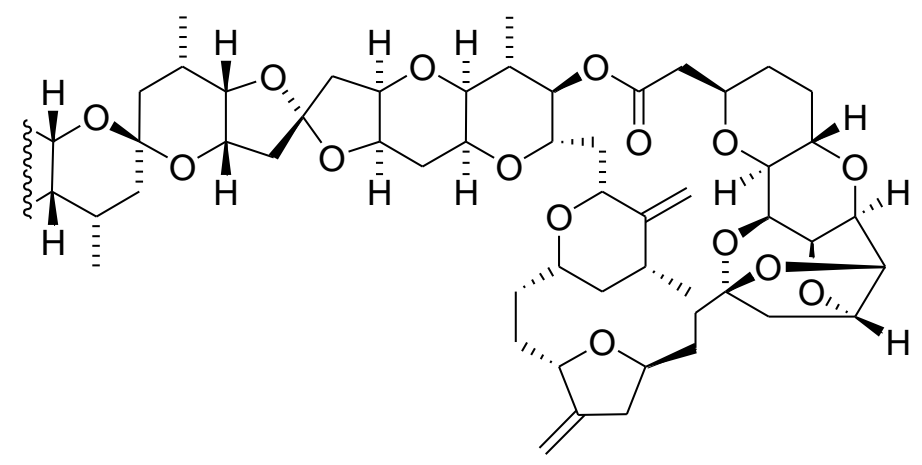<smiles>CC12CC(C(O)CO)OC1CCO2</smiles>

homohalichondrin B<smiles>O=C(O)C[C@H]1O[C@@H]2CC[C@H](O)[C@H]21</smiles>

norhalichondrin B

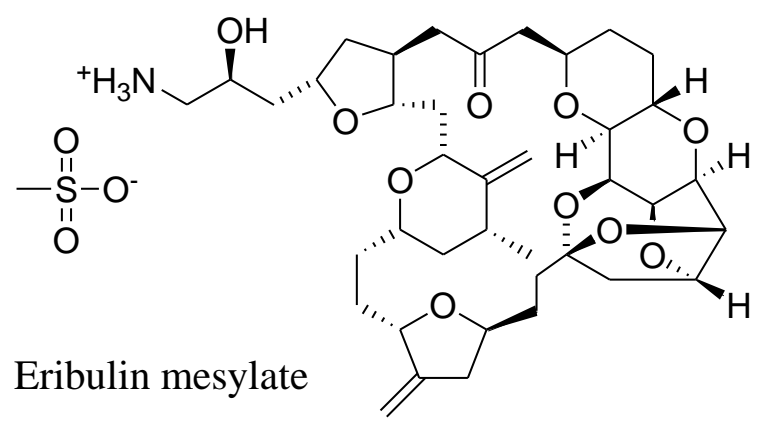

Zampanolide (Figure 1.17) is a macrolide initially isolated from the Japanese marine sponge Fasciospongia rimosa by Tanaka and Higa in $1996 .{ }^{40}$ Zampanolide has recently also been extracted from the Tongan sponge Cacospongia mycofijiensis by Northcote's group. ${ }^{41}$ Zampanolide is a potent microtubule stabilising agent with an $\mathrm{IC}_{50}$ of 2 to $10 \mathrm{nM}$ for growth inhibition of a number of cancer cell lines. ${ }^{41}$ Zampanolide causes $\mathrm{G}_{2} / \mathrm{M}$ arrest of the cell cycle and promotes microtubule bundle formation at interphase. ${ }^{41}$ 
Figure 1.17 Zampanolide.

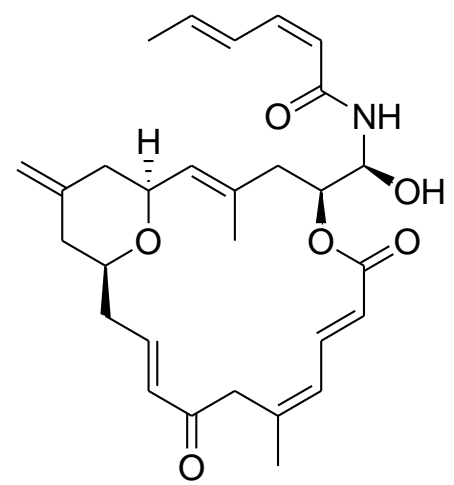

\subsection{Peloruside A}

Peloruside A (1, Figure 1.18) is a novel cytotoxic marine natural product isolated from the New Zealand sponge Mycale hentscheli in 2000 by Northcote's group. ${ }^{42}$ Northcote also reported the isolation of peloruside B to D, mycalamides (a family of heterocyclic amides), and the macrolide pateamine in the same sponge. ${ }^{42}$ Peloruside A has a highly oxygenated 16-membered macrolide ring containing a dihydropyran ring, a gem-dimethyl group, and a hemiketal. Its side chain bears a branched Z-olefin. Preliminary biological analysis indicated that peloruside $\mathrm{A}$ is cytotoxic with an $\mathrm{IC}_{50}$ of 6 to $66 \mathrm{nM}$ in a number of cancer cell lines. ${ }^{43,46,47}$

Peloruside B (2, Figure 1.18) is a 3-des-O-methyl variant of peloruside A which showed a slightly reduced bioactivity compared to peloruside $\mathrm{A} .{ }^{44}$ Peloruside $\mathrm{C}(\mathbf{3}$, Figure 1.18) is a dideoxy variant of peloruside A and has a significantly reduced bioactivity. ${ }^{45}$ Peloruside D (4, Figure 1.18) was found to be biologically inactive. ${ }^{45}$ 
Figure 1.18 The naturally occurring members of the peloruside family.

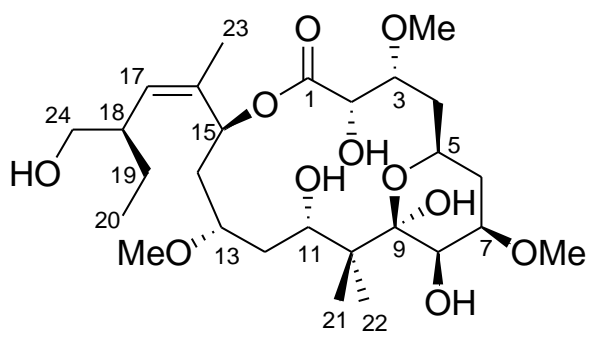

(+)-Peloruside A

1

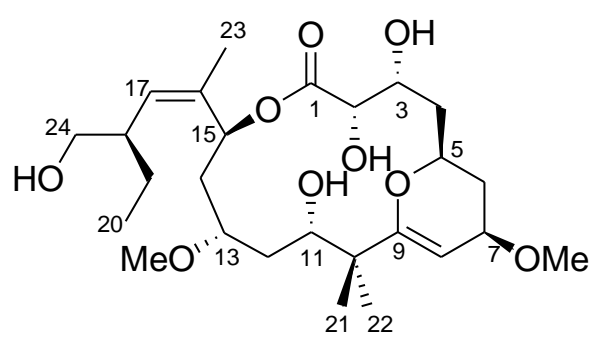

Peloruside C

3

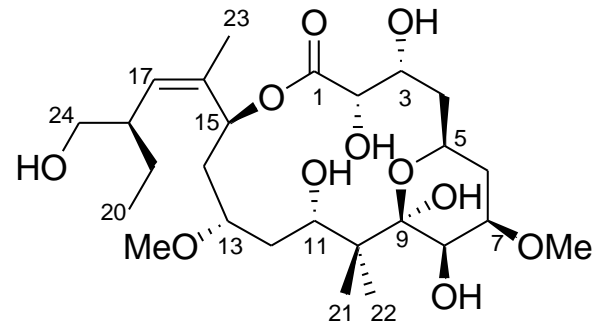

Peloruside B

2

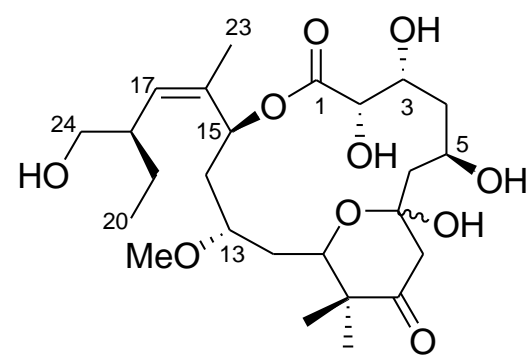

Peloruside D

4

\subsubsection{Biological activity of peloruside A}

A biological study by the Miller group established that peloruside A is a microtubule interactive agent with microtubule-stabilising activity (Figure 1.19). ${ }^{43}$ Peloruside A promotes tubulin hyperassembly and cellular microtubule stabilisation leading to $\mathrm{G}_{2} / \mathrm{M}$ phase cell cycle blockage and cell apoptosis. ${ }^{46,47,48}$ Peloruside $\mathrm{A}$ is therefore a potential agent for anticancer therapy. Peloruside A binds to a non-taxane site, believed to be located in the $\beta$-tubulin subunit. Furthermore, peloruside A displays synergy with taxoids and has potential as a synergistic drug with other microtubule stabilising agents such as the taxanes, epothilones, and (+)-discodermalide. ${ }^{46,47,48}$ 
Figure $1.19 \alpha$-Tubulin antibody staining of microtubules in 1A9 ovarian cancer cells.

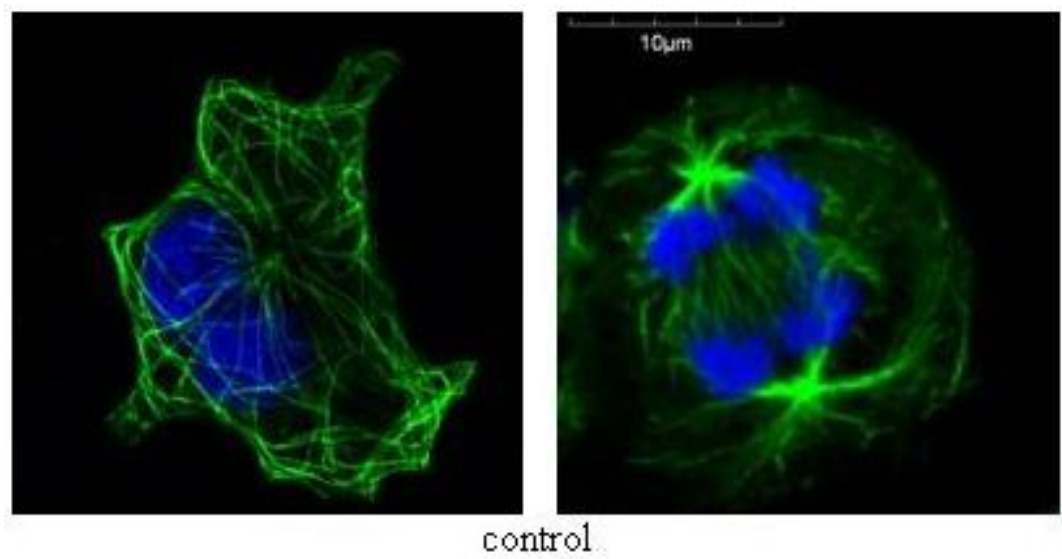

40 nM peloruside $\mathrm{A}$

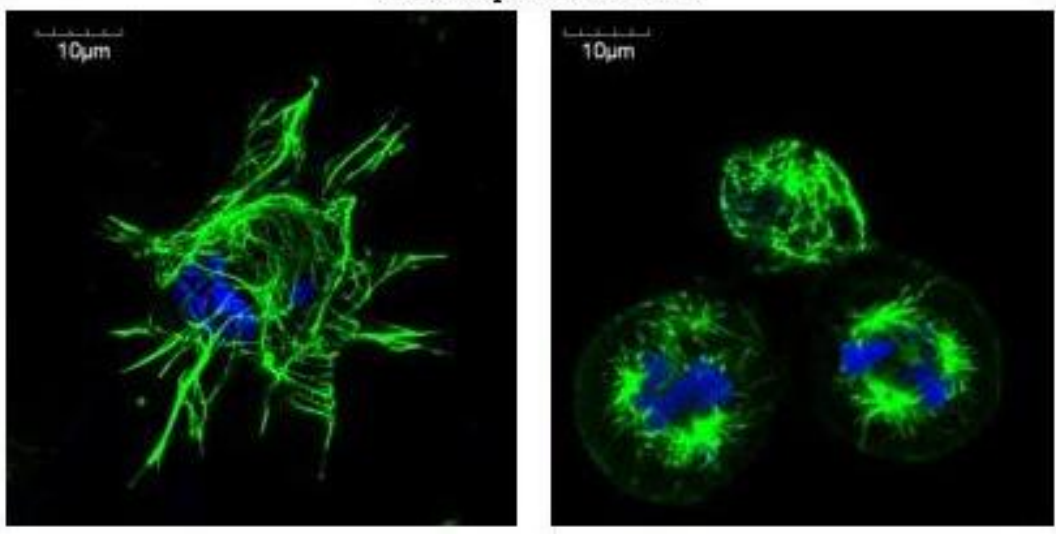

Microtubules are shown in green.

Used with the permission of Prof. John Miller and confocal images supplied by Arun Kanakkanthara.

The physical properties of peloruside A excel over those of most taxoid drugs as it is less lipophilic, thus less susceptible to over-expressed Pgp (P-glycoprotein) efflux pumps in multidrug resistant cells. ${ }^{43,46}$ Susceptibility to over-expression of Pgp efflux pumps has been an issue that has undermined the efficacy and safety of other anticancer drugs. Cancerous cells have the tendency to over-express the Pgp efflux pumps, which non-specifically remove the more lipophilic molecules from cells and thus lower the efficacy of many drugs.

\subsubsection{Synthesis of peloruside $A$}

The scarcity of the available natural source of peloruside A has led to aquaculturebased attempts to produce the cytotoxic agent, however production of the natural 
product in large quantities by this approach has not yet been fruitful. ${ }^{49}, 50$ The absolute stereochemistry of peloruside A was revealed in the course of its first reported total synthesis by De Brabander's group. ${ }^{51}$ The product turned out to be the unnatural enantiomer, (-)-peloruside A (5, Figure 1.20). ${ }^{51}$ Unfortunately, this unnatural enantiomer of peloruside A does not express cellular cytotoxicity. ${ }^{51}$

Figure 1.20 Synthetic and semisynthetic variants of (+)-peloruside A.

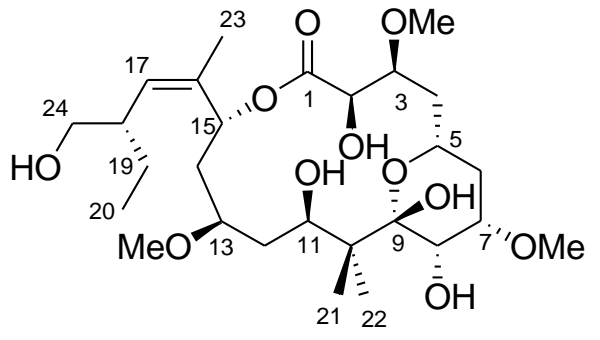

5

(-)-Peloruside A

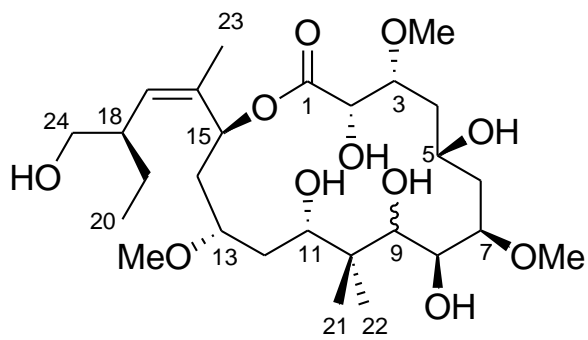

7

$\mathrm{NaBH}_{4}$ reduction analogue of

Peloruside A

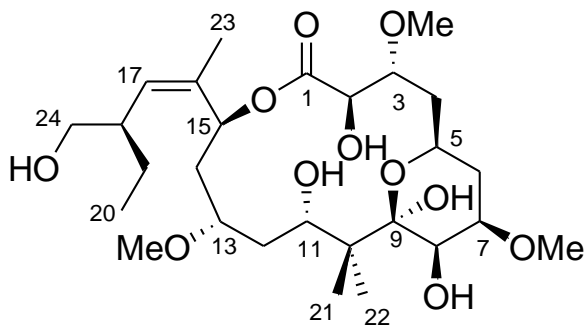

6

(-)-2-epi-Peloruside A

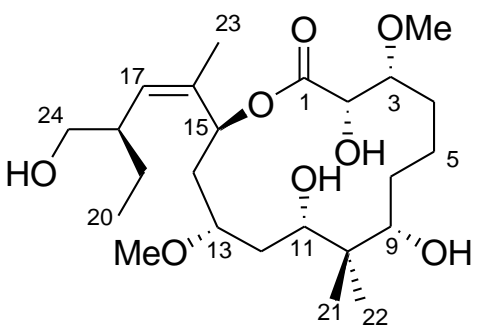

8

Monocyclic peloruside A analogue

The first total synthesis of natural (+)-peloruside A was achieved in 2005 by Jin and Tayor. ${ }^{52}$ Following in their footsteps, Ghosh and Evans have also achieved the total synthesis of peloruside A. ${ }^{53,54}$ Smith and co-workers reported the total synthesis of ()-2-epi-peloruside A (6, Figure 1.20), an unexpected synthetic result due to torsional strain-driven epimerisation at $\mathrm{C}_{2}$ during the macrolactonisation step. ${ }^{57}$ However, the cytotoxic potential of (-)-2-epi-peloruside A has yet to be determined. Almost all of the total synthesis strategies developed for peloruside A to date used convergent synthetic approaches with aldol coupling as the key reaction. ${ }^{55,56}$ The major synthetic approaches are discussed below. 
Aside from (-)-2-epi-peloruside A, two other analogues (7 and 8, Figure 1.20) have already been made and tested with a disappointing lack of cytotoxic potential compared to peloruside A. ${ }^{43,58}$ Analogue 7 is a product of sodium borohydride reduction of peloruside $A$, resulting in the loss of the $C_{5}-C_{9}$ pyran moiety and formation of hydroxyls at $\mathrm{C}_{5}$ and $\mathrm{C}_{9}{ }^{43}$ Analogue 8 was designed without the $\mathrm{C}_{5}-\mathrm{C}_{9}$ pyran backbone. ${ }^{45}$ Analogues $\mathbf{8}$ and $\mathbf{7}$ lack the pyran moiety and similarly showed loss of bioactivity, which highlighted the importance of the $\mathrm{C}_{5}-\mathrm{C}_{9}$ pyran backbone in the structure of peloruside A.

\subsubsection{Synthesis of (-)-peloruside A by De Brabander (Scheme 1.2) ${ }^{51}$}

De Brabander's approach to the synthesis of peloruside A begins from the PMB ( $p$ methoxybenzyl) protected hexenediol 14. TES (triethyl silyl) protection of the $\mathrm{C}_{5}$ alcohol followed by oxidative cleavage of the $C_{3}$ alkene provided aldehyde 15 . Addition of a (Z)-alkoxyallylborane $\mathbf{1 6}$ to the aldehyde $\mathbf{1 5}$ followed by methylation of the resulting alcohol provided alkene 17. Deprotection and oxidation of the $\mathrm{C}_{7}$ hydroxyl gave the aldehyde 18. Subsequent aldol reaction with 19 followed by DessMartin oxidation provided $\beta$-diketone 20.

The $\beta$-diketone 20 was cyclised to give the dihydropyranone 21. Luche reduction, epoxidation, methanolysis, and methylation furnished the functionalised dihydropyran. Protection of $\mathrm{C}_{8}$ hydroxyl as a TES ether provided 22. Methyl ester functionality at $\mathrm{C}_{1}$ was formed through oxidative transformation of the alkene double bond to an acid followed by diazomethane treatment to give 23. Deprotection and oxidation of the $\mathrm{C}_{11}$ hydroxyl gave the aldehyde $\mathbf{2 4}$. Allylation with allyldiethylborane gave the allyl alcohol 25. Subsequent oxidative cleavage of the $\mathrm{C}_{13}$ alkene finished the synthesis of the major portion of the target structure as the aldehyde $\mathbf{2 6}$.

The methyl ketone 13 was synthesised from 2,5-dihydrofuran through zirconium catalysed asymmetric carbomagnesation. ${ }^{16}$ The resulting enantiopure homoallylic alcohol 10 was acylated with methacryloyl chloride. The resultant olefin 11 was ringclosed using Grubb's $2^{\text {nd }}$ generation catalyst to facilitate the metathesis. The resulting lactone 12 was treated with methyllithium to provide the methyl ketone and followed with silylation to protect the primary alcohol. 
Scheme 1.2 Synthetic route to (-)-peloruside A by De Brabander. ${ }^{51}$
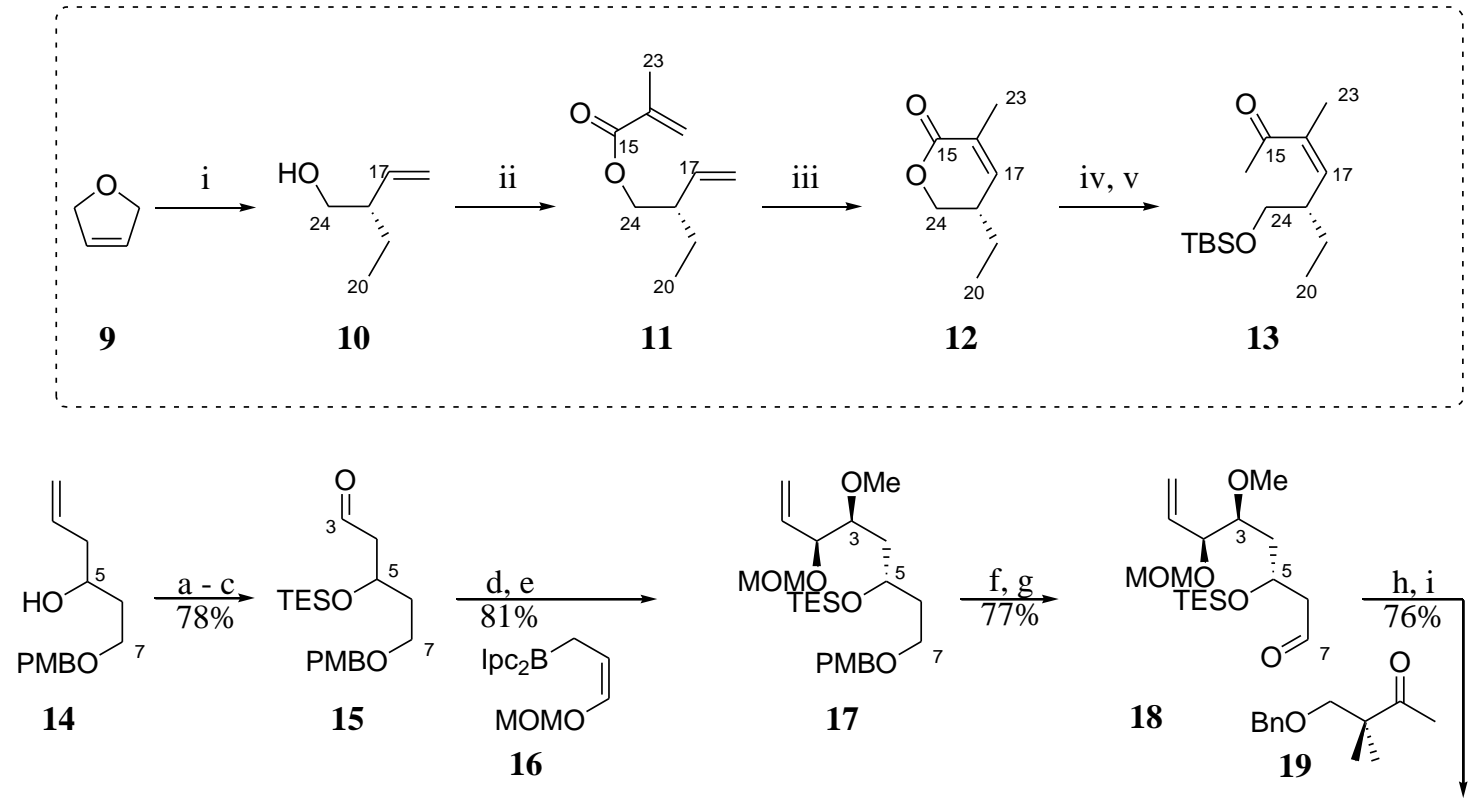

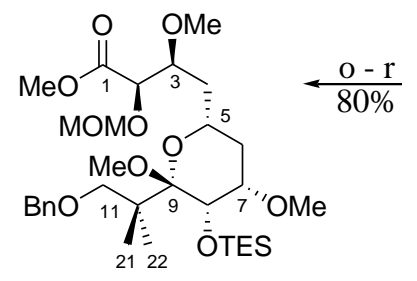

23

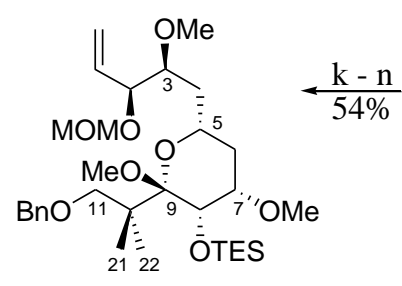

22<smiles>C=CC(OC)C(C)OC1CC(=O)C=C(C(C)COc2ccccc2)C1</smiles>

21

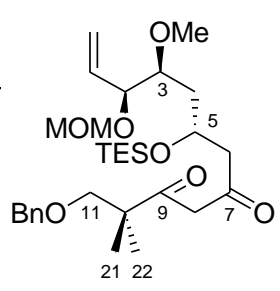

20

$\mathrm{s}, \mathrm{t} \mid 90 \%$

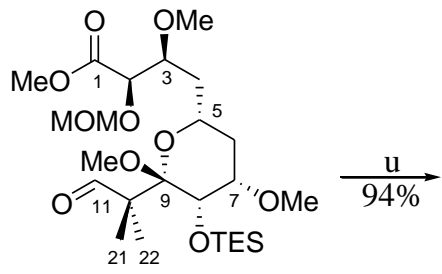

24

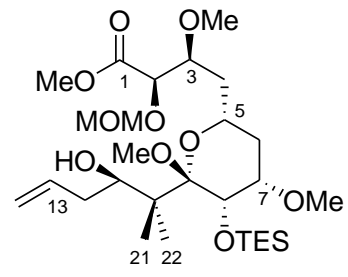

25
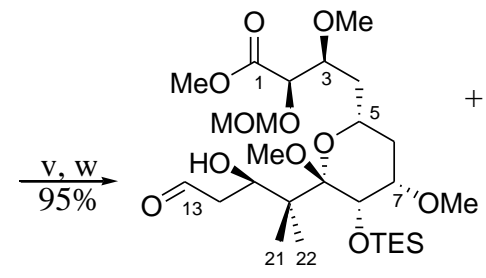

26

(-)-Peloruside $A \frac{\mathrm{Z}}{65 \%}$

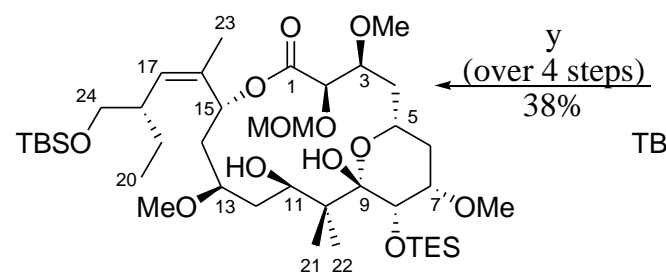

28

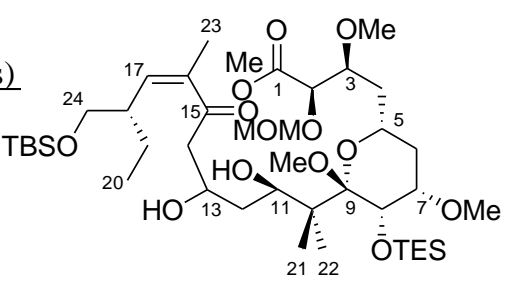

27

Conditions: (i) EtMgBr, (S)-(EBTHI)-Zr-BINOL, THF, ${ }^{59}$ (ii) methacryloyl chloride, DIPEA, DMAP, DCM; (iii) 10 mol\% Grubbs' $2^{\text {nd }}$ generation catalyst, DCM, reflux, $17 \mathrm{~h}$; (iv) $\mathrm{MeLi}, \mathrm{THF},-78{ }^{\circ} \mathrm{C}$; or $\mathrm{Me}_{3} \mathrm{SiCH}_{2} \mathrm{Li}$, pentane, $-78{ }^{\circ} \mathrm{C}$; (v) $\mathrm{TBSCl}$, 
imidazole, DMAP, DMF; (a) TESOTf, 2,6-lutidine, DCM; (b) catalytic $\mathrm{OsO}_{4}, \mathrm{NMO}$, acetone $/ \mathrm{H}_{2} \mathrm{O}$; (c) $\mathrm{Pb}(\mathrm{OAc})_{4}$, pyridine, DCM; (d) $s \mathrm{BuLi}$, THF, $-78{ }^{\circ} \mathrm{C}, 15 \mathrm{~min}$, then (+)-Ipc ${ }_{2} \mathrm{BOMe},-78{ }^{\circ} \mathrm{C}, 1 \mathrm{~h}, 0,{ }^{\circ} \mathrm{C}, 1.5 \mathrm{~h}$, then $15 ;-95^{\circ} \mathrm{C}, 3 \mathrm{~h}$, slowly warmed to RT, $30 \% \mathrm{H}_{2} \mathrm{O}_{2}, \mathrm{NaOH}, 16 \mathrm{~h}$; (e) $\mathrm{NaH}, \mathrm{MeI}, \mathrm{DMF},-5{ }^{\circ} \mathrm{C}$; (f) DDQ, DCM/ $\mathrm{H}_{2} \mathrm{O}, 0{ }^{\circ} \mathrm{C}$; (g) $\mathrm{SO}_{3}$.pyridine, TEA, DMSO, DCM, $0{ }^{\circ} \mathrm{C}$; (h) 19, LDA, THF, $-78{ }^{\circ} \mathrm{C}$, then $18,-78{ }^{\circ} \mathrm{C}$; (i) Dess-Martin periodinane, DCM, $-10{ }^{\circ} \mathrm{C}$; (j) PTSA, PhMe, RT; (k) $\mathrm{NaBH}_{4}$, $\mathrm{CeCl}_{3} .7 \mathrm{H}_{2} \mathrm{O}, \mathrm{MeOH},-30{ }^{\circ} \mathrm{C}$; (l) $m \mathrm{CPBA}, \mathrm{NaHCO}_{3}, \mathrm{DCM} / \mathrm{MeOH}, 0^{\circ} \mathrm{C}$; (m) $t \mathrm{BuOK}$, MeI, THF, $0{ }^{\circ} \mathrm{C}$; (n) TESOTf, 2,6-lutidine, DCM; (o) catalytic $\mathrm{OsO}_{4}, \mathrm{NMO}$, acetone $/ \mathrm{H}_{2} \mathrm{O}$; (p) $\mathrm{Pb}(\mathrm{OAc})_{4}$, pyridine, DCM; (q) $\mathrm{NaClO}_{2}, \mathrm{NaH}_{2} \mathrm{PO}_{4}$, 2-methyl-2butene, $t \mathrm{BuOH} / \mathrm{H}_{2} \mathrm{O}$; (r) $\mathrm{CH}_{2} \mathrm{~N}_{2}, \mathrm{Et}_{2} \mathrm{O}, 0{ }^{\circ} \mathrm{C}$; (s) $\mathrm{H}_{2}, 10 \% \mathrm{Pd} / \mathrm{C}, \mathrm{MeOH} ;(\mathrm{t})$ $\mathrm{SO}_{3}$.pyridine, TEA, DMSO, DCM, $0{ }^{\circ} \mathrm{C}$; (u) allylBEt $2, \mathrm{Et}_{2} \mathrm{O},-10{ }^{\circ} \mathrm{C}$; (v) catalytic $\mathrm{OsO}_{4}, \mathrm{NMO}$, acetone/ $\mathrm{H}_{2} \mathrm{O}$; (w) $\mathrm{Pb}(\mathrm{OAc})_{4}$, pyridine, DCM; (x) 13, DIPEA, Et ${ }_{2} \mathrm{BuOTf}$ DCM, $-78{ }^{\circ} \mathrm{C}, 15 \mathrm{~min},-30{ }^{\circ} \mathrm{C}, 45 \mathrm{~min}$, add 26, $-78{ }^{\circ} \mathrm{C}, 2 \mathrm{~h}$; (y1) 20 eqv $\mathrm{Me}_{3} \mathrm{OBF}_{4}, 2-$ 6-di-tert-butyl-4-methylpyridine, DCM, RT; (y2) 20 eqv $(R)$ - or (S)-B-Me-CBS, 7 egv $\mathrm{BH}_{3} . \mathrm{SMe}_{2}, \mathrm{DCM},-30{ }^{\circ} \mathrm{C}, 1 \mathrm{~h}$, to RT $4 \mathrm{~h}$, add MeOH; (y3) $0.3 \mathrm{~N}$ aq. LiOH, THF, RT; (y4) $\mathrm{PPh}_{3}$, DIAD, THF, RT, $15 \mathrm{~min}$, add seco-acid over $2 \mathrm{~h}$, then $1 \mathrm{~h}$ at $0{ }^{\circ} \mathrm{C}$; (z) $4 \mathrm{~N}$ $\mathrm{HCl}, \mathrm{THF}, \mathrm{RT}, 3 \mathrm{~h}$.

A late stage 1,3-anti aldol coupling between the side chain $\mathrm{C}_{14}-\mathrm{C}_{24}$ methyl ketone $\mathbf{1 3}$ and fully functionalised $\mathrm{C}_{1}-\mathrm{C}_{13}$ aldehyde $\mathbf{2 6}$ was the key step in the synthesis. The aldol reaction was rather unselective and gave a 2:1 separable mixture of product with $87 \%$ yield. Proceeding with both epimers of the aldol product 27 , the $\mathrm{C}_{13}$ hydroxyl was methylated and the $\mathrm{C}_{15}$ ketone was asymmetrically reduced to give another set of epimers.

Using all of the four resulting epimers, Mitsunobu macrolactonisation gave only lactone 28. This leads to the conclusion that geometrial/conformational constrains of the epimers drove a configuration-dependent mechanistic switch during the macrolactonisation. The configuration-dependent mechanistic switch occurred via an acyloxyphosphonium intermediate (retention) for the $(R)-\mathrm{C}_{15}$ epimer and via an alkoxyphosphonium intermediate (inversion) for the $(S)-\mathrm{C}_{15}$ epimer. Simultaneous cleavage of MOM (methoxymethyl) and TES protecting groups concluded the synthesis of (-)-peloruside A. The synthesis sequence took 29 steps with an overall yield of $3 \%$ from the hexenediol 14. 
1.7.2.2 Synthesis of (+)-peloruside A by Jin and Taylor (Scheme 1.3) $)^{52,60}$

Jin and Taylor approached the synthesis of (+)-peloruside A from a readily available oxazolidinone 34. ${ }^{60}$ Stereoselective alkylation of the oxazolidinone with benzyloxymethyl chloride promoted by titanium tetrachloride, followed by exchange of protecting groups and reductive removal of the chiral auxiliary gave the monoprotected diol 35. Dess-Martin oxidation and Still-Gennari olefination provided the (Z)-trisubsituted alkene $36 .{ }^{60}$ Subsequent conversion of the $C_{15}$ methyl ester to the corresponding aldehyde followed by Brown asymmetric allylation provided the allyl alcohol 37 with a 97:3 diastereomeric ratio. ${ }^{60}$

The desired 1,3-syn relationship between $C_{13}$ and $C_{15}$ hydroxyls was generated by a sterically directed electrophilic iodination sequence to give the six-membered carbonate $38 .{ }^{60}$ Successive epoxidation and reaction with a dithiane synthon, after methylation and dithiane hydrolysis, gave the $\beta$-methoxy aldehyde 39. Mukaiyama aldol reaction of the $\beta$-methoxy aldehyde 39 with the enol silane $\mathbf{4 0}$ gave an 8:1 diasteromeric mixture in favour of the 1,3-anti relationship between $\mathrm{C}_{11}$ and $\mathrm{C}_{13}$ hydroxyls. ${ }^{60}$ Subsequent protection of the $\mathrm{C}_{11}$ hydroxyl as a MOM ether completed the synthesis of the ketone $\mathbf{4 1} .^{52}$

The aldehyde $\mathbf{3 3}$ was synthesised from the commercially available ( $S$ )-glycidyl tosylate $29 .{ }^{52}(S)$-Glycidyl tosylate was treated with lithiated dithiane, followed by copper-catalysed Grignard addition. ${ }^{52}$ The resulting secondary alcohol was silylated and the dithiane was hydrolysed. ${ }^{52}$ Coupling of the resulting aldehyde $\mathbf{3 0}$ with the oxazolidinone $\mathbf{3 1}$ provided the aldol adduct $\mathbf{3 2}$ as a single diastereomer. ${ }^{52}$ Methylation, reprotection of $\mathrm{C}_{2}$ with methoxymethyl chloride, and finally oxidative cleavage of the terminal alkene by ozone gave the aldehyde 33 . 
Scheme 1.3 Synthetic route to (+)-peloruside A by Jin and Taylor. ${ }^{52,60}$

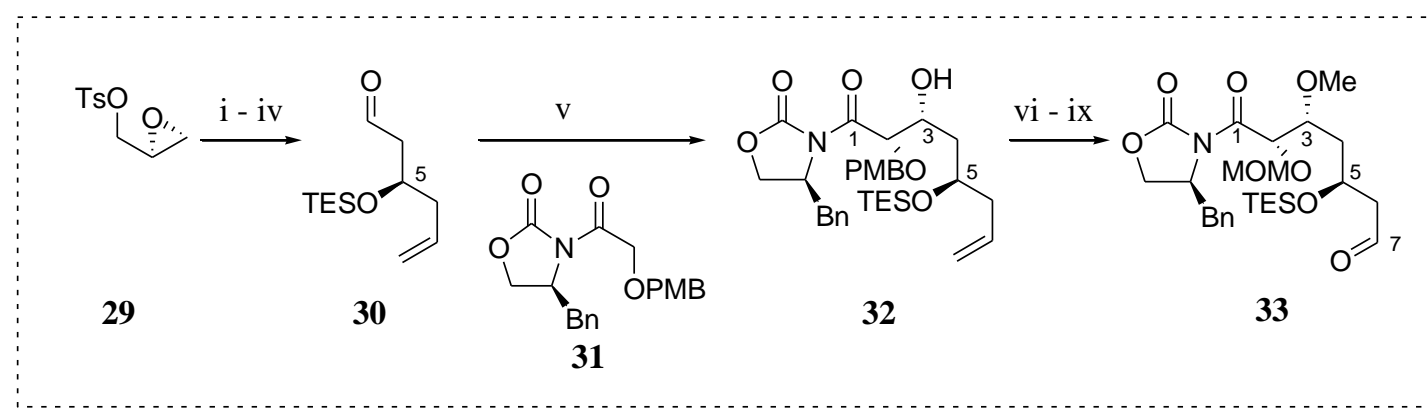

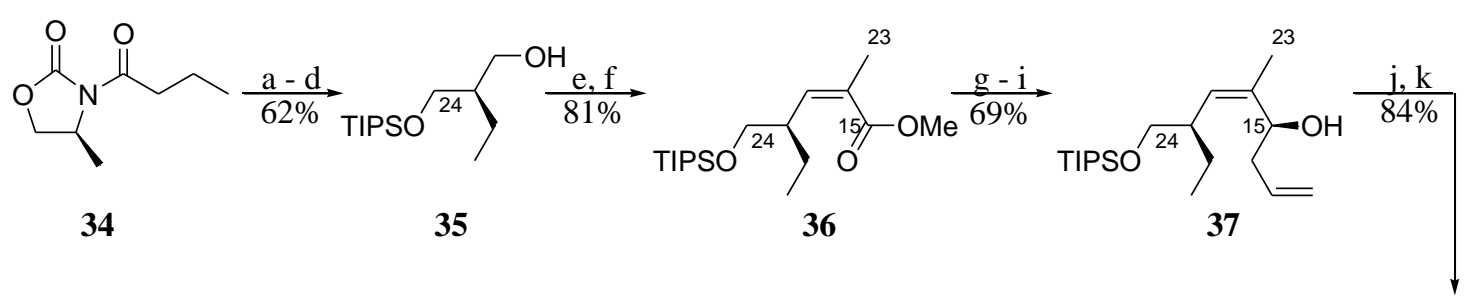

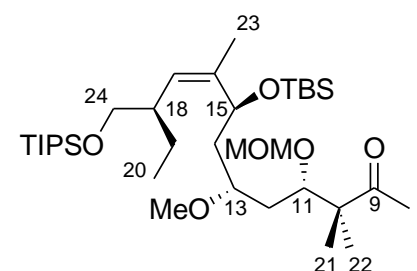

$\begin{array}{r}\mathrm{s}, \mathrm{t} \\ 85 \%\end{array} \mid+\mathbf{3 3}$

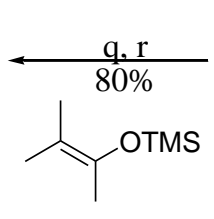

40

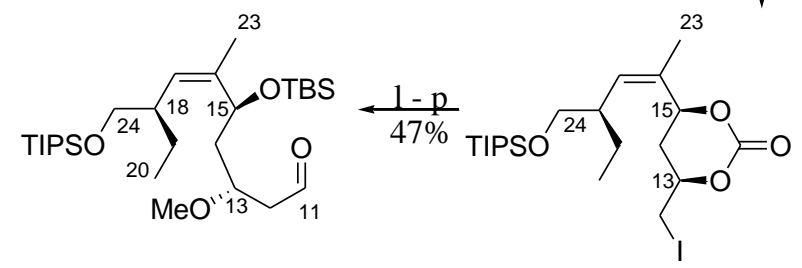

39

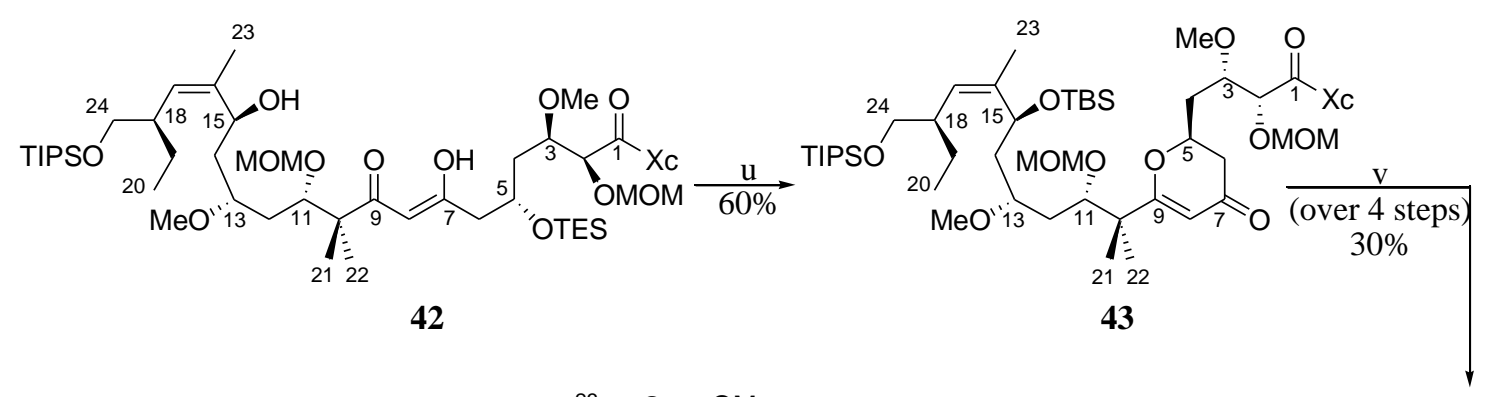

(+)-Peloruside $\mathrm{A} \frac{\mathrm{y}, \mathrm{z}}{43 \%}$ $\mathrm{Xc}_{\mathrm{C}}=\mathrm{s}_{\mathrm{B}}$

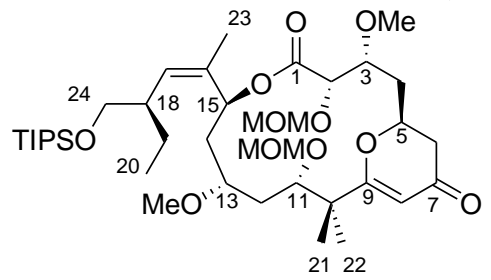

44

Conditions: (i) $n \mathrm{BuLi}$, dithiane; (ii) vinylMgBr, $\mathrm{CuI}$; (iii) $\mathrm{TESCl}$; $\mathrm{MeI}$; (iv) $\mathrm{CaCO}_{3}$; (v) $\mathrm{Bu}_{2} \mathrm{BOTf}$, TEA; (vi) $\mathrm{Me}_{3} \mathrm{OBF}_{4}$; (vii) $\mathrm{DDQ}$; (viii) $\mathrm{MOMCl}$; (ix) ozone, $\mathrm{PPh}_{3}$; (a) $\mathrm{TiCl}_{4}, \mathrm{BOMCl}$; (b) $\mathrm{H}_{2}, \mathrm{Pd} / \mathrm{C}$; (c) TIPSCl; (d) $\mathrm{LiBH}_{4}$; (e) Dess-Martin periodinane; (f) 
18-crown-6, bis(2,2,2-trifluoroethyl)-1-(methoxycarbonyl)ethylphosphonate, THF, KHMDS; (g) DIBAL-H; (h) Dess-Martin periodinane; (i) (+)-Ipc ${ }_{2}$ Ballyl; (j) Boc-ON; (k) NIS, MeCN; (l) $\mathrm{K}_{2} \mathrm{CO}_{3}, \mathrm{MeOH}$; (m) TBSCl, imidazole; (n) 1,3-dithiane, $n \mathrm{BuLi}$; (o) $t \mathrm{BuOK}, \mathrm{MeI}$; (p) $\mathrm{MeI}, \mathrm{MeCN} / \mathrm{H}_{2} \mathrm{O}$; (q) $\mathrm{BF}_{3} . \mathrm{OEt}_{2}, \mathrm{DCM},-78{ }^{\circ} \mathrm{C}$; (r) $\mathrm{MOMCl}$, DIPEA; (s) LDA; (t) Dess-Martin periodinane; (u) PTSA, PhMe; (v1) HF.pyridine; (v2) TIPSCl; (v3) LiOH, $\mathrm{H}_{2} \mathrm{O}$; (v4) 2,4,6- $\mathrm{Cl}_{3} \mathrm{C}_{6} \mathrm{H}_{2} \mathrm{COCl}$, TEA, DMAP; (w) $\mathrm{NaBH}_{4}$, $\mathrm{CeCl}_{3}$; (x) $m \mathrm{CPBA}$; (y) $\mathrm{Me}_{3} \mathrm{OBF}_{4}, 2,6$-di- $t$ Bu-pyridine; (z) $4 \mathrm{~N} \mathrm{HCl}$.

An aldol coupling of the $C_{1}-C_{7}$ aldehyde 33 segment with the $C_{8}-C_{24}$ ketone 41 provided the aldol adduct as a mixture of diastereomers, which was oxidised to give the $\beta$-diketone $\mathbf{4 2}$. The pyranone $\mathbf{4 3}$ was obtained following an approach adapted from De Brabander's synthesis of peloruside A. ${ }^{51}$ Desilylation followed by resilylation with triisopropylsilyl chloride and removal of the auxiliary with lithium hydroxide provided a seco-acid which was activated to undergo Yamaguchi macrolactonisation, yielding $44 .^{52}$

A stereoselective Luche reduction followed by epoxidation of the resulting allylic alcohol yielded the triol $\mathbf{4 5}$, and provided for a selective deprotection of the $\mathrm{C}_{11} \mathrm{MOM}$ in the process. ${ }^{52}$ Jin and Taylor proposed intramolecular glycal epoxide ring fragmentation involving the MOM group, passing through a six-membered transition state, followed by hydrolysis of the intermediate oxo-carbenium ion and the loss of the resulting unstable methyl glycoside upon workup as a rationalisation for the deprotection of the $\mathrm{C}_{11}$ MOM. ${ }^{52}$ Subsequent methylation and global deprotection gave the desired (+)-peloruside A. ${ }^{52}$ The synthesis was achieved in 29 steps with an overall yield of $0.4 \%$ from the oxazolidinone 34 .

\subsubsection{Synthesis of (+)-peloruside A by Ghosh (Scheme 1.4) $)^{53,61}$}

Ghosh opted to synthesise peloruside A from the commercially available (-)-2,3-Oisopropylidene- $D$-threitol $\mathbf{5 2} .^{53}$ The threitol 52 was monoprotected, iodinated, and vinylated to give the alkene 53. The isopropylidene was removed and iodoetherification followed by methylation of the $\mathrm{C}_{3}$ hydroxyl led to the 5-membered cyclic iodoether $54 .{ }^{53}$ The iodoether $\mathbf{5 4}$ was then cleaved and the $\mathrm{C}_{2}$ hydroxyl was protected as MOM ether, overall achieving differential protection at the $\mathrm{C}_{2}$ and $\mathrm{C}_{3}$ 
ethers. The resulting olefin $\mathbf{5 5}$ was converted to an aldehyde, then Brown allylation performed to give the allylic alcohol $56 .{ }^{53}$

The allyl alcohol 56 was silylated and the terminal olefin was again converted to an aldehyde then subjected to Z-selective Ando method of HWE (Horner-WadsworthEmmons olefination to provide the Z-olefin $57 .{ }^{53}$ Sharpless asymmetric dihydroxylation of the olefin $\mathbf{5 7}$ gave a diol which was protected as an isopropylidene acetal 58 under acidic conditions. Subsequent DIBAL-H (diisobutylaluminium hydride) reduction, Grignard addition to the aldehyde, and Dess-Martin oxidation of the alcohol gave the desired enone 59. ${ }^{53}$

The aldehyde $\mathbf{5 1}$ was synthesised from the oxazolidinone 46. Asymmetric alkylation of the imide 46 with benzyloxymethylene chloride followed by reductive removal of the chiral oxazolidinone gave the alcohol $47 .{ }^{61}$ Swern oxidation and the subsequent $Z$ selective HWE reaction of the aldehyde with the sodium enolate of (ocreosol $)_{2} \mathrm{P}=\mathrm{O}\left(\mathrm{CH}_{3}\right) \mathrm{CHCO}_{2} \mathrm{Et}$ provided tri-substituted Z-olefin $4{ }^{61}$ Subsequent DIBAL-H reduction, Dess-Martin oxidation and Brown asymmetric allylboration gave the homoallylic alcohol 49 as the major diastereomer $(\mathrm{dr}=97: 3) .{ }^{61}$ Protection of the $\mathrm{C}_{15}$ hydroxyl as TES ether followed by oxidative cleavage to an aldehyde and the subsequent asymmetric allylation gave alcohol 50 with 5:1 diastereomeric ratio. ${ }^{53}$ Subsequent methylation and oxidative cleavage of the $\mathrm{C}_{11}$ olefin provided the aldehyde $\mathbf{5 1 .}$ 
Scheme 1.4 Synthetic route to (+)-peloruside A by Ghosh. ${ }^{53,61}$

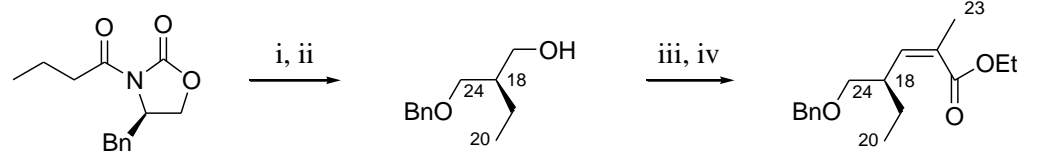

$$
\begin{aligned}
& 46 \\
& \text { v - vii }
\end{aligned}
$$
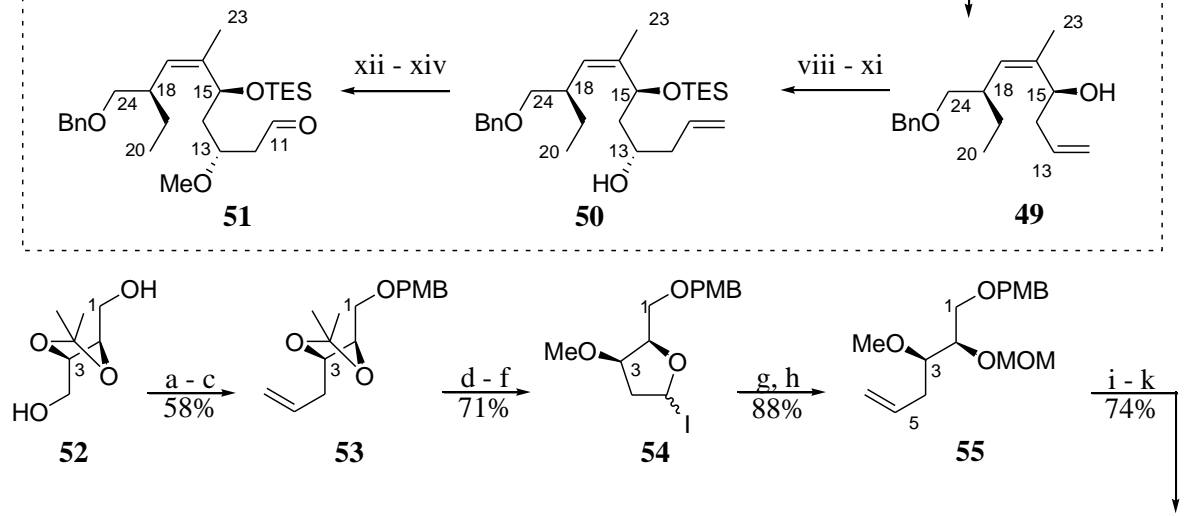<smiles>C=C(C)C(=O)OC1OC(C)(C)OC1COCCOC</smiles>

59

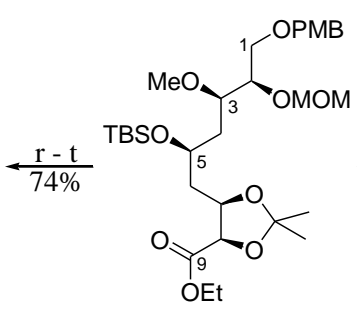

58

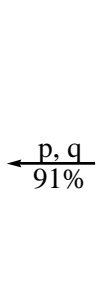

$\frac{p, q}{91 \%}$<smiles>CCOC(=O)/C=C\C[C@H](C[C@@H](OCC)[C@H](COC)OC)OC</smiles>

57<smiles>C=CCC(O)CC(OC)C(COCCCCCC)OC</smiles>

56

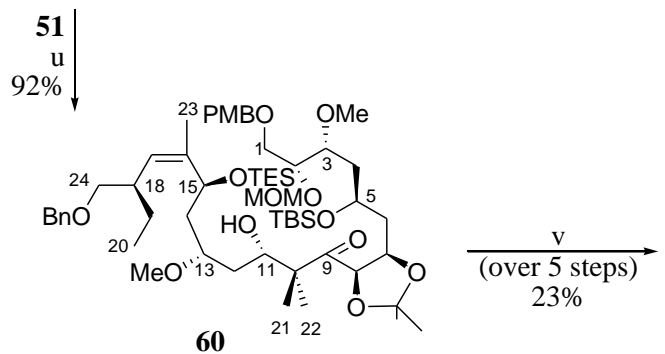

60

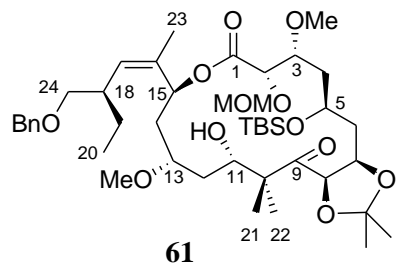

(+)-Peloruside A
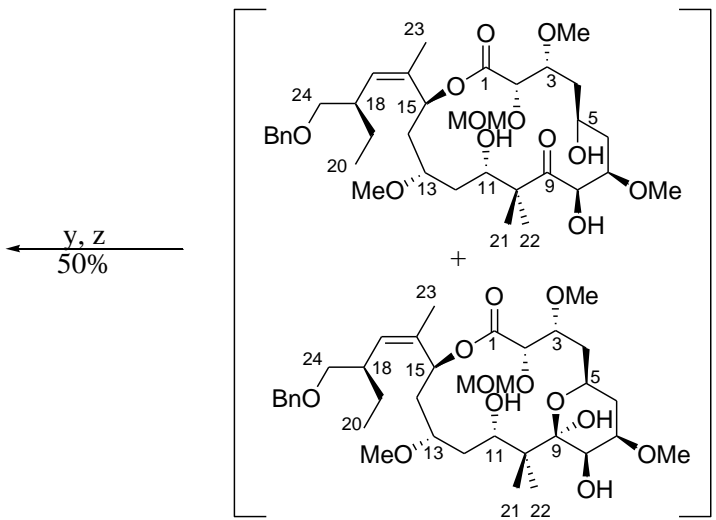

62

Conditions: (i) $\mathrm{TiCl}_{4}$, TEA, DCM, $\mathrm{PhCH}_{2} \mathrm{OCH}_{2} \mathrm{Cl}, 0{ }^{\circ} \mathrm{C}, 1.5 \mathrm{~h}$; (ii) $\mathrm{LiBH}_{4}, \mathrm{MeOH}$, THF, $23{ }^{\circ} \mathrm{C}, 1 \mathrm{~h}$; (iii) $(\mathrm{COCl})_{2}$, DMSO, TEA, DCM, -60 ${ }^{\circ} \mathrm{C}, 45 \mathrm{~min}$; (iv) (o- 
creosol $)_{2} \mathrm{P}(\mathrm{O})(\mathrm{Me}) \mathrm{CHCO}_{2} \mathrm{Et}, \mathrm{NaH}, \mathrm{THF},-78$ to $-40{ }^{\circ} \mathrm{C}, 2 \mathrm{~h}$; (v) DIBAL-H, DCM, -78 to $-40{ }^{\circ} \mathrm{C}, 1 \mathrm{~h}$; (vi) Dess-Martin periodinane, $\mathrm{NaHCO}_{3}, \mathrm{DCM}, 23{ }^{\circ} \mathrm{C}, 1.5 \mathrm{~h}$; (vii) (+)$\mathrm{Ipc}_{2}$ Ballyl, $\mathrm{Et}_{2} \mathrm{O},-80{ }^{\circ} \mathrm{C}, 3 \mathrm{~h}$; (viii) TESOTf, 2,6-lutidine; (ix) $\mathrm{OsO}_{4}, \mathrm{NMO}$; (x) $\mathrm{Pb}(\mathrm{OAc})_{4}, \mathrm{DCM}$; (xi) (-)-Ipc $\mathrm{IBOMe}_{2}$, allylMgBr; (xii) $\mathrm{Me}_{3} \mathrm{OBF}_{4}$, Proton-sponge ${ }^{\circledR}$; (xiii) $\mathrm{OsO}_{4}, \mathrm{NMO}$; (xiv) $\mathrm{Pb}(\mathrm{OAc})_{4}, \mathrm{DCM}$; (a) $\mathrm{NaH}, \mathrm{PMBCl}$; (b) $\mathrm{PPh}_{3}, \mathrm{I}_{2}$, imidazole; (c) CuI, vinylMgBr; (d) $10 \% \mathrm{HCl}, \mathrm{MeOH}$; (e) $\mathrm{I}_{2}, \mathrm{NaHCO}_{3}$; (f) $\mathrm{Me}_{3} \mathrm{OBF}_{4}$, Protonsponge $^{\circledR}$; (g) Zn, aqueous EtOH; (h) MOMCl, DIPEA; (i) $\mathrm{OsO}_{4}, \mathrm{NMO}$; (j) $\mathrm{NaIO}_{4}$, aqueous THF; (k) Ipc $\mathrm{Ipallyl}_{2} \mathrm{Et}_{2} \mathrm{O}$; (l) $\mathrm{TBSCl}$, imidazole; (m) $\mathrm{OsO}_{4}, \mathrm{NMO}$; (n) $\mathrm{NaIO}_{4}$, aqueous THF; (o) $(o \text {-cresol })_{2} \mathrm{P}(\mathrm{O}) \mathrm{CH}_{2} \mathrm{CO}_{2} \mathrm{Et}, \mathrm{NaH}$; (p) AD-mix- $\alpha, t \mathrm{BuOH}$ $\mathrm{H}_{2} \mathrm{O}$; (q) $\mathrm{CH}_{2}=\mathrm{C}(\mathrm{OMe}) \mathrm{Me}$, PPTS; (r) DIBAL-H, THF; (s) $i \operatorname{PrMgBr}$; (t) Dess-Martin periodinane; (u) L-selectride, $\mathrm{Et}_{2} \mathrm{O},-78{ }^{\circ} \mathrm{C}$, then 51, $1 \mathrm{~h}$; (v1) DDQ (cat.), aq. THF; (v2) DDQ, DCM; (v3) TPAP, NMO, DCM; (v4) $\mathrm{NaClO}_{2}, \mathrm{NaH}_{2} \mathrm{PO}_{4}$; (v5) 2,4,6$\mathrm{Cl}_{3} \mathrm{C}_{6} \mathrm{H}_{2} \mathrm{COCl}$, DIPEA, then DMAP, toluene; (w) $1 \mathrm{M} \mathrm{HCl}$, THF; (x) $\mathrm{Me}_{3} \mathrm{OBF}_{4}$, 2,6di- $t$ Bu-pyridine; (y) Pd/C, MeOH, formic acid; (z) $4 \mathrm{M} \mathrm{HCl,} \mathrm{THF.}$

A conjugate reduction-aldol coupling between the enone $\mathbf{5 9}$ and the aldehyde $\mathbf{5 1}$ completed the $\mathrm{C}_{1}-\mathrm{C}_{24}$ backbone, which proceed by selective enolisation. The aldol product 60 was obtained as a 4:1 mixture of diastereomers. ${ }^{53}$ The $\mathrm{C}_{15}$ TES and $\mathrm{C}_{1}$ PMB protecting groups were then selectively removed with DDQ. The primary alcohol at $\mathrm{C}_{1}$ was oxidised to an aldehyde which was then further oxidised to a carboxylic acid. The carboxylic acid was subjected to Yamaguchi lactonisation to provide the corresponding macrolactone $61 .{ }^{53}$ The subsequent deprotection of the $\mathrm{C}_{5}$ TBS (tert-butyldimethylsilyl) and the isopropylidene protecting groups gave a mixture of ketone and hemi-ketal. Selective methylation of the resulting diol converted the $\mathrm{C}_{7}$ hydroxyl to the desired methyl ether, giving $62 .{ }^{53}$ The benzyl ether at $\mathrm{C}_{24}$ was removed by transfer hydrogenation. The subsequent treatment with aqueous acid removed the MOM ether at $\mathrm{C}_{2}$, completing the synthesis of (+)-peloruside A. ${ }^{53}$ The synthesis was completed in 30 steps with $1 \%$ total yield from (-)-2,3-Oisopropylidene- $D$-threitol.

\subsubsection{Synthesis of (+)-peloruside A by Evans (Scheme 1.5) ${ }^{54}$}

The Evans group based their synthesis of peloruside A on aldol coupling reactions to build the skeleton of peloruside A. The peloruside A backbone was assembled from 
three major synthons: the $\mathrm{C}_{1}-\mathrm{C}_{6}$ methyl ketone $\mathbf{6 6}$, the $\mathrm{C}_{7}-\mathrm{C}_{11}$ aldehyde $\mathbf{7 0}$, and the $\mathrm{C}_{12}-\mathrm{C}_{24}$ methyl ketone $\mathbf{7 8}$. The synthesis of the methyl ketone $\mathbf{7 8}$ commenced from the oxazolidinone alcohol 73. ${ }^{62}$ Silylation of the $\mathrm{C}_{24}$ hydroxyl followed by removal of the oxazolidinone moiety provided the alcohol 74. Subsequent Swern oxidation and phosphonate coupling provided the enoate 75. DIBAL-H reduction of the ester $\mathbf{7 5}$ gave the allylic alcohol 76. Subsequent oxidation and Brown allylation of the resulting aldehyde gave the alcohol 77. Protection of the $\mathrm{C}_{15}$ hydroxyl as a PMB ether and redox reaction provided the methyl ketone $\mathbf{7 8 .}$

The synthesis of the aldehyde $\mathbf{7 0}$ was started from $(S)$-pantolactone (67). The pantolactone 67 was benzylated and the lactone was ring opened to the corresponding Weinreb amide. Subsequent silylation of the $C_{11}$ hydroxyl gave 68. Olefination of the amide 68 provided the ketone 69. Chelation-controlled reduction of the ketone 69 provided the corresponding alcohol with 95:5 diastereomeric ratio. Protection of the resulting $\mathrm{C}_{8}$ hydroxyl with tert-butyldimethylsilyl chloride followed by oxidative cleavage at $\mathrm{C}_{7}$ furnished the aldehyde 70. Methyl ketone $\mathbf{6 6}$ was synthesised from commercially available (S)-4-benzyl-2-oxazolidinone, which was converted to the corresponding glycolate oxazolidinone 63 and coupled to the aldehyde 64 . The subsequent 1,2-syn aldol product $\mathbf{6 5}$ was methylated and the $\mathrm{C}_{5}$ acetal was removed to provide the methyl ketone $\mathbf{6 6}$.

1,5-Anti aldol coupling, mediated by 9-BBNOTf (9-Borabicyclo[3.3.1]nonyl trifluoromethanesulfonate), between the methyl ketone $\mathbf{6 6}$ and aldehyde $\mathbf{7 0}$ provided the alcohol 71 with an excellent diastereoselectivity $(\mathrm{dr}=98: 2)$. However, the selectivity for the desired $(R)$-diastereomer depends on the dialkylboryl enolate employed in the reaction and the size of the $\mathrm{C}_{11}$ protecting group. The use of dicyclohexylboron chloride as coupling reagent saw a shift to favour the $(S)$ diastereomer as the major product. Similarly, using a larger BOM (benzyloxymethyl) as $\mathrm{C}_{11}$ protecting group reduced the diastereoselectivity of the 1,5-anti aldol coupling reaction. The $\mathrm{C}_{5}$ ketone was selectively reduced to give the corresponding 1,3-anti diol $(\mathrm{dr}=10: 1)$. The less hindered $\mathrm{C}_{5}$ hydroxyl was selectively silylated followed by methylation of the $\mathrm{C}_{7}$ hydroxyl. The subsequent hydrogenation and Dess-Martin oxidation provided the $\mathrm{C}_{7}-\mathrm{C}_{11}$ synthon $\mathbf{7 0}$. 
Scheme 1.5 Synthetic route to (+)-peloruside A by Evans. ${ }^{54}$
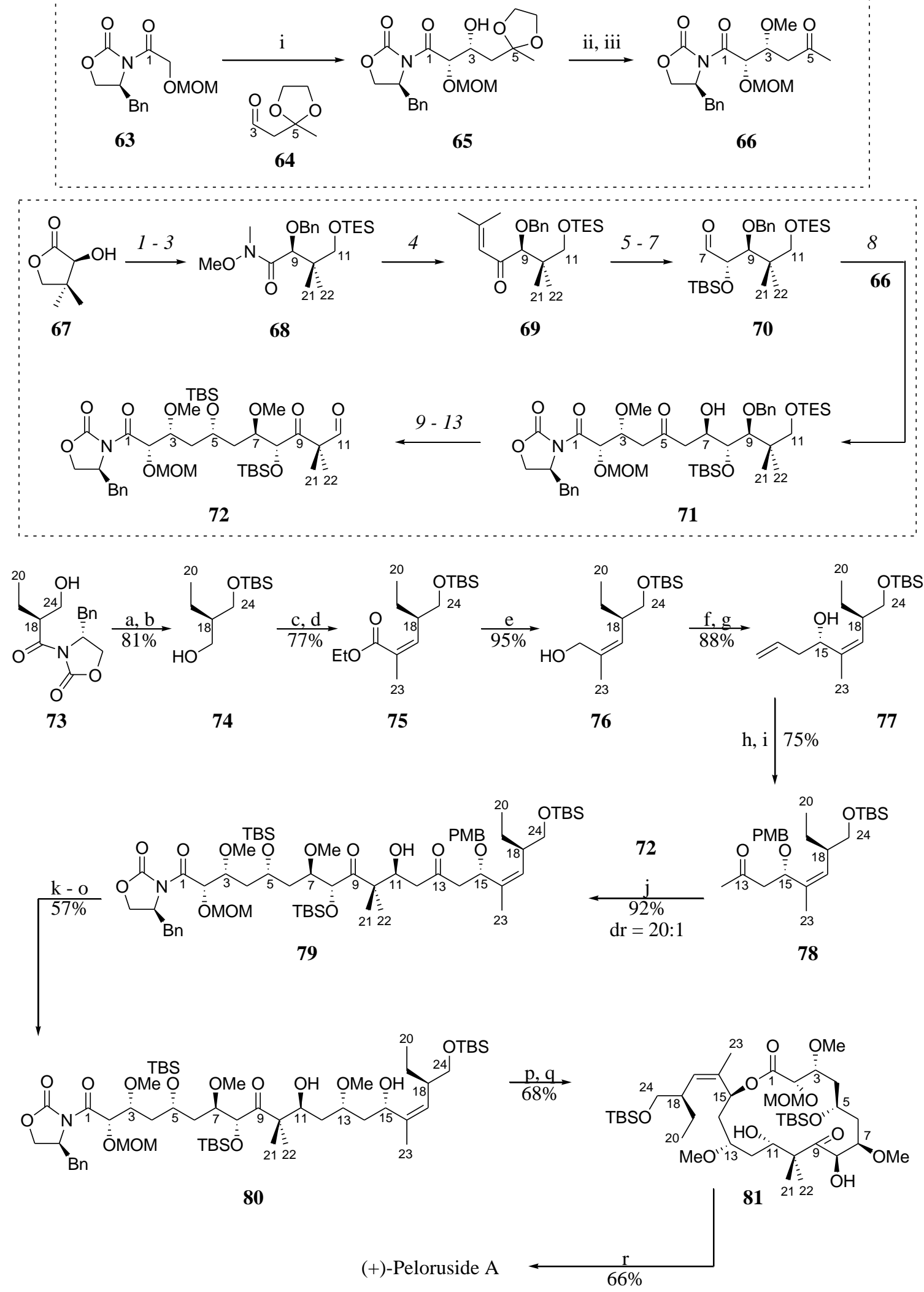

Conditions: (i) $\mathrm{Bu}_{2} \mathrm{BOTf}$, DIPEA; (ii) $\mathrm{Me}_{3} \mathrm{OBF}_{4}$, Proton-sponge ${ }^{\circledR}$; (iii) PPTS, acetone, $\Delta$; (1) $\mathrm{BnON}(\mathrm{H}) \mathrm{CCl}_{3}, \mathrm{HOTf}, \mathrm{RT}$; (2) $\mathrm{Me}_{2} \mathrm{Al}, \mathrm{MeON}(\mathrm{H}) \mathrm{Me} . \mathrm{HCl}, \mathrm{DCM}, 0{ }^{\circ} \mathrm{C}$; (3) 
TESCl, TEA, DMAP, RT ; (4) $\mathrm{Me}_{2} \mathrm{C}=\mathrm{CHBr}, t \mathrm{BuLi}, \mathrm{Et}_{2} \mathrm{O}$; (5) $\mathrm{Zn}\left(\mathrm{BH}_{4}\right)_{2},-30{ }^{\circ} \mathrm{C}$; (6) TBSCl; (7) $\mathrm{O}_{3}, \mathrm{PPh}_{3}$; (8) 9-BBNOTf, TEA, toluene; (9) $\mathrm{Me}_{4} \mathrm{~N}(\mathrm{OAc})_{3} \mathrm{BH}, \mathrm{AcOH}$, $\mathrm{MeCN},-30{ }^{\circ} \mathrm{C}$; (10) TBSCl, imidazole, RT; (11) $\mathrm{Me}_{3} \mathrm{OBF}_{4}$, Proton-sponge ${ }^{\circledR}, \mathrm{DCM}$, RT; (12) $\mathrm{Pd}(\mathrm{OH})_{2} / \mathrm{C}, \mathrm{H}_{2}$, EtOAc, RT; (13) Dess-Martin periodinane, pyridine, DCM, $0{ }^{\circ} \mathrm{C}$; (a) TBSCl, imidazole, DMF; (b) $\mathrm{LiBH}_{4}, \mathrm{H}_{2} \mathrm{O}, \mathrm{Et}_{2} \mathrm{O}, 20^{\circ} \mathrm{C}$; (c) $(\mathrm{COCl})_{2}, \mathrm{DMSO}$, TEA, $-78{ }^{\circ} \mathrm{C}$ to RT; (d) $(\mathrm{PhO})_{2} \mathrm{P}(=\mathrm{O}) \mathrm{CH}(\mathrm{Me}) \mathrm{CO}_{2} \mathrm{Et}, \mathrm{NaH}, \mathrm{THF},-78$ to $0{ }^{\circ} \mathrm{C}$; (e) DIBAL-H, DCM, $-78{ }^{\circ} \mathrm{C}$; (f) $\mathrm{MnO}_{2}$, DCM, RT; (g) (+)-IpcBallyl, Et $2 \mathrm{O},-78{ }^{\circ} \mathrm{C}$; (h) $\mathrm{NaH}$, THF, $0{ }^{\circ} \mathrm{C}$; then PMBBr, 3:1 THF/DMF, RT; (i) $\mathrm{PdCl}_{2}, \mathrm{Cu}(\mathrm{OAc})_{2} . \mathrm{H}_{2} \mathrm{O}, \mathrm{O}_{2}, 7: 1$ DMF/H $\mathrm{H}_{2} \mathrm{O}, \mathrm{RT}$; (j) 9-BBNOTf, DIPEA, 72; (k) (iPr) $)_{2} \mathrm{SiHCl}, \mathrm{DMAP}, \mathrm{DMF}$; (l) $\mathrm{SnCl}_{4}$, $-78{ }^{\circ} \mathrm{C}$; (m) TBAF, HOAc, THF, $-20{ }^{\circ} \mathrm{C}$; (n) $\mathrm{Me}_{3} \mathrm{OBF}_{4}$, Proton-sponge ${ }^{\circledR}$, DCM, RT; (o) DDQ; (p) $\mathrm{H}_{2} \mathrm{O}_{2}$, LiOH; (q) 2,4,6- $\mathrm{Cl}_{3} \mathrm{C}_{6} \mathrm{H}_{2} \mathrm{COCl}$, DIPEA, THF, RT, then DMAP, toluene, $60{ }^{\circ} \mathrm{C}$; (r) $4 \mathrm{~N} \mathrm{HCl}, \mathrm{MeOH}, 1 \mathrm{~h}, 0{ }^{\circ} \mathrm{C}, 2 \mathrm{~h}, \mathrm{RT}$.

A second 1,5-anti aldol coupling by 9 -BBNOTf between the methyl ketone $\mathbf{7 8}$ and aldehyde 72 completed the backbone of peloruside A. The stereoselectivity was dependent on the reduced steric hindrance and enhanced electronic effects provided by the neighbouring $C_{9}$ carbonyl. The resulting aldol product 79 was obtained in 20:1 diastereomeric ratio. Subsequent conversion of the $C_{11}$ hydroxyl, stereoselective reduction of the $C_{15}$ ketone, removal of the resulting $C_{11}-C_{13}$ disilyloxane protecting group, selective methylation of $\mathrm{C}_{13}$ and deprotection of $\mathrm{C}_{15}$ gave the diol 80. Removal of the chiral auxiliary followed by Yamaguchi macrolactonisation afforded the desired macrolactone 81. Subsequent global deprotection of the macrolactone 81 concluded the synthesis of (+)-peloruside A. The synthesis was achieved within 18 steps with a total yield of $12 \%$ from the oxazolidinone alcohol $\mathbf{7 3 .}$

\subsubsection{Synthesis of peloruside A analogues}

The following section will discuss the synthesis approaches towards the (-)-2-epipeloruside A analogue by Smith, monocyclic peloruside A analogue by Wullschleger, and peloruside B by Ghosh. 


\subsubsection{1 (-)-2-epi-peloruside A}

The original synthetic route of the Smith group was designed to provide (+)peloruside A. The synthetic strategy (Scheme 1.6) ${ }^{57}$ made use of ARC (anion relay chemistry) reaction as a key step for the assembly of the $\mathrm{C}_{1}-\mathrm{C}_{8}$ synthon $\mathbf{9 5}$. The synthesis began with ARC reaction between the lithium anion of the dithiane 91 and the two known epoxides 90 and 92 to give the alcohol 93.

Subsequently, the $\mathrm{C}_{7}$ hydroxyl was methylated and the $\mathrm{C}_{3}$ TBS protecting group was removed. The $\mathrm{C}_{5}$ dithiane was converted to ketone and then selectively reduced. The resulting 1,3-syn diol was protected with acetonide. Subsequent hydrogenolysis to remove the $C_{1}$ benzyl protecting group afforded the alcohol 94 . Conversion of the alcohol 94 to the corresponding methyl ester followed by oxidative cleavage of the PMB functionality and Parikh-Doering oxidation of the terminal hydroxyl provided the aldehyde 95.

The $\mathrm{C}_{9}-\mathrm{C}_{24}$ synthon 89 was synthesised from (+)-3-ethylbut-3-en-1-ol (82). The $\mathrm{C}_{24}$ hydroxyl was protected as BPS (tert-butyldiphenylsilyl) ether followed by ozonolysis of the alkene double bond to afford the aldehyde 83. A Z-selective Still-Gennari olefination yielded the ester $\mathbf{8 4}$ as a single diastereomer. Subsequent reduction followed by oxidation provided an aldehyde which underwent Brown allylation to give the allylic alcohol $\mathbf{8 5}$. The alcohol $\mathbf{8 5}$ was obtained in $77 \%$ yield with a 20:1 diastereomeric ratio.

Conversion of the $\mathrm{C}_{15}$ hydroxyl to PMB ether followed by dihydroxylation and oxidative cleavage provided the aldehyde 86. Subsequent coupling of the aldehyde $\mathbf{8 6}$ with the dithianated ketone $\mathbf{8 7}$ provided the desired $\beta$-hydroxy ketone $\mathbf{8 8}$ in $86 \%$ yield with a 20:1 diasteromeric ratio. A selective Evans-Tischenko reduction by $\mathrm{SmI}_{2}$ installed the $\mathrm{C}_{11}$ sterochemistry as a propionate ester, which was hydrolysed and protected as MOM ether. Subsequent DIBAL-H reduction and methylation provided the dithiane 89. 
Scheme 1.6 Synthetic route to (-)-2-epi-peloruside A by Smith. ${ }^{57}$

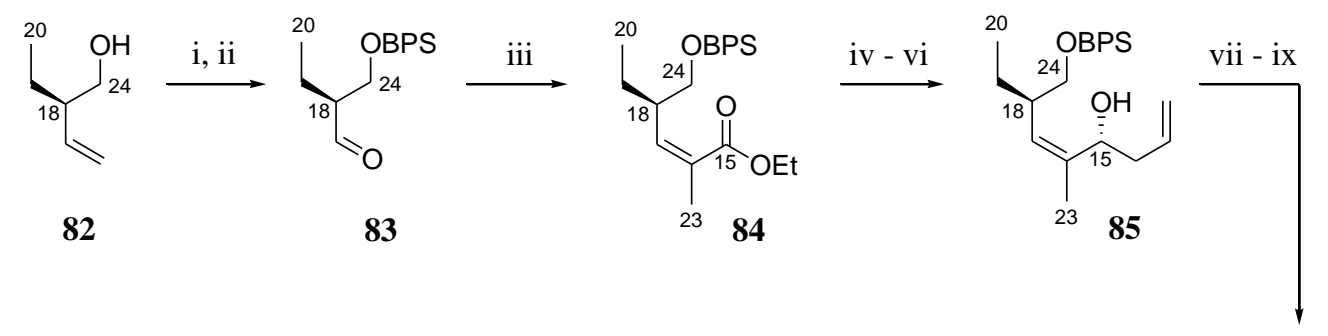

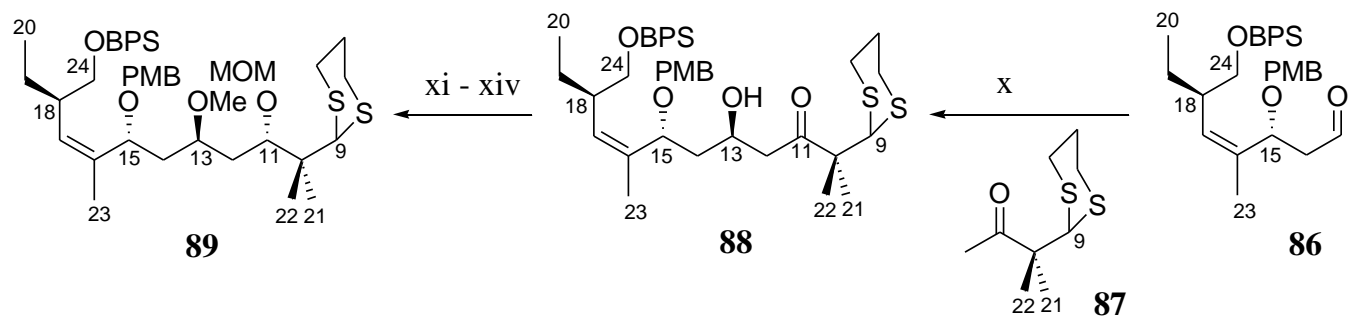

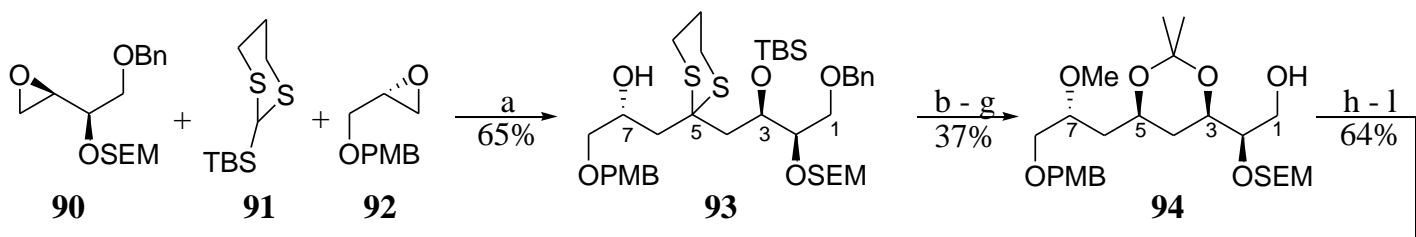

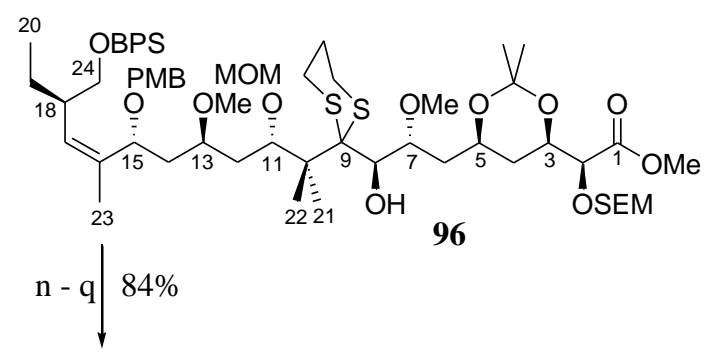

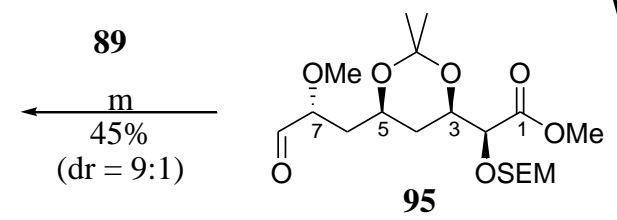

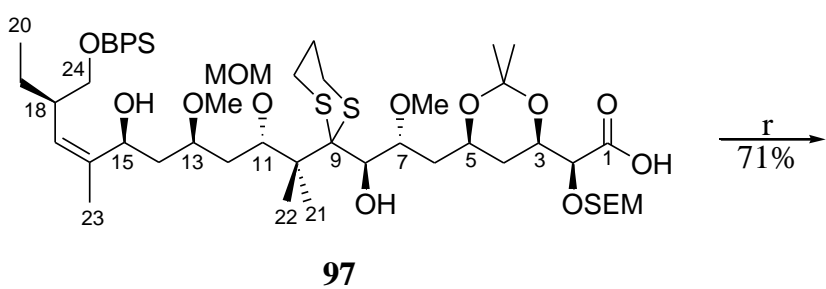

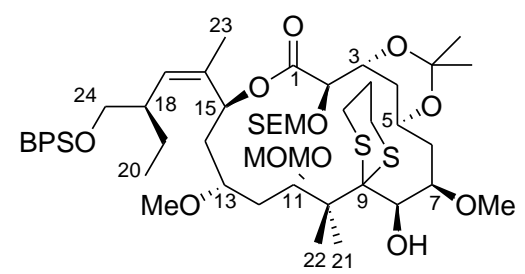

98

(-)-2-epi-Peloruside A
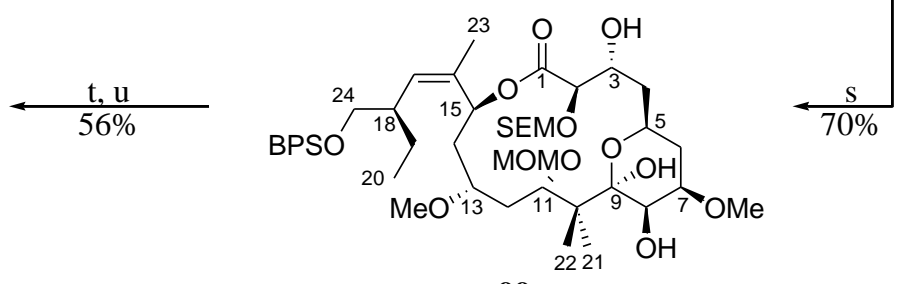

99

Conditions: (i) $\mathrm{BPSCl}, \mathrm{TEA}$; (ii) $\mathrm{O}_{3}, \mathrm{PPh}_{3}$; (iii) $\left(\mathrm{CF}_{3} \mathrm{CH}_{2} \mathrm{O}\right)_{2} \mathrm{P}(\mathrm{O}) \mathrm{C}(\mathrm{Me}) \mathrm{CO}_{2} \mathrm{Et}$, KHMDS, 18-crown-6, THF; (iv) DIBAL-H; (v) $\mathrm{SO}_{3}$.pyridine, DMSO; (vi) (+)- 
$\mathrm{Ipc}_{2}$ Ballyl; (vii) $\mathrm{PMBCl}, \mathrm{NaH}, \mathrm{TBAI}$; (viii) $\mathrm{AD}-$ mix- $\beta, t \mathrm{BuOH}$; (ix) $\mathrm{NaIO}_{4}, \mathrm{THF}$, $\mathrm{H}_{2} \mathrm{O}$; (x) LiHMDS, TMSCl, $\mathrm{C}\left(\mathrm{SC}_{3} \mathrm{H}_{6} \mathrm{~S}\right) \mathrm{C}(\mathrm{Me})_{2} \mathrm{C}(\mathrm{O}) \mathrm{Me}, \mathrm{BF}_{3} \cdot \mathrm{OEt}_{2}$; (xi) $\mathrm{SmI}_{2}$, EtCHO; (xii) MOMCl, DIPEA; (xiii) DIBAL-H; (xiv) MeI, NaH, 15-crown-5; (a) 91, $t \mathrm{BuLi}, \mathrm{Et}_{2} \mathrm{O}$, then 90 in $\mathrm{Et}_{2} \mathrm{O}$, then 92, THF, HMPA; (b) MeI, NaH; (c) TBAF; (d) $\mathrm{Hg}\left(\mathrm{CIO}_{4}\right)_{2}$; (e) $\mathrm{NaBH}_{4}, \mathrm{Et}_{2} \mathrm{BOMe}$; (f) DMP, PPTS; (g) $\mathrm{Pd}(\mathrm{OH})_{2},\left(\mathrm{C}_{6} \mathrm{H}_{7}\right) \mathrm{CH}_{3}, \mathrm{CaCO}_{3}$, EtOH; (h) $\mathrm{SO}_{3}$.pyridine, DMSO; (i) $\mathrm{NaCIO}_{2}, \mathrm{NaHPO}_{4}$, 2-methyl-2-butene; (j) TMSCHN 2 , MeOH; (k) DDQ, pH 7.0 buffer; (l) $\mathrm{SO}_{3}$.pyridine, DMSO; (m) 89, $t \mathrm{BuLi}$, HMPA, THF, $-78{ }^{\circ} \mathrm{C}, 30 \mathrm{~min}$, then 95, THF, $-78{ }^{\circ} \mathrm{C}, 4 \mathrm{~h}$; (n) DDQ, pH 7.0; (o) $\mathrm{SO}_{3}$.pyridine, DMSO; (p) (R)-Me-CBS, BH 3 .THF; (q) LiOH, $\mathrm{H}_{2} \mathrm{O}$, THF; (r) 2,4,6$\mathrm{Cl}_{3} \mathrm{C}_{6} \mathrm{H}_{2} \mathrm{COCl}$, DIPEA, THF, DMAP, $\mathrm{PhCH}_{3}, 90{ }^{\circ} \mathrm{C}$; (s) $\mathrm{PhI}\left(\mathrm{O}_{2} \mathrm{CCF}_{3}\right)_{2}, \mathrm{MeCN}, \mathrm{H}_{2} \mathrm{O}$, $0{ }^{\circ} \mathrm{C}$ to RT; (t) $\mathrm{Me}_{3} \mathrm{OBF}_{4}$, 2,6-di-tert-butyl-4-methylpyridine; (u) $4 \mathrm{~N} \mathrm{HCl}, \mathrm{MeOH}$.

Felkin-Anh controlled coupling between the lithium anion derived from $\mathrm{C}_{9}-\mathrm{C}_{24}$ dithiane 89 and $\mathrm{C}_{1}-\mathrm{C}_{8}$ aldehyde 95 produced the full $\mathrm{C}_{1}-\mathrm{C}_{24}$ backbone. The coupled product 96 was obtained with a 9:1 diastereomeric ratio. The initial attempt to utilise Mitsunobu protocol for macrolactonisation, after liberation of the $\mathrm{C}_{15}$ hydroxyl and the carboxylic acid, failed to provide the desired result. Therefore, the attempt was deflected to inverting the $\mathrm{C}_{15}$ hydroxyl for the purpose of achieving Yamaguchi macrolactonisation.

The PMB protecting group of the $\mathrm{C}_{15}$ was removed to reveal the secondary hydroxyl group, which was then oxidised. Subsequent asymmetric CBS (Corey-BakshiShibata) reduction selectively provided the required stereogenicity. Saponification provided the seco-acid $\mathbf{9 7}$. The Yamaguchi macrolactonisation protocol generated the macrolide 98. However, the formation of the macrolide 98 involved an unexpected epimerisation at $\mathrm{C}_{2}$. A computer generated conformational study showed that, as a result of torsional strain in the macrocyclic ring, the major torsional differences between the lower energy conformers resided in the $C_{1}-C_{2}$ bond. The epimerisation was a result of the macrolide adopting the more stable conformation.

Subsequent treatment of the macrolide $\mathbf{9 8}$ with Stork reagent resulted in the removal of the $\mathrm{C}_{3}-\mathrm{C}_{5}$ isopropylidene protecting group and hydrolysis of the 1,3-dithiane at $\mathrm{C}_{9}$, with concomitant hemiketal formation to give 99. Selective methylation of the $\mathrm{C}_{3}$ hydroxyl followed by global deprotection afforded the (-)-2-epi-variant of peloruside 
A. The synthesis was achieved in 21 linear steps with $2 \%$ total yield from the known epoxide 90.

\subsubsection{Monocyclic peloruside A analogue}

Recently, Wullschleger reported the synthesis (Scheme 1.7$)^{58}$ of the first synthetic analogue of peloruside A with significant structural changes. The analogue was a monocyclic version of peloruside $A$ which lacks the $\mathrm{C}_{6}-\mathrm{C}_{8}$ part of the pyran ring. The analogue was synthesised in 19 steps with an overall yield of $4 \%$ from epoxide $\mathbf{1 0 8}$. Antipoliferative activity assessment against three human cell line revealed that the monocyclic analogue has less bioactivity compared to peloruside $\mathrm{A}$. The $\mathrm{IC}_{50}$ towards MCF-7 and HCT116 cell lines is $>20 \mu \mathrm{M}$ and the $\mathrm{IC}_{50}$ towards A549 cell line is 16.4 $\mu \mathrm{M}$.

The synthetic route adopted by Wullschleger utilised conversion of $(S)$-aspartic acid to the epoxide 108. Ring opening and coupling of the epoxide 108 with lithiated dithiane 109, obtained from 2,2-dimethylpropane-1,3-diol, followed by conversion of the resulting hydroxyl at $\mathrm{C}_{13}$ to methyl ether provided 110. Subsequent removal of the $\mathrm{C}_{11}$ dithiane and $\mathrm{C}_{9}$ TBS protecting groups, followed by Swern oxidation of the resulting alcohol afforded the aldehyde $\mathbf{1 1 1}$.

Asymmetric allyltitanation installed the olefin of homoallylic alcohol 112 with up to 70:1 diastereomeric ratio. The $\mathrm{C}_{11}$ ketone was selectively reduced to give 1,3-anti diol. Double silylation of the resulting $\mathrm{C}_{11}$ and $\mathrm{C}_{9}$ hydroxyls as TBS ether ensued. Subsequent oxidative cleavage to remove the $\mathrm{C}_{15} \mathrm{PMB}$ protecting group followed by oxidation of the resulting alcohol gave the aldehyde $\mathbf{1 1 3}$.

The $\mathrm{C}_{16}-\mathrm{C}_{24}$ synthon $\mathbf{1 0 3}$ was synthesised from the oxazolidinone $\mathbf{1 0 0}$. Diastereoselective Evans alkylation of the oxazolidinone 100 with benzyloxymethyl chloride using $\mathrm{TiCl}_{4}$ provided the starting building block $101{ }^{62}$ Reductive removal of the oxazolidinone moiety of $\mathbf{1 0 1}$ afforded the alcohol 102. Subsequent Swern oxidation followed by $Z$-selective Wittig olefination furnished the vinyl iodide $\mathbf{1 0 3}(\mathrm{dr}$ $=10: 1)$. 
Scheme 1.7 Synthetic route to monocyclic peloruside A analogue by Wullschleger. ${ }^{58}$
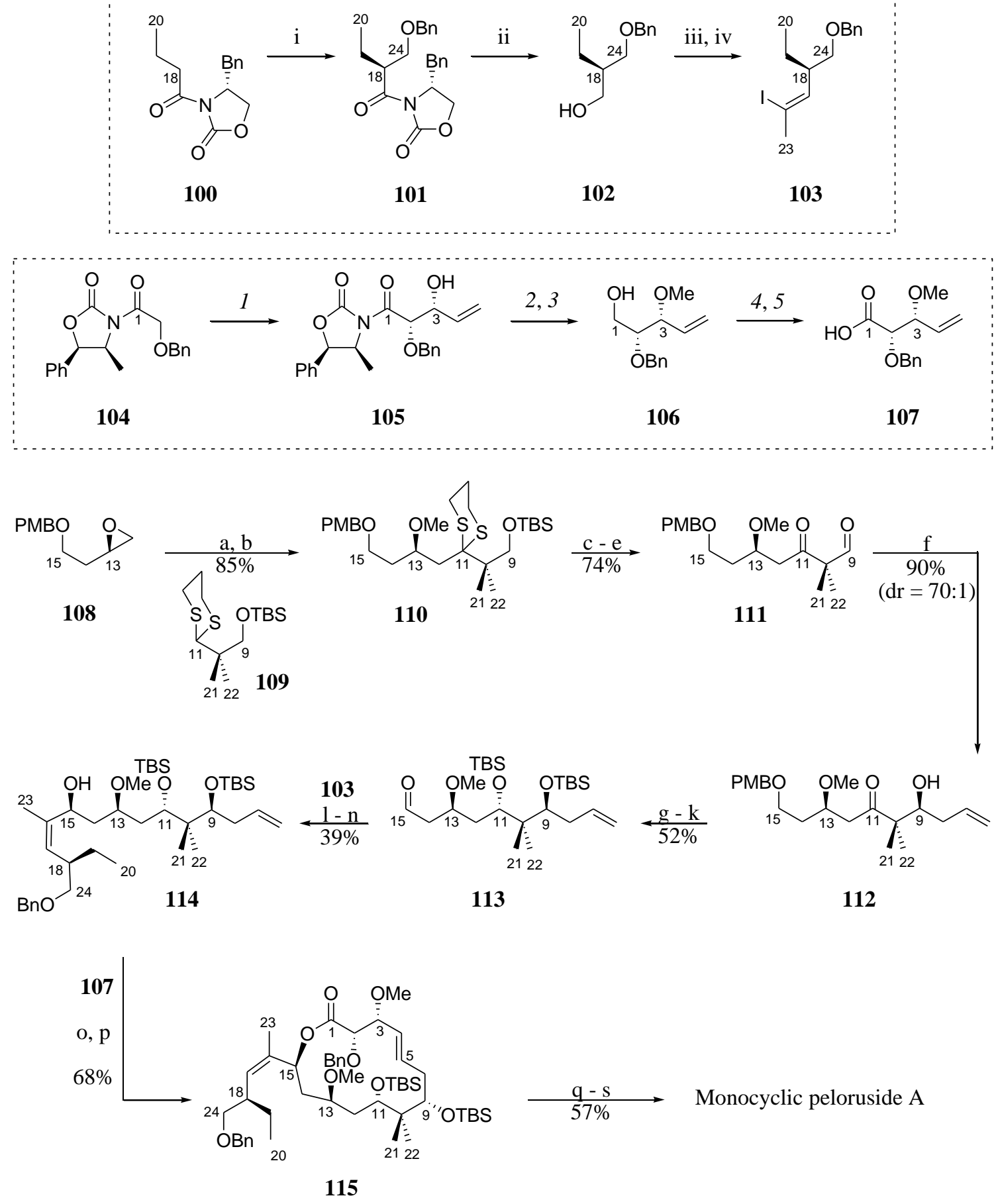

Conditions: (i) $\mathrm{BOMCl}, \mathrm{TiCl}_{4} ;{ }^{62}$ (ii) $\mathrm{LiBH}_{4}, \mathrm{EtOH}, \mathrm{Et}_{2} \mathrm{O}, 0{ }^{\circ} \mathrm{C}$; (iii) $(\mathrm{COCl})_{2}, \mathrm{DMSO}$, TEA, $-78{ }^{\circ} \mathrm{C}$; (iv) $\mathrm{Ph}_{3} \mathrm{P}=\mathrm{C}(\mathrm{Me}) \mathrm{I},-78{ }^{\circ} \mathrm{C}$; (1) $\mathrm{TiCl}_{4}$, DIPEA, NMP, acrolein, DCM, -78 ${ }^{\circ} \mathrm{C}$; (2) $\mathrm{Me}_{3} \mathrm{OBF}_{4}$, Proton-sponge ${ }^{\circledR}$; (3) $\mathrm{LiBH}_{4}, \mathrm{MeOH}$, THF, $0{ }^{\circ} \mathrm{C}$; (4) DMP, DCM; (5) $\mathrm{NaClO}_{2}, \mathrm{NaH}_{2} \mathrm{PO}_{4}, 2$-methyl-2-butene; (a) 109, $n \mathrm{BuLi}$, RT, then 110; (b) NaH, MeI, 15-crown-5; (c) $\mathrm{NaHCO}_{3}, \mathrm{I}_{2}$; (d) PTSA; (e) $(\mathrm{COCl})_{2}$, DMSO, TEA, -78 ${ }^{\circ} \mathrm{C}$; (f) asymmetric allyltitanation; (g) $\mathrm{Me}_{4} \mathrm{NBH}(\mathrm{OAc})_{3},-20{ }^{\circ} \mathrm{C}, 4$ days; (h) $\mathrm{TBSCl}$, 
imidazole; (i) TBSOTf, lutidine; (j) DDQ; k) DMP; (l) 103, $t \mathrm{BuLi},-78{ }^{\circ} \mathrm{C}, \mathrm{Et}_{2} \mathrm{O}$, then 113; (m) Dess-Martin periodinane; (n) (R)-B-Me-CBS, catecholborane; (o) 107, TEA, DMAP, 2,4,6- $\mathrm{Cl}_{3} \mathrm{C}_{6} \mathrm{H}_{2} \mathrm{COCl}$, toluene; (p) Grubbs' $2^{\text {nd }}$ generation catalyst, $\mathrm{ClCH}_{2} \mathrm{CH}_{2} \mathrm{Cl}, 80{ }^{\circ} \mathrm{C}$; (q) HF.pyridine, THF; (r) PADA, AcOH, $40{ }^{\circ} \mathrm{C}, \mathrm{DCM}$; (s) $\mathrm{Pd} / \mathrm{C}, \mathrm{H}_{2}$, EtOAc.

Lithiation of the vinyl iodide $\mathbf{1 0 3}$ and addition to the aldehyde $\mathbf{1 1 3}$ and the vinyl iodide 103 provided the allyl alcohol 114 with $(S)-\mathrm{C}_{15}$ hydroxyl functionality in 2:1 diastereomeric ratio. In an attempt to enhance the yield, the diastereomeric mixture was oxidised to a ketone and the subsequent stereoselective reduction gave a stereochemically pure $\mathbf{1 1 4}$.

The $\mathrm{C}_{1}-\mathrm{C}_{4}$ synthon 107 was obtained from the oxazolidinone 104. An aldol coupling between acrolein and the oxazolidinone 104 provided an allyl alcohol (105) in 69\% yield. Methylation of the resulting $\mathrm{C}_{3}$ hydroxyl followed with reductive removal of the auxiliary gave the alcohol 106. Subsequent two-step oxidation at $\mathrm{C}_{1}$ provided the carboxylic acid $\mathbf{1 0 7 .}$

Yamaguchi esterification between the allyl alcohol $\mathbf{1 1 4}$ and the carboxylic acid $\mathbf{1 0 7}$ assembled the required backbone for the analogue. Subsequent RCM (ring closing metathesis) by Grubbs' $2^{\text {nd }}$ generation catalyst completed the macrolide formation, giving the $E$-isomer 115. The TBS protecting groups were duly removed and the alkene double bond selectively reduced. The hydrogenation reaction to remove the benzyl protecting groups completed the synthesis of the monocyclic analogue of peloruside A.

\subsubsection{Peloruside B}

Ghosh and collaborators have recently reported the discovery and total synthesis of peloruside $\mathrm{B}$, the 3-des- $O$-methyl variant of peloruside A. ${ }^{44}$ Peloruside $\mathrm{B}$ was isolated from Mycale hentscheli from Kapiti Island in New Zealand. Biological studies on peloruside $\mathrm{B}$ showed a comparable, albeit lower, bioactivity to peloruside A. Peloruside B also promotes apoptosis by acting as microtubule stabiliser and interrupts the cell cycle at the $\mathrm{G}_{2} / \mathrm{M}$ phase. ${ }^{44}$ However, peloruside $\mathrm{B}$ is less cytotoxic 
when compared to peloruside A. Peloruside A has an $\mathrm{IC}_{50}$ of only $10 \pm 4 \mathrm{nM}$ for HL60 cells while peloruside $\mathrm{B}$ has $\mathrm{IC}_{50}$ of $33 \pm 10 \mathrm{nM}$ for the same cell type. ${ }^{44}$

The total synthesis of peloruside B was achieved utilising a similar synthetic strategy to that employed for peloruside A. ${ }^{53,61}$ The key reaction steps involved Sharpless dihydroxylation, Brown's symmetric allylboration, reductive aldol coupling and Yamaguchi macrolactonisation (Scheme 1.8). The convergent synthesis of peloruside $\mathrm{B}$ was completed in 29 steps with the total yield of $0.3 \% .^{44}$

The synthesis commenced by protection of the hydroxyls of diethyl $D$-tartrate as MOM acetals followed by LAH (lithium aluminium hydride) reduction of the esters to a diol and monoprotection of the $\mathrm{C}_{1}$ hydroxyl as the PMB ether. The resulting alcohol 117 was iodinated and vinylated to give the alkene $118 .{ }^{44}$ A sequence of similar transformation as in the synthesis of peloruside A provided the desired enone 122. ${ }^{44,53,61}$

The aldehyde $\mathbf{5 1}$ was synthesised by the methodology used in Ghosh's synthesis of peloruside A. ${ }^{53,61}$ Conjugate reductive aldol coupling between the enone $\mathbf{1 2 2}$ and the aldehyde 51 gave the completed $\mathrm{C}_{1}-\mathrm{C}_{24}$ aldol product $123 .{ }^{44}$ The formation of the aldol product 123 was lower yielding compared to the corresponding aldol product $\mathbf{6 0}$ in the synthesis of peloruside A but the diastereoselectivity was slightly improved. ${ }^{44}$, 53,61

Subsequent protection of the $\mathrm{C}_{11}$ hydroxyl as a TES ether followed by the removal of $\mathrm{C}_{1} \mathrm{PMB}$ protecting group afforded the alcohol 124. ${ }^{44}$ Two step consecutive oxidation of the alcohol 124 gave the corresponding carboxylic acid moiety at $\mathrm{C}_{1}$. Removal of the TES protecting group at $\mathrm{C}_{11}$ and $\mathrm{C}_{15}$ provided 125 . Yamaguchi macrolactonisation followed by the desilylation of the $C_{5}$ hydroxyl gave $\mathbf{1 2 6}$ as a 6:1 mixture of hemiketal and hydroxyketone. ${ }^{44}$

Removal of the isopropylidene protecting group from the hemiketal and hydroxyketone mixture 126 gave the corresponding diol at $\mathrm{C}_{7}$ and $\mathrm{C}_{8}{ }^{44}$ Subsequent selective methylation of the $\mathrm{C}_{7}$ hydroxyl and the removal of the MOM protecting 
group from $\mathrm{C}_{2}$ and $\mathrm{C}_{3}$, followed by catalytic transfer hydrogenation to remove the benzyl moiety at $\mathrm{C}_{24}$, completed the synthesis of peloruside $\mathrm{B} .{ }^{44}$

Scheme 1.8 Synthetic route to peloruside B by Ghosh. ${ }^{44,53,61}$

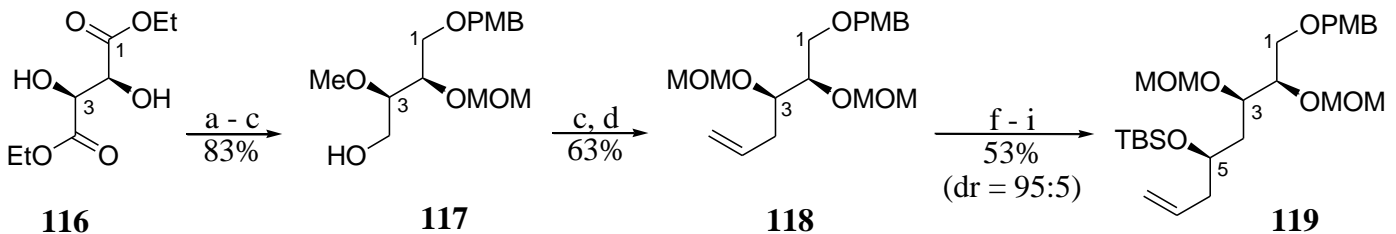<smiles>C=C(C)C(=O)C1OC(C)(C)OC1CC(CC(C)(C)C)OC</smiles>

122

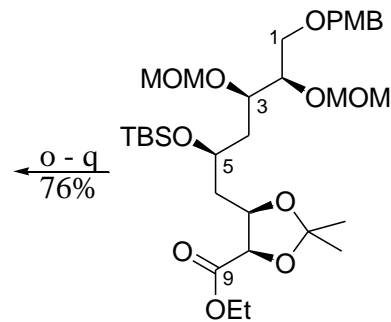

121

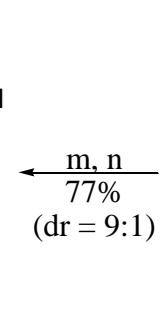

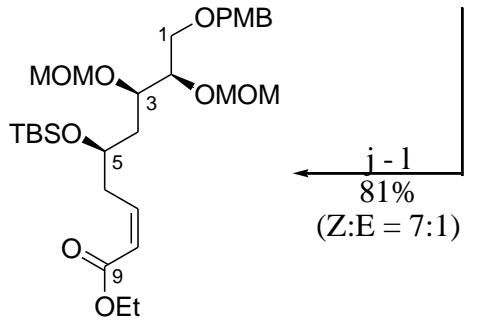

120

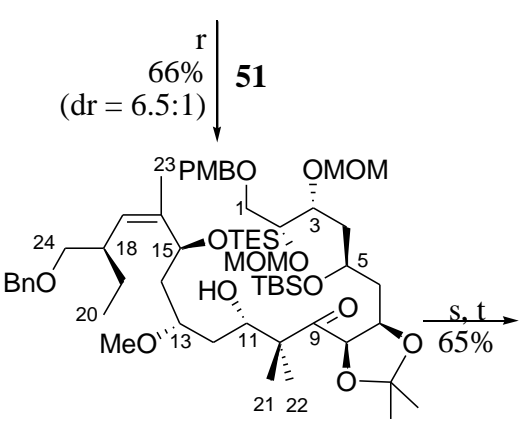

123

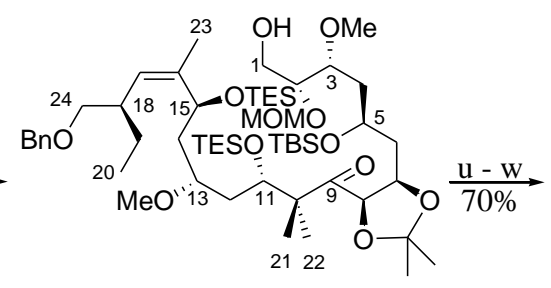

124

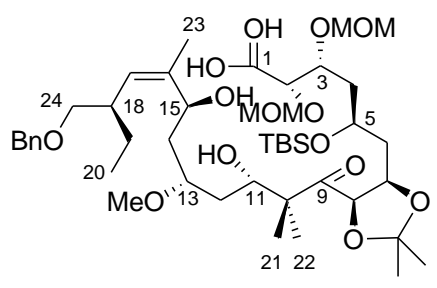

125
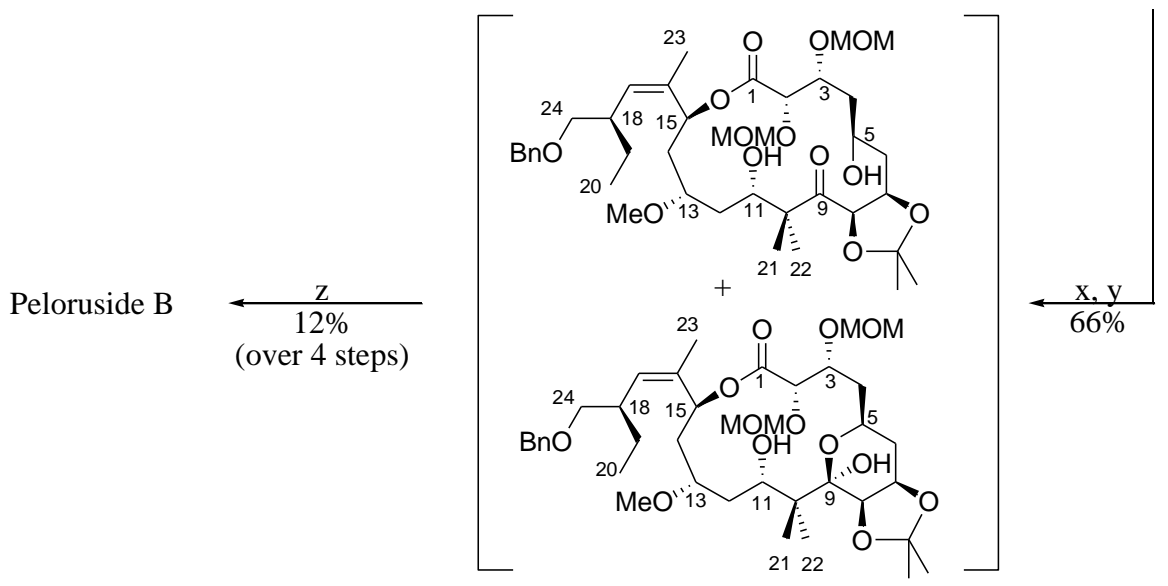

126

Conditions: (a) $\mathrm{P}_{2} \mathrm{O}_{5}, \mathrm{CH}_{2}(\mathrm{OMe})_{3}$; (b) $\mathrm{LAH}$; (c) $\mathrm{NaH}, \mathrm{PMBCl}$; (d) $\mathrm{PPh}_{3}, \mathrm{I}_{2}$, imidazole; (e) $\mathrm{CuI}$, vinylMgBr; (f) $\mathrm{OsO}_{4}, \mathrm{NMO}$; (g) $\mathrm{NaIO}_{4}$, aq. THF; (h) $\mathrm{Ipc}_{2}$ Ballyl, $\mathrm{Et}_{2} \mathrm{O}$; (i) $\mathrm{TBSCl}$, imidazole; (j) $\mathrm{OsO}_{4}, \mathrm{NMO}$; (k) $\mathrm{NaIO}_{4}$, aq. THF; (l) (o- 
cresol) $)_{2} \mathrm{P}(\mathrm{O}) \mathrm{CH}_{2} \mathrm{CO}_{2} \mathrm{Et}, \mathrm{NaH}$; (m) AD-mix- $\alpha, t \mathrm{BuOH}-\mathrm{H}_{2} \mathrm{O}$; (n) $\mathrm{CH}_{2}=\mathrm{C}(\mathrm{OMe}) \mathrm{Me}$, PPTS; (o) DIBAL-H, THF; (p) isopropylMgBr; (q) Dess-Martin periodinane; (r) Lselectride, $\mathrm{Et}_{2} \mathrm{O},-78{ }^{\circ} \mathrm{C}$, then 51, 1 h; (s) TESOTf; (t) DDQ, pH 7 buffer; (u) DMP; (v) $\mathrm{NaCIO}_{2}, \mathrm{NaH}_{2} \mathrm{PO}_{4}$; (w) 2\% HF.pyridine, THF; (x) 2,4,6- $\mathrm{Cl}_{3} \mathrm{C}_{6} \mathrm{H}_{2} \mathrm{COCl}$, DIPEA, then DMAP; (y) HF.pyridine; (w1) $80 \%$ aqueous acetic acid, $50{ }^{\circ} \mathrm{C}, 3 \mathrm{~h}$; (w2) $\mathrm{Me}_{3} \mathrm{OBF}_{4}$, 2,6-di- $t \mathrm{Bu}-$ pyridine; (w3) $4 \mathrm{M} \mathrm{HCl}$, THF; (w4) Pd/C, MeOH, formic acid.

\subsection{Laulimalide}

Laulimalide (127, Figure 1.21) is a cytotoxic natural product that was isolated in 1988 from a Vanuatu chocolate sponge Cacospongia mycofijiensis by Quinoa. ${ }^{63}$ Independently, Corley also isolated laulimalide from an Indonesian sponge Hyattella $s p$. in $1988 .^{64}$ Both groups also found laulimalide in the predator nudibranch Chromodoriz lochi that feeds on the sponges. ${ }^{63,64}$ Laulimalide has since been found in other species of sponges such as Dactylospongia sp. and Fasciospongia rimosa. ${ }^{65,66}$

Figure 1.21 Laulimalide family.

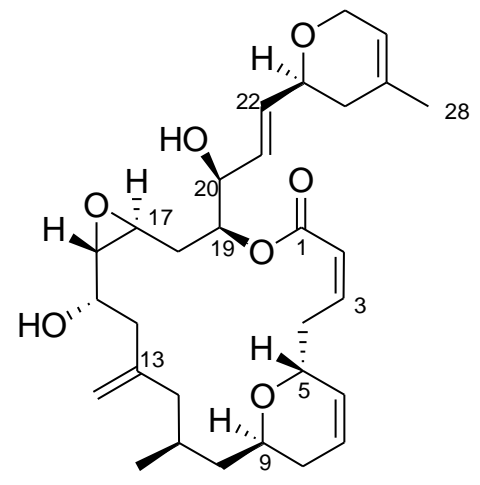

127

(-)-Laulimalide

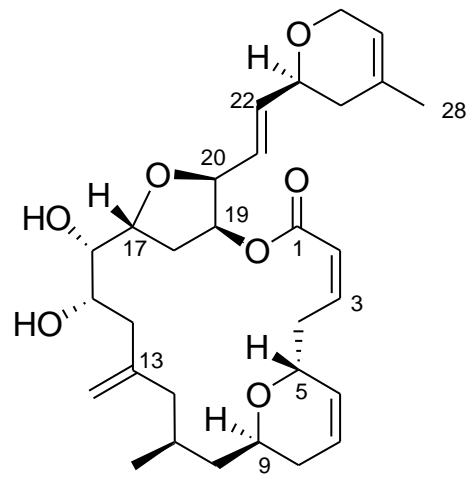

128

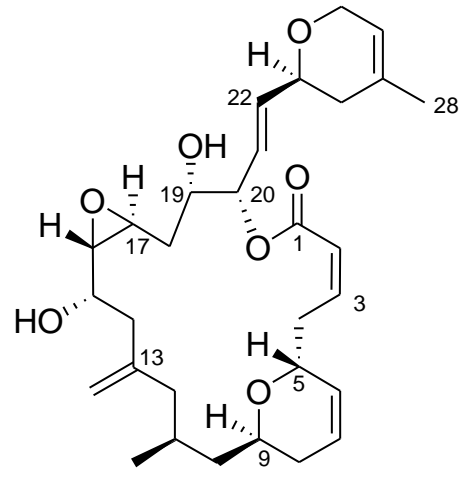

129

Neolaulimalide

Laulimalide is a polyoxygenated 20-membered ring system containing two dihydropyran rings, several olefins, and a highly unstable epoxide. The laulimalide family also include two isomers of laulimalide: isolaulimalide (128, Figure 1.21) is an acid-catalysed epoxide ring-opened isomer, and neolaulimalide (129, Figure 1.21) is a ring-expanded regioisomer. ${ }^{67,68}$ 


\subsubsection{Biological activity of laulimalide}

Biological studies have shown that the laulimalides are biologically active cytotoxic agents. ${ }^{47,69,70}$ Laulimalide has an $\mathrm{IC}_{50}$ ranging from 6 to $15 \mathrm{nM}$ depending on the cell line. ${ }^{68}$ Neolaulimalide is less potent than laulimalide, with an $\mathrm{IC}_{50}$ of 10 to $50 \mathrm{nM} .^{68}$ Isolaulimalide is the least active of the laulimalide family, with an $\mathrm{IC}_{50}$ of only $20 \mu \mathrm{M}$ in almost all the cell lines tested. ${ }^{68}$ Bioactivity studies have shown that laulimalide is a microtubule stabilising agent that initiates mitotic arrest in proliferating cells, leading to apoptosis.

Like peloruside A, laulimalide also has reduced susceptibility towards Pgp efflux pumps and is more potent in multidrug resistant cells than the taxoid drugs. ${ }^{47} \mathrm{~A}$ bioactivity study has established that laulimalide binds at the $\beta$-tubulin subunit. ${ }^{47}$ Laulimalide does not bind to the taxane site, and therefore has a potential use as a synergistic drug with taxanes. ${ }^{47}$ Further studies to establish the binding site found that laulimalide and peloruside A do not synergise and compete with each other for binding to tubulin. The results indicate that peloruside and laulimalide bind to the same site on the $\beta$-tubulin. ${ }^{47}$

\subsubsection{Synthesis of laulimalide}

The complex structure and pharmaceutical potential of laulimalide have driven several attempts at the total synthesis of this natural product. The first total synthesis of (-)-laulimalide was reported by Ghosh and co-workers in a lengthy 35-step sequence with $0.1 \%$ overall yield. ${ }^{71,72,73}$ The synthesis strategy features RCM reactions for the construction of the dihydropyran rings, a Julia-Kocienski coupling between the $\mathrm{C}_{3}-\mathrm{C}_{16}$ and $\mathrm{C}_{17}-\mathrm{C}_{28}$ synthons (147 and 140, Scheme 1.9), and intramolecular Still-Gennari variation of HWE olefination that provide a 1:2 mixture of cis- and tran-isomers followed by photoisomerisation of the tran-isomer to a mixture of cis- and trans-isomers for the construction of the macrolactone. ${ }^{71,73}$

The synthesis of synthon 147 commenced from the alcohol 141 which was obtained from methyl $(S)$-3-hydroxy-2-methylpropionate. ${ }^{73}$ Conversion of the alcohol 141 to the allyl alcohol 142 was achieved through mesylate formation, sodium cyanide 
displacement, DIBAL-H reduction and Brown allylation of the resulting aldehyde. Subsequent alkylation, RCM, DIBAL-H reduction and ethyl glycoside formation furnished the desired dihydropyran 143 as a single anomer. ${ }^{73}$

The ethyl acetal 143 was stereoselectively alkylated to an aldehyde, which was reduced with sodium borohydride. The resulting hydroxyl was protected as a TBS ether. Subsequent removal of the benzyl protecting group was followed by conversion of the alcohol to the iodide $144 .^{71,73}$ Alkylation with sulfonyl lactone 131 gave the $\mathrm{C}_{3}-\mathrm{C}_{16}$ fragment 145 as a 4.2:1 diastereomeric mixture. Subsequent conversion of the sulfonated lactone to the alcohol $\mathbf{1 4 6}$ was followed by MOM protection of the $\mathrm{C}_{15}$ hydroxyl, PMB removal and Swern oxidation to provide the aldehyde $147 .^{71,73}$

The $\mathrm{C}_{17}-\mathrm{C}_{28}$ segment $\mathbf{1 4 0}$ was synthesised from the tetrahydropyranyl glycidol $\mathbf{1 3 2}$. Epoxide ring opening of 132 and PMB protection of the resulting alcohol 133 followed by removal of the THP (tetrahydropyranyl) protecting group and Swern oxidation gave the aldehyde $134 .^{73}$ Additionally, epoxide ring opening and alkylation of 132 by isopropylmagnesium bromide gave the homoallylic alcohol 135 . Subsequent treatment with allylbromide provided the diene 136 which underwent RCM followed by removal of the THP protecting group to give the dihydropyran 137. ${ }^{73}$ Subsequent Swern oxidation followed by Corey-Fuch homologation provided the dibromo-olefin 138.

The ensuing coupling between the alkynyl anion derived from $\mathbf{1 3 8}$ and the aldehyde 134 afforded the alcohol 139 (syn:anti $=1.8: 1) .{ }^{71,} 73$ Due to poor selectivity and separability, the $\mathrm{C}_{20}$ hydroxyl was oxidised to a ketone and then selectively reduced with L-selectride to give only the syn-isomer 139. Subsequent reduction of the alkyne to an alkene and PMB deprotection followed by protection of the resulting diol with $p$-methoxybenzylidene acetal and DIBAL-H reduction gave the alcohol 140. ${ }^{71,73}$ 
Scheme 1.9 Synthetic route to (-)-laulimalide by Ghosh. ${ }^{71,73}$
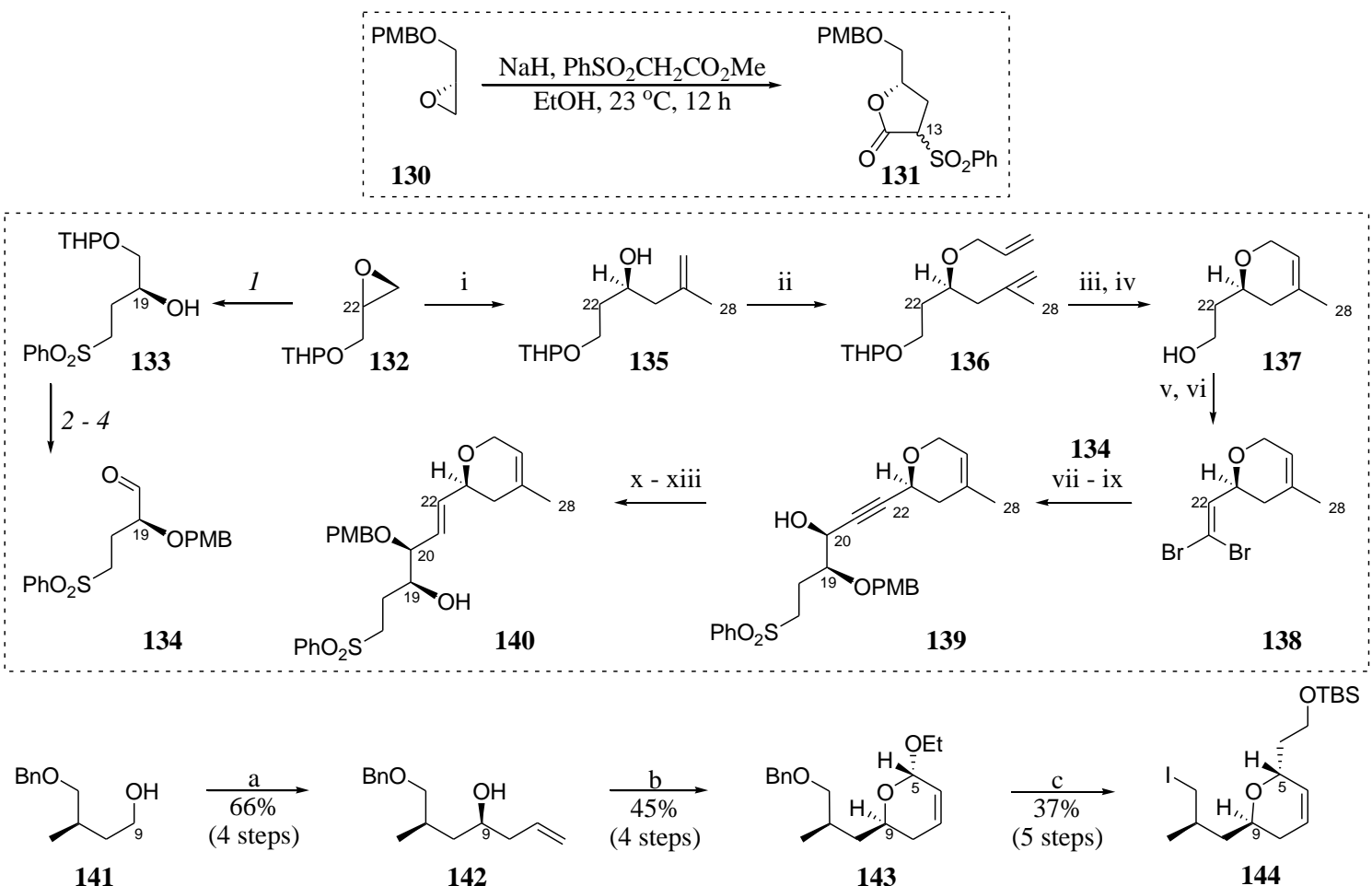

141

142

143

$$
\begin{array}{r|r}
\mathrm{d} & \mathbf{1 3 1} \\
(\mathrm{dr}=4.2: 1) & \mathbf{1 3 1}
\end{array}
$$

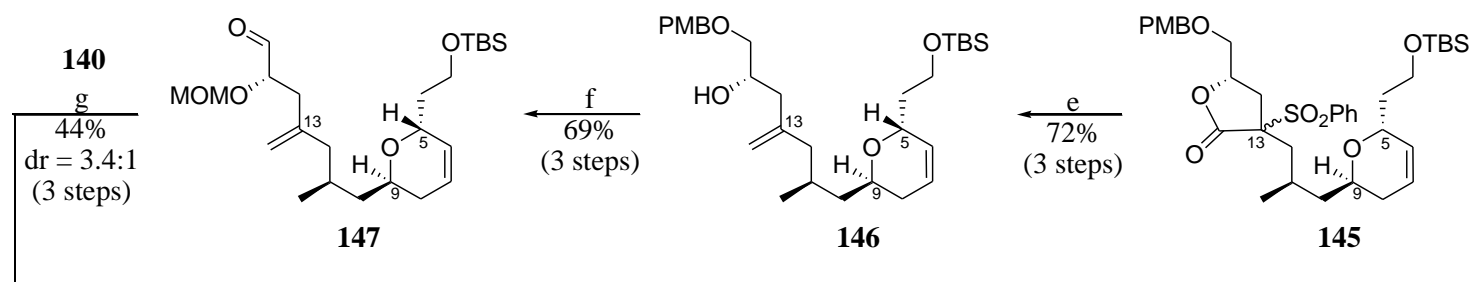

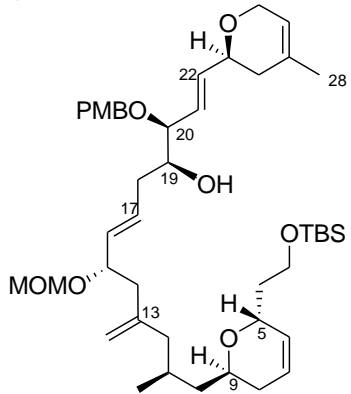

148

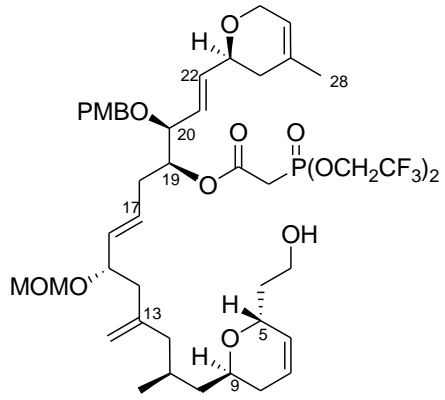

149

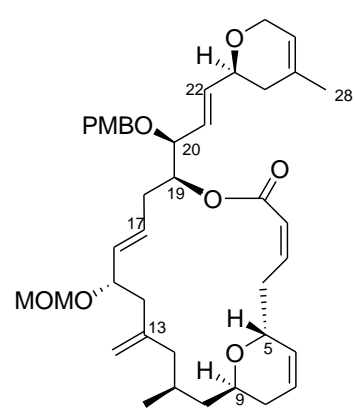

150

(-)-Laulimalide $\frac{\mathrm{j}}{(34 \%}$

Conditions: (1) $\mathrm{PhSO}_{2} \mathrm{CH}_{3}, n \mathrm{BuLi}$, THF, $0{ }^{\circ} \mathrm{C}, 1 \mathrm{~h}$, then HMPA, -78 to $23{ }^{\circ} \mathrm{C}, 2 \mathrm{~h}$; (2) $\mathrm{NaH}, \mathrm{PMBCl}, \mathrm{DMF}, 0$ to $23{ }^{\circ} \mathrm{C}$; (3) $\mathrm{CSA}, \mathrm{MeOH}$; (4) DMSO, $(\mathrm{COCl})_{2}$, DIPEA, $\mathrm{DCM},-78{ }^{\circ} \mathrm{C}$; (i) isopropylMgBr, catalytic $\mathrm{CuCN}, \mathrm{THF},-78$ to $23{ }^{\circ} \mathrm{C}, 2 \mathrm{~h}$; (ii) $\mathrm{KH}$, catalytic 18 -crown-6, allylbromide, THF, 0 to $23{ }^{\circ} \mathrm{C}$; (iii) $10 \mathrm{~mol} \%$ Grubbs' $2^{\text {nd }}$ 
generation catalyst, DCM, $23{ }^{\circ} \mathrm{C}, 2 \mathrm{~h}$; (iv) CSA, MeOH; (v) DMSO, $(\mathrm{COCl})_{2}$, DIPEA, DCM, $-78{ }^{\circ} \mathrm{C}$; (vi) $\mathrm{CBr}_{4}, \mathrm{PPh}_{3}$, DCM, 0 to $23{ }^{\circ} \mathrm{C}, 30 \mathrm{~min}$ (vii) 138, $n \mathrm{BuLi}$, $78{ }^{\circ} \mathrm{C}, 1 \mathrm{~h}$ and $23{ }^{\circ} \mathrm{C}, 1 \mathrm{~h}$, then $134,-78^{\circ} \mathrm{C}$; (viii) Dess-Martin periodinane, DCM, 23 ${ }^{\circ} \mathrm{C}$; (ix) L-selectride, THF, $-78{ }^{\circ} \mathrm{C}$; (x) Red-Al ${ }^{\circledR}$, THF, - $20{ }^{\circ} \mathrm{C}$; xi) TFA, DCM, $23{ }^{\circ} \mathrm{C}$; (xii) $p$-methoxybenzylidene acetal, CSA, DCM, $23{ }^{\circ} \mathrm{C}$; (xiii) DIBAL-H, DCM, -78 ${ }^{\circ} \mathrm{C}$; (a1) $\mathrm{MsCl}$, TEA, DCM, $0{ }^{\circ} \mathrm{C}, 30 \mathrm{~min}$; (a2) $\mathrm{NaCN}$, DMSO, $60{ }^{\circ} \mathrm{C}, 2 \mathrm{~h}$; (a3) DIBAL-H, DCM, $0{ }^{\circ} \mathrm{C}, 30 \mathrm{~min}$; (a4) (-)-IpcBallyl, THF, -100 ${ }^{\circ} \mathrm{C}$; (b1) acryloyl chloride, TEA, DCM, 0 to $23{ }^{\circ} \mathrm{C}$; (b2) 10 mol\% Grubbs' $2^{\text {nd }}$ generation catalyst, catalytic $\mathrm{Ti}(\mathrm{O} i \mathrm{Pr})_{4}, 40^{\circ} \mathrm{C}, 5 \mathrm{~h}$; (b3) DIBAL-H, DCM, - $78^{\circ} \mathrm{C}$; (b4) CSA, EtOH; (c1) $\mathrm{H}_{2} \mathrm{C}=\mathrm{CHOTBS}$, Montmorillonite K-10, DCM, $23{ }^{\circ} \mathrm{C}$; (c2) $\mathrm{NaBH}_{4}, \mathrm{MeOH}, 0{ }^{\circ} \mathrm{C}$; (c3) TBSCl, imidazole, DMF, $23{ }^{\circ} \mathrm{C}$; (c4) Li, liquid ammonia; (c5) $\mathrm{I}_{2}, \mathrm{PPh}_{3}$, imidazole, $\mathrm{Et}_{2} \mathrm{O} / \mathrm{MeCN}$ (2:1); (d) 131, NaH, DMF, $0{ }^{\circ} \mathrm{C}$ for $15 \mathrm{~min}$, then $144,60{ }^{\circ} \mathrm{C}$ for $12 \mathrm{~h}$; (e1) Red-Al ${ }^{\circledR}$, THF, $0{ }^{\circ} \mathrm{C}$; (e2) PhCOCl, TEA, DMAP, DCM; (e3) $\mathrm{Na}\left(\mathrm{Hg}\right.$ ), $\mathrm{NaHPO}_{4}$, $\mathrm{MeOH},-20$ to $23{ }^{\circ} \mathrm{C}$; (f1) $\mathrm{MOMCl}$, DIPEA, DCM; (f2) DDQ, pH 7 buffer; (f3) DMSO, $(\mathrm{COCl})_{2}$, DIPEA, DCM, $-78{ }^{\circ} \mathrm{C}$; (g1) 140, $n \mathrm{BuLi},-78{ }^{\circ} \mathrm{C}$, THF, 15 min, then 147, -78 to $-40{ }^{\circ} \mathrm{C}, 2 \mathrm{~h}$; (g2) $\mathrm{Ac}_{2} \mathrm{O}$, TEA, DMAP, DCM; (g3) $\mathrm{Na}(\mathrm{Hg}), \mathrm{NaHPO}_{4}$, $\mathrm{MeOH},-20$ to $23{ }^{\circ} \mathrm{C}$; (h1) bis-(2,2,2-trifluoroethyl)-phosphonoacetic acid, 2,4,6$\mathrm{Cl}_{3} \mathrm{C}_{6} \mathrm{H}_{2} \mathrm{COCl}$, DIPEA, DMAP; (h2) AcOH/THF/ $\mathrm{H}_{2} \mathrm{O}$ (3:1:1), $23{ }^{\circ} \mathrm{C}$; (i1) DessMartin periodinane, DCM, $23{ }^{\circ} \mathrm{C}$; (i2) $\mathrm{K}_{2} \mathrm{CO}_{3}, 18$-crown-6, -20 to $0{ }^{\circ} \mathrm{C}$; (i3) $h v, \mathrm{Et}_{2} \mathrm{O}$, 50 min; (j1) PPTS, $t \mathrm{BuOH}, 84{ }^{\circ} \mathrm{C}$; (j2) $t \mathrm{BuOOH},(+)-\mathrm{DET}$, Ti(OiPr) $)_{4},-20{ }^{\circ} \mathrm{C}$; (j3) DDQ, pH 7 buffer, $23{ }^{\circ} \mathrm{C}$.

Julia-Kocienski olefination was employed in the coupling of the alcohol 140 and the aldehyde 147. Subsequent acylation and treatment with $\mathrm{Na}(\mathrm{Hg})$ provided the coupling product 148 as a 3.4:1 mixture of trans- and cis- isomers. ${ }^{71,}{ }^{73}$ Still-Gennari reagent formation followed by removal of the TBS ether provided 149. Dess-Martin oxidation followed by Z-selective HWE cyclisation gave a mixture of 2:1 trans- and cismacrolactones that were separable by chromatography. Subsequent photoisomerisation of the trans-isomer provide $\mathbf{1 5 0}$ as a $1: 1$ mixture. ${ }^{71}$ Subsequent removal of the MOM ether followed by Sharpless epoxidation with (+)-diethyl tartrate and removal of the PMB ether completed the synthesis of (-)-laulimlide. ${ }^{71}$

Initially, the synthetic approach intended to utilise RCM to install the cis-olefin geometry and simultaneously form the macrolactone. However, various attempts 
resulted in decomposition of the starting material. The approach was shifted to employing intramolecular HWE reaction. Although the desired cis-macrolide was obtained, the yield was low because formation of the trans-isomer was favoured and various attempts to influence the regioselectivity proved unsatisfactory. ${ }^{71,} 72,73$ Following a review of the synthetic strategy, Yamaguchi macrolactonisation reaction was investigated. ${ }^{73}$ The Yamaguchi protocol proceeded with a satisfactory $68 \%$ yield, giving the corresponding cis-macrolide as a single isomer. $^{72,73}$

Following the synthesis by Ghosh, several other successful total syntheses of (-)laulimalide have been reported. Mulzer reported several approaches to the synthesis of (-)-laulimalide. ${ }^{74-80}$ Mulzer's first synthesis of (-)-laulimalide, reported in 2001, relied on a novel bi-directional RCM for the formation of the side chain dihydropyran, Julia-Kocienski olefination to install the $\mathrm{C}_{16}=\mathrm{C}_{17}$ trans-olefin bond (trans: is $=$ 11.4:1), Still-Gennari cyclisation to simultaneously perform the macrolactonisation and form the $\mathrm{C}_{2}=\mathrm{C}_{3}$ cis-olefin bond (trans: cis $=1.8: 1$ ), and Sharpless asymmetric epoxidation of the $\mathrm{C}_{16}=\mathrm{C}_{17}$ trans-olefin to an epoxide. ${ }^{74}$

In the same year, Mulzer reported another synthesis of (-)-laulimalide. ${ }^{75}$ The synthetic approach featured a competing silicon-mediated allyl transfer macrocyclisation that was governed by the orthogonality of two hydroxyl protecting groups. ${ }^{75}$ The mild absolutely anhydrous conditions employed in the reaction successfully prevented isomerisation of the established $\mathrm{C}_{2}=\mathrm{C}_{3}$ cis-olefin bond. ${ }^{75}$ Other key synthetic steps included a modified Kuwajioma's protocol using lithium chloride to provide the allyl silane precursor for the allyl transfer reaction, RCM to form the side chain dihydropyran ring and Sharpless asymmetric epoxidation to installed the $C_{16}=C_{17}$ epoxide. $^{75}$

In the following year, Mulzer reported four other syntheses of (-)-laulimalide. ${ }^{76-79}$ The first synthesis featured two alternative routes for macrolactonisation: a Still-Gennari olefination and an Alexakis-type allylsilane/acetal addition. ${ }^{76} \mathrm{RCM}$ for the formation of the dihydropyran rings and a Sharpless asymmetric epoxidation to install the epoxide moiety were the other key reaction steps. ${ }^{76}$ The second synthetic strategy highlighted the use of allylsilane addition to a chiral acetal as the major coupling step, Ando modified HWE olefination for the formation of the cis-olefin ( cis:trans =1:2.7), 
Yamaguchi macrolactonisation for the ring closure of the carbon skeleton and selective Sharpless epoxidation to furnish the epoxide moiety. ${ }^{77}$

The third synthesis utilised a novel asymmetric acyl halide-aldehyde cyclocondensation reaction to define the requisite stereochemical relationships. ${ }^{78}$ The synthesis strategy also featured RCM with Schrock's reagent for the dihydropyran formations, Yamaguchi macrolactonisation for the macrolide formation, alkyne hydrogenation with Lindlar's catalyst for the installation of the $\mathrm{C}_{2}=\mathrm{C}_{3}$ cis-olefin, and diastereoselective Sharpless epoxidation. ${ }^{78}$ The fourth was a formal synthesis with improved efficiency, with an Evans' alkylation, a Brown allylation and a stereocontrolled ene-reaction as the key reactions. ${ }^{79}$

Paterson reported a 27-step total synthesis of (-)-laulimalide with an overall yield of $2.9 \% .^{81}$ The synthesis utilised diastereoselective chiral boron enolate coupling reaction, Mitsunobu macrolactonisation, enantioselective Jacobsen hetero-Diels-Alder formation of the side chain dihydropyran, and Sharpless asymmetric epoxidation. ${ }^{81}$ Wender adopted a convergent synthetic strategy that relied on a complex asymmetric Sakurai coupling of an allyl silane with an aldehyde in the formation of the $\mathrm{C}_{14}-\mathrm{C}_{15}$ bond and regioselective macrolactonisation of an unprotected $\mathrm{C}_{19}-\mathrm{C}_{20}$ diol to provide the target 20 -membered macrolactone in 25 steps with an overall yield of $3.5 \%$. ${ }^{82}$

Williams' strategies for the synthesis of (-)-laulimalide featured asymmetric allylation that incorporated the $\mathrm{C}_{16}-\mathrm{C}_{17}$ trans-epoxide at an early stage in the synthesis pathway, chelation-controlled alkenylzincate addition, asymmetric conjugate addition with Yamamoto organocopper reagents and allenylstannane Ferrier reaction for the direct attachment of a $\mathrm{C}_{1}$ propargyl substituent to the dihydropyran moiety. ${ }^{83}$ Crimmins' synthesis of (-)-laulimalide highlighted the use of Evans asymmetric alkylation reactions to install the $\mathrm{C}-\mathrm{O}$ bonds, a diastereoselective allylstannane addition for the assembly of the carbon skeleton, and Mitsunobu macrolactonisation for the macrocycle formation. ${ }^{84}$

Uenishi and Ohmi approached the synthesis of (-)-laulimalide with a focus on the preparation of the dihydropyran moieties using a $\mathrm{Pd}^{\mathrm{II}}$ and $\mathrm{Pd}^{0}$-catalysed stereospecific ring formation by 6-exo-trig and 6-endo-trig cyclisations. ${ }^{85}$ Other key reactions 
included a Sakurai-Hosomi coupling to assemble of the carbon skeleton and Yamaguchi protocol for macrolactonization. ${ }^{85}$ Trost's synthetic strategy for (-)laulimalide utilised atom-economic transformations to achieved an efficient and convergent pathway that employed Rh-catalysed cycloisomerisation to form the endocyclic dihydropyran, a dinuclear Zn-catalysed asymmetric glycolate aldol to obtain the syn-1,2-diol, and an intramolecular Rh-catalysed alkene-alkyne coupling via isomerisation to form the macrocycle. ${ }^{86}$

Research has also been focused on developing analogues of laulimalide. ${ }^{67,68,70,87-91}$ The analogue studies have attempted various modifications of the side-chain groups, the epoxy moiety and the side-chain dihydropyran. ${ }^{67}, 68,70,87-91$ Although an impressive range of analogues have been produced, none is more potent than the original laulimalide. Most of the synthesised analogues of laulimalide have moderate to total loss of cytotoxic activity. Recently, Mulzer successfully synthesised a desdihydropyran analogue of laulimalide (Figure 1.22). ${ }^{91}$ Bioactivity studies on the analogue showed a total loss of bioactivity that highlighted the importance of the $\mathrm{C}_{5}-$ $\mathrm{C}_{9}$ endocyclic dihydropyran moiety of laulimalides. ${ }^{91}$ 
Figure 1.22 Several analogues of laulimalide. ${ }^{67,68,70,87-91}$

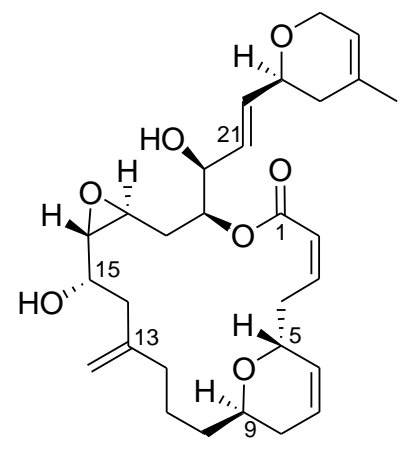

11-des-methyl laulimalide

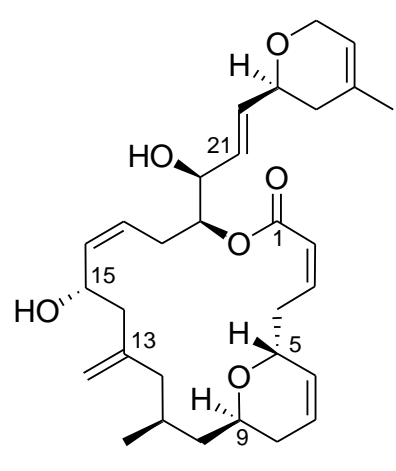

$\mathrm{C}_{16}{ }^{-} \mathrm{C}_{17^{-}}$-des-epoxy laulimalide

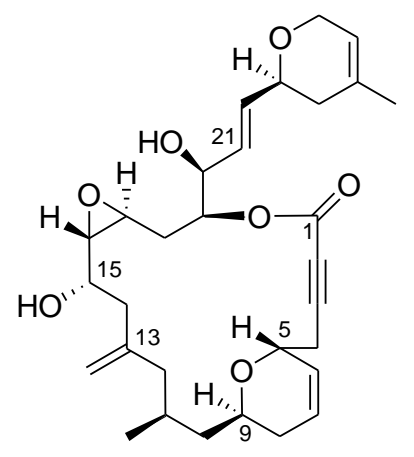

$\mathrm{C}_{2}-\mathrm{C}_{3}$-alkynoate laulimalide

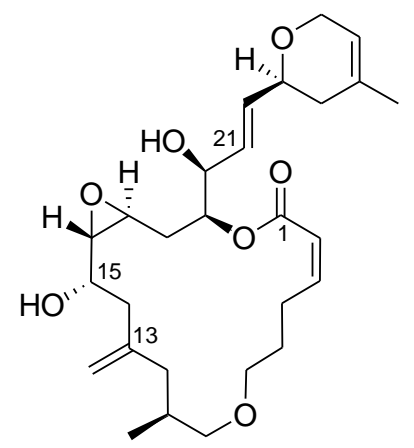

des-dihydropyran laulimalide

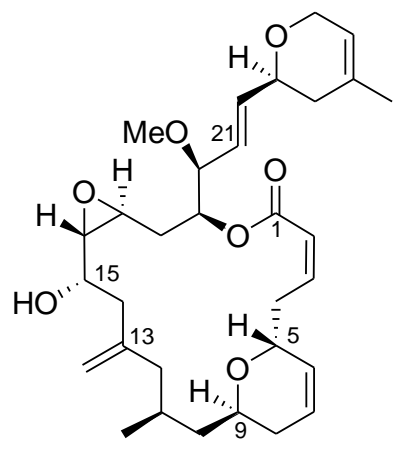

$\mathrm{C}_{20}$-methoxy laulimalide<smiles>[R]C(O)CC1O[C@H]1[C@H](O)CC(=C)CCC[C@H]1CC=C[C@H](C/C=C\C(=O)O)O1</smiles><smiles>[R]#CC(O)C=CC1CCCCC1</smiles><smiles></smiles><smiles>Cc1cccc(/C=C/C(C)O)c1</smiles>

Analogues of laulimalide by side chain modifications 


\section{Chapter 2 - Objectives and strategies}

\subsection{The research aim}

An analogue of a natural product is a compound with structural variation(s) compared to the naturally occurring lead compound, in which one or more parts of its carbon skeleton and/or functional groups have been replaced, rearranged or deleted. An analogue can be designed and modified to fit certain pharmacological specifications as required by its intended role. For the proposed research, the intention is to design an analogue to peloruside A that has comparable or better bioactivity to the parent compound. Restricted availability of the natural supply and the anticancer qualities of peloruside A are some of the reasons for its increasing attraction as a synthetic target. However, synthesis of peloruside $\mathrm{A}$ is difficult due to the complexity of its structure and its numerous stereogenic centres. The pursuit of a simplified analogue has obvious benefits.

Peloruside A has ten stereocentres in its structure, four of which are located in the tetrahydropyran ring. Therefore, analogues simplified at the pyran moiety seemed to be a practical approach. Taking into consideration the fact that peloruside $\mathrm{A}$ and laulimalide share similar macrocyclic rings with embedded pyran rings, we proposed the synthesis of an analogue of peloruside A that incorporates the simpler backbone dihydropyran ring of laulimalide (151, Figure 2.1). The dihydropyran ring of laulimalide has only two stereocentres: two fewer than peloruside A. Therefore, the demand for stereospecific synthetic steps is also reduced.

Figure 2.1 The proposed hybrid peloruside-laulimalide analogue.

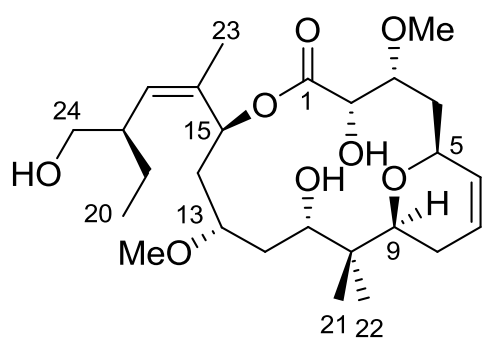


The importance of the pyran ring for the bioactivity of peloruside $\mathrm{A}$ has been confirmed by Wullschleger and co-workers in the course of their synthesis of a monocyclic peloruside A analogue. ${ }^{58} \mathrm{~A}$ study by Mulzer of a des-dihydropyran analogue of laulimalide showed that the dihydropyran structure is also important here. ${ }^{91}$ Although, several computational studies based on spectroscopic data have made predictions on the interaction sites of both peloruside A and laulimalide with the tubulin dimer, ${ }^{33,92,93,94}$ information regarding the exact binding interaction is still unavailable. Therefore, the strategy of incorporating the pyran structure of laulimalide into the backbone of peloruside A has the potential of providing an insight into the interaction of the pyran functionality of both peloruside $\mathrm{A}$ and laulimalide within the binding pocket of the $\beta$-tubulin.

The proposed hybrid peloruside-laulimalide analogue 151 will feature mainly the backbone structure of peloruside $A$, with the exception of the $\mathrm{C}_{5}-\mathrm{C}_{9}$ pyranose ring. The dihydropyran ring motif of laulimalide, with an alkene between $\mathrm{C}_{6}$ and $\mathrm{C}_{7}$, is the primary target. The pyranose ring of peloruside $A$ has a methyl ether group at the $C_{7}$ position, a hydroxyl moiety at the $\mathrm{C}_{8}$ position, as well as the $\mathrm{C}_{9}$ hemiacetal group. The elimination of two stereogenic centres and three oxygen moieties from the original pyran structure of peloruside $\mathrm{A}$ is expected to simplify the synthesis of the proposed analogue compared to peloruside A.

The choice of peloruside A as the backbone donor took into consideration the greater stability of peloruside A than laulimalide. Laulimalide readily isomerises to isolaulimalide, due to the instability of its $\mathrm{C}_{16}-\mathrm{C}_{17}$ epoxide moiety. Therefore, the proposed analogue $\mathbf{1 5 1}$ will have the general (stable) structure of peloruside A while minimising the problem of isomerisation and still retaining the important dihydropyran feature of laulimalide. Furthermore, we anticipated that an analogue that incorporates the active features of both peloruside A and laulimalide would retain the potent biological cytotoxicity of its parent macrolides.

Aside from the primary analogue 151, several other analogues can be obtained through variation of the synthetic route. Simple modification of the pyran ring, achieved utilising similar synthetic routes or addition of further synthetic steps, will also be explored. Our intention is to delve further into the study of the importance of 
the pyran structure for the bioactivity of peloruside A and laulimalide. Therefore, producing several analogues that feature different functionalities might give further insight into the interaction between the pyran moiety and the binding pocket it occupies in the $\beta$-tubulin.

Variation in the functionality might alter the hydrophobic/hydrophilic interactions within the binding pocket. Similarly, altered bulk might govern the orientation of the structure within the pocket. Simple modifications such as hydrogenation and dihydroxylation of the alkene can provide an idea of the importance of the functional groups and the hydrophobic/hydrophilic nature of the binding pocket. A methylsubstituted alkene is expected to be introduced into the pyran structure by slight modification of the reagents used.

\subsection{Retrosynthetic strategy}

The synthesis of the analogue 151 (Scheme 2.1) will utilise, as the final step, a global deprotection after formation of the macrocycle by a Yamaguchi protocol. The assembly of the carbon skeleton will be achieved through a 1,5-anti aldol coupling of the $\mathrm{C}_{1}-\mathrm{C}_{11}$ aldehyde 172 and the $\mathrm{C}_{12}-\mathrm{C}_{24}$ ketone 180. A subsequent stereoselective reduction of the $\mathrm{C}_{13}$ ketone and methylation of the resulting hydroxyl will provide the requisite methyl ether functionality of the natural product.

The synthesis of the $C_{1}-C_{11}$ synthon 172 will employ an oxazolidinone-directed 1,2syn aldol reaction between the $\mathrm{C}_{1}-\mathrm{C}_{2}$ oxazolidinone 159 and the $\mathrm{C}_{3}-\mathrm{C}_{11}$ aldehyde 168. Subsequent methylation of the $C_{3}$ hydroxyl will provide the necessary methyl ether functionality. The $\mathrm{C}_{1}-\mathrm{C}_{2}$ synthon is obtainable from bromoacetic acid (191) and (S)-4-benzyloxazolidin-2-one (157). The $\mathrm{C}_{3}-\mathrm{C}_{11}$ synthon is available from 2,2dimethyl-1,3-propanediol (192), allylmagnesium bromide (193), acryloyl chloride (194) and vinyloxy-trimethylsilane (195) through a series of reactions. The first step of the sequence will be the monoprotection of the diol 192. The next step will be the oxidation of the remaining hydroxyl group to an aldehyde. This will be followed by Brown allylation with allylmagnesium bromide and esterification with acryloyl 
chloride. The subsequent step will be a RCM reaction to form the dihydropyran ring. The final step in the series will be an alkylation with vinyloxy-trimethylsilane.

Scheme 2.1 Proposed retrosynthesis for the hybrid peloruside-laulimalide analogue 151.

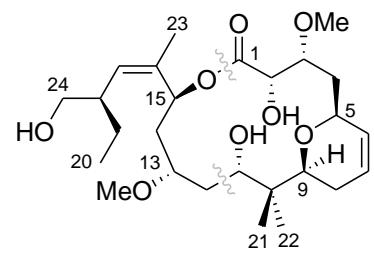

151

Global deprotection

Yamaguchi macrolactonisation

Reduction and methylation

1,5-anti Aldol reaction

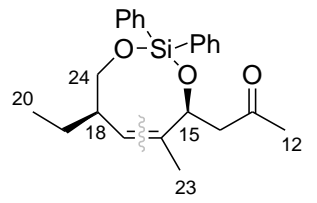

180

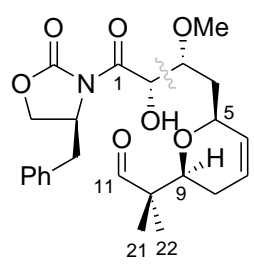

172

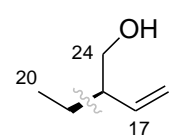

(R)-178

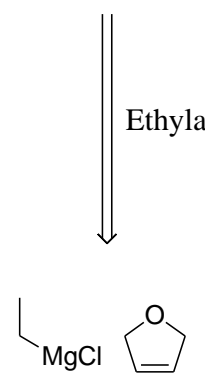

198199<smiles>C=C(C)CC(O)CC(C)=O</smiles>

177

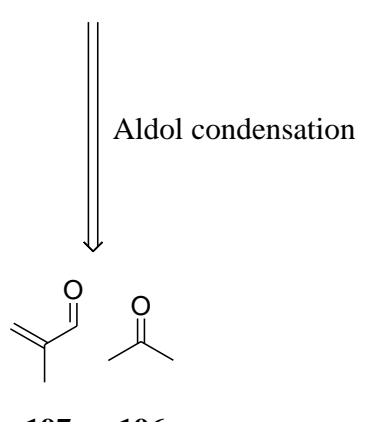

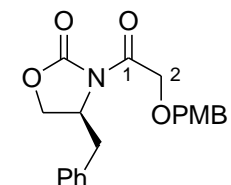

159<smiles>O=C1NC(Cc2ccccc2)CO1</smiles>

157

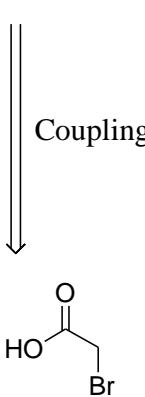

191
$\Downarrow \begin{aligned} & \text { Methylation } \\ & 1,2-\text { syn Aldol reaction }\end{aligned}$

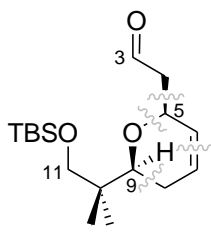

168

Alkylation

Ring closing metathesis

Esterification

Allylation

Swern oxidation Monoprotection<smiles>CC(C)CO</smiles>

$\stackrel{\text { OTMS }}{\mathrm{Cl}}$

194195

The synthesis of the $\mathrm{C}_{12}-\mathrm{C}_{24}$ synthon will involve a RCM reaction to install the $Z$ olefin of the side chain through the formation of an eight-membered silocene. Cosilylation of the $\mathrm{C}_{12}-\mathrm{C}_{16} \beta$-hydroxy ketone $\mathbf{1 7 7}$ and the $\mathrm{C}_{17}-\mathrm{C}_{24}$ alcohol $\mathbf{1 7 8}$ will give the necessary diene. The $\mathrm{C}_{12}-\mathrm{C}_{16}$ synthon is accessible from an aldol coupling 
reaction between acetone (196) and methacrolein (197). The $\mathrm{C}_{12}-\mathrm{C}_{16}$ synthon is obtainable from an ethylation reaction of 2,5-dihydrofuran (199) with ethylmagnesium chloride (198).

Several analogues featuring further modifications on the pyran moiety, namely $\mathbf{1 5 2}$ to 155 as shown below (Figure 2.2) will be attempted. Hydrogenation ${ }^{95}$ of the $\mathrm{C}_{6}=\mathrm{C}_{7}$ alkene of the $\mathrm{C}_{5}-\mathrm{C}_{11}$ lactone will provide a precursor to the analogue 152. Sharpless asymmetric dihydroxylation ${ }^{96}$ or potassium permanganate oxidation ${ }^{97}$ of the $\mathrm{C}_{6}=\mathrm{C}_{7}$ alkene will give the hydroxyl functionalities for the analogue 153. Acetonide formation $^{98}$ will protect the resulting diol throughout the rest of the reaction sequences.

Figure 2.2 Proposed variations of the primary analogue 151.

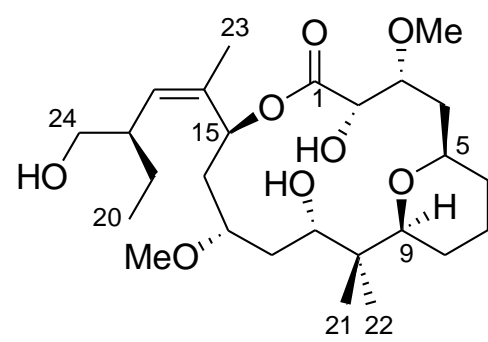

152

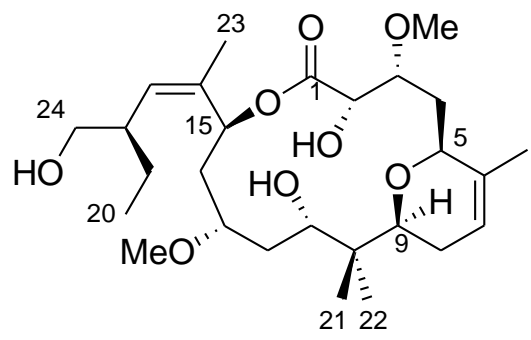

154

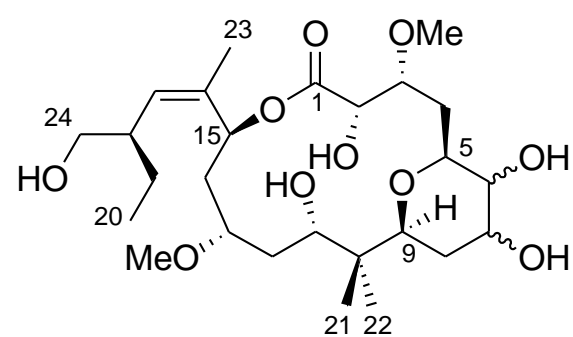

153

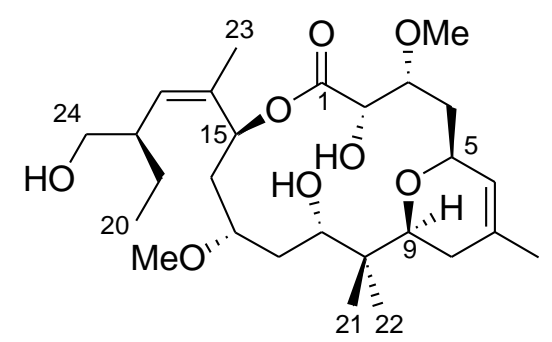

155

Substituting acryloyl chloride with methacryloyl chloride during esterification of the $\mathrm{C}_{7}-\mathrm{C}_{11}$ alcohol is expected to give the analogue 154. RCM of the resulting diene will give a methylated alkene at $\mathrm{C}_{6}$. Similarly, substituting allylmagnesium bromide with methallylmagnesium bromide or methallyllithium ${ }^{99}$ during the synthesis of the boron reagent for Brown allylation, will provide the precursor to analogue 155. Esterification with acryloyl chloride and RCM will provide a methylated alkene at $\mathrm{C}_{7}$. 


\subsection{Research precedence}

An attempt to synthesise the analogue $\mathbf{1 5 1}$ has been previously undertaken by Dr. Emma Casey (née Turner) during her PhD research. ${ }^{100}$ Therefore, the preparation of the ketone 180 has been established. ${ }^{101}$ Similarly, Casey has also paved the way towards the synthesis of the aldehyde 172. ${ }^{100}$ The main focus of this research is to complete the synthesis of the full analogue, particularly the 1,5-anti aldol coupling of the aldehyde 172 and ketone 180. Previous studies have shown that the 1,5-anti aldol reaction is highly dependent on the size and electronic nature of the substrates, as well as the type of the boron reagent used. ${ }^{102}$ Although the use of phenylsilane compared to non-aromatic silane substituents dramatically increased the enantioselectivity of the 1,5-anti induction, the yield has been moderate. ${ }^{102}$

\subsection{The research objectives}

The objective for the current study was to synthesise the aldehyde $\mathbf{1 7 2}$ and the ketone 180 in reasonable quantity. The RCM reaction and 1,5-anti aldol reaction, will be critically evaluated and, whenever possible, optimised. New reaction conditions that might benefit and improve current established synthetic protocols will be explored. Possible reaction conditions for derivatisations of the pyran ring will be examined. Any unpredicted outcomes to established reactions will be critically evaluated and, whenever possible, resolved. 


\section{Chapter 3 - Results and discussion}

\subsection{Synthesis of $C_{1}-C_{11}$}

The peloruside A analogue 151 will be synthesised in a convergent manner from two smaller fragments, the $\mathrm{C}_{1}-\mathrm{C}_{11}$ segment 172 and the $\mathrm{C}_{12}-\mathrm{C}_{24}$ segment 180 (Scheme 3.1). The $C_{1}-C_{11}$ segment of the peloruside $A$ analogue 151 will be synthesised from two smaller fragments, a $C_{1}-C_{2}$ enolate 159 and a $C_{3}-C_{11}$ aldehyde 168. The construction of the $\mathrm{C}_{1}-\mathrm{C}_{11}$ synthon was to be completed by a 1,2-syn aldol coupling reaction that would connect the $\mathrm{C}_{1}-\mathrm{C}_{2}$ enolate and the $\mathrm{C}_{3}-\mathrm{C}_{11}$ aldehyde. Methylation of the $\mathrm{C}_{3}$ hydroxyl will provide the necessary methyl ether functionality.

Scheme 3.1 Retrosynthesis of $\mathrm{C}_{1}-\mathrm{C}_{11}$ segment 172.

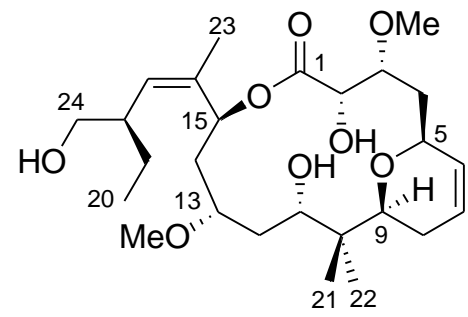

151

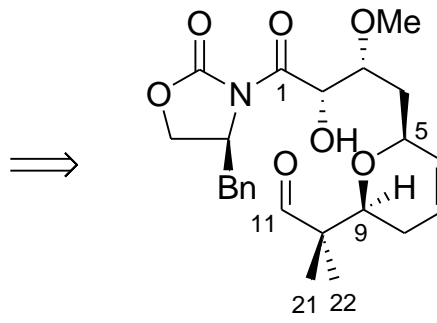

172

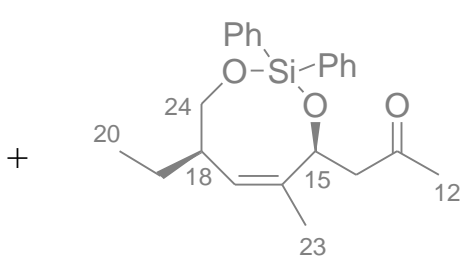

180<smiles>C=CCCCCCC(=O)N1C(=O)OCC1Br</smiles>

159
Methylation 1,2-syn Aldol reaction

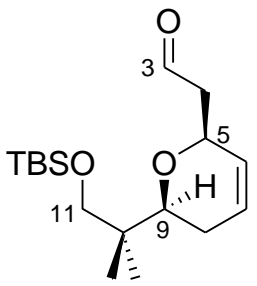

168

\subsubsection{Synthesis of the $C_{1}-C_{2}$ synthon}

The synthesis of the $\mathrm{C}_{1}-\mathrm{C}_{2}$ enolate $\mathbf{1 5 9}$ (Scheme 3.2) began from the commercially available bromoacetic acid (191). Reaction of the bromoacetic acid with 4methoxybenzyl alcohol provided the carboxylic acid 158 with a PMB ether at the $\mathrm{C}_{2}$ position in 53\% yield. A subsequent reaction between the carboxylic acid $\mathbf{1 5 8}$ and the 
known oxazolidinone 157 gave the chiral auxiliary derived $C_{1}-C_{2}$ fragment 159 in $48 \%$ yield.

Scheme 3.2 Synthesis of $\mathrm{C}_{1}-\mathrm{C}_{2}$ synthon.<smiles>CCOCC(=O)OCC(=O)OCC(=O)OCC(=O)OCC(=O)O</smiles>

157

Conditions: (a) $\mathrm{NaH}$, THF, $0{ }^{\circ} \mathrm{C}$, then 4-methoxybenzyl alcohol, RT for $15 \mathrm{~min}$, then $0{ }^{\circ} \mathrm{C}$, then 191, RT, 5 h; (b) 158, MeCN, TEA, HBTU, RT, 30 min, then 157, $n \mathrm{BuLi}$, THF, $-78{ }^{\circ} \mathrm{C}, 15 \mathrm{~min}$, then RT, $2 \mathrm{~h}$.

The oxazolidinone 157 was synthesised by well established methodology in two steps from the commercially available amino acid $L$-phenylalanine. ${ }^{103}$ Thus sodium borohydride reduction of $L$-phenylalanine provided phenylalaninol. ${ }^{103}$ Reaction of the phenylalaninol with potassium carbonate and diethyl carbonate at $78{ }^{\circ} \mathrm{C}$ afforded the oxazolidinone $\mathbf{1 5 7}$ in $50 \%$ yield over two steps.

\subsubsection{Synthesis of the $C_{3}-C_{11}$ synthon}

The synthesis of $\mathrm{C}_{3}-\mathrm{C}_{11}$ synthon 168 (Scheme 3.3) commenced from 2,2-dimethyl1,3-propanediol. Monosilylation of the diol with tert-butyldimethylsilyl chloride yielded $60 \%$ of the desired monoprotected alcohol 160. The other $40 \%$ was isolated as the disilylated product.

The subsequent Swern oxidation provided the aldehyde 161 in $86 \%$ optimised yield. The initial oxidation attempts with one equivalent of oxalyl chloride gave lower yields (48\%). The improvement in the yield was achieved through changes to the use of 1.6 equivalents of oxalyl chloride. An allowance was also made for formation of the dimethylchlorosulfonium intermediate over a longer period. These factors improved the conversion of the alcohol $\mathbf{1 6 0}$ to the aldehyde $\mathbf{1 6 1}$. 
Brown allylation ${ }^{104}$ of the aldehyde 161 with (-)- $\mathrm{Ipc}_{2}$ Ballyl afforded the homoallylic alcohol 163 with 70\% yield and good stereoselectivity (95\% ee). The enantiomeric excess of the alcohol 163 was determined through formation of the corresponding Mosher's esters and NMR analysis using the method developed by Dale and Mosher. ${ }^{105}$ Acylation of the alcohol 163 with acryloyl chloride under mild basic conditions gave the diene $\mathbf{1 6 4}$ in $82 \%$ yield.

Scheme 3.3 Synthesis of $\mathrm{C}_{3}-\mathrm{C}_{11}$ synthon.<smiles>CC(CO)CO</smiles>

192

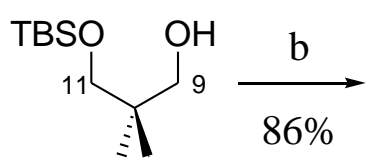

160<smiles>CC(C=O)C=O</smiles>

161

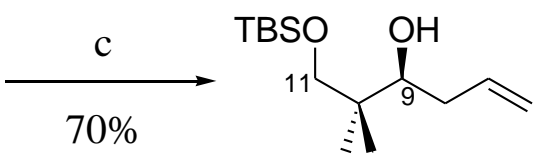

(95\% ee)

163

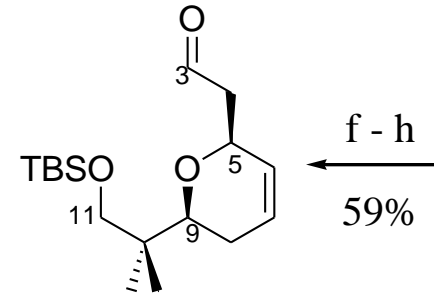

168<smiles>C[C@H](C=[18O])[C@H]1CC=CC(=O)O1</smiles>

165<smiles>C=CC[C@H](OC(=O)C=C)[C@@H](C)C=[GeH2]</smiles>

164

Conditions: (a) DMF, $0{ }^{\circ} \mathrm{C}$, then TBSCl, RT; (b) $(\mathrm{COCl})_{2}$, DMSO, TEA, DCM, -78 ${ }^{\circ} \mathrm{C}$; (c) (-)-Ipc 2 Ballyl, $-100{ }^{\circ} \mathrm{C}, 2 \mathrm{~h}$; (d) acryloyl chloride, DIPEA, DCM, $0{ }^{\circ} \mathrm{C}$ to RT; (e) $5 \mathrm{~mol} \%$ Grubbs' $2^{\text {nd }}$ geneneration catalyst, DCM, RT; (f) DIBAL-H, DCM, -23 ${ }^{\circ} \mathrm{C}, 45 \mathrm{~min}$; (g) TEA, $\mathrm{Ac}_{2} \mathrm{O}, \mathrm{DMAP}, \mathrm{DCM}, \mathrm{RT}$; (h) $\mathrm{H}_{2} \mathrm{C}=\mathrm{CHOTMS}, \mathrm{BF}_{3} \cdot \mathrm{Et}_{2} \mathrm{O}$, $\mathrm{MeCN}, \mathrm{RT}, 3.5 \mathrm{~h}$.

The subsequent RCM reaction using Grubbs' $2^{\text {nd }}$ generation catalyst initially gave poor yields. The ${ }^{1} \mathrm{H}$ NMR and TLC (thin layer chromatography) of the crude reaction mixture showed only a single product and a considerable amount of retained starting diene, the isolated amount of the clean $\alpha, \beta$-unsaturated lactone 165 was disappointingly low (19\%). Changes in reaction time and concentration did not give an improved result.

An apparent improvement in the observed crude reaction mixture was detected with the use of a new batch of Grubbs' $2^{\text {nd }}$ generation catalyst. Although the ratio of diene 
to lactone observed through the ${ }^{1} \mathrm{H}$ NMR data had increased considerably, the isolated yield of lactone 165 barely increased (33\%). Changing the isolation protocol by removing the charcoal adsorption step with a slow elution through a silica column remarkably provided the clean lactone $\mathbf{1 6 5}$ in $90 \%$ yield.

Subsequent three-step reaction sequence converted the lactone 165 to the aldehyde 168 in $59 \%$ yield. DIBAL-H reduction ${ }^{106}$ of the lactone 165 gave the corresponding lactol as a mixture of diastereomers. Acetylation of both diastereomers of the lactol gave the corresponding acetate as a mixture of diastereomers, finally, alkylation at $\mathrm{C}_{5}$ of the dihydropyran with vinyloxy-trimethylsilane gave the aldehyde $\mathbf{1 6 8}$ as a single product. The resolution of the diastereomeric mixture in the formation of $\mathbf{1 6 8}$ was attributed to the fact that an $S_{N} 1$ reaction mechanism dominates, in which an oxonium ion was formed following the loss of the acetal group. Subsequent addition by the enol ether with concomitant loss of the silyl group selectively occurs from the top face to give the $(S, S)$-aldehyde 168.

The stereoselectivity of $\mathbf{1 6 8}$ was determined in the previous study by Turner through the nOe correlation between protons of $\mathrm{C}_{4}$ and $\mathrm{C}_{9}$, and the lack of correlation between the protons of $\mathrm{C}_{5}$ and $\mathrm{C}_{9} .{ }^{100}$ The yield was dependent on the quality of the vinyloxytrimethylsilane. Freshly distilled reagent provided reasonable (59\%) yield over three steps. Undistilled, it was found that the vinyloxy-trimethylsilane had polymerised. The quality of the vinyloxy-trimethylsilane reagent was determined using ${ }^{1} \mathrm{H}$ NMR spectrum.

\subsubsection{Aldol coupling of the $C_{1}-C_{2}$ and $C_{3}-C_{11}$ fragments}

Upon successful synthesis of both the chiral auxiliary-bound $C_{1}-C_{2}$ synthon 159 and the aldehyde 168, an oxazolidinone-directed 1,2-syn aldol coupling reaction was attempted to acquire the complete $\mathrm{C}_{1}-\mathrm{C}_{11}$ synthon (Scheme 3.4). Although the TLC analysis of the reaction indicated the presence of compounds other than the starting

materials, the ${ }^{1} \mathrm{H}$ NMR spectrum contained only the starting materials. Purification of the crude reaction mixture through a silica column confirmed this when only the starting aldehyde 168 and ketone 159 were recovered. The tendency of the expected 1,2 -syn aldol product to undergo retro-aldolation upon prolonged exposure to an 
acidic environment provides a possible explanation for the disappearance of the detected non-starting material compounds, due to the entire reaction mixture having been left in the deuterated chloroform overnight. Therefore, in subsequent attempts, the exposure period in NMR solvent was reduced to an hour at the most. Furthermore, the compound was chromatographed with 1\% TEA (triethylamine) in the eluting solvent to counter the acidity of the silica column. These precautionary steps proved to be fruitful and the desired $\mathrm{C}_{1}-\mathrm{C}_{11}$ alcohol 169 was obtained in $52 \%$ yield. The inherent instability of the alcohol $\mathbf{1 6 9}$ meant that prolonged storage was inadvisable, even under argon at $-18{ }^{\circ} \mathrm{C}$. Therefore, the alcohol 169 was usually immediately methylated upon collection.

Scheme 3.4 Completion of $\mathrm{C}_{1}-\mathrm{C}_{11}$ synthon.

$$
159+168 \underset{52 \%}{\stackrel{\mathrm{a}}{\longrightarrow}}
$$

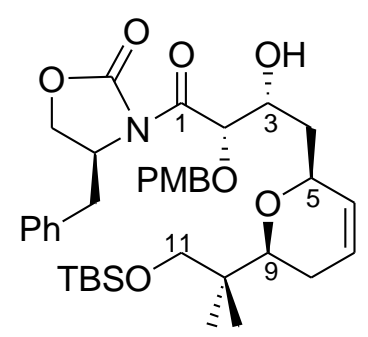

169

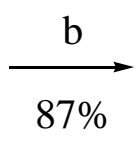

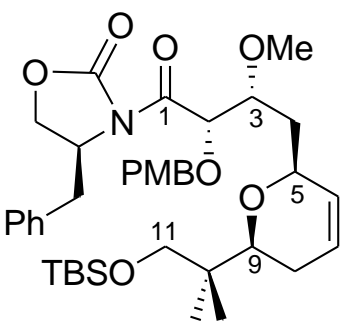

170<smiles>C=C[C@H](C)[C@H]1CC=C[C@@H](C[C@@H](OC)C(OC)C(=O)N2C(=O)OC[C@H]2Cc2ccccc2)O1</smiles>

172

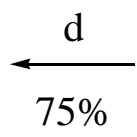<smiles>COC(C[C@@H]1C=CC[C@@H]([C@@H](C)C=O)O1)C(OC)C(=O)N1C(=O)OC[C@H]1Cc1ccccc1</smiles>

171

Conditions: (a) $\mathbf{1 5 9}$, toluene, $-50{ }^{\circ} \mathrm{C}$, TEA, $\mathrm{Bu}_{2} \mathrm{BOTf}, 1.5 \mathrm{~h}$, then 168 in toluene, then $-30{ }^{\circ} \mathrm{C}$ for $2 \mathrm{~h}$; (b) $\mathrm{Me}_{3} \mathrm{OBF}_{4}$, Proton-sponge ${ }^{\circledR}, 0{ }^{\circ} \mathrm{C}$; (c) $\mathrm{HCl}, \mathrm{MeOH}, \mathrm{RT}$; (d) DessMartin periodinane, pyridine, $0{ }^{\circ} \mathrm{C}, 5 \mathrm{~h}$.

The methylation of the $\mathrm{C}_{3}$ hydroxyl was achieved with $\mathrm{Me}_{3} \mathrm{OBF}_{4}$ and Protonsponge $^{\circledR}$, giving the methyl ester $\mathbf{1 7 0}$ in $87 \%$ yield. The initial methylation attempt failed to provide the desired methyl ether $\mathbf{1 7 0}$ and degradation of the starting material back to the aldehyde $\mathbf{1 6 8}$ and ketone $\mathbf{1 5 9}$ in the reaction mixture was noted through 
chromatography and in the ${ }^{1} \mathrm{H}$ NMR spectrum. This suggested the possibility that the reaction conditions were either too acidic or basic. Further investigation into the reagent used in the reaction indicated that the batch of $\mathrm{Me}_{3} \mathrm{OBF}_{4}$ had degraded.

Upon changing to a newly opened bottle of $\mathrm{Me}_{3} \mathrm{OBF}_{4}$, the reaction was performed and the desired compound $\mathbf{1 7 0}$ obtained. However, the yield of the desired product was very poor. A closer look into the side products showed that the majority of the compound had lost the oxazolidinone at $\mathrm{C}_{1}$ and had been converted to the methyl ester 173 (Table 3.1). The surprising conclusion was that boron side products and hydrolysis of the $\mathrm{Me}_{3} \mathrm{OBF}_{4}$ led to methanolysis of the oxazolidinone.

Therefore, in subsequent attempts, the amounts of the $\mathrm{Me}_{3} \mathrm{OBF}_{4}$ and Proton-sponge ${ }^{\circledR}$ were gradually reduced from initially fifteen equivalents relative to the alcohol $\mathbf{1 6 9}$ (Table 3.1). Optimum results were obtained with two equivalent of $\mathrm{Me}_{3} \mathrm{OBF}_{4}$ and Proton-sponge ${ }^{\circledR}$, three hours reaction time and the reaction mixture maintained at 0 ${ }^{\circ} \mathrm{C}$. Using these conditions, the final attempt to methylate the $\mathrm{C}_{3}$ hydroxyl provided $\mathbf{1 7 0}$ in excellent isolated yields of $87 \%$.

Table 3.1 Methylation of $\mathrm{C}_{3}$ hydroxyl.

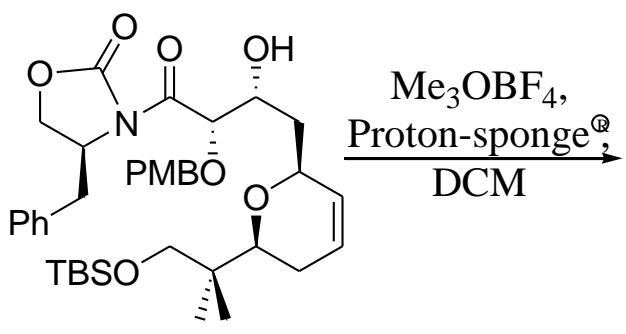

169<smiles>COC(CC(=O)N1C(=O)OC[C@H]1Cc1ccccc1)C[C@@H]1C=CC[C@@H]([C@@H](C)COC(C)(C)C)O1</smiles>

170

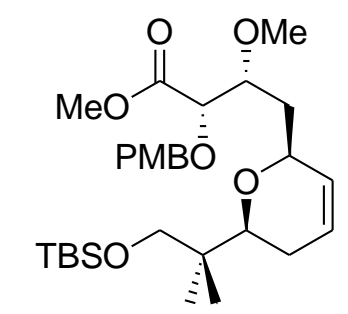

173

\begin{tabular}{|c|c|c|c|}
\hline Reagents (eqv) & Time (h) & Temperature $\left({ }^{\circ} \mathbf{C}\right)$ & $\mathbf{1 7 0 : 1 7 3}(\%$ yield) \\
\hline 15 & 16 & 0 to RT & $7: 21$ \\
\hline 12 & 3 & 0 to RT & $21: 7$ \\
\hline 6 & 3 & 0 & $82: 16$ \\
\hline 2 & 3 & 0 & $87: 11$ \\
\hline
\end{tabular}

The TBS protecting group at the $\mathrm{C}_{11}$ was removed by methanolysis in the presence of hydrogen chloride to provide the alcohol 171 in $60 \%$ yield. Subsequent Dess-Martin 
oxidation of the $\mathrm{C}_{11}$ hydroxyl proceeded with ease to provide the corresponding aldehyde 172 in $75 \%$ yield. With the methodology to produce protected $C_{1}-C_{11}$ aldehyde $\mathbf{1 7 2}$ in hand, a reliable route to protected $\mathrm{C}_{12}-\mathrm{C}_{24}$ was required prior to their aldol coupling to form the complete $\mathrm{C}_{1}-\mathrm{C}_{24}$ backbone of the peloruside $\mathrm{A}$ analogue 151.

\subsection{Synthesis of $\mathrm{C}_{12}-\mathrm{C}_{24}$}

The $\mathrm{C}_{12}-\mathrm{C}_{24}$ synthon was synthesised from two smaller fragments, a $\mathrm{C}_{12}-\mathrm{C}_{16} \beta$ hydroxy ketone 177 and a $\mathrm{C}_{17}-\mathrm{C}_{24}$ homoallylic alcohol 178 (Scheme 3.5). The synthesis employed a double-silylation reaction to give a tethered diene $\mathbf{1 7 9}$, followed by a RCM reaction to form a ketone with an eight-membered silicon bis-ether ring 180. The formation of the silocene $\mathbf{1 8 0}$ also provided for formation of the required $Z$ olefin in the side chain of peloruside A.

Scheme 3.5 Retrosynthesis of $\mathrm{C}_{12}-\mathrm{C}_{24}$ synthon.

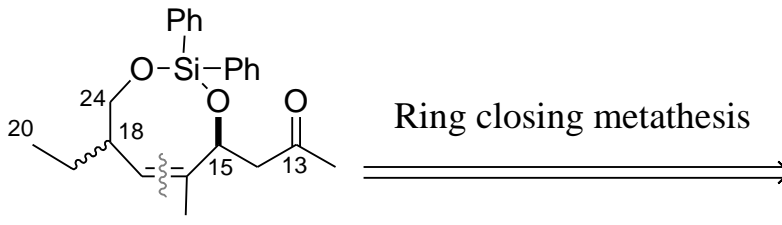

180

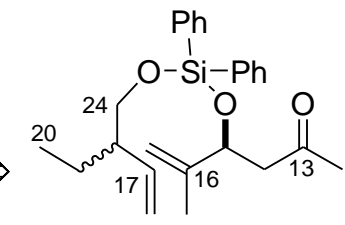

179

$\|$ Double silylation

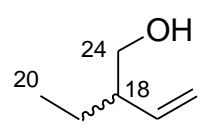

178

Ethylation

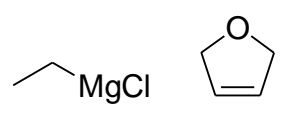

198

199<smiles>C=C(C)C(O)CC(C)=O</smiles>

177

Aldol coupling<smiles>C=C(C)C=O</smiles>

$196 \quad 197$ 


\subsubsection{Synthesis of the $\mathrm{C}_{12}-\mathrm{C}_{16}$ synthon}

Aldol coupling between methacrolein and acetone (Scheme 3.6) proceeded without hindrance to provide the desired $\beta$-hydroxy ketone 177 with a yield of $89 \%$. However, repeated attempts to determine the enantiomeric excess of the $\beta$-hydroxy ketone 177 by formation of Mosher's esters were unsuccessful due to the tendency of the $\mathrm{C}_{15}$ hydroxyl to eliminate. Attempts to follow the formation of Mosher's ester with in situ ${ }^{1} \mathrm{H}$ NMR reactions ${ }^{107}$ showed that the elimination occurred in tandem with the formation of the Mosher's esters. However, the $[\alpha]_{\mathrm{D}}$ of 177 compared with molecules prepared by Paterson suggested formation of the correct enantiomer as the major product. ${ }^{108}$

Scheme 3.6 Synthesis of $\mathrm{C}_{12}-\mathrm{C}_{16}$ synthon.

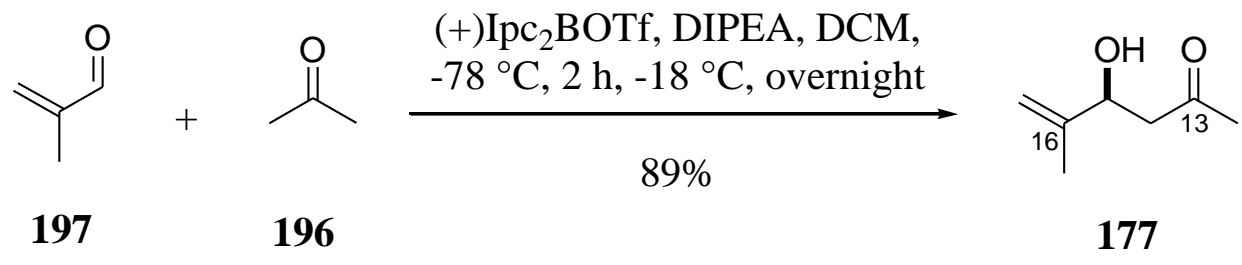

\subsubsection{Synthesis of the $C_{17}-C_{24}$ synthon}

The initial synthetic strategy to obtain ethylbutenol 178 (Scheme 3.7) involved an asymmetric carbomagnesation method developed by Hoveyda. ${ }^{109,110}$ The asymmetric carbomagnesation protocol employed $3 \mathrm{~mol} \%$ of dichloro[(S,S)-ethylenebis(4,5,6,7tetrahydro-1-indenyl)]zirconium(IV) as the asymmetric catalyst to direct the formation of the desired $(R)$-178 from 2,5-dihydrofuran and ethylmagnesium chloride. However, due to the low yield (20\%) of the reaction and cost consideration for the synthesis of a starting material, bis(cyclopentadienyl)zirconium(IV) dichloride was used instead. Bis(cyclopentadienyl)zirconium(IV) dichloride is not enantioselective but gave a better yield and provided the ethylbutenol 178 as a racemic mixture in $53 \%$ yield. It has been noted previously that the subsequent RCM is diastereoselective, leading to kinetic resolution in this reaction ${ }^{101}$ and thereby rendering prior resolution of $\mathbf{1 7 8}$ unnecessary. 
Scheme 3.7 Synthesis of $\mathrm{C}_{17}-\mathrm{C}_{24}$ synthon.

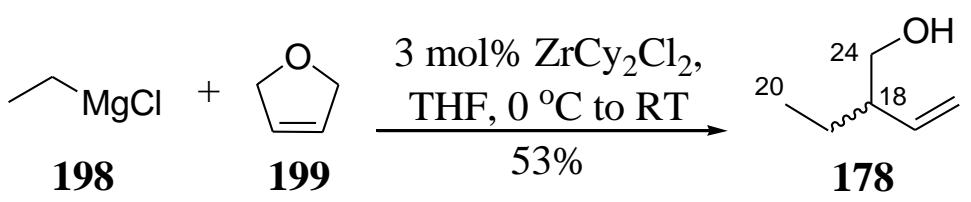

\subsubsection{Double-silylation reaction to form silyl bis-ether 179}

Upon acquisition of both the alcohol 178 and the $\beta$-hydroxy ketone 177, their one-pot tethering to dichlorodiphenylsilane was attempted. Several of the initial trials failed to provide the desired diene 179. Instead, starting materials, mono-tethered butenol or/and mono-tethered $\beta$-hydroxy ketone were recovered from the reaction mixture. These results led to the conclusion that partial hydrolysis of the dichlorodiphenylsilane reagent (200) to chlorodiphenylsilanol (201) and/or diphenylsilanediol (202) had reduced the reactivity of the reagent towards silyl ether formation (Scheme 3.8). This issue was overcome by freshly distilling the reagent prior to the reaction, thus ensuring that only non-hydrolysed reagent was present in the reaction mixture.

Scheme 3.8 Hydrolysis of dichlorodiphenylsilane to chlorodiphenylsilanol and diphenylsilanediol.

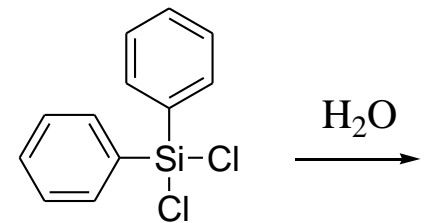

200

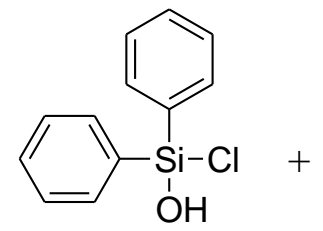

201

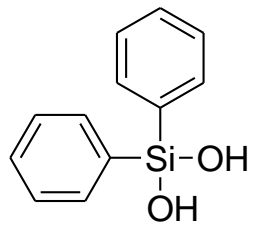

202

However, with the previous problem solved, another issue arose. Although the consecutive attempts successfully produced the desired diene 179, the reaction yield was disappointingly low (10\%). Further investigation revealed that the low yield was partly due to the formation of doubly-tethered alcohol 203 (Scheme 3.9). The solution that was adopted to reduce the problem was to shorten the time frame for coupling of the alcohol 178 to the diphenylsilane. This was done by closely monitoring the reaction progression. The $\beta$-hydroxy ketone $\mathbf{1 7 7}$ was added into the reaction mixture as soon as a trace of bis-homoallylic alcohol $\mathbf{2 0 3}$ was detected by chromatographic analysis. The $\beta$-hydroxy ketone 177 should be able to compete with 178 for 
attachment to the silane 204. The reduction of alcohol tethering time gave the diene $\mathbf{1 7 9}$ in a slightly improved yield of $38 \%$.

Scheme 3.9 Formation of bis-homoallylic alcohol 203.

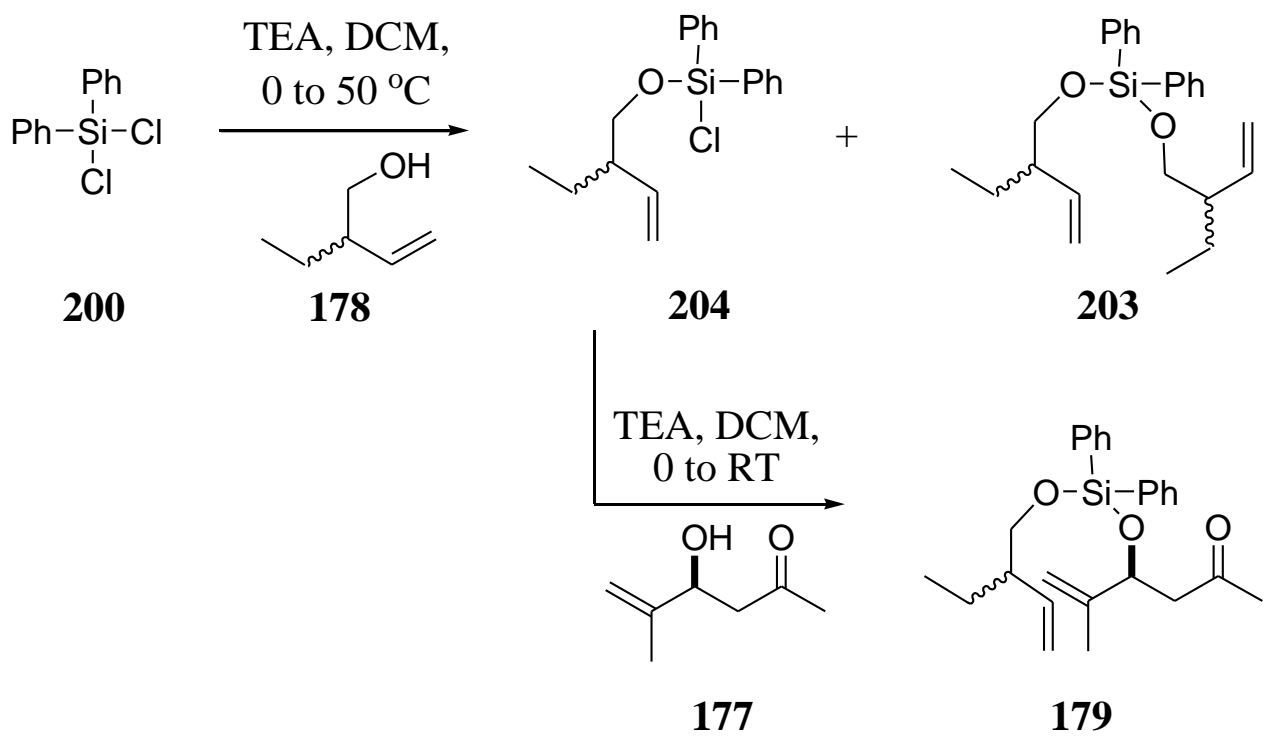

\subsubsection{Ring closing metathesis reaction}

The diene 179 was subjected to RCM using Grubbs' $2^{\text {nd }}$ generation catalyst. Initially, the diene solution was added gradually into a refluxing solution of the catalyst to ensure minimal cross-metathesis. ${ }^{100}$ However, the formation of the eight-membered ring was slow and the yield very poor (Scheme 3.10). Although the desired intramolecular metathesis accounted for the majority of the isolated material $(\mathbf{1 8 0}$, in $30 \%$ ), the intermolecular cross-metathesis product $\mathbf{2 1 0}$ was isolated in $13 \%$ yield. The side products 212 , the product of cross-metathesis with the styrene by-product, and 215, the product of alkene isomerisation, were isolated as a 1:1 mixture in $12 \%$ combined yield. 
Scheme 3.10 The cross-metathesis products of diene 179.<smiles>C=C[C@H](CC)CO[Si](O[C@@H](CC(C)=O)C(=C)C)(c1ccccc1)c1ccccc1</smiles>

179

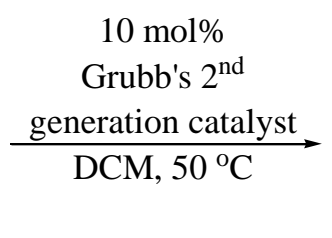

Grubb's $2^{\text {nd }}$

eneration catalyst

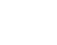

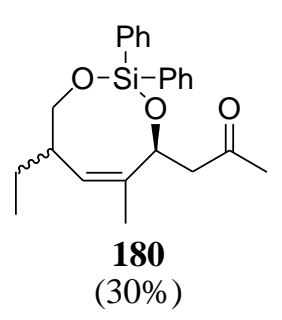

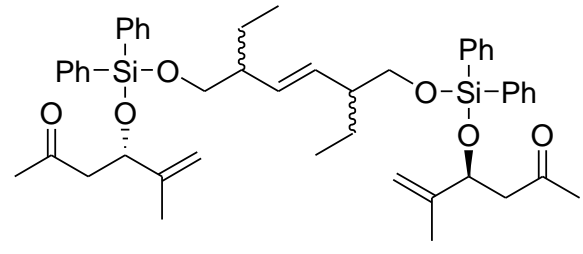

210

$(13 \%)$<smiles>C=C(C)[C@H](CC(C)=O)O[Si](OC[C@@H](C=Cc1ccccc1)CC)(c1ccccc1)c1ccccc1</smiles>

212

(6\%)<smiles>C=C(CC)CO[Si](O[C@H](CC(C)=O)C(=C)C)(c1ccccc1)c1ccccc1</smiles>

215

(6\%)

The structure of $\mathbf{2 1 0}$ was determined from spectral examination of the HRMS, ${ }^{1} \mathrm{H}$ and ${ }^{13} \mathrm{C}$ NMR spectra, COSY, HSQC and HMBC data. The HRMS evaluation provided a calculated mass of $\mathrm{m} / \mathrm{z} 811.3826$ which fitted the formula of $\mathrm{C}_{48} \mathrm{H}_{60} \mathrm{O}_{6} \mathrm{Si}_{2} \mathrm{Na}$. The spectroscopic data (Table 3.2) for the ketone portion of $\mathbf{2 1 0}$ matched the chemical shifts of both the $\beta$-hydroxy ketone 177 and the corresponding portion in the diene 179. Observed changes in the spectroscopic data of the $\mathrm{C}_{17}-\mathrm{C}_{24}$ allylic portion between 210 and the starting material 179 included an upfield shift of approximately $0.4 \mathrm{ppm}$ in the ${ }^{1} \mathrm{H}$ NMR of $\mathrm{C}_{17}$ and transformation of the peak from a multiplet to a doubles of doublet, which indicates a disubstituted alkene. Together with this, an absence of signals corresponding to the original olefinic methylene adjacent to $\mathrm{C}_{17}$ further confirmed the cross-metathesis. Due to the symmetrical nature of the molecule, the cis/trans geometry of $\mathbf{2 1 0}$ was not resolved. 
Table 3.2 Spectroscopic evidence for the cross-metathesised diene product $\mathbf{2 1 0}$.

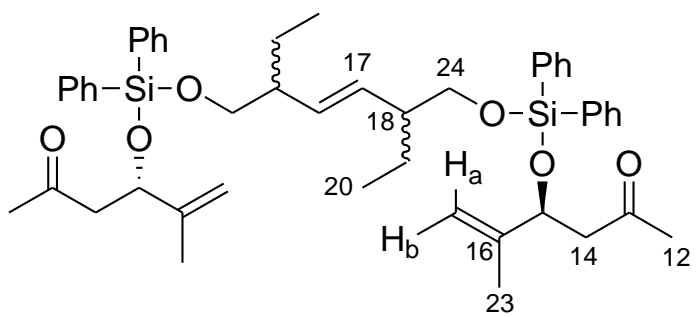

210

\begin{tabular}{|c|l|l|c|}
\hline $\boldsymbol{\delta}^{\mathbf{1 3}} \mathbf{C}$ & \multicolumn{1}{|c|}{$\boldsymbol{\delta}^{\mathbf{1}} \mathbf{H}$} & \multicolumn{1}{|c|}{ COSY } & position \\
\hline 206.69 & - & - & 13 \\
\hline 145.56 & - & $7.40,7.32$ & 16 \\
\hline 135.19 & $7.60(\mathrm{~m}, 8 \mathrm{H})$ & - & $\mathrm{Ph}$ \\
\hline 132.72 & - & 2.07 & $\mathrm{Ph}$ \\
\hline 132.72 & $5.21(\mathrm{dd}, J=2.5,5.2 \mathrm{~Hz}, 2 \mathrm{H})$ & 17 \\
\hline 139.34 & $7.40(\mathrm{~m}, 4 \mathrm{H})$ & $7.60,7.32$ & $\mathrm{Ph}$ \\
\hline 127.86 & $7.32(\mathrm{~m}, 8 \mathrm{H})$ & $7.60,7.40$ & $\mathrm{Ph}$ \\
\hline 112.28 & $4.88(\mathrm{~d}, J=8.0 \mathrm{~Hz}, 2 \mathrm{H})$, & $1.68 ;$ & $\mathrm{a}$, \\
& $4.74(\mathrm{~m}, 2 \mathrm{H})$ & $2.76,1.68$ & $\mathrm{~b}$ \\
\hline 73.41 & $4.74(\mathrm{~m}, 2 \mathrm{H})$ & $2.78,1.68$ & 15 \\
\hline 66.67 & $3.59(\mathrm{~m}, 4 \mathrm{H})$ & 2.07 & 24 \\
\hline 50.44 & $2.76(\mathrm{~m}, 2 \mathrm{H}), 2.54(\mathrm{~m}, 2 \mathrm{H})$ & 4.74 & 14 \\
\hline 47.10 & $2.07(\mathrm{bs}, 2 \mathrm{H})$ & $5.21,3.59,1.21$ & 18 \\
\hline 31.00 & $2.04(\mathrm{~d}, J=12.0 \mathrm{~Hz}, 6 \mathrm{H})$ & - & 12 \\
\hline 24.09 & $1.62(\mathrm{~m}, 2 \mathrm{H})$, & $1.21,0.86 ;$ & 19 \\
\hline 17.52 & $1.68(\mathrm{~d}, J=7.8 \mathrm{~Hz}, 6 \mathrm{H})$ & $4.88,4.47$ & 23 \\
\hline 11.72 & $0.82(\mathrm{~m}, 6 \mathrm{H})$ & $1.62,1.21$ & $207,1.62,0.86$ \\
\hline
\end{tabular}

In order to improve the yield of the RCM reaction and reduce cross-metathesis, several modifications of the reaction conditions ${ }^{100}$ were tried. Better reaction conditions were found to involve addition of five small portions of the Grubbs' $2^{\text {nd }}$ generation catalyst into a refluxing solution of diene in dichloromethane every hour. A total of $10 \mathrm{~mol} \%$ of the catalyst was used for the reaction. Although the yield was improved slightly, cross-metathesis was still a problem. In order to discourage crossmetathesis, the concentration of the reaction mixture was lowered. However, changes 
in the concentration of the reaction mixture did not alter the amount of the crossmetathesis.

Aside from the expected product and the cross-metathesis product 210, an equal mixture of $\mathbf{2 1 2}$ (Table 3.3) and $\mathbf{2 1 5}$ (Table 3.4) were observed. The side-products 212 and 215 were inseparable by silica column chromatography and were initially thought to be a single compound. The structures of the side-product 212 and 215 were determined from the ${ }^{1} \mathrm{H}$ and ${ }^{13} \mathrm{C}$ NMR, COSY, HSQC and HMBC spectral data. Examination of the spectroscopic data showed that some of the peaks were similar to those of the $\beta$-hydroxy in the diene 179. The integration of these peaks in the proton spectrum gave a 2:1 ratio. Furthermore, the integration of the ${ }^{1} \mathrm{H}$ NMR for the phenyl moiety accounted for 25 protons. Evaluation of the remaining peaks through HMBC data showed disconnection of certain peaks, leading to a conclusion that two compounds were involved. 
Table 3.3 Spectroscopic evidence for the side-product 212.

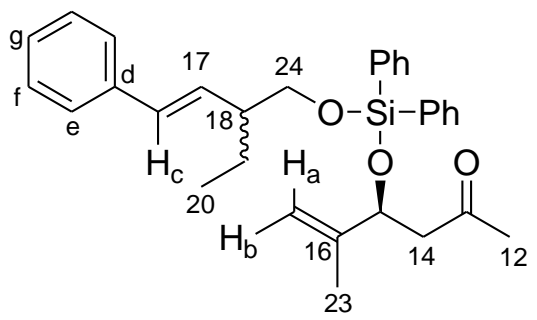

212

\begin{tabular}{|c|c|c|c|}
\hline$\delta^{13} \mathrm{C}$ & $\delta^{1} \mathbf{H}$ & COSY & position \\
\hline 206.73 & - & - & 13 \\
\hline 145.56 & - & - & 16 \\
\hline 137.86 & - & - & $\mathrm{d}$ \\
\hline 135.21 & $7.63(\mathrm{~m}, 4 \mathrm{H})$ & 7.36 & $\mathrm{Ph}$ \\
\hline 132.17 & - & - & $\mathrm{Ph}$ \\
\hline 132.17 & $6.02(\mathrm{dd}, J=8.7 \mathrm{~Hz}, 16.0 \mathrm{~Hz}, 1 \mathrm{H})$ & $6.40,2.32$ & 17 \\
\hline 131.29 & $6.40(\mathrm{~d}, J=15.8 \mathrm{~Hz}, 1 \mathrm{H})$ & 6.02 & $\mathrm{c}$ \\
\hline 130.36 & $7.36(\mathrm{~m}, 2 \mathrm{H})$ & - & $\mathrm{Ph}$ \\
\hline 128.58 & $7.36(\mathrm{~m}, 2 \mathrm{H})$ & 7.19 & $\mathrm{f}$ \\
\hline 127.86 & $7.36(\mathrm{~m}, 4 \mathrm{H})$ & 7.63 & $\mathrm{Ph}$ \\
\hline 127.06 & $7.19(\mathrm{t}, J=7.2 \mathrm{~Hz}, 1 \mathrm{H})$ & 7.36 & $\mathrm{~g}$ \\
\hline 126.14 & $7.36(\mathrm{~m}, 2 \mathrm{H})$ & - & $\mathrm{e}$ \\
\hline 112.40 & $\begin{array}{l}4.89(\mathrm{~d}, J=7.9 \mathrm{~Hz}, 1 \mathrm{H}), \\
4.77(\mathrm{~m}, 1 \mathrm{H})\end{array}$ & $\begin{array}{l}4.77 \\
4.89\end{array}$ & $\begin{array}{l}\mathrm{a}, \\
\mathrm{b}\end{array}$ \\
\hline 73.45 & $4.77(\mathrm{~m}, 1 \mathrm{H})$ & $2.54,2.78$ & 15 \\
\hline 66.55 & $3.72(\mathrm{~d}, J=6.1 \mathrm{~Hz}, 2 \mathrm{H})$ & 2.32 & 24 \\
\hline 50.45 & $2.78(\mathrm{~m}, 1 \mathrm{H}), 2.54(\mathrm{~m}, 1 \mathrm{H})$ & 4.77 & 14 \\
\hline 47.48 & $2.32(\mathrm{~m}, 1 \mathrm{H})$ & $3.72,1.39$ & 18 \\
\hline 30.99 & $2.03(\mathrm{~d}, J=13.2 \mathrm{~Hz}, 3 \mathrm{H})$ & - & 12 \\
\hline 24.18 & $\begin{array}{l}1.62(\mathrm{dd}, J=6.6 \mathrm{~Hz}, 22.0 \mathrm{~Hz}, 1 \mathrm{H}) \\
1.39(\mathrm{~m}, 1 \mathrm{H})\end{array}$ & $\begin{array}{l}1.39,0.88 \\
2.32,1.62,0.88\end{array}$ & 19 \\
\hline 17.48 & $1.69(\mathrm{~d}, J=6.9 \mathrm{~Hz}, 3 \mathrm{H})$ & - & 23 \\
\hline 11.83 & $0.88(\mathrm{t}, J=7.7 \mathrm{~Hz}, 3 \mathrm{H})$ & $1.62,1.39$ & 20 \\
\hline
\end{tabular}


Examination of one of the disconnected portions as individual compounds showed an expected correlation to the phenyl moiety, leading to a conclusion that the 5 superfluous aromatic protons observed previously were a part of the allylic portion. HMBC and COSY correlations were employed in the determination of the structural connectivity between the phenyl moiety and the $\mathrm{C}_{17}$ alkene. The evidence of a shielding effect of the aromatic moiety was apparent in the downfield shift of the $\mathrm{C}_{17}$ alkene. The side-product 212 was a product of metathesis between the diene 179 with styrene resulting from the initial cycle of the catalytic reaction (Scheme 3.11).

Table 3.4 Spectroscopic evidence for the side-product 215.

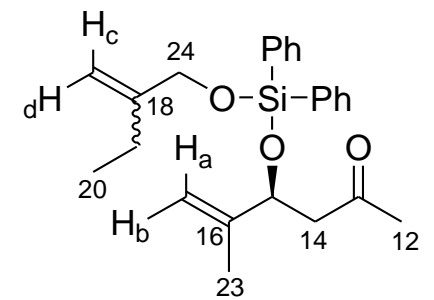

215

\begin{tabular}{|c|l|l|c|}
\hline $\boldsymbol{\delta}^{\mathbf{1 3}} \mathbf{C}$ & \multicolumn{1}{|c|}{$\boldsymbol{\delta}^{\mathbf{1}} \mathbf{H}$} & $\mathbf{C O S Y}$ & position \\
\hline 206.73 & - & - & 13 \\
\hline 149.49 & - & - & 18 \\
\hline 145.56 & - & - & 16 \\
\hline 135.21 & $7.63(\mathrm{~m}, 4 \mathrm{H})$ & 7.36 & $\mathrm{Ph}$ \\
\hline 132.17 & - & - & $\mathrm{Ph}$ \\
\hline 130.36 & $7.36(\mathrm{~m}, 2 \mathrm{H})$ & - & $\mathrm{Ph}$ \\
\hline 127.86 & $7.36(\mathrm{~m}, 4 \mathrm{H})$ & 7.63 & $\mathrm{Ph}$ \\
\hline 112.40 & $4.89(\mathrm{~d}, J=7.9 \mathrm{~Hz}, 1 \mathrm{H}), 4.77(\mathrm{~m}, 1 \mathrm{H})$ & $4.77 ; 4.89$ & $\mathrm{a}, \mathrm{b}$ \\
\hline 107.81 & $5.11(\mathrm{~s}, 1 \mathrm{H}), 4.84(\mathrm{~s}, 1 \mathrm{H})$ & $4.84 ; 5.11$ & $\mathrm{c}, \mathrm{d}$ \\
\hline 73.45 & $4.77(\mathrm{~m}, 1 \mathrm{H})$ & $2.54,2.78$ & 15 \\
\hline 65.90 & $4.19(\mathrm{~s}, 2 \mathrm{H})$ & - & 24 \\
\hline 50.45 & $2.78(\mathrm{~m}, 1 \mathrm{H}), 2.54(\mathrm{~m}, 1 \mathrm{H})$ & 4.77 & 14 \\
\hline 30.99 & $2.03(\mathrm{~d}, J=13.2 \mathrm{~Hz}, 3 \mathrm{H})$ & - & 12 \\
\hline 25.56 & $2.03(\mathrm{~m}, 2 \mathrm{H})$ & 1.01 & 19 \\
\hline 17.48 & $1.69(\mathrm{~d}, J=6.9 \mathrm{~Hz}, 3 \mathrm{H})$ & - & 23 \\
\hline 12.27 & $1.01(\mathrm{t}, J=7.4 \mathrm{~Hz}, 3 \mathrm{H})$ & 2.03 & 20 \\
\hline
\end{tabular}


Examination of the ${ }^{13} \mathrm{C}$ NMR spectrum accounted for five carbon environments not assigned to the side-product 212. The COSY correlation showed that the alkene moieties only connected to two methylene carbons. The upfield methylene carbon showed connectivity to a methyl group. The downfield methylene only showed connectivity to the alkene, leading to the conclusion that it was the oxy-methylene. Further investigation regarding the reaction conditions and the nature of the olefin, revealed its propensity to isomerise in the presence of Grubbs' $2^{\text {nd }}$ generation catalyst. ${ }^{111}$ The observed side-product $\mathbf{2 1 5}$ is probably obtained from isomerisation into olefin 213 and cross-metathesis (Scheme 3.11).

The formation of the side products $\mathbf{2 1 0}, \mathbf{2 1 2}$, and 215 were unexpected. A study by Courchay found that the coordination of the substrate with the metal centre of Grubbs' $2^{\text {nd }}$ generation catalyst during the metallo-cyclobutane formation was the determinant to the product formed. ${ }^{112}$ Although two possible routes might provide for the desired dioxysilocene 180, from the outcome of the reaction and the ease of access, it was deduced that complexation of the metal centre to ethylbutene was preferred (Scheme 3.11). ${ }^{112}$ However, if prior to the second cyclobutene formation, another diene molecule was available, cross-metathesis will be more kinetically favoured, resulting in the side product 210. Therefore high dilution was the key to the formation of dioxysilocene $\mathbf{1 8 0}$.

With both the $C_{1}-C_{11}$ segment 172 and the $C_{12}-C_{24}$ segment 180 necessary for the backbone assembly of peloruside A analogue $\mathbf{1 5 1}$ in hand, an aldol coupling was attempted using dibutylboryl trifluoromethanesulfonate. The detailed of the study will be discussed in the next section. 
Scheme 3.11 Proposed mechanism of formation for the observed RCM products.

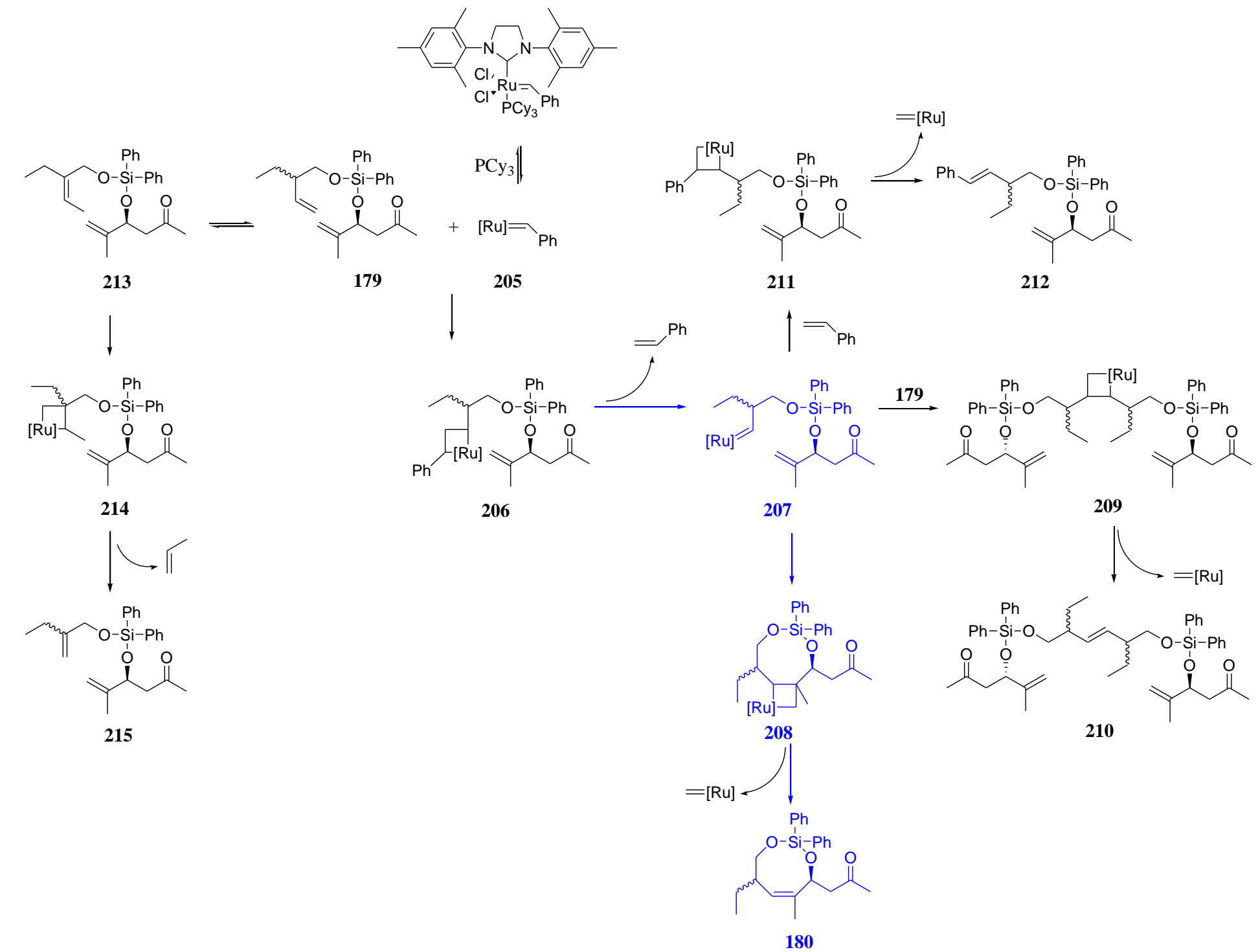




\subsection{Attempts to synthesise $\mathrm{C}_{1}-\mathrm{C}_{24}$ by aldol reaction}

Dibutylboryl trifluoromethanesulfonate $\left(\mathrm{Bu}_{2} \mathrm{BOTf}\right)$ was employed as the coupling agent in the attempts to couple the ketone $\mathbf{1 8 0}$ and aldehyde $\mathbf{1 7 2}$ to obtain the desired $\mathrm{C}_{1}-\mathrm{C}_{24}$ precursor of the analogue 151 (Scheme 3.12). Unfortunately, the aldol coupling was unsuccessful and only degraded starting material was recovered. The failure of the reaction was attributed to lack of solubility of the aldehyde 172. The presence of the chiral auxiliary was suggested as the cause of the insolubility of the aldehyde $\mathbf{1 7 2}$.

Scheme 3.12 Attempted aldol reaction of the ketone $\mathbf{1 8 0}$ and aldehyde $\mathbf{1 7 2}$.

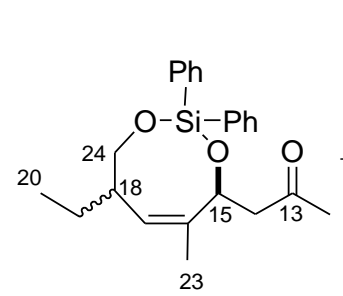

180

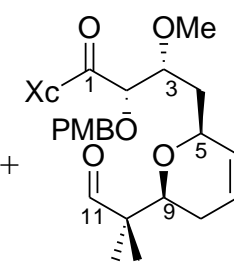

172

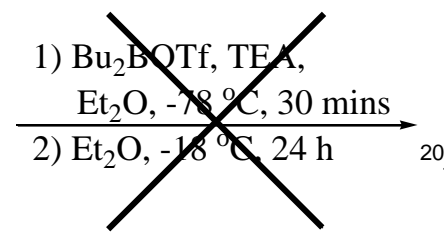

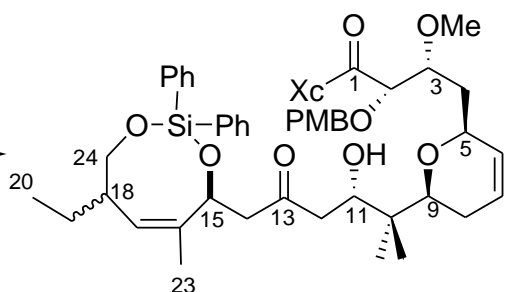

216<smiles>[X]#CN1C(=O)OC[C@H]1Pc1ccccc1</smiles>

Therefore, in subsequent attempts, the oxazolidinone at $\mathrm{C}_{1}$ of the aldehyde $\mathbf{1 7 2}$ was replaced by a methyl ester. This was achieved by methanolysis of the oxazolidinone 170 by reaction of sodium methoxide in the presence of dimethyl carbonate to give the corresponding methyl ester $\mathbf{1 7 3}$ in $69 \%$ yield. The presence of dimethyl carbonate in this reaction was found to be necessary to obtain the desired methyl ester. ${ }^{100}$ This was due to undesired methoxide ion attack on the endo-cyclic carbonyl, giving an amide plus dimethyl carbonate as the by-product. Presumably, this results from the high degree of steric hindrance at the normally preferred site of nucleophilic attack. However, by adding an excess (five equivalents) of dimethyl carbonate in the reaction mixture, the equilibrium of this undesired ring-opening was returned towards the starting material, by Le Chatelier's principle, thus facilitating reaction of methanol with the correct $\mathrm{C}_{1}$-carbonyl. ${ }^{113}$ The subsequent removal of the silyl protecting group 
and TEMPO-BAIB oxidation of the resulting alcohol provided the aldehyde $\mathbf{1 7 5}$ in $85 \%$ yield over two steps (Scheme 3.13).

Scheme 3.13 Synthesis of the aldehyde $\mathbf{1 7 5}$.

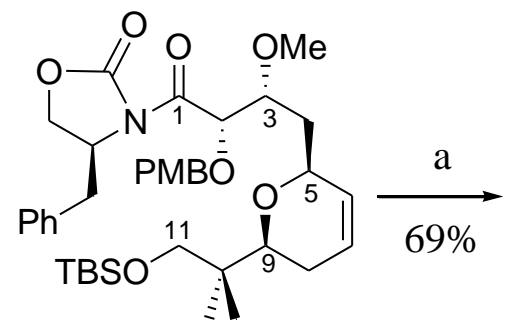

170

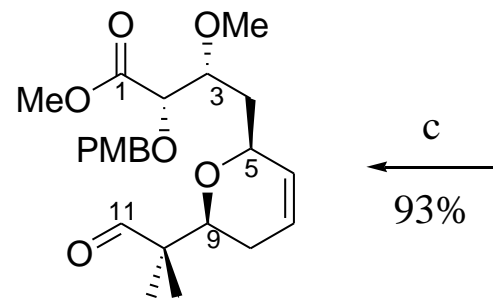

175

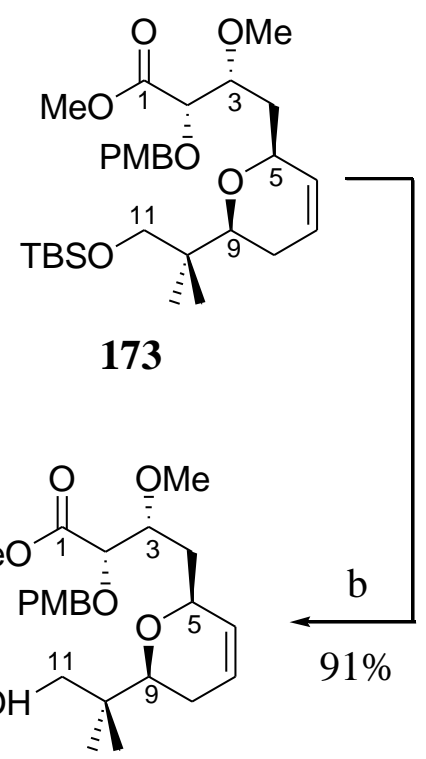

174

Conditions: (a) $\mathrm{CO}(\mathrm{OMe})_{2}, \mathrm{NaOMe}, \mathrm{DCM}, 0^{\circ} \mathrm{C}, 1.5 \mathrm{~h}$; (b) $\mathrm{MeOH}$, concentrated $\mathrm{HCl}$, RT, 30 min; (c) BAIB, TEMPO, DCM, RT, 5 h.

The aldol coupling was attempted with the aldehyde 175 and the ketone 180 (Scheme 3.14). Although the lack of solubility was no longer an issue, the reaction still failed, instead the starting materials decomposed in the reaction mixture. Initially, the failure was attributed to the degradation of the $\mathrm{Bu}_{2} \mathrm{BOTf}$ reagent. However, the successive coupling attempts with a newly opened bottle of reagent were also unsuccessful. Effort was also made to distil the $\mathrm{Bu}_{2} \mathrm{BOTf}$, but the reagent degraded during the process. Various changes to the reaction conditions including the boron reagent, the base, and time-scale for the enolate formation were investigated in later attempts. 
Scheme 3.14 Attempted aldol reaction of the ketone $\mathbf{1 8 0}$ and aldehyde $\mathbf{1 7 5}$.

180
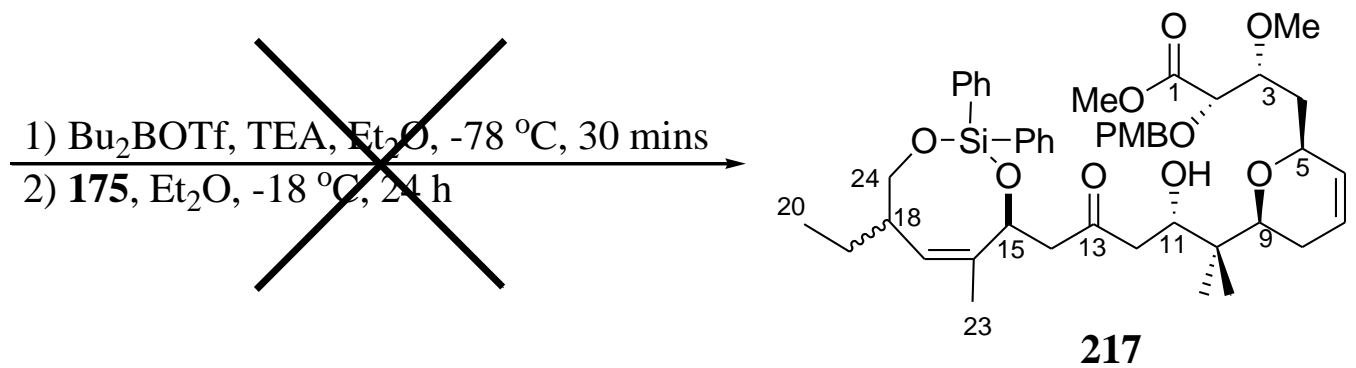

9-BBNOTf has been used to couple the $C_{1}-C_{11}$ fragment 72 with the $C_{12}-C_{24}$ fragment 78 in Evans' synthesis of peloruside A (Scheme 3.15) ${ }^{54}$ The required 1,5anti-stereoselectivity was obtained with 20:1 diastereomeric ratio and 92\% yield of the $\mathrm{C}_{1}-\mathrm{C}_{24}$ precursor 79 .

Scheme 3.15 Evans' aldol reaction between $\mathrm{C}_{1}-\mathrm{C}_{11}$ with $\mathrm{C}_{12}-\mathrm{C}_{24}$ using 9-BBNOTf. ${ }^{54}$

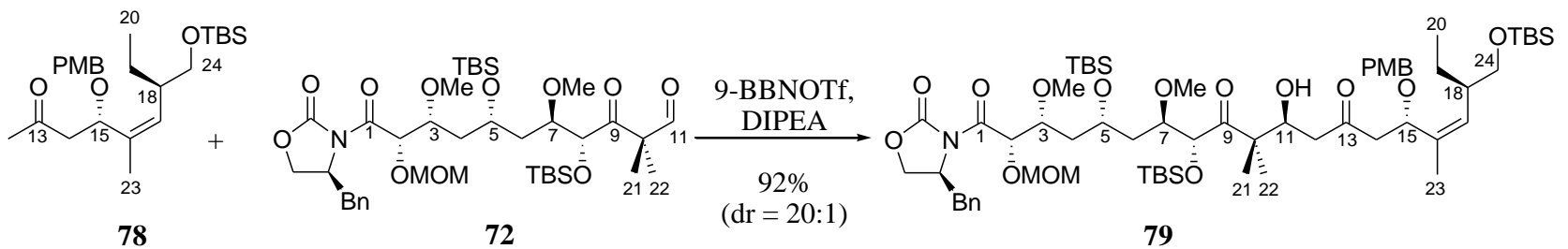

Unfortunately, the aldol coupling attempts between the aldehyde $\mathbf{1 7 5}$ and the ketone 180 using 9-BBNOTf also ended in failure with the starting materials decomposing in the reaction mixture (Scheme 3.16).

Scheme 3.16 Attempted aldol reaction of the ketone $\mathbf{1 8 0}$ and aldehyde $\mathbf{1 7 5}$.

180
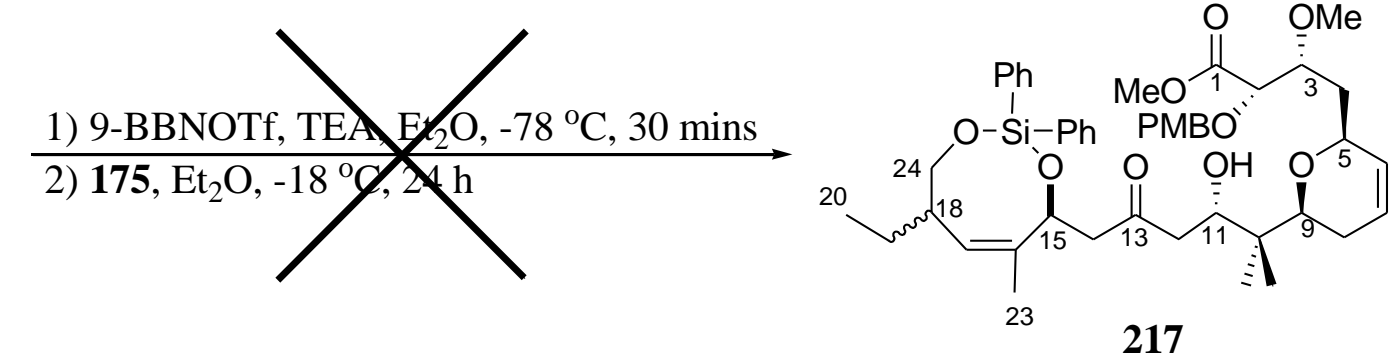

Since changing the coupling agent from $\mathrm{Bu}_{2}$ BOTf to 9-BBNOTf did not provide an encouraging outcome, alternation of the base to DIPEA ( $N, N$-diisopropylethylamine) was investigated. However, due to time constraints, a model with $\mathrm{C}_{5}-\mathrm{C}_{11}$ aldehyde 182 instead of the full $\mathrm{C}_{1}-\mathrm{C}_{11}$ aldehyde 175 was used. In order to obtain the aldehyde 
182, the silylated lactone 165 was treated with hydrochloric acid and methanol to remove the TBS group. The resulting alcohol 181 was then subjected to TEMPOBAIB oxidation to give the aldehyde $\mathbf{1 8 2}$ in an unoptimised $36 \%$ yield over two steps (Scheme 3.17).

Scheme 3.17 Synthesis of the aldehyde $\mathbf{1 8 2}$.<smiles>C[C@@H](C=[GeH2])[C@H]1CC=CC(=O)O1</smiles>

165

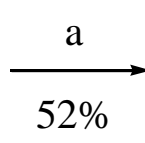

$52 \%$<smiles>C[C@H](C=O)[C@H]1CC=CC(=O)O1</smiles>

181<smiles>C[C@H](C=O)[C@H]1CC=CC(=O)O1</smiles>

182

Conditions: (a) $\mathrm{MeOH}$, concentrated $\mathrm{HCl}, \mathrm{RT}, 30 \mathrm{~min}$; (b) BAIB, TEMPO, DCM, $\mathrm{RT}, 5.5 \mathrm{~h}$.

The aldol coupling between the aldehyde $\mathbf{1 8 2}$ and the ketone 180 using $\mathrm{Bu}_{2} \mathrm{BOTf}$ as the coupling agent and DIPEA as the base was attempted (Scheme 3.18). Disappointingly, the reaction failed to provide the desired $\mathrm{C}_{5}-\mathrm{C}_{24}$ 1,5-anti aldol product 218, however consumption of the starting materials was observed. The alcohol 181 was observed in the reaction mixture in $38 \%$ yield. Initially, the presence of the alcohol 181 in the reaction mixture was attributed to contamination of the starting aldehyde 182. However, closer analysis of the starting material indicated the absence of the precursor alcohol. An alternative conclusion was drawn that the aldehyde 182 was converted to the alcohol 181 in the reaction mixture.

Scheme 3.18 Aldol coupling of the aldehyde 182 and the ketone 180 using DIPEA as base.

180

1) $\mathrm{Bu}_{2} \mathrm{BOTF}, \mathrm{DIPA}, 2 \mathrm{t}_{2} \mathrm{O},-78^{\circ} \mathrm{C}, 30 \mathrm{mins}$<smiles>CC[C@H]1C=C(C)[C@H](CC(=O)CC(O)[C@H](C)[C@H]2CC=CC(=O)O2)O[Si](c2ccccc2)(c2ccccc2)OC1</smiles>

1) $\mathrm{Bu}_{2}$ BOTF, DIPEA, $\mathrm{Et}_{2} \mathrm{O},-78^{\circ} \mathrm{C}, 30 \mathrm{mins}$

2) $182, \mathrm{Et}_{2} \mathrm{O},-18{ }^{\circ} \mathrm{C}, 24 \mathrm{~h}$<smiles>C[C@H](CO)[C@H]1CC=CC(=O)O1</smiles>

218 
Recent developments by Mojtahedi and Abaee of the classic Cannizzaro reaction appear relevant to this discovery. ${ }^{114,} 115$ The Cannizzaro reaction is a well known redox conversion of a non-enolisable aldehyde to the corresponding alcohol and carboxylic acid in the presence of a strong aqueous base. ${ }^{116}$ Mojtahedi and Abaee reported a convenient conversion of aryl aldehydes to mixtures of the corresponding alcohols and carboxylic acids at room temperature using TEA as the base and lithium bromide or $\mathrm{MgBr}_{2} . \mathrm{OEt}_{2}$ as the Lewis acid catalyst. ${ }^{114,115}$ According to the mechanism proposed by Mojtahedi and Abaee, magnesium or lithium coordinates to two aldehyde molecules through the carbonyl oxygens. Nucleophilic nitrogen attack by the base on the carbonyl carbon of one of the coordinated aldehydes enables a hydride transfer to the neighbouring carbonyl. Following the loss of coordination and water work-up, aldehyde and carboxylic acid are formed. ${ }^{114,115}$ In the presence of excess $\mathrm{Bu}_{2} \mathrm{BOTf}$ and DIPEA, and taking into consideration the restricted accessibility of the sixmembered aldol transition state in our system, the Cannizzaro conversion was a possible explanation for the observed formation of the alcohol $\mathbf{1 8 1}$ from the aldehyde 182 in the reaction mixture. A mechanism related to that of Mojtahedi and Abaee is proposed in Scheme 3.19. This would indicate that the acid 219 should be formed in equimolar amounts relative to the alcohol. However, 219 was not isolated and presumed lost during work-up due to its solubility in the aqueous phase.

Scheme 3.19 Proposed mechanism for the formation of the alcohol $\mathbf{1 8 1}$ by Cannizzaro reaction.

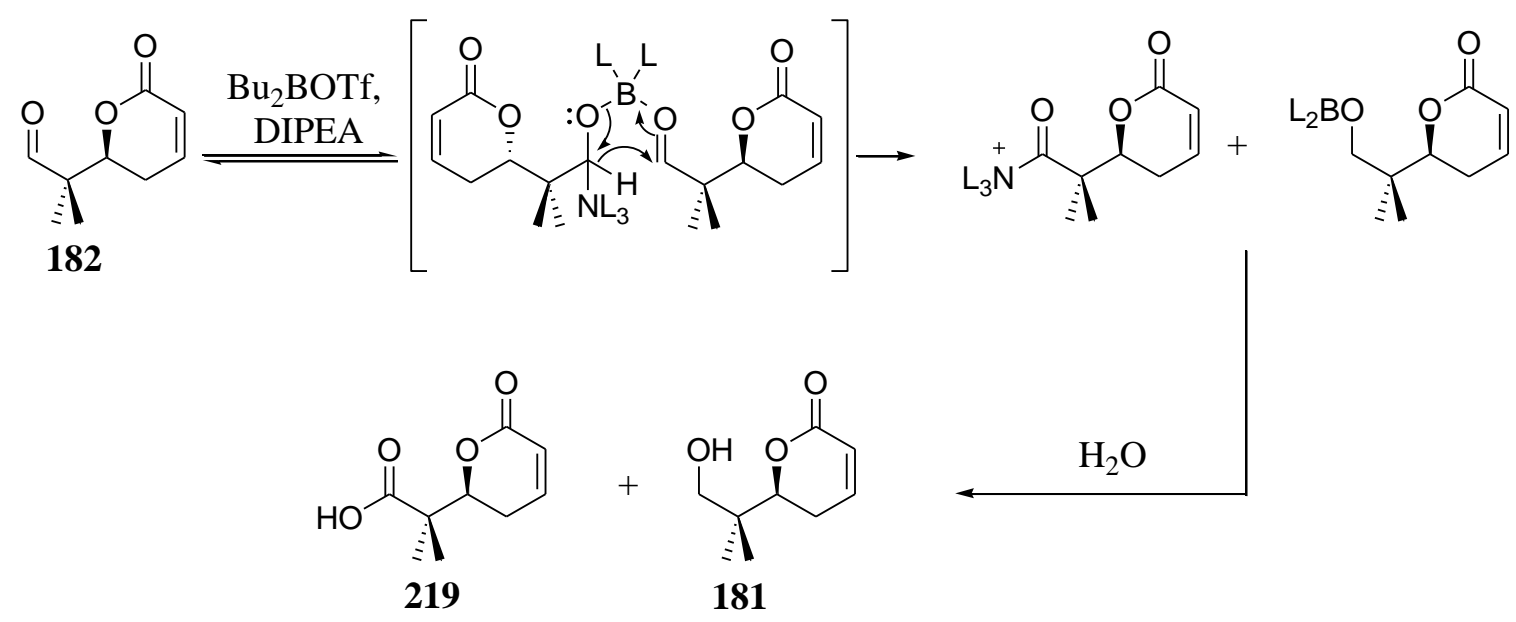


A study with the aldehyde $\mathbf{1 8 2}$ using the reaction conditions for the aldol coupling in the absence of the ketone $\mathbf{1 8 0}$ was attempted to provide further evidence for the proposed hypothesis. Two equivalents of DIPEA and four equivalents of $\mathrm{Bu}_{2} \mathrm{BOTf}$ were added into a reaction vessel under argon in a $-78{ }^{\circ} \mathrm{C}$ cold bath followed by the solution of the aldehyde $\mathbf{1 8 2}$ in diethyl ether. The reaction mixture was then warmed to $-18{ }^{\circ} \mathrm{C}$ and allowed to react overnight. However, the alcohol 181 was not isolated as a product from the reaction. Instead, the bicyclic lactone 220 (Table 3.5) was isolated from the reaction mixture in $17 \%$ yield as a mixture of major and minor isomers in a diastereomeric ratio of 2:1. The structure of the bicyclic lactone $\mathbf{2 2 0}$ was determined from spectroscopic examination of the COSY, ${ }^{1} \mathrm{H}$ and ${ }^{13} \mathrm{C}$ NMR spectral data.

Table 3.5 Spectroscopic evidence for the bicyclic lactone $\mathbf{2 2 0}$.

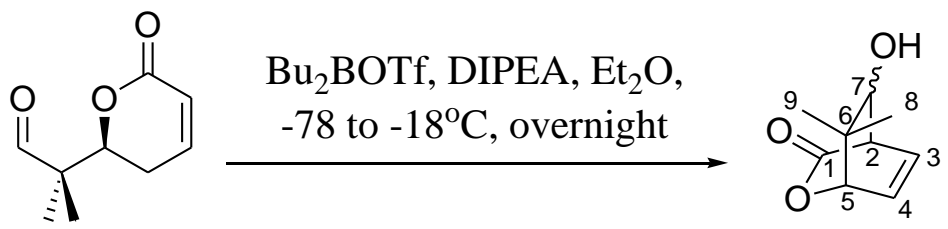

182

220

\begin{tabular}{|r|r|c|r|c|}
\hline \multicolumn{2}{|c|}{ major } & position & \multicolumn{2}{|c|}{ minor } \\
\cline { 1 - 1 } $\boldsymbol{\delta}^{\mathbf{1 3}} \mathbf{C}$ & $\boldsymbol{\delta}^{\mathbf{1}} \mathbf{H}$ & & $\boldsymbol{\delta}^{\mathbf{1 3}} \mathbf{C}$ & $\boldsymbol{\delta}^{\mathbf{1}} \mathbf{H}$ \\
\hline 172.00 & - & 1 & 172.00 & \\
\hline 133.63 & $6.40(\mathrm{~m}, 1 \mathrm{H})$ & 3 & 133.43 & $6.40(\mathrm{~m}, 1 \mathrm{H})$ \\
\hline 128.53 & $6.51(\mathrm{~m}, 1 \mathrm{H})$ & 4 & 129.02 & $6.68(\mathrm{~m}, 1 \mathrm{H})$ \\
\hline 83.37 & $3.65(\mathrm{~s}, 1 \mathrm{H})$ & 7 & 82.91 & $3.85(\mathrm{~s}, 1 \mathrm{H})$ \\
\hline 73.95 & $4.63(\mathrm{~m}, 1 \mathrm{H})$ & 5 & 72.86 & $4.63(\mathrm{~m}, 1 \mathrm{H})$ \\
\hline 51.35 & & 6 & 50.69 & \\
\hline 39.65 & $3.54(\mathrm{~m}, 1 \mathrm{H})$ & 2 & 41.97 & $3.72(\mathrm{~m}, 1 \mathrm{H})$ \\
\hline 28.65 & $1.03(\mathrm{~s}, 3 \mathrm{H})$ & 9 & 26.97 & $0.97(\mathrm{~s}, 3 \mathrm{H})$ \\
\hline 21.13 & $1.20(\mathrm{~s}, 3 \mathrm{H})$ & 8 & 21.58 & $1.21(\mathrm{~s}, 3 \mathrm{H})$ \\
\hline
\end{tabular}

The ${ }^{13} \mathrm{C}$ NMR spectrum of lactone 220 showed doubling of peaks and the COSY correlation of the protons gave two sets of distinct peaks which suggested the presence of diastereomers. The diastereomeric ratio was calculated from integration of the ${ }^{1} \mathrm{H}$ NMR spectrum. The NMR data suggested that the alkene was not part of an 
$\alpha, \beta$-unsaturated aldehyde as found in $\mathbf{1 8 2}$ and the methylene of the original lactone was no longer detected. However, two pairs of oxymethine peaks were observed: the signals at $c a .4 .63 \mathrm{ppm}$ were obviously similar to those of the same position in the original lactone, but the other set at 3.5-4 ppm did not correspond to any signals from the aldehyde $\mathbf{1 8 2}$.

A series of possible reaction mechanisms that might provide for the formation of the second oxymethine from the aldehyde $\mathbf{1 8 2}$ in the given conditions were evaluated. The mechanism that was deemed most probable led to the formation of the cyclic lactone 220 (Scheme 3.20). The mechanism presumed deprotonation of the methylene of the pyran ring in $\mathbf{1 8 2}$ and coordination of the dibutylboron reagent to the lactone carbonyl oxygen, leading to enolate formation. An ensuing intramolecular aldol reaction produced the lactone $\mathbf{2 2 0}$. The proposed structure of lactone $\mathbf{2 2 0}$ matched the available spectroscopic data of similar compounds. ${ }^{117,118,119}$

Scheme 3.20 Proposed mechanism of formation of cyclic lactone $\mathbf{2 2 0}$.

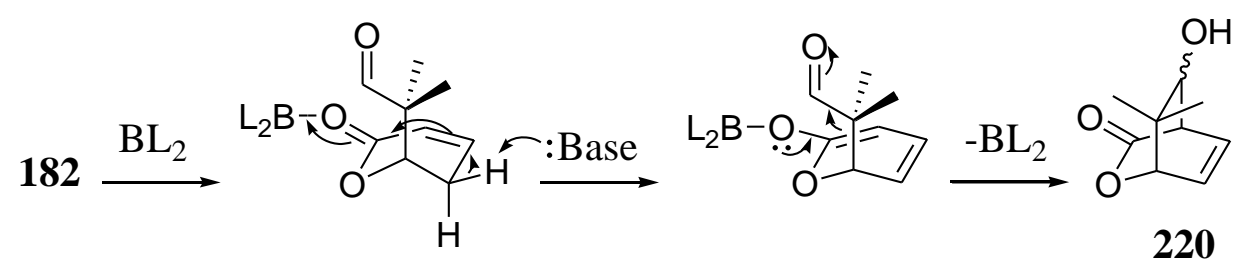

The formation of the lactone $\mathbf{2 2 0}$ in this reaction but not the earlier attempted coupling between $\mathbf{1 8 0}$ and $\mathbf{1 8 2}$ is presumed to be due to the presence of excess boron reagent and base in the reaction mixture. In the original protocol, the base and boron reagent were consumed in the formation of the enolate from the ketone $\mathbf{1 8 0}$ prior to addition of the aldehyde 182. However, in the absence of ketone 180, the lactone serves as an enolate precursor.

Another study with the aldehyde $\mathbf{1 8 2}$ was performed using two equivalents of triethylamine as the base and $\mathrm{Bu}_{2} \mathrm{BOTf}$ (Scheme 3.21). The compounds 221 and 222 were isolated in $26 \%$ and $4 \%$ yield, respectively, from the reaction mixture. 
Scheme 3.21 Study of the aldehyde $\mathbf{1 8 2}$ with two equivalents of TEA and $\mathrm{Bu}_{2} \mathrm{BOTf}$.<smiles>C[C@@H](C=O)C1CC=CC(=O)O1</smiles>

182

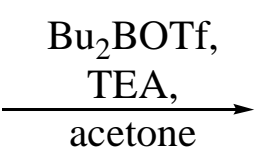

acetone<smiles>CC(=O)C[C@H](O)[C@@H](C)[C@H]1CC=CC(=O)O1</smiles>

221<smiles>CCCCCB1OB(CCCC)OC(C)(C[C@H](O)[C@@H](C)[C@H]2CC=CC(=O)O2)O1</smiles>

222

The structure of compound 221 was determined from examination of the HRMS, ${ }^{1} \mathrm{H}$ and ${ }^{13} \mathrm{C}$ NMR, COSY, HSQC and HMBC spectral data (Table 3.6). The HRMS evaluation provided a calculated mass of $249.1103 \mathrm{~m} / \mathrm{z}$ which fitted the formula of $\mathrm{C}_{12} \mathrm{H}_{18} \mathrm{O}_{4} \mathrm{Na}$. The COSY spectra showed two distinct coupled systems. The ${ }^{1} \mathrm{H}$ spectra indicated 2:1 mixture of diastereomers. The presence of the mixture was most evident from the signal assigned to the $\mathrm{C}_{5}$ and $\mathrm{C}_{7}$ proton peaks. The spectroscopic characteristics of the lactone portion and the neighbouring gem-dimethyl group within compound 221 were similar to those of the starting aldehyde 182. The remaining protons and carbons were assigned as belonging to a hydroxy ketone. The connection of the hydroxy ketone portion to the lactone was identifiable from the HMBCs correlation of the oxymethine protons at $3.97 \mathrm{ppm}$ and $4.28 \mathrm{ppm}$ to the protons of the gem-dimethyl group. It seemed that an unexpected aldol reaction between 182 and acetone had occurred; the introduction of an acetone impurity into the reaction mixture possibly resulted from a contaminated needle. 
Table 3.6 Determination of compound 221.<smiles>O=C(O)C[C@@H](O)[C@H]([18F])[C@H]1CC=CC(=O)O1</smiles>

221

\begin{tabular}{|c|c|c|c|c|c|c|}
\hline \multicolumn{3}{|c|}{ Major } & \multirow[t]{2}{*}{ position } & \multicolumn{3}{|c|}{ minor } \\
\hline$\delta^{13} \mathrm{C}$ & $\delta^{1} \mathbf{H}$ & COSY & & $\delta^{13} \mathrm{C}$ & $\delta^{1} \mathbf{H}$ & COSY \\
\hline 210.86 & - & - & 9 & 210.00 & - & - \\
\hline 164.90 & - & - & 1 & 164.66 & - & - \\
\hline 146.09 & $6.92(\mathrm{~m}, 1 \mathrm{H})$ & $\begin{array}{l}6.01, \\
2.44\end{array}$ & 3 & 145.90 & $6.92(\mathrm{~m}, 1 \mathrm{H})$ & $\begin{array}{l}6.01, \\
2.44\end{array}$ \\
\hline 121.19 & $6.01(\mathrm{~m}, 1 \mathrm{H})$ & $\begin{array}{l}6.92, \\
2.44\end{array}$ & 2 & 121.33 & $6.01(\mathrm{~m}, 1 \mathrm{H})$ & $\begin{array}{l}6.92, \\
2.44\end{array}$ \\
\hline 81.93 & $\begin{array}{l}4.50 \\
(\mathrm{dd}, J=6.5 \mathrm{~Hz}, \\
10.0 \mathrm{~Hz}, 1 \mathrm{H})\end{array}$ & 2.44 & 5 & 80.85 & $\begin{array}{l}4.65 \\
(\mathrm{dd}, J=3.7 \mathrm{~Hz}, \\
12.5 \mathrm{~Hz}, 1 \mathrm{H})\end{array}$ & 2.44 \\
\hline 71.59 & $\begin{array}{l}3.97 \\
(\mathrm{dd}, J=2.0 \mathrm{~Hz}, \\
9.9 \mathrm{~Hz}, 1 \mathrm{H})\end{array}$ & 2.65 & 7 & 69.85 & $\begin{array}{l}4.28 \\
(\mathrm{dd}, J=2.0 \mathrm{~Hz}, \\
10.2 \mathrm{~Hz}, 1 \mathrm{H})\end{array}$ & 2.65 \\
\hline 44.93 & $2.65(\mathrm{~m}, 2 \mathrm{H})$ & 3.97 & 8 & 44.75 & $2.65(\mathrm{~m}, 2 \mathrm{H})$ & 4.28 \\
\hline 40.20 & - & - & 6 & 40.31 & - & - \\
\hline 31.04 & $2.22(\mathrm{~m}, 3 \mathrm{H})$ & - & 10 & 31.09 & $2.22(\mathrm{~m}, 3 \mathrm{H})$ & - \\
\hline 24.72 & $2.44(\mathrm{~m}, 2 \mathrm{H})$ & $\begin{array}{l}6.92, \\
4.50\end{array}$ & 4 & 24.68 & $2.44(\mathrm{~m}, 2 \mathrm{H})$ & $\begin{array}{l}6.92, \\
4.65\end{array}$ \\
\hline 20.15 & $0.94(\mathrm{~s}, 3 \mathrm{H})$ & - & 11 & 18.94 & $0.94(\mathrm{~s}, 3 \mathrm{H})$ & - \\
\hline 18.48 & $1.06(\mathrm{~s}, 3 \mathrm{H})$ & - & 12 & 17.97 & $0.89(\mathrm{~s}, 3 \mathrm{H})$ & - \\
\hline
\end{tabular}

A proper determination of the stereochemistry of compound 221 was unfeasible due to the issue of recovering a pure compound in reasonable quantity. However, since the oxymethine chiral centre within the pyran ring was controlled in its generation, the chirality of the newly formed hydroxyl group can be postulated based on the theory proposed by Kishi. ${ }^{120}$ Kishi's study of the ${ }^{13} \mathrm{C}$ NMR spectra of 1,3-diols showed that in all the studied systems, the ${ }^{13} \mathrm{C}$ chemical shift of position 3 in a syn-diol is 
downfield by approximately $2 \mathrm{ppm}$ compared to the corresponding anti-diol. ${ }^{120}$ Extending this to the hydroxylactone in compound 221, the major diastereomer $(\delta$ $71.59 \mathrm{ppm})$ may be the syn-diol and the minor diastereomer ( $\delta 69.85 \mathrm{ppm})$ the antidiol.

Examination of the HRMS, ${ }^{1} \mathrm{H}$ and ${ }^{13} \mathrm{C}$ NMR spectra, COSY, HSQC and HMBC data of compound $\mathbf{2 2 2}$ (Table 3.7) identified it as the hydrated version of $\mathbf{2 2 1}$ that formed a complex with the residual boron reagent. The identification of compound 222 has been arduous and puzzling at times. The presence of an acetal at $\mathrm{C}_{9}$ was indicated by its ${ }^{13} \mathrm{C}$ chemical shift ( $\delta 91.45 \mathrm{ppm}$ ) and this was backed up by the magnitude of the geminal coupling of the $\mathrm{C}_{8}$ protons $(J=13.5 \mathrm{~Hz})$. This is typical of methylene groups adjacent to an acetal group. ${ }^{121,122}$ By comparison, the geminal coupling in the ketone 221 was $J=18.2 \mathrm{~Hz}$. The boron residue complex was identified through GC-MS. A peak identified as 2,4,6-tributyl boroxin was observed in the GC-MS and was proposed to be the result of breakdown of a 2,4-dibutyl-trioxadiborinane as part of the hydrate 222. Further HRMS analysis showed a peak at $417.1893 \mathrm{~m} / \mathrm{z}$ that matched the formula of $\mathrm{C}_{20} \mathrm{H}_{36} \mathrm{O}_{6} \mathrm{~B}_{2} \mathrm{Na}$ as required for acetal 222 . 
Table 3.7 Determination of compound 222.

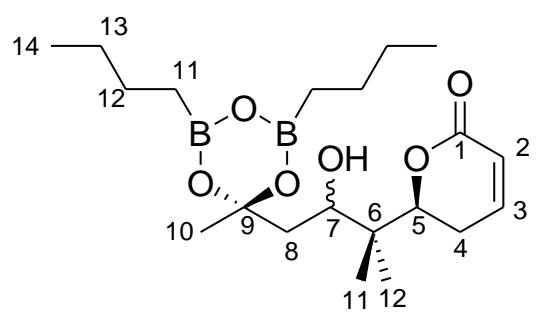

222

\begin{tabular}{|c|l|l|c|}
\hline $\boldsymbol{\delta}^{13} \mathbf{C}$ & \multicolumn{1}{|c|}{$\boldsymbol{\delta}^{\mathbf{l}} \mathbf{H}$} & \multicolumn{1}{c|}{ COSY } & position \\
\hline 164.87 & - & - & 1 \\
\hline 145.93 & $6.94(\mathrm{~m}, 1 \mathrm{H})$ & $6.04,2.43$ & 3 \\
\hline 121.15 & $6.04(\mathrm{~d}, J=9.8 \mathrm{~Hz}, 1 \mathrm{H})$ & 6.94 & 2 \\
\hline 91.45 & - & - & 9 \\
\hline 82.16 & $4.48(\mathrm{dd}, J=3.6 \mathrm{~Hz}, 12.8 \mathrm{~Hz}, 1 \mathrm{H})$ & $2.53,2.43$ & 5 \\
\hline 70.00 & $4.33(\mathrm{dd}, J=2.7 \mathrm{~Hz}, 11.8 \mathrm{~Hz}, 1 \mathrm{H})$ & $1.86,1.72$ & 7 \\
\hline 39.95 & - & - & 6 \\
\hline 37.65 & $1.86(\mathrm{dd}, J=2.8 \mathrm{~Hz}, 13.5 \mathrm{~Hz}, 1 \mathrm{H})$, & $4.33,1.72 ;$ & 8 \\
& $1.72(\mathrm{dd}, J=12.3 \mathrm{~Hz}, 13.4 \mathrm{~Hz}, 1 \mathrm{H})$ & $4.33,1.86$ & \\
\hline 26.06 & $1.28(\mathrm{~m}, 8 \mathrm{H})$ & $0.86,0.69$ & 12,13 \\
\hline 25.21 & $3.49(\mathrm{bs}, 3 \mathrm{H})$ & - & 10 \\
\hline 24.69 & $2.53(\mathrm{~m}, 1 \mathrm{H})$, & $4.48,2.43 ;$ & 4 \\
& $2.43(\mathrm{~m}, 1 \mathrm{H})$ & $6.94,4.48,2.53$ & \\
\hline 19.36 & $0.96(\mathrm{~s}, 3 \mathrm{H})$ & - & 11 \\
\hline 18.14 & $1.05(\mathrm{~s}, 3 \mathrm{H})$ & - & 12 \\
\hline 14.01 & $0.86(\mathrm{t}, J=7.1 \mathrm{~Hz}, 6 \mathrm{H})$ & 1.28 & 14 \\
\hline 13.88 & $0.69(\mathrm{t}, J=7.3 \mathrm{~Hz}, 4 \mathrm{H})$ & 1.28 & 11 \\
\hline
\end{tabular}

Due to constraints of time, further attempts to investigate the failure of the aldol coupling reactions were discontinued. The disappointing results from the coupling attempts were attributed to the quality of the boron reagents and the bulkiness and rigidity of the $\mathrm{C}_{1}-\mathrm{C}_{11}$ aldehyde and $\mathrm{C}_{12}-\mathrm{C}_{24}$ ketone synthons. Due to steric hindrance from the enol-boron complex, the bulky aldehyde was unable to intercept the sixmembered transition state required for the aldol reaction. This suggestion was based on a successful aldol coupling study by Turner using the ketone $\mathbf{1 8 0}$ and a desdimethyl version of the aldehyde $\mathbf{1 7 5} .^{100}$ 


\subsection{Synthesis of other analogues}

The syntheses of the analogues 152 to 155 (Figure 2.2, Chapter 2) through derivatisations of the pyran ring were attempted. For the precursor to analogue 152, which was to have a fully saturated pyran ring, hydrogenation of the $\alpha, \beta$-unsaturated lactone 165 with Adam's catalyst was attempted and the saturated lactone 187 was acquired in $71 \%$ yield (Scheme 3.22). The subsequent reduction and acetylation proceeded as expected and provided the acetate 189 in quantitative amount. However, attempted substitution at $\mathrm{C}_{5}$ with vinyloxy-trimethylsilane to provide the corresponding $\mathrm{C}_{3}-\mathrm{C}_{11}$ aldehyde failed to provide the desired aldehyde $\mathbf{2 2 5}$.

Scheme 3.22. The synthesis of precursor to analogue 152.

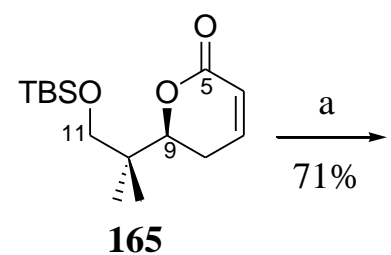

165

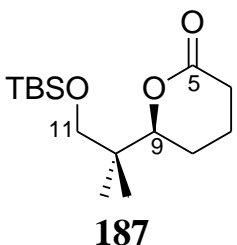

187

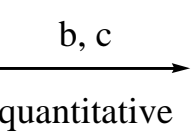

quantitative

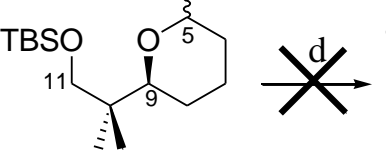

189

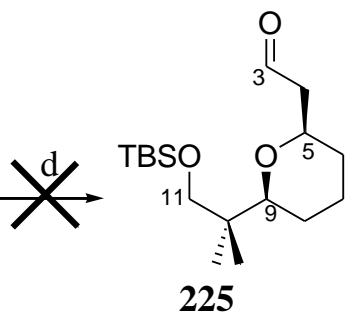

225

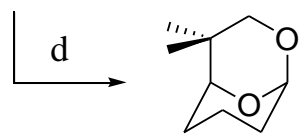

226

Conditions: (a) $\mathrm{PtO}_{2}, \mathrm{H}_{2}$, EtOAc, RT, 4 h; (b) DIBAL-H, DCM, -23 ${ }^{\circ} \mathrm{C}, 45 \mathrm{~min}$; (c) TEA, $\mathrm{Ac}_{2} \mathrm{O}$, DMAP, DCM, RT; (d) $\mathrm{H}_{2} \mathrm{C}=\mathrm{CHOTMS}, \mathrm{BF}_{3} . \mathrm{Et}_{2} \mathrm{O}, \mathrm{MeCN}, \mathrm{RT}, 3.5 \mathrm{~h}$.

Further investigation of the reaction mixture by chromatography led to the isolation of 4,4-dimethyl-2,9-dioxa-bicyclo[3.3.1]nonane (226, Scheme 3.24) in $26 \%$ from the lactone 187. Although the lack of material did not allow for in-depth characterisation, the structure of bicycle 226 was elucidated from the ${ }^{1} \mathrm{H}$ NMR spectrum through the presence of an oxymethine at $\delta 5.30$ and $4.05 \mathrm{ppm}$. Methylene peaks were found as multiplets at $\delta 3.53-3.32$ and 2.05-1.25 ppm, and the gem-dimethyl signals at $\delta 0.92$ and $0.88 \mathrm{ppm}$. Although a compound with an exact structural match to bicycle 226 is not known for use as a spectroscopic reference, similar compounds can be found in the work of Aiguade and Astashko. ${ }^{123,124}$ 
In the earlier substitution of the dihydropyran 165 by vinyloxy-trimethylsilane, we proposed that the presence of the alkene helps to provide stabilisation of the carbocation (Scheme 3.23). The subsequent top-face attack on the oxonium ion resonance form by a nucleophile such as the vinyloxy-trimethylsilane provides the correct stereoselectivity and the desired aldehyde $\mathbf{1 6 8}$.

Scheme 3.23 Substitution of $\alpha, \beta$-unsaturated pyran ring.

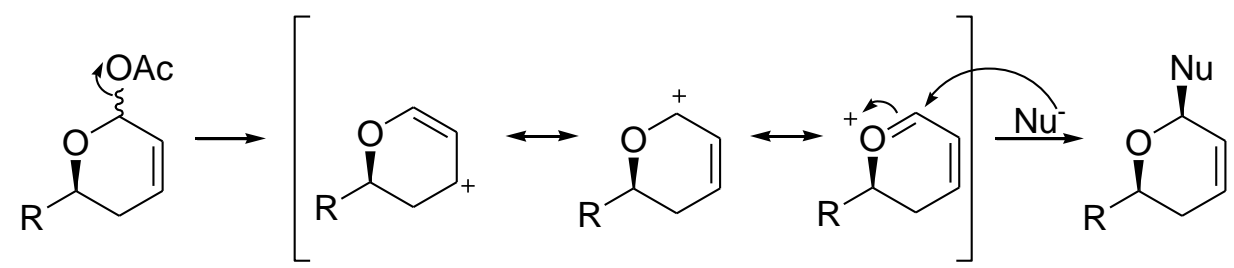

In the case of our saturated pyran ring system, the oxonium ion formed lacks the $\pi$ bond stabilisation. The oxonium ion is therefore more readily attacked by the electron rich silylated oxygen and undergoes intramolecular cyclisation (Scheme 3.24). ${ }^{125}$ Also important was the chair conformation of the pyran system that provided a favourable orientation to enable the interception by the nucleophile. The silyl protecting group will would have been cleaved before or during work up, and the bicycle 226 was isolated by chromatography. The changes in the conformation of the pyran ring from a half-chair in the dihydropyran $\mathbf{1 6 5}$, due to the limitation imposed by the olefin moiety, to the full-chair conformation in $\mathbf{1 8 9}$ may also assist the formation of the bicyclic structure of $\mathbf{2 2 6}$.

Scheme 3.24 Proposed mechanism for the formation of 4,4-dimethyl-2,9-dioxabicyclo[3.3.1] nonane 226.

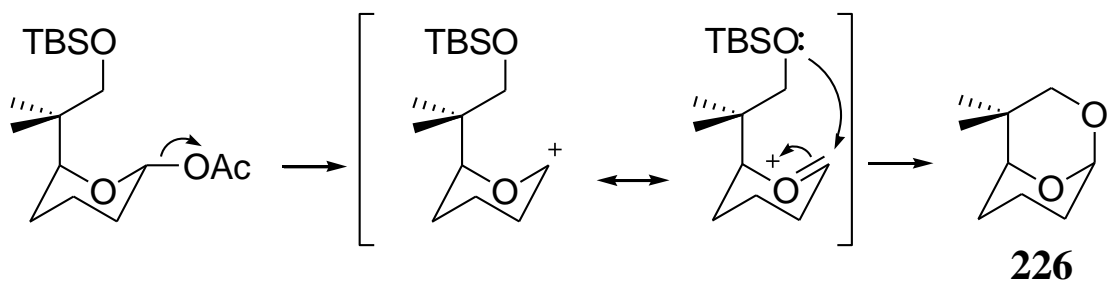

Precedence consistent with the formation of the bicyclic compound $\mathbf{2 2 6}$ was found in the work of a PhD from the same group working on cyclopropanated carbohydrates. A part of the study was focussed on the influence of various protecting groups on the ring expansion reaction of a cyclopropanated glycal to form the corresponding 
oxepine. ${ }^{126}$ The study found that, in the presence of a Lewis acid, the silyl protecting group was cleaved from the primary alcohol during the reaction. ${ }^{126}$ This intramolecular nucleophile competed with the intermolecular nucleophile to give the bicyclic oxepine as the major product in cases where the external nucleophile was particularly unreactive (Scheme 3.25). ${ }^{126}$

Scheme 3.25 Interception of an oxonium intermediate by an internal silyloxy nucleophile by Batchelor. ${ }^{126}$
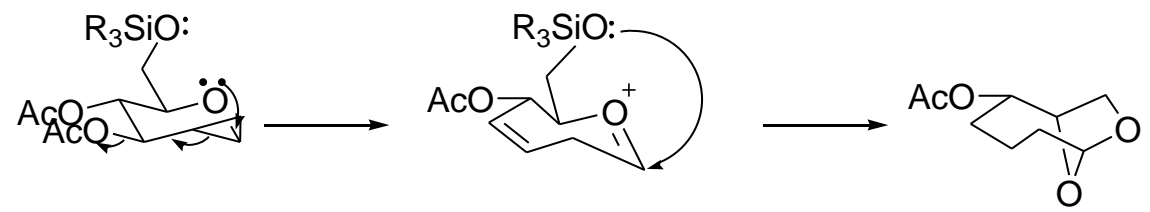

Attempts at the dihydroxylation of the $\mathrm{C}_{6}=\mathrm{C}_{7}$ alkene to provide the precursor to the analogue 153 resulted in complete degradation of the starting material. Combined with the above-discussed problem of substituting the unsaturated pyran, further attempts at functionalisation of the pyran ring by removal of the alkene bond were abandoned. It was decided that functionalisation will be best achieved immediately prior to the 1,5-anti coupling or, preferably, at the very end of the synthesis.

Attention then turned to acquiring a precursor to the alkenyl methyl analogues $\mathbf{1 5 4}$ and 155. The attempt to obtain a precursor to the analogue 154 was through esterification of the allyl alcohol 163 with methacryloyl chloride. However, due to the degraded quality of the methacryloyl chloride used, the alcohol 163 was desilylated in the reaction mixture and a double esterification with the degraded substrate occurred instead of the desired monoesterification to give 227 (Scheme 3.26). Therefore, it was decided to temporarily abandon the attempt to obtain a precursor to the analogue 154 .

Scheme 3.26 The attempted synthesis of precursor to analogue $\mathbf{1 5 4}$.

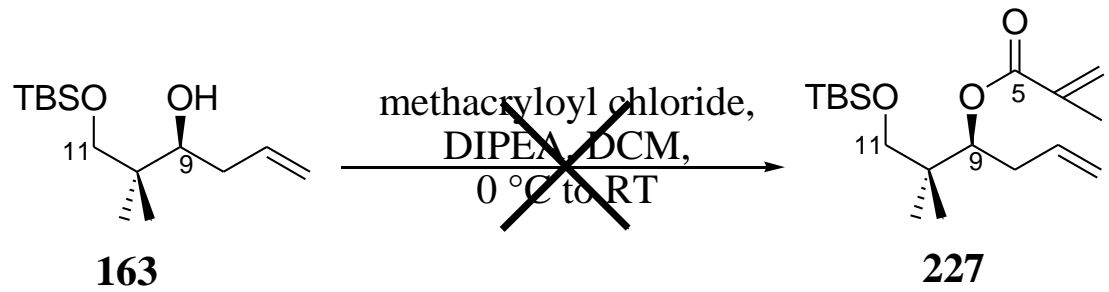


A precursor to the analogue $\mathbf{1 5 5}$ was attempted by installation of a methyl group at $\mathrm{C}_{7}$. After various attempts, the aldehyde $\mathbf{1 6 1}$ was successfully methallylated to give the alcohol 183 (Scheme 3.27). However, this zinc-mediated methallyllation was poor yielding (25\%) and not stereoselective. An initial attempt with methallylmagnesium bromide returned the starting aldehyde 161. An attempt to obtain methallyl alcohol 183 asymmetrically using methallyldiisopinocamphenylborane failed to provide the desired result.

Scheme 3.27 The synthesis of a precursor to analogue $\mathbf{1 5 5}$.<smiles>CC(C=O)C=O</smiles>

161

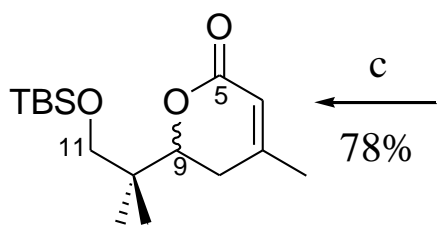

185<smiles>C=C(C)C[C@H](O)[C@@H](C)C=[Mg]</smiles>

183

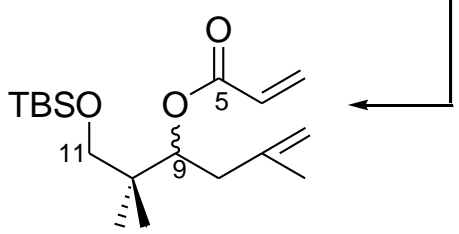

184

Conditions: (a) 3-bromo-2-methylpropane, zinc powder, THF, $65{ }^{\circ} \mathrm{C}, 20 \mathrm{~min}$; (b) acryloyl chloride, DIPEA, DCM, $0{ }^{\circ} \mathrm{C}$ to RT; (c) 5 mol\% Grubbs' $2^{\text {nd }}$ generation catalyst., DCM, RT.

The methallyl alcohol 183 was subjected to an esterification with acryloyl choride and provided the desired diene 184 in moderate yield (60\%). RCM of the diene 184 gave the 7-methyl lactone $\mathbf{1 8 5}$ in $\mathbf{7 8 \%}$ yield. The presence of the additional methyl group at $\mathrm{C}_{7}$ was anticipated to provide steric hindrance and lower the reaction efficiency significantly compared to the diene 164. A decrease of $12 \%$ in yield was observed between the formation of lactone $\mathbf{1 6 5}$ and the $C_{7}$-methyl lactone $\mathbf{1 8 5}$. Although the synthesis of the precursor was achieved, following the discovery that the subsequent aldol coupling reaction was unproductive, further analogue development was halted. 


\subsection{Evaluation of the synthetic strategy}

Utilising the synthetic strategy proposed in chapter 2, the necessary carbon skeleton for the peloruside $\mathrm{A}$ analogue $\mathbf{1 5 1}$ was obtained as two main fragments: the main $\mathrm{C}_{1-}$ $\mathrm{C}_{11}$ backbone and the sidechain $\mathrm{C}_{12}-\mathrm{C}_{24}$. The $\mathrm{C}_{1}-\mathrm{C}_{11}$ backbone was synthesised with a total yield of $4 \%$ in 13 steps from 2,2-dimethyl-1,3-propanediol. The sidechain $\mathrm{C}_{12}-$ $\mathrm{C}_{24}$ was synthesised with a total yield of $11 \%$ in 3 steps from acetone. However, to our disappointment, the coupling reaction to assemble the two fractions has been unsuccessful.

As discussed in section 1.7, De Brabander's synthesis of (-)-peloruside A took 29 steps with an overall yield of $3 \% .{ }^{51}$ Jin and Taylor synthesised (+)-peloruside A with an overall yield of $0.4 \%$ in 29 steps. ${ }^{52}$ Ghosh achieved the synthesis of (+)-peloruside A in 30 steps with an overall yield of $1 \% .{ }^{53}$ Evans' synthesis of $(+)$-peloruside A was a marked improvement with a total yield of $12 \%$ and overall 18 steps. ${ }^{54}$ Smith's unexpected synthesis of (-)-2-epi-peloruside A was completed in 21 steps with a $2 \%$ total yield. ${ }^{57}$ Ghosh's synthesis of peloruside B took an overall 29 steps and gave an overall yield of $0.3 \% .^{44}$

(+)-Peloruside A is generally acknowledged to be a challenging synthetic target due to its numerous stereocentres and large ring size. The effectiveness of our synthetic strategy for the analogue 151 was evaluated by comparing with the previous syntheses of peloruside A. The analogue $\mathbf{1 5 1}$ was intended to provide an alternative to peloruside A that would be easier to synthesise and better yielding. However, given the optimised yields of the aldehyde 175 and ketone 180, and setting aside the troublesome aldol coupling, the end-game manipulations that will include $\mathrm{C}_{13}$ reduction and methylation, protecting group manipulations, macrolactonisation and global deprotection are each going to further reduce the overall yield significantly. If each of these steps were to proceed with approximately $60 \%$ yield, the total overall yield would be approximately $0.3 \%$ in 20 steps. This analysis leads us to the key conclusion that our proposed route to $\mathbf{1 5 1}$ is too inefficient compared to the literature syntheses of peloruside A, and indicates that further work on the 1,5-anti aldol coupling of $\mathbf{1 7 5}$ and $\mathbf{1 8 0}$ is not warranted. 
Furthermore, an alteration of the synthetic approach to the major fragments to $\mathbf{1 5 1}$ is necessary. Although the $\mathrm{C}_{1}-\mathrm{C}_{11}$ fragment can be synthesised reliably, the optimised $4 \%$ yield for this fragment alone is unsatisfactory when compared to the total yields for peloruside A achieved by others, particularly Evans. This is especially true when bearing in mind that this fragment contains a simplification of the peloruside structure designed to improve synthetic yields. The synthetic strategy also failed to be efficient in the generation of the sidechain $\mathrm{C}_{12}-\mathrm{C}_{24}$ fragment. Although the fragment was readily available within three synthetic steps from acetone, the yield of each reaction step was poor. Furthermore, the dichloro[ $(S, S)$-ethylenebis(4,5,6,7-tetrahydro-1indenyl)]zirconium(IV) and Grubbs' $2^{\text {nd }}$ generation catalyst needed for the generation of the $\mathrm{C}_{12}-\mathrm{C}_{24}$ fragment are uneconomical for large scale synthesis. Therefore, an alternative synthetic strategy to build the sidechain fragment should be contemplated.

\subsection{Conclusion}

The attempt to synthesise the desired analogue 151 thus far has been unsuccessful. The main $\mathrm{C}_{1}-\mathrm{C}_{11}$ backbone was successfully synthesised from 2,2-dimethyl-1,3propanediol, allylmagnesium bromide, acryloyl chloride, vinyloxy-trimethylsilane, bromoacetic acid and (S)-4-benzyloxazolidin-2-one. The key steps in the synthesis of the main $\mathrm{C}_{1}-\mathrm{C}_{11}$ backbone were Brown allylation, $\mathrm{RCM}$ to provide the $\alpha, \beta$ unsaturated pyran ring of laulimalide, formation of the aldehyde 168 by alkylation reaction with vinyloxy-trimethylsilane, 1,2-syn aldol coupling to assemble the main $\mathrm{C}_{1}-\mathrm{C}_{11}$ backbone and the subsequent methylation of the resulting alcohol to provide the methyl ester moiety at $\mathrm{C}_{3}$.

The synthesis of the sidechain $\mathrm{C}_{12}-\mathrm{C}_{24}$ was achieved from acetone, methacrolein, 2,5dihydrofuran and ethylmagnesium chloride. The key reaction steps in the synthesis of the sidechain $\mathrm{C}_{12}-\mathrm{C}_{24}$ involved an aldol coupling reaction to provide the $\beta$-hydroxy ketone 177, an asymmetric carbomagnesation reaction to obtain the ethylbutenol $\mathbf{1 7 8}$, A double silylation reaction to get the diene 179, and a RCM reaction to acquire the ketone 180. The RCM reaction gave the desired dioxasilocene 180 in poor yield due to intermolecular cross metathesis, formation of methylidene complex and ethylbutene isomerisation. 
The subsequent attempts to induce 1,5-anti aldol coupling between $\mathrm{C}_{11}$ aldehyde of the main $\mathrm{C}_{1}-\mathrm{C}_{11}$ backbone and the $\mathrm{C}_{12}$ ketone of the $\mathrm{C}_{12}-\mathrm{C}_{24}$ sidechain were unsuccessful. The failure of the aldol coupling reactions was attributed to the steric hindrance posed by the bulkiness of the $C_{1}-C_{11}$ structure as well as the $C_{12}-C_{24}$ sidechain. The model study using the $\mathrm{C}_{11}-\mathrm{C}_{5}$ pyran 127 illustrated the problems posed by the bulkiness of the ketone sidechain. Due to the steric hindrance from the ketoneboron complex, the aldehyde was unable to intercept the six-membered transition state required for the 1,5-anti aldol reaction.

Instead, the aldehyde complexed with the excess boron reagent in a Cannizzaro type reaction. Attempts to understanding the aldol coupling reaction and the Cannizzaro type reaction led to the discovery of several interesting side products. The conclusion obtained at the end of the attempt to synthesise the desired analogue 151 was that 1,5anti aldol coupling between the $\mathrm{C}_{11}$ aldehyde and the $\mathrm{C}_{12}$ ketone is not an efficient route to assembly the $\mathrm{C}_{1}-\mathrm{C}_{11}$ mainchain to the $\mathrm{C}_{12}-\mathrm{C}_{24}$ sidechain.

Attempts at the synthesis of the analogues 152, 153, 154, and 155 were also unsuccessful. The presence of an $\alpha, \beta$-unsaturated alkene provides a crucial conformational constraint and oxonium carbocation stabilisation that enable substitution of vinyloxy-trimethylsilane at $\mathrm{C}_{5}$ and prevent intramolecular cyclisation. Therefore, functionalisation of the pyran ring that results in the removal of the $\alpha, \beta$ unsaturation should be avoided at this stage. The syntheses of the precursors to the analogues 152, 153, 154, and 155 have thus far been temporarily discontinued until the assembly $\mathrm{C}_{1}-\mathrm{C}_{24}$ of the proposed peloruside $\mathrm{A}$ analogue becomes feasible. 


\section{Chapter 4 - Future work}

Future studies will include analysis of an alternative route to the analogue 151. A more linear synthetic strategy that builds the analogue in a stepwise fashion using aldol chemistry is a possible alternative approach to obtain the desired analogue $\mathbf{1 5 1}$. For instance, construction of the $\mathrm{C}_{11}-\mathrm{C}_{12}$ bond as an earlier step using an aldol reaction of simpler, less bulky substrates is anticipated to be more fruitful. Subsequent elongation to the full analogue backbone could set up a similar end-game to that originally proposed. One possible scenario is presented in scheme 4.1. Thus, 151 could be generated from the linear precursor 228, akin to compound $\mathbf{2 1 6}$ in section 3.3, by deprotection and Yamaguchi macrolactonisation.

Scheme 4.1 Alternative retrosynthesis for analogue $\mathbf{1 5 1 .}$

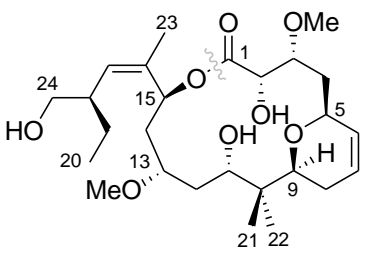

151

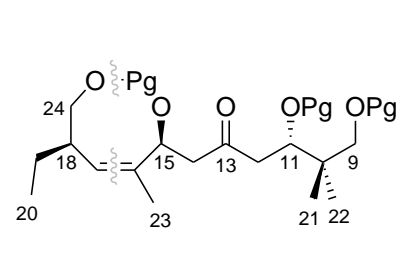

231
Global deprotection

Yamaguchi macrolactonisation

Auxiliary removal

Reduction and methylation at $\mathrm{C}_{13}$

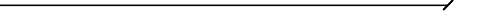

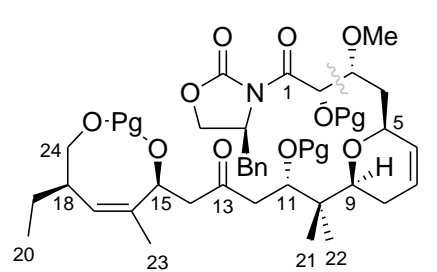

228

Methylation at $\mathrm{C}_{3}$ 1,2-syn Aldol reaction Alkylation

Ring closing metathesis Esterification

Allylation

Deprotection and oxidation at $\mathrm{C}_{9}$

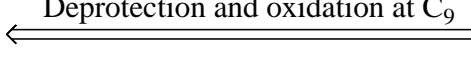

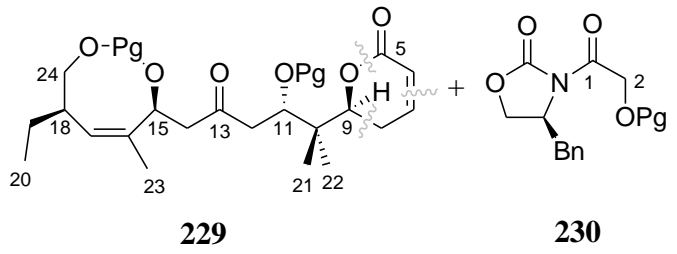

Ring closing metathesis Alkylation Deprotection and silylation at $\mathrm{C}_{15}$

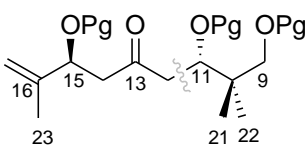

232
Protection at $\mathrm{C}_{11}$

1,5-anti aldol

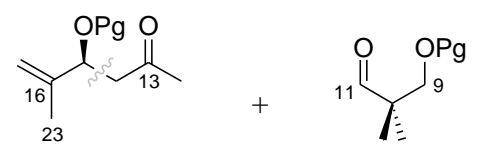

234
233

Precursor 228 can be constructed from truncated skeleton 229 by elongation with vinyloxy-trimethylsilane followed by an Evans aldol reaction with 230. The $\mathrm{C}_{5}-\mathrm{C}_{24}$ portion 229 could in turn be derived from the $\mathrm{C}_{9}-\mathrm{C}_{16}$ segment 232 via the $\mathrm{C}_{9}-\mathrm{C}_{24}$ fragment 231. This sequence would enable the key $\mathrm{C}_{11}-\mathrm{C}_{12}$ connection to be made by 
1,5-anti aldol reaction of partners 233 and 234, having much lower bulk than those previously employed in our route to $\mathbf{1 5 1}$.

Furthermore, there are numerous alternative routes to install the $\mathrm{C}_{18}-\mathrm{C}_{24}$ fragments into the precursor 232 in scheme 4.1, other than using the current silocene methodology. Such approach in the end game has the advantages of providing an opportunity for orthogonal protection of the $\mathrm{C}_{15}$ and $\mathrm{C}_{24}$ hydroxyl groups and facilitating the selective revelation of the $\mathrm{C}_{15}$ hydroxyl prior to macrolactonisation.

Future studies should also look into other possible disconnections applicable to a convergent route, particularly those that avoid the problematic coupling adjacent to the quaternary carbon centre at $\mathrm{C}_{11}$. Further research should be focussed on understanding of the role of the gem-dimethyl moiety at $\mathrm{C}_{10}$ in the aldol coupling between ketone 180 and the aldehyde 175. An alternative protocol to install the gemdimethyl group using a similar approach to that of Jin and Taylor (Scheme 4.2) would involve aldol coupling to construct the $\mathrm{C}_{10}-\mathrm{C}_{11}$ bond. ${ }^{60}$ Thus, Mukaiyama aldol reaction of the $\mathrm{C}_{11}-\mathrm{C}_{24}$ hemisphere with silyl enol ether $\mathbf{4 0}$ could be tested for efficacy with the expectation that this less complex nucleophilic partner would have better reactivity than the enolate of ketone $\mathbf{1 8 0}$ with the aldehyde $\mathbf{1 7 5}$.

Scheme 4.2 Alternative route for installation of the $\mathrm{C}_{10}$ gem-dimethyl group.<smiles>CC[C@H]1C=C(C)[C@@H](CC(=O)CC=O)O[Si-](c2ccccc2)(c2ccccc2)OC1</smiles>

235

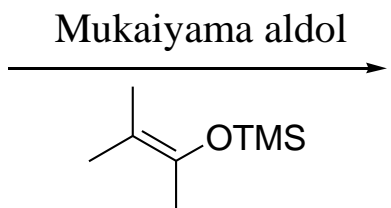

40

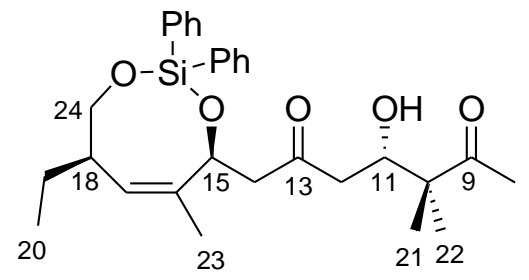

236

Future studies should contemplate an alternative route to generate the sidechain $\mathrm{C}_{12}-$ $\mathrm{C}_{24}$ fragment as the current synthetic strategy is not sufficiently high yielding. Although the fragment was readily available within three synthetic steps from acetone, the yield of each reaction step was poor and the catalysts employed were uneconomical for large scale synthesis. 


\section{Chapter 5 - Experimental methods}

Unless otherwise stated, all of the following conditions apply to all presented reactions. All reactions were performed under zero grade argon at atmospheric pressure in vacuum- and flame-dried vessels. Standard syringe techniques were applied whenever necessary. Acetonitrile, dichloromethane, and triethylamine were freshly distilled from calcium hydride. Tetrahydrofuran was freshly distilled from the sodium benzophenone ketyl radical ion. Methanol and toluene were distilled from sodium. Acetone was distilled from calcium sulfate. Anhydrous diethyl ether and hexane were dried with sodium. Sodium hydride was obtained as $60 \%(\mathrm{w} / \mathrm{w})$ dispersion in mineral oil and washed with anhydrous hexane prior to use. Anhydrous sodium methoxide was prepared fresh for each reaction in dried vessel. Sodium pieces were cleaned with anhydrous hexane, vacuum dried, and then dissolved in anhydrous methanol. Excess methanol was removed by vacuum and sodium methoxide was obtained as white powder. $0.5 \mathrm{M}$ sodium phosphate buffer at $\mathrm{pH} 7.0$ was prepared from $0.5 \mathrm{M}$ solutions of sodium dihydrogen phosphate and disodium hydrogen phosphate. All other reagents were of commercial quality and distilled prior to use whenever necessary. The measurements of reagents and products were accurate to two decimal places, unless otherwise stated. The progress of each reaction was monitored using aluminium-backed TLC on plates pre-coated with UV254 silica. UV radiation at $254 \mathrm{~nm}$, iodine dip, and anisaldehyde dip were employed as means of visualisation. Product purification was achieved by column chromatography, performed with P60 silica gel and solvent system as indicated. ${ }^{1} \mathrm{H}$ and ${ }^{13} \mathrm{C}$ NMR spectra were recorded on a Varian Unity Inova 500 spectrometer. $\mathrm{CDCl}_{3}$ solvent peak (7.26 ppm for ${ }^{1} \mathrm{H}$ and $77.16 \mathrm{ppm}$ for ${ }^{13} \mathrm{C}$ ) was used as references for all observed chemical shifts. Optical rotation was measured on a Perkin-Elmer Polarimeter (sodium lamp) at the concentration of $\mathrm{mg} / 10 \mathrm{~mL}$. High-resolution mass spectrometry was performed on a Waters Q-TOF PremierTM Tandem Mass Spectrometer. 
<smiles>NC(CO)Cc1ccccc1</smiles>

suspended in tetrahydrofuran $(200.00 \mathrm{~mL})$, then cooled to $0{ }^{\circ} \mathrm{C}$. L-phenylalanine $(16.53 \mathrm{~g}, 100.07 \mathrm{mmol})$ was added into the reaction flask. A solution of iodine (31.82 $\mathrm{g}, 125.37 \mathrm{mmol})$ in tetrahydrofuran $(140.00 \mathrm{~mL})$ was added dropwise into the stirring reaction mixture. The resulting reaction mixture was stirred at $0{ }^{\circ} \mathrm{C}$ for 30 minutes and then refluxed at $80{ }^{\circ} \mathrm{C}$ for 36 hours. The reaction mixture was returned to room temperature and slowly quenched with methanol $(150 \mathrm{~mL})$ over 2 hours. The reaction mixture was concentrated under vacuum. The white solid obtained was dissolved in $20 \%(\mathrm{w} / \mathrm{w})$ potassium hydroxide solution $(300 \mathrm{~mL})$ and stirred at room temperature for 36 hours. The aqueous mixture was extracted with dichloromethane ( $3 \times 150 \mathrm{~mL})$. The organic extracts were combined and washed with saturated aqueous brine $(2 \mathrm{x}$ $100 \mathrm{~mL}$ ) and then dried with anhydrous magnesium sulfate. The solvent was removed under vacuum and white solid obtained. Recrystallisation from hot ethyl acetate provided 156 as white fine crystals $(9.78 \mathrm{~g}, 64.68 \mathrm{mmol}, 65 \%) .{ }^{1} \mathrm{H} \mathrm{NMR}(500 \mathrm{MHz}$, $\left.\mathrm{CDCl}_{3}\right) \delta 7.33-7.19(\mathrm{~m}, 5 \mathrm{H}), 3.64(\mathrm{dd}, J=3.9 \mathrm{~Hz}, 10.5 \mathrm{~Hz}, 1 \mathrm{H}), 3.38(\mathrm{dd}, J=7.3 \mathrm{~Hz}$, $10.5 \mathrm{~Hz}, 1 \mathrm{H}), 3.12(\mathrm{~m}, 1 \mathrm{H}), 2.80(\mathrm{dd}, J=5.4 \mathrm{~Hz}, 13.4 \mathrm{~Hz}, 1 \mathrm{H}), 2.53(\mathrm{dd}, J=8.6 \mathrm{~Hz}$, $13.4 \mathrm{~Hz}, 1 \mathrm{H}) .{ }^{100,103}$

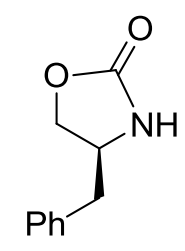

\section{(S)-4-Benzyloxazolidin-2-one (157)}

Potassium carbonate $(0.41 \mathrm{~g}, 2.97 \mathrm{mmol})$ was flame dried in a distillation apparatus. 156 (3.00 g, $19.84 \mathrm{mmol}$ ) was added, followed by diethyl carbonate $(5.20 \mathrm{~mL}, 5.07 \mathrm{~g}, 42.92 \mathrm{mmol})$. The reaction mixture was stirred and heated to $78{ }^{\circ} \mathrm{C}$. Ethanol was distilled from the reaction mixture and the residual liquid returned to room temperature. The reaction was quenched with distilled water (15 $\mathrm{mL})$. The aqueous slurry was extracted with dichloromethane $(3 \mathrm{x} 40 \mathrm{~mL})$. The organic extracts were combined and washed with saturated aqueous brine $(50 \mathrm{~mL})$ and then dried with anhydrous magnesium sulfate. The solvent was removed under vacuum and white crystals obtained. Recrystallisation from hot ethyl acetate and hexane provided 157 as white long crystals (2.70 g, $15.24 \mathrm{mmol}, 77 \%) .{ }^{1} \mathrm{H}$ NMR (500 $\left.\mathrm{MHz}, \mathrm{CDCl}_{3}\right) \delta$ 7.37-7.18 (m, 5H), 4.94 (bs, 1H), 4.49 (t, $\left.J=8.3 \mathrm{~Hz}, 1 \mathrm{H}\right), 4.17$ (dd, $J$ $=5.5 \mathrm{~Hz}, 8.7 \mathrm{~Hz}, 1 \mathrm{H}), 4.09(\mathrm{~m}, 1 \mathrm{H}), 2.87(\mathrm{~m}, 2 \mathrm{H}) .^{100,103}$ 
$\overbrace{\text { OPMB }}$

\section{2-(4-Methoxybenzyloxy)acetic acid (158)}

Sodium hydride (4.22 g, $175.63 \mathrm{mmol}, 60 \%$ in mineral oil) was divided into two portions and washed with anhydrous hexane $(3 \times 20 \mathrm{~mL})$. The first portion of sodium hydride was suspended in tetrahydrofuran $(36.00 \mathrm{~mL})$ and cooled to $0{ }^{\circ} \mathrm{C}$. 4-Methoxybenzyl alcohol $(6.50 \mathrm{~mL}, 7.23 \mathrm{~g}, 52.36 \mathrm{mmol})$ was added dropwise and the reaction mixture stirred for 15 minutes. The reaction was then returned to room temperature and stirred for 15 minutes, then recooled to $0{ }^{\circ} \mathrm{C}$. The second portion of sodium hydride was suspended in tetrahydrofuran $(18.00 \mathrm{~mL})$ at 0 ${ }^{\circ} \mathrm{C}$. A solution of bromoacetic acid (6.95 g, $\left.50.02 \mathrm{mmol}\right)$ in tetrahydrofuran (18.00 $\mathrm{mL}$ ) was added dropwise and the reaction mixture stirred for 5 minutes. The activated alcohol mixture was cannulated dropwise into the carboxylate mixture. The reaction mixture was returned to room temperature and stirred for 3 hours. The reaction was quenched with distilled water $(20 \mathrm{~mL})$ and stirred until the slurry fully dissolved. The organic solvent was removed under vacuum and the aqueous layer washed with diethyl ether $(2 \times 50 \mathrm{~mL})$. The aqueous layer was acidified with concentrated sulphuric acid $(1 \mathrm{~mL})$ to $\mathrm{pH} 4$ and extracted with diethyl ether $(3 \times 50 \mathrm{~mL})$. The organic extracts were combined and washed with distilled water $(2 \times 30 \mathrm{~mL})$ and then dried with anhydrous magnesium sulfate. Removal of solvent under vacuum provided 158 as white long crystals (5.20 g, $26.50 \mathrm{mmol}, 53 \%) .{ }^{1} \mathrm{H}$ NMR (500 MHz, $\left.\mathrm{CDCl}_{3}\right) \delta$ $7.27(\mathrm{~d}, 8.8 \mathrm{~Hz}, 2 \mathrm{H}), 6.91(\mathrm{~d}, J=8.2 \mathrm{~Hz}, 2 \mathrm{H}), 4.59$ (s, 2H), 4.08 (s, 2H), 3.89 (s, $3 \mathrm{H}){ }^{100}$<smiles>O=C(CO[14C](=O)c1ccccc1)N1C(=O)OC[C@H]1Cc1ccccc1</smiles>

\section{(S)-4-Benzyl-3-(2-[4-methoxybenzyloxy]acetyl)oxazolidin-2- one (159)}

To a solution of 158 (3.87 g, $19.72 \mathrm{mmol})$ in acetonitrile (159.00 $\mathrm{mL})$ at room temperature, was added triethylamine $(3.50 \mathrm{~mL}, 2.54 \mathrm{~g}, 25.11 \mathrm{mmol})$ and HBTU ( $8.24 \mathrm{~g}, 21.73 \mathrm{mmol})$. The reaction mixture was stirred for 30 minutes and gradually turned orange coloured. To a solution of $157(3.50 \mathrm{~g}, 19.75 \mathrm{mmol})$ in tetrahydrofuran $(25.00 \mathrm{~mL})$ at $-78{ }^{\circ} \mathrm{C}$, was added butyllithium $(2.0 \mathrm{M}$ in cyclohexane, $11.00 \mathrm{~mL}, 22.00 \mathrm{mmol})$. The reaction mixture was stirred for 15 minutes. The activated carboxylic acid mixture was cannulated dropwise into the deprotonated oxazolidinone mixture. The reaction mixture was returned to room temperature and 
stirred for 2 hours. The reaction was quenched with saturated aqueous brine $(50 \mathrm{~mL})$. The aqueous and organic layers were separated. The aqueous layer was extracted with dichloromethane $(3 \times 50 \mathrm{~mL})$. The organic extracts were combined and washed with $10 \% \mathrm{HCl}(100 \mathrm{~mL})$, followed with saturated aqueous $\mathrm{NaHCO}_{3}(100 \mathrm{~mL})$, and finally with distilled water $(100 \mathrm{~mL})$. The organic extract was dried with anhydrous magnesium sulfate and concentrated. Gradient flash chromatography (5:1 to 1:1 hexane/ethyl acetate) provided 159 as a white solid (3.34 g, $9.40 \mathrm{mmol}, 48 \%)$. $\mathrm{R}_{f} 0.21$ (2:1 hexane/ethyl acetate). ${ }^{1} \mathrm{H}$ NMR $\left(500 \mathrm{MHz}, \mathrm{CDCl}_{3}\right) \delta 7.36-7.27(\mathrm{~m}, 5 \mathrm{H}), 7.21(\mathrm{~d}$, $J=7.0 \mathrm{~Hz}, 2 \mathrm{H}), 6.90(\mathrm{~d}, J=7.9 \mathrm{~Hz}, 2 \mathrm{H}), 4.70(\mathrm{~m}, 1 \mathrm{H}), 4.68(\mathrm{~s}, 2 \mathrm{H}), 4.63(\mathrm{~s}, 2 \mathrm{H})$, $4.25(\mathrm{~m}, 2 \mathrm{H}), 3.81(\mathrm{~s}, 3 \mathrm{H}), 3.33(\mathrm{dd}, J=3.3 \mathrm{~Hz}, 13.5 \mathrm{~Hz}, 1 \mathrm{H}), 2.81(\mathrm{dd}, J=9.3 \mathrm{~Hz}$, $13.5 \mathrm{~Hz}, 1 \mathrm{H}){ }^{100}$

\section{TBSO $\mathrm{OH}$ 3-(tert-Butyldimethylsilyloxy)-2,2-dimethylpropan-1-ol (160)}

To a solution of 2,2-dimethyl-1,3-propanediol (5.23 g, $50.22 \mathrm{~mol})$ in $\mathrm{N}, \mathrm{N}$-dimethylformamide $(16.00 \mathrm{~mL})$ at $0{ }^{\circ} \mathrm{C}$, was added imidazole $(6.81 \mathrm{~g}, 100.03$ mmol) and tert-butyldimethylsilyl chloride $(7.54 \mathrm{~g}, 50.03 \mathrm{mmol})$. The reaction mixture was returned to room temperature and stirred overnight. The reaction was diluted with diethyl ether $(100 \mathrm{~mL})$ and extracted with saturated aqueous $\mathrm{NaHCO}_{3}(3$ x $30 \mathrm{~mL})$, followed by distilled water $(2 \times 30 \mathrm{~mL})$. The organic extract was dried with anhydrous magnesium sulfate and concentrated. Flash chromatography (20:1 hexane/ethyl acetate) provided $\mathbf{1 6 0}$ as a colourless oil $(6.57 \mathrm{~g}, 30.08 \mathrm{mmol}, 60 \%) . \mathrm{R}_{f}$ $0.28\left(10: 1\right.$ hexane/ethyl acetate). ${ }^{1} \mathrm{H}$ NMR $\left(500 \mathrm{MHz}, \mathrm{CDCl}_{3}\right) \delta 3.47(\mathrm{~s}, 4 \mathrm{H}), 2.88(\mathrm{t}, J$ $=5.8 \mathrm{~Hz}, 1 \mathrm{H}), 0.90(\mathrm{~s}, 9 \mathrm{H}), 0.88(\mathrm{~s}, 6 \mathrm{H}), 0.06(\mathrm{~s}, 6 \mathrm{H}) .{ }^{100}$

\section{TBSO O 3-(tert-Butyldimethylsilyloxy)-2,2-dimethylpropanal (161)}

To a solution of oxalyl chloride $(4.00 \mathrm{~mL}, 6.00 \mathrm{~g}, 47.27 \mathrm{~mol})$ in dichloromethane $(46.00 \mathrm{~mL})$ at $-78{ }^{\circ} \mathrm{C}$, was added dropwise dimethyl sulfoxide (4.30 $\mathrm{mL}, 4.73 \mathrm{~g}, 60.54 \mathrm{mmol})$. The reaction mixture was stirred for 30 minutes and a solution of $160(6.57 \mathrm{~g}, 30.08 \mathrm{mmol})$ in dichloromethane $(60.00 \mathrm{~mL})$ was added dropwise. The reaction mixture was stirred for 30 minutes and triethylamine (17.00 $\mathrm{mL}, 12.34 \mathrm{~g}, 121.97 \mathrm{mmol}$ ) was added dropwise. The reaction mixture was stirred for a further 2 hours. The reaction was quenched with saturated aqueous $\mathrm{NaHCO}_{3}(50$ 
$\mathrm{mL}$ ) and returned to room temperature. The aqueous and organic layers were separated. The aqueous layer was extracted with dichloromethane ( 3 x $50 \mathrm{~mL})$. The organic extracts were combined and washed with saturated aqueous $\mathrm{NaHSO}_{3}(2 \times 50$ $\mathrm{mL})$ and then with saturated aqueous brine $(75 \mathrm{~mL})$. The organic extract was dried with anhydrous magnesium sulfate and concentrated. Flash chromatography (20:1 hexane/ethyl acetate) provided 161 as a colourless oil (5.60 g, $25.88 \mathrm{mmol}, 86 \%)$. $\mathbf{R}_{f}$ 0.73 (10:1 hexane/ethyl acetate). ${ }^{1} \mathrm{H}$ NMR $\left(500 \mathrm{MHz}, \mathrm{CDCl}_{3}\right) \delta 9.57$ (s, 1H), 3.59 (s, $2 \mathrm{H}), 1.04(\mathrm{~s}, 6 \mathrm{H}), 0.87(\mathrm{~s}, 9 \mathrm{H}), 0.03(\mathrm{~s}, 6 \mathrm{H}){ }^{100}$

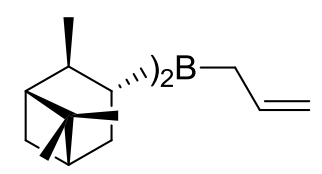

\section{(-)-B-Allyldiisopinocamphenylborane (162)}

To a solution of (+)- $\alpha$-pinene $(19.00 \mathrm{~mL}, 16.30 \mathrm{~g}, 119.67 \mathrm{mmol})$ in tetrahydrofuran $(12.00 \mathrm{~mL})$ at room temperature was added dropwise borane dimethyl sulfide complex (4.00 mL, $3.20 \mathrm{~g}, 42.17 \mathrm{mmol})$. The reaction mixture was cooled to $-18{ }^{\circ} \mathrm{C}$ and a white solid settled out overnight. The solvent was removed and the white solid was rinsed with anhydrous diethyl ether $(3 \times 15.00 \mathrm{~mL})$, then dried under vacuum. The white solid was suspended in anhydrous diethyl ether $(20.00 \mathrm{~mL})$ and cooled to $0{ }^{\circ} \mathrm{C}$. Methanol $(3.80 \mathrm{~mL}, 3.01 \mathrm{~g}, 93.81 \mathrm{mmol})$ was added dropwise and the resulting reaction mixture was stirred until no white solid remained. The reaction mixture was concentrated under vacuum, then returned to atmospheric pressure and diluted in anhydrous diethyl ether $(20.00 \mathrm{~mL})$ at $0{ }^{\circ} \mathrm{C}$. Allylmagnesium bromide solution (1.0 M in diethyl ether, $25.00 \mathrm{~mL}, 25.00 \mathrm{mmol})$ was added dropwise. The reaction mixture was returned to room temperature and stirred for 4 hours. A white slurry formed was used immediately for formation of $\mathbf{1 6 3}$.00, $104^{104}$

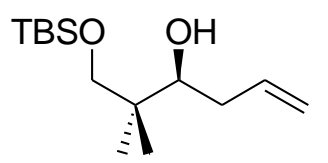

(S)-1-(tert-Butyldimethylsilyloxy)-2,2-dimethylhex-5-en-3-ol

To the white slurry containing $162(25.00 \mathrm{~mol})$ at $-100{ }^{\circ} \mathrm{C}$, was added dropwise a solution of 161 (5.60 g, $25.88 \mathrm{mmol})$. The reaction mixture was stirred for 2 hours and quenched with sequential addition of methanol $(5 \mathrm{~mL}), 0.5 \mathrm{M}$ sodium phosfate buffer ( $\mathrm{pH} 7.0,5 \mathrm{~mL}$ ), and $30 \%$ hydrogen peroxide $(5 \mathrm{~mL})$. The solution was stirred at room temperature overnight. The aqueous and organic layers were separated. The aqueous layer was extracted with ethyl acetate $(3 \times 50 \mathrm{~mL})$. The organic extracts were 
combined and washed with saturated aqueous $\mathrm{NH}_{4} \mathrm{Cl}(3 \times 40 \mathrm{~mL})$ and then dried with anhydrous magnesium sulfate and concentrated. Gradient flash chromatography (50:1 to 10:1 hexane/ethyl acetate) provided $\mathbf{1 6 3}$ as a colourless oil (4.71 g, $18.22 \mathrm{mmol}$, $70 \%, 95 \%$ ee). $\mathrm{R}_{f} 0.39$ (10:1 hexane/ethyl acetate). IR $\left(\mathrm{KBr}, \mathrm{cm}^{-1}\right) v_{\max } 3495.0$,

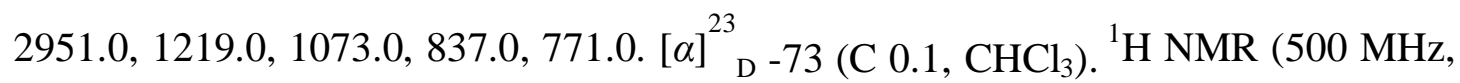
$\left.\mathrm{CDCl}_{3}\right) \delta 5.94(\mathrm{~m}, 1 \mathrm{H}), 5.10(\mathrm{~m}, 2 \mathrm{H}), 3.55(\mathrm{~d}, J=10.0 \mathrm{~Hz}, 1 \mathrm{H}), 3.48(\mathrm{~s}, 2 \mathrm{H}), 2.27(\mathrm{~m}$, $1 \mathrm{H}), 2.09(\mathrm{~m}, 1 \mathrm{H}), 0.91(\mathrm{~s}, 3 \mathrm{H}), 0.90(\mathrm{~s}, 9 \mathrm{H}), 0.84(\mathrm{~s}, 3 \mathrm{H}), 0.07(\mathrm{~s}, 6 \mathrm{H}) .{ }^{100,104}$<smiles>C=CCC(OC(=O)C=C)[C@@H](C)COCCCC</smiles>

(S)-1-(tert-Butyldimethylsilyloxy)-2,2-dimethylhex-5-en-3-yl acrylate (164)

To a solution of $\mathbf{1 6 3}(4.52 \mathrm{~g}, 17.49 \mathrm{mmol})$ in dichloromethane $(96.00 \mathrm{~mL})$ at $0{ }^{\circ} \mathrm{C}$, was added $N, N$-diisopropylethylamine $(7.60 \mathrm{~mL}, 5.64 \mathrm{~g}, 43.63$ mmol), followed by acryloyl chloride $(2.80 \mathrm{~mL}, 3.12 \mathrm{~g}, 34.46 \mathrm{mmol})$. The reaction mixture was returned to room temperature and stirred overnight. The reaction was quenched with saturated aqueous $\mathrm{NH}_{4} \mathrm{Cl}(50 \mathrm{~mL})$. The aqueous and organic layers were separated. The aqueous layer was extracted with dichloromethane ( 3 x $50 \mathrm{~mL})$. The organic extracts were combined and washed with saturated aqueous brine (100 $\mathrm{mL})$. The organic extract was dried with anhydrous magnesium sulfate and concentrated. Flash chromatography (20:1 hexane/ethyl acetate) provided 164 as a colourless oil (4.50 g, $14.40 \mathrm{mmol}, 82 \%) . \mathrm{R}_{f} 0.64$ (10:1 hexane/ethyl acetate). ${ }^{1} \mathrm{H}$ NMR $\left(500 \mathrm{MHz}, \mathrm{CDCl}_{3}\right) \delta 6.37(\mathrm{dd}, J=1.5 \mathrm{~Hz}, 17.3 \mathrm{~Hz}, 1 \mathrm{H}), 6.10(\mathrm{dd}, J=10.5 \mathrm{~Hz}$, $17.3 \mathrm{~Hz}, 1 \mathrm{H}), 5.79$ (dd, $J=1.6 \mathrm{~Hz}, 10.4 \mathrm{~Hz}, 1 \mathrm{H}), 5.73$ (m, 1H), 5.09 (dd, $J=2.9 \mathrm{~Hz}$, $10.3 \mathrm{~Hz}, 1 \mathrm{H}), 5.02(\mathrm{~d}, J=18.6 \mathrm{~Hz}, 1 \mathrm{H}), 4.97(\mathrm{~d}, J=10.3 \mathrm{~Hz}, 1 \mathrm{H}), 3.33(\mathrm{~d}, J=5.6 \mathrm{~Hz}$, 2H), $2.44(\mathrm{~m}, 1 \mathrm{H}), 2.25(\mathrm{~m}, 1 \mathrm{H}), 0.91(\mathrm{~s}, 3 \mathrm{H}), 0.89$ (s, 9H), 0.87 (s, 3H), 0.01 (s, $6 \mathrm{H}){ }^{100}$<smiles>C[C@@H](COC(C)(C)C)[C@H]1CC=CC(=O)O1</smiles>

(S)-6-(1-[tert-Butyldimethylsilyloxy]-2-methylpropan-2-yl)-5,6dihydropyran-2-one (165)

To a solution of $164(4.50 \mathrm{~g}, 14.40 \mathrm{mmol})$ in dichloromethane $(1440.00 \mathrm{~mL})$ at room temperature, was added Grubbs' $2^{\text {nd }}$ generation catalyst $(0.63$ $\mathrm{g}, 0.74 \mathrm{mmol}$ ). The reaction mixture was stirred overnight. The reaction mixture was 
concentrated to a brown oil. Flash chromatography (10:1 hexane/ethyl acetate) provided 165 as a yellow oil (3.68 g, $12.94 \mathrm{mmol}$, 90\%). $\mathrm{R}_{f} 0.18$ (10:1 hexane/ethyl acetate). ${ }^{1} \mathrm{H}$ NMR $\left(500 \mathrm{MHz}, \mathrm{CDCl}_{3}\right) \delta 6.92(\mathrm{~m}, 1 \mathrm{H}), 6.01(\mathrm{~d}, J=9.6 \mathrm{~Hz}, 1 \mathrm{H}), 4.36$ $(\mathrm{d}, J=13.8 \mathrm{~Hz}, 1 \mathrm{H}), 3.53(\mathrm{dd}, J=4.4 \mathrm{~Hz}, 14.2 \mathrm{~Hz}, 1 \mathrm{H}), 3.37(\mathrm{dd}, J=4.4 \mathrm{~Hz}, 14.2$ Hz, 1H), $2.44(\mathrm{~m}, 1 \mathrm{H}), 2.27(\mathrm{~m}, 1 \mathrm{H}), 0.97(\mathrm{~s}, 3 \mathrm{H}), 0.91(\mathrm{~s}, 3 \mathrm{H}), 0.87$ (s, 9H), 0.03 (s, $6 \mathrm{H}){ }^{100}$

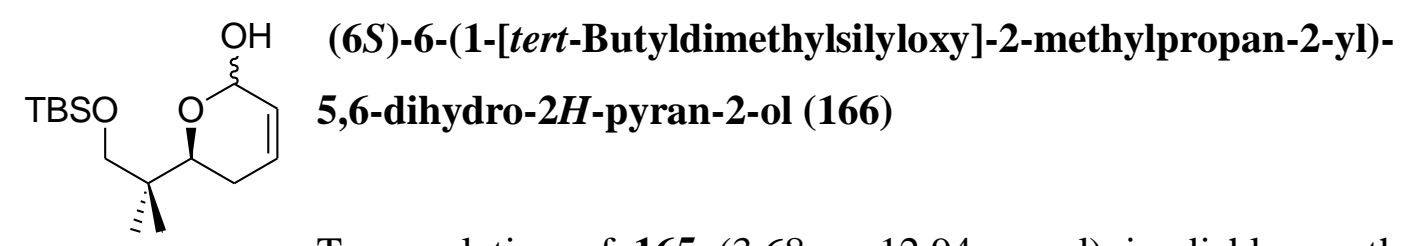

To a solution of 165 (3.68 g, $12.94 \mathrm{mmol})$ in dichloromethane (182.00 mL) at $-23{ }^{\circ} \mathrm{C}$, was added diisobutylaluminium hydride $(1.0 \mathrm{M}$ in toluene, $20.00 \mathrm{~mL}, 20.00 \mathrm{mmol}$ ) and the reaction mixture was stirred for 45 minutes. The reaction was quenched with methanol $(10 \mathrm{~mL})$ and returned to room temperature. A saturated aqueous solution of Rochelle's salt $(100 \mathrm{~mL})$ was added to the reaction mixture. The aqueous and organic layers were separated. The aqueous layer was extracted with dichloromethane $(3 \times 50 \mathrm{~mL})$. The organic extracts were combined and dried with anhydrous magnesium sulfate. Removal of solvent provided $\mathbf{1 6 6}$ as a brown oil and was used without further purification. $\mathrm{R}_{f} 0.22$ (10:1 hexane/ethyl acetate). ${ }^{1} \mathrm{H}$ NMR (500 MHz, $\left.\mathrm{CDCl}_{3}\right) \delta 6.05(\mathrm{~m}, 1 \mathrm{H}), 5.79(\mathrm{~d}, J=10.0 \mathrm{~Hz}, 1 \mathrm{H}), 5.37$ $(\mathrm{m}, 1 \mathrm{H}), 3.87(\mathrm{dd}, J=3.0 \mathrm{~Hz}, 11.5 \mathrm{~Hz}, 1 \mathrm{H}), 3.45(\mathrm{~d}, J=9.5 \mathrm{~Hz}, 1 \mathrm{H}), 3.34(\mathrm{~d}, J=9.5$ $\mathrm{Hz}, 1 \mathrm{H}), 2.13$ (m, 1H), 1.90 (m, 1H), 0.89 (s, 9H), 0.85 (s, 6H), 0.03 (s, 6H). ${ }^{100,106}$<smiles>CC(=O)O[C@H]1C=CC[C@@H]([C@@H](C)COC(C)(C)C)O1</smiles>

(6S)-6-(1-[tert-Butyldimethylsilyloxy]-2-methylpropan-2-yl)5,6-dihydro-2H-pyran-2-yl acetate (167)

To a solution of $\mathbf{1 6 6}$ (assumed to be $12.94 \mathrm{mmol}$ ) in dichloromethane $(104.00 \mathrm{~mL})$ at room temperature, was added triethylamine $(4.50$ $\mathrm{mL}, 3.27 \mathrm{~g}, 32.29 \mathrm{mmol})$. Acetic anhydride $(2.00 \mathrm{~mL}, 2.16 \mathrm{~g}, 31.16 \mathrm{mmol})$ was added to the reaction mixture, followed by $N, N$-dimethyl-4-aminopyridine $(0.02 \mathrm{~g}, 0.16$ mmol). The reaction mixture was stirred overnight at room temperature. The reaction mixture was extracted with saturated aqueous $\mathrm{KHSO}_{4}(25 \mathrm{~mL})$, followed with saturated aqueous $\mathrm{NaHCO}_{3}(25 \mathrm{~mL})$ and saturated aqueous brine $(25 \mathrm{~mL})$. The organic layer was dried with anhydrous magnesium sulfate. Removal of solvent 
provided 167 as a brown oil and was used without further purification. $\mathbf{R}_{f} 0.19$ (10:1 hexane/ethyl acetate). ${ }^{1} \mathrm{H}$ NMR (500 MHz, $\left.\mathrm{CDCl}_{3}\right) \delta 6.28(\mathrm{~m}, 1 \mathrm{H}), 6.16(\mathrm{~m}, 1 \mathrm{H}), 6.10$ (m, 1H), 5.73 (d, $J=10.0 \mathrm{~Hz}, 1 \mathrm{H}), 5.63(\mathrm{~d}, 10.0 \mathrm{~Hz}, 1 \mathrm{H}), 3.82(\mathrm{dd}, J=3.3 \mathrm{~Hz}, 11.6$ $\mathrm{Hz}, 1 \mathrm{H}), 3.74(\mathrm{dd}, J=3.3 \mathrm{~Hz}, 11.6 \mathrm{~Hz}, 1 \mathrm{H}), 3.45$ (dd, $J=9.5 \mathrm{~Hz}, 27.9 \mathrm{~Hz}, 1 \mathrm{H}), 3.28$ $(\mathrm{dd}, J=9.5 \mathrm{~Hz}, 23.0 \mathrm{~Hz}, 1 \mathrm{H}), 2.23(\mathrm{~s}, 3 \mathrm{H}), 2.10(\mathrm{~m}, 2 \mathrm{H}), 0.89$ (s, 9H), $0.87(\mathrm{~s}, 3 \mathrm{H})$, $0.83(\mathrm{~s}, 3 \mathrm{H}), 0.02(\mathrm{~s}, 6 \mathrm{H}){ }^{100}$

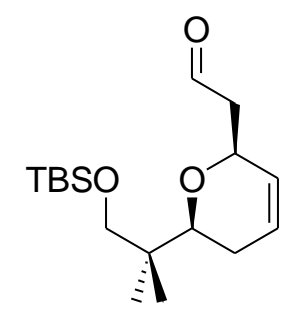

2-([2S,6S]-6-[1-\{tert-Butyldimethylsilyloxy\}-2-methylpropan-2yl]-5,6-dihydro-2H-pyran-2-yl)acetaldehyde (168)

To a solution of 167 (assumed to be $12.94 \mathrm{mmol}$ ) in acetonitrile $(130.00 \mathrm{~mL})$ at room temperature was added freshly distilled vinyloxy-trimethylsilane $(2.90 \mathrm{~mL}, 2.26 \mathrm{~g}, 19.44 \mathrm{mmol})$, followed with freshly distilled boron trifluoride diethyl etherate $(0.16 \mathrm{~mL}, 0.18 \mathrm{~g}, 1.30 \mathrm{mmol})$. The reaction mixture was stirred for 3.5 hours at room temperature. The reaction was quenched with saturated aqueous $\mathrm{NaHCO}_{3}(100 \mathrm{~mL})$. The aqueous and organic layers were separated. The aqueous layer was extracted with dichloromethane $(3 \times 100 \mathrm{~mL})$. The organic extracts were combined and dried with anhydrous magnesium sulfate, then concentrated. Flash chromatography (20:1 hexane/ethyl acetate) provided 168 as a colourless oil (2.39 g, $7.65 \mathrm{mmol}, 59 \%) . \mathrm{R}_{f} 0.35$ (10:1 hexane/ethyl acetate). ${ }^{1} \mathrm{H}$ NMR $\left(500 \mathrm{MHz}, \mathrm{CDCl}_{3}\right) \delta 9.82(\mathrm{~s}, 1 \mathrm{H}), 5.92(\mathrm{~m}, 1 \mathrm{H}), 5.68(\mathrm{~d}, J=10.3 \mathrm{~Hz}, 1 \mathrm{H}), 4.78(\mathrm{~m}$, 1H), 3.57 (dd, $J=2.8 \mathrm{~Hz}, 10.9 \mathrm{~Hz}, 1 \mathrm{H}), 3.43(\mathrm{~d}, J=10.2 \mathrm{~Hz}, 1 \mathrm{H}), 3.24$ (d, $J=10.2$ $\mathrm{Hz}, 1 \mathrm{H}), 2.82(\mathrm{~m}, 1 \mathrm{H}), 2.46(\mathrm{~d}, J=11.9 \mathrm{~Hz}, 1 \mathrm{H}), 2.13(\mathrm{~m}, 1 \mathrm{H}), 1.87(\mathrm{~d}, J=17.2 \mathrm{~Hz}$, $1 \mathrm{H}), 0.89(\mathrm{~s}, 9 \mathrm{H}), 0.84(\mathrm{~s}, 3 \mathrm{H}), 0.82(\mathrm{~s}, 3 \mathrm{H}), 0.02(\mathrm{~s}, 6 \mathrm{H}){ }^{100}$

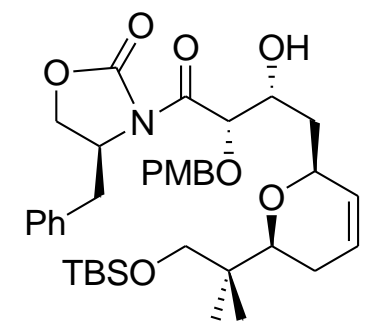

$$
\text { (S)-4-Benzyl-3-([2S,3R]-4-[\{2S,6S\}-6- }\{1-(\text { tert- }
$$
butyldimethylsilyloxy)-2-methylpropan-2-yl\}-5,6-dihydro2H-pyran-2-yl]-3-hydroxy-2-[4methoxybenzyloxy]butanoyl)oxazolidin-2-one (169)

To a solution of 159 (3.34 g, $9.40 \mathrm{mmol})$ in toluene $(50.00 \mathrm{~mL})$ at $-50{ }^{\circ} \mathrm{C}$, was added triethylamine $(1.50 \mathrm{~mL}, 1.09 \mathrm{~g}, 10.76 \mathrm{mmol})$, followed by dibutylboryl trifluoromethanesulfonate $(1.0 \mathrm{M}$ in dichloromethane, $10.00 \mathrm{~mL}, 10.00 \mathrm{mmol})$. The reaction mixture was stirred for 1.5 hours and a solution of $168(2.39 \mathrm{~g}, 7.65 \mathrm{mmol})$ in 
toluene $(23.00 \mathrm{~mL})$ was added. The reaction mixture was warmed gradually to $-30{ }^{\circ} \mathrm{C}$ and stirred for 2 hours. The reaction was quenched with sequential addition of $0.5 \mathrm{M}$ sodium phosfate buffer ( $\mathrm{pH} 7.0,5 \mathrm{~mL})$, methanol $(5 \mathrm{~mL})$, tetrahydrofuran $(5 \mathrm{~mL})$, and $30 \%$ hydrogen peroxide $(5 \mathrm{~mL})$. The reaction mixture was warmed to $0{ }^{\circ} \mathrm{C}$ and stirred for 60 minutes. The reaction mixture was returned to room temperature and the solvent removed under vacuum. The white solid was dissolved in saturated aqueous $\mathrm{NaHCO}_{3}(50 \mathrm{~mL})$ and ethyl acetate $(50 \mathrm{~mL})$. The aqueous and organic layers were separated. The aqueous layer was extracted with ethyl acetate $(3 \times 50 \mathrm{~mL})$. The organic extracts were combined and dried with anhydrous magnesium sulfate, then concentrated. Flash chromatography (1\% triethylamine in 2:1 hexane/ethyl acetate) provided 169 as a colourless oil (2.66 g, $3.98 \mathrm{mmol}, 52 \%) . \mathrm{R}_{f} 0.31$ (2:1 hexane/ethyl acetate). ${ }^{1} \mathrm{H}$ NMR $\left(500 \mathrm{MHz}, \mathrm{CDCl}_{3}\right) \delta 7.34-7.28(\mathrm{~m}, 5 \mathrm{H}), 7.21(\mathrm{~d}, J=7.1 \mathrm{~Hz}, 2 \mathrm{H})$, $6.89(\mathrm{dd}, J=2.1 \mathrm{~Hz}, 6.5 \mathrm{~Hz}, 2 \mathrm{H}), 5.81(\mathrm{~m}, 1 \mathrm{H}), 5.67(\mathrm{~d}, J=9.4 \mathrm{~Hz}, 1 \mathrm{H}), 5.19(\mathrm{~d}, J=$ $3.0 \mathrm{~Hz}, 1 \mathrm{H}), 4.65(\mathrm{~m}, 1 \mathrm{H}), 4.63(\mathrm{~s}, 2 \mathrm{H}), 4.53(\mathrm{~m}, 1 \mathrm{H}), 4.15(\mathrm{~m}, 2 \mathrm{H}), 3.79(\mathrm{~m}, 1 \mathrm{H})$, $3.78(\mathrm{~s}, 3 \mathrm{H}), 3.46(\mathrm{~m}, 1 \mathrm{H}), 3.43(\mathrm{~d}, J=9.6 \mathrm{~Hz}, 1 \mathrm{H}), 3.30(\mathrm{~d}, J=9.7 \mathrm{~Hz}, 1 \mathrm{H}), 3.27$ $(\mathrm{dd}, J=3.2 \mathrm{~Hz}, 13.8 \mathrm{~Hz}, 1 \mathrm{H}), 2.67(\mathrm{dd}, J=9.8 \mathrm{~Hz}, 13.2 \mathrm{~Hz}, 1 \mathrm{H}), 2.11(\mathrm{~m}, 1 \mathrm{H}), 1.87$ $(\mathrm{m}, 2 \mathrm{H}), 1.70(\mathrm{~m}, 1 \mathrm{H}), 0.91(\mathrm{~s}, 3 \mathrm{H}), 0.87(\mathrm{~s}, 9 \mathrm{H}), 0.82(\mathrm{~s}, 3 \mathrm{H}), 0.01(\mathrm{~s}, 6 \mathrm{H}){ }^{100}$

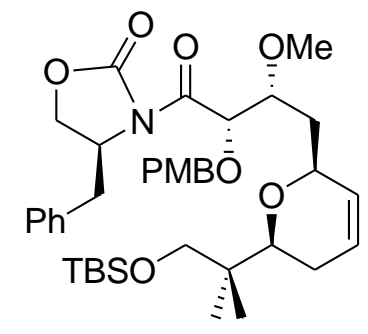

\section{(S)-4-Benzyl-3-([2S,3R]-4-[\{2S,6S\}-6- $\{1-($ tert-} butyldimethylsilyloxy)-2-methylpropan-2-yl\}-5,6-dihydro2H-pyran-2-yl]-3-methoxy-2-[4methoxybenzyloxy]butanoyl)oxazolidin-2-one (170)

To a solution of 169 (2.66 g, $3.98 \mathrm{mmol})$ in dichloromethane $(100.00 \mathrm{~mL})$ at $0{ }^{\circ} \mathrm{C}$, was added 1:1 (mol/mol) mixture of trimethyloxonium tetrafluoroborate $(1.18 \mathrm{~g}, 7.96$ mmol) and Proton-sponge ${ }^{\circledR}(1.71 \mathrm{~g}, 7.96 \mathrm{mmol})$. The reaction mixture was stirred for 3 hours at $0{ }^{\circ} \mathrm{C}$. The reaction was quenched with saturated aqueous $\mathrm{NaHCO}_{3}(50 \mathrm{~mL})$. The aqueous and organic layers were separated. The aqueous layer was extracted with dichloromethane $(3 \times 50 \mathrm{~mL})$. The organic extracts were combined and washed with saturated aqueous brine $(75 \mathrm{~mL})$. The organic extract was dried with anhydrous magnesium sulfate and concentrated. Gradient flash chromatography (5:1 to 2:1 hexane/ethyl acetate) provided $\mathbf{1 7 0}$ as a colourless oil (2.37 g, $3.48 \mathrm{mmol}, 87 \%)$. $\mathbf{R}_{f}$ 0.52 (10:1 hexane/ethyl acetate). ${ }^{1} \mathrm{H}$ NMR $\left(500 \mathrm{MHz}, \mathrm{CDCl}_{3}\right) \delta$ 7.33-7.28 (m, 5H), $7.20(\mathrm{~d}, J=7.0 \mathrm{~Hz}, 2 \mathrm{H}), 6.86(\mathrm{dd}, J=2.1 \mathrm{~Hz}, 6.8 \mathrm{~Hz}, 2 \mathrm{H}), 5.81(\mathrm{~m}, 1 \mathrm{H}), 5.64(\mathrm{~d}, J=$ 
$10.3 \mathrm{~Hz}, 1 \mathrm{H}), 5.50(\mathrm{~d}, J=4.7 \mathrm{~Hz}, 1 \mathrm{H}), 4.58(\mathrm{~m}, 1 \mathrm{H}), 4.57(\mathrm{~s}, 2 \mathrm{H}), 4.36(\mathrm{~d}, J=10.3$ $\mathrm{Hz}, 1 \mathrm{H}), 4.13(\mathrm{~m}, 2 \mathrm{H}), 3.83(\mathrm{~m}, 1 \mathrm{H}), 3.76(\mathrm{~s}, 3 \mathrm{H}), 3.50$ (d, J = 9.4 Hz, 1H), 3.45 (s, $3 \mathrm{H}), 3.41(\mathrm{dd}, J=2.7 \mathrm{~Hz}, 10.5 \mathrm{~Hz}, 1 \mathrm{H}), 3.30(\mathrm{~d}, J=9.4 \mathrm{~Hz}, 1 \mathrm{H}), 3.18(\mathrm{dd}, J=3.2 \mathrm{~Hz}$, $13.8 \mathrm{~Hz}, 1 \mathrm{H}), 2.58$ (dd, $J=10.0 \mathrm{~Hz}, 13.2 \mathrm{~Hz}, 1 \mathrm{H}), 2.12(\mathrm{~m}, 1 \mathrm{H}), 1.97$ (m, 1H), 1.86 (d, $J=17.0 \mathrm{~Hz}, 1 \mathrm{H}), 1.47$ (m, 1H), 0.95 (s, 3H), 0.88 (s, 9H), 0.84 (s, 3H), 0.02 (s, $6 \mathrm{H}){ }^{100}$

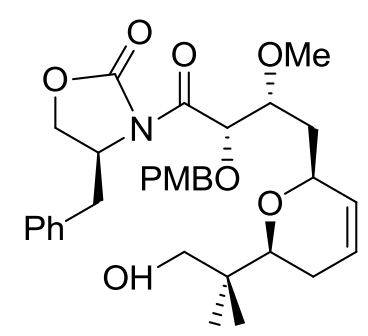

(S)-4-Benzyl-3-([2S,3R]-4-[\{2S,6S\}-6- $\{1-h y d r o x y-2-$ methylpropan-2-yl\}-5,6-dihydro-2H-pyran-2-yl]-3methoxy-2-[4-methoxybenzyloxy]butanoyl)oxazolidin-2-one (171)

To a solution of $\mathbf{1 7 0}(0.10 \mathrm{~g}, 0.15 \mathrm{mmol})$ in methanol $(2.00 \mathrm{~mL})$ at room temperature, was added hydrogen chloride solution $(2.0 \mathrm{M}$ in diethyl ether, $0.10 \mathrm{~mL}, 0.20 \mathrm{mmol})$. The reaction mixture was stirred for 15 minutes. The reaction was quenched with saturated aqueous $\mathrm{NaHCO}_{3}(2 \mathrm{~mL})$. The reaction mixture was extracted with dichloromethane $(3 \times 6 \mathrm{~mL})$. The organic extracts were combined and dried with anhydrous magnesium sulfate, then concentrated. Gradient flash chromatography (2:1 to $1: 1$ hexane/ethyl acetate) provided $\mathbf{1 7 1}$ as a colourless oil (0.05 g, $0.09 \mathrm{mmol}$, $60 \%) . \mathrm{R}_{f} 0.26$ (2:1 hexane/ethyl acetate). ${ }^{1} \mathrm{H} \mathrm{NMR}\left(500 \mathrm{MHz}, \mathrm{CDCl}_{3}\right) \delta$ 7.36-7.29 (m, $5 \mathrm{H}), 7.20(\mathrm{~d}, J=7.0 \mathrm{~Hz}, 2 \mathrm{H}), 6.87(\mathrm{dd}, J=2.1 \mathrm{~Hz}, 6.8 \mathrm{~Hz}, 2 \mathrm{H}), 5.84(\mathrm{~m}, 1 \mathrm{H}), 5.62(\mathrm{~d}$, $J=10.3 \mathrm{~Hz}, 1 \mathrm{H}), 5.45(\mathrm{~d}, J=4.1 \mathrm{~Hz}, 1 \mathrm{H}), 4.59(\mathrm{dd}, J=11.6 \mathrm{~Hz}, 26.8 \mathrm{~Hz}, 2 \mathrm{H}), 4.57$ $(\mathrm{m}, 1 \mathrm{H}), 4.36(\mathrm{~d}, J=10.8 \mathrm{~Hz}), 4.16(\mathrm{~m}, 2 \mathrm{H}), 3.80(\mathrm{~m}, 1 \mathrm{H}), 3.77(\mathrm{~s}, 3 \mathrm{H}), 3.68(\mathrm{dd}, J=$ $5.1 \mathrm{~Hz}, 10.7 \mathrm{~Hz}, 1 \mathrm{H}), 3.60(\mathrm{dd}, J=3.0 \mathrm{~Hz}, 10.9 \mathrm{~Hz}, 1 \mathrm{H}), 3.43$ (s, 3H), 3.25 (d, $J=5.7$ $\mathrm{Hz}, 10.7 \mathrm{~Hz}, 1 \mathrm{H}), 3.17$ (m, 1H), 2.61 (dd, $J=9.8 \mathrm{~Hz}, 13.4 \mathrm{~Hz}, 1 \mathrm{H}), 2.14$ (m, 1H), $1.96(\mathrm{~m}, 1 \mathrm{H}), 1.86(\mathrm{~m}, 1 \mathrm{H}), 1.46(\mathrm{~m}, 1 \mathrm{H}), 0.96(\mathrm{~s}, 3 \mathrm{H}), 0.83(\mathrm{~s}, 3 \mathrm{H}){ }^{100}$<smiles>CO[C@H](C(=O)N1C(=O)OC[C@H]1Cc1ccccc1)[C@@H](C[C@@H]1C=CC[C@H]([C@@H](C)C=O)O1)OC</smiles>

2-([2S,6S]-6-[\{2R,3S\}-4-\{(S)-4-Benzyl-2-oxooxazolidin-3yl\}-2-methoxy-3-\{4-methoxybenzyloxy\}-4-oxobutyl]-3,6dihydro-2H-pyran-2-yl)-2-methylpropanal (172)

Dess-Martin periodinane $(0.13 \mathrm{~g}, 0.31 \mathrm{mmol})$ was suspended in dichloromethane $(3.80 \mathrm{~mL})$ at $0{ }^{\circ} \mathrm{C}$. Pyridine $(0.07 \mathrm{~mL}, 0.07 \mathrm{~g}, 0.87 \mathrm{mmol})$ was added to the suspension and a solution of $\mathbf{1 7 1}(0.09 \mathrm{~g}, 0.16 \mathrm{mmol})$ in dichloromethane (2.40 
$\mathrm{mL}$ ) was then added dropwise into the reaction mixture. The reaction mixture was stirred for 5 hours at $0{ }^{\circ} \mathrm{C}$. The reaction was quenched with saturated aqueous $\mathrm{NaS}_{2} \mathrm{O}_{3}$ $(2 \mathrm{~mL})$ and saturated aqueous $\mathrm{NaHCO}_{3}(2 \mathrm{~mL})$. The aqueous and organic layers were separated. The aqueous layer was extracted with dichloromethane $(3 \times 5 \mathrm{~mL})$. The organic extracts were combined and dried with anhydrous magnesium sulfate, then concentrated. Flash chromatography (2:1 hexane/ethyl acetate) provided $\mathbf{1 7 2}$ as a white solid (0.07 g, $0.12 \mathrm{mmol}, 75 \%)$. $\mathrm{R}_{f} 0.19$ (2:1 hexane/ethyl acetate). ${ }^{1} \mathrm{H}$ NMR $\left(500 \mathrm{MHz}, \mathrm{CDCl}_{3}\right) \delta 9.53(\mathrm{~s}, 1 \mathrm{H}), 7.36-7.29(\mathrm{~m}, 5 \mathrm{H}), 7.21(\mathrm{~d}, J=7.0 \mathrm{~Hz}, 2 \mathrm{H}), 6.87$ $(\mathrm{d}, J=8.8 \mathrm{~Hz}, 2 \mathrm{H}), 5.82(\mathrm{~m}, 1 \mathrm{H}), 5.65(\mathrm{~d}, J=10.3 \mathrm{~Hz}, 1 \mathrm{H}), 5.41(\mathrm{~d}, J=4.1 \mathrm{~Hz}, 1 \mathrm{H})$, 4.59 (m, 1H), 4.63 (d, $J=11.4 \mathrm{~Hz}, 1 \mathrm{H}), 4.52$ (d, $11.4 \mathrm{~Hz}, 1 \mathrm{H}), 4.34$ (m, 1H), 4.19 (m, 2H), 3.77 (s, 3H), $3.73(\mathrm{~m}, 1 \mathrm{H}), 3.68(\mathrm{~m}, 1 \mathrm{H}), 3.37$ (s, 3H), 3.22 (dd, J = 3.2 Hz, 13.2 Hz, 1H), $2.66(\mathrm{dd}, J=9.9 \mathrm{~Hz}, 13.4 \mathrm{~Hz}, 1 \mathrm{H}), 2.11(\mathrm{~m}, 1 \mathrm{H}), 1.91(\mathrm{~m}, 2 \mathrm{H}), 1.52(\mathrm{~m}$, $1 \mathrm{H}), 1.04(\mathrm{~s}, 3 \mathrm{H}), 1.02(\mathrm{~s}, 3 \mathrm{H}){ }^{100}$

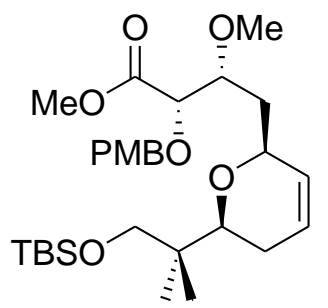

(2S,3R)-Methyl 4-([2S,6S]-6-[1-\{tert-butyldimethylsilyloxy\}-2methylpropan-2-yl]-5,6-dihydro-2H-pyran-2-yl)-3-methoxy2-(4-methoxybenzyloxy)butanoate (173)

To a solution of $\mathbf{1 7 0}(1.09 \mathrm{~g}, 1.60 \mathrm{mmol})$ in dichloromethane $(17.00 \mathrm{~mL})$ at $0{ }^{\circ} \mathrm{C}$, was added dimethyl carbonate $(0.69 \mathrm{~mL}, 0.74 \mathrm{~g}, 8.19 \mathrm{mmol})$, followed by fresh anhydrous sodium methoxide $(0.44 \mathrm{~g}, 8.15 \mathrm{mmol})$. The yellowcoloured reaction mixture was stirred at $0{ }^{\circ} \mathrm{C}$ for 1.5 hours. The reaction was quenched with distilled water $(20 \mathrm{~mL})$. The aqueous and organic layers were separated. The aqueous layer was extracted with dichloromethane (3 x $20 \mathrm{~mL})$. The organic extracts were combined and washed with $10 \%$ hydrochloric acid (20 mL). The organic extract was dried with anhydrous magnesium sulfate and concentrated. Gradient flash chromatography (5:1 hexane/ethyl acetate to neat ethyl acetate) provided 173 as a colourless oil $(0.59 \mathrm{~g}, 1.10 \mathrm{mmol}, 69 \%) . \mathrm{R}_{f} 0.53$ (2:1 hexane/ethyl acetate). ${ }^{1} \mathrm{H}$ NMR $\left(500 \mathrm{MHz}, \mathrm{CDCl}_{3}\right) \delta 7.25(\mathrm{~d}, J=8.8 \mathrm{~Hz}, 2 \mathrm{H}), 6.86(\mathrm{dd}, J=2.1 \mathrm{~Hz}$, $8.8 \mathrm{~Hz}, 2 \mathrm{H}), 5.82(\mathrm{~m}, 1 \mathrm{H}), 5.63(\mathrm{~d}, J=10.3 \mathrm{~Hz}, 1 \mathrm{H}), 4.70(\mathrm{~d}, J=11.9 \mathrm{~Hz}, 1 \mathrm{H}), 4.38$ (m, 1H), $4.38(\mathrm{~d}, J=11.5 \mathrm{~Hz}, 2 \mathrm{H}), 3.90(\mathrm{~d}, J=4.2 \mathrm{~Hz}, 1 \mathrm{H}), 3.80(\mathrm{~s}, 3 \mathrm{H}), 3.76(\mathrm{~s}, 3 \mathrm{H})$, $3.46(\mathrm{~s}, 3 \mathrm{H}), 3.43(\mathrm{~d}, J=9.5 \mathrm{~Hz}, 1 \mathrm{H}), 3.37(\mathrm{dd}, J=2.9 \mathrm{~Hz}, 10.7 \mathrm{~Hz}, 1 \mathrm{H}), 3.33$ (d, $J=$ $9.5 \mathrm{~Hz}, 1 \mathrm{H}), 2.10(\mathrm{~m}, 1 \mathrm{H}), 1.83(\mathrm{~d}, J=17.1 \mathrm{~Hz}, 1 \mathrm{H}), 1.65$ (m, 2H), 0.92 (s, 3H), 0.87 $(\mathrm{s}, 9 \mathrm{H}), 0.83$ (s, 3H), 0.02 (s, 6H). ${ }^{13} \mathrm{C} \mathrm{NMR}\left(500 \mathrm{MHz}, \mathrm{CDCl}_{3}\right) \delta 171.63,159.50$, 
129.90, 129.90, 129.83, 129.47, 125.03, 113.95, 113.87, 79.68, 78.29, 72.55, 71.24, $69.75,69.46,59.86,55.39,51.96,38.94,34.85,26.05,25.40,20.83,20.62,18.39$, $5.35,-5.45 .^{100,113}$<smiles>COC(=O)C(CC1C=CC[C@@H]([C@@H](C)CO)O1)[C@H](C)CO</smiles>

(2S,3R)-Methyl 4-([2S,6S]-6-[1-hydroxy-2-methylpropan-2-yl]5,6-dihydro-2H-pyran-2-yl)-3-methoxy-2-(4methoxybenzyloxy)butanoate (174)

To a solution of $173(0.18 \mathrm{~g}, 0.34 \mathrm{mmol})$ in methanol $(1.40 \mathrm{~mL})$ at room temperature was added, dropwise, 36\% aqueous hydrochloric acid solution $(0.01 \mathrm{~mL})$. The reaction mixture was stirred for 30 minutes. The reaction was quenched with saturated aqueous $\mathrm{NaHCO}_{3}(1 \mathrm{~mL})$. The reaction mixture was extracted with dichloromethane $(3 \times 3 \mathrm{~mL})$. The organic extracts were combined and dried with anhydrous magnesium sulfate, then concentrated. Flash chromatography (5:1 hexane/ethyl acetate) provided 174 as a colourless oil $(0.13 \mathrm{~g}, 0.31 \mathrm{mmol}, 91 \%)$. $\mathrm{R}_{f} 0.16$ (2:1 hexane/ethyl acetate). ${ }^{1} \mathrm{H}$ NMR $\left(500 \mathrm{MHz}, \mathrm{CDCl}_{3}\right) \delta 7.27(\mathrm{~d}, J=8.5 \mathrm{~Hz}$, $2 \mathrm{H}), 6.87(\mathrm{~d}, J=2.1 \mathrm{~Hz}, 8.5 \mathrm{~Hz}, 2 \mathrm{H}), 5.83(\mathrm{~m}, 1 \mathrm{H}), 5.61(\mathrm{~d}, J=10.0 \mathrm{~Hz}, 1 \mathrm{H}), 4.70(\mathrm{~d}$, $J=11.7 \mathrm{~Hz}, 1 \mathrm{H}), 4.40(\mathrm{~d}, J=11.7 \mathrm{~Hz}, 2 \mathrm{H}), 4.39(\mathrm{~m}, 1 \mathrm{H}), 4.02(\mathrm{~d}, J=4.4 \mathrm{~Hz}, 1 \mathrm{H})$, $3.80(\mathrm{~s}, 3 \mathrm{H}), 3.76(\mathrm{~s}, 3 \mathrm{H}), 3.68(\mathrm{~d}, 11.0 \mathrm{~Hz}, 1 \mathrm{H}), 3.51(\mathrm{dd}, J=3.0 \mathrm{~Hz}, 11.0 \mathrm{~Hz}, 1 \mathrm{H})$, $3.44(\mathrm{~s}, 3 \mathrm{H}), 3.26(\mathrm{dd}, J=4.6 \mathrm{~Hz}, 10.7 \mathrm{~Hz}, 1 \mathrm{H}), 3.03(\mathrm{bs}, 1 \mathrm{H}), 2.14(\mathrm{~m}, 1 \mathrm{H}), 1.85$ (m, 2H), 1.45 (m, 1H), $0.96(\mathrm{~s}, 3 \mathrm{H}), 0.83(\mathrm{~s}, 3 \mathrm{H}) .{ }^{13} \mathrm{C} \mathrm{NMR}\left(500 \mathrm{MHz}, \mathrm{CDCl}_{3}\right) \delta 171.62$, 159.62, 130.06,129.39, 129.09, 124.73, 113.95, 78.35, 78.15, 73.03, 72.48, 70.26, $70.08,59.46,55.42,52.12,38.00,34.64,25.30,22.74,19.64 .{ }^{100}$<smiles>COC(=O)C(OC)[C@H](CC1C=CC[C@H]([C@@H](C)C=O)O1)OC</smiles>

(2S,3R)-Methyl 3-methoxy-2-(4-methoxybenzyloxy)-4-([2S,6S]6-[2-methyl-1-oxopropan-2-yl]-5,6-dihydro-2H-pyran-2yl)butanoate (175)

To a solution of $\mathbf{1 7 4}(0.12 \mathrm{~g}, 0.28 \mathrm{mmol})$ in dichloromethane (4.20 $\mathrm{mL})$ at room temperature was added (bisacetoxyiodo)benzene $(0.20 \mathrm{~g}, 0.62 \mathrm{mmol})$ and TEMPO (5.00 mg, $0.03 \mathrm{mmol})$. The reaction mixture was stirred for 5 hours at room temperature. The reaction was quenched with saturated aqueous $\mathrm{Na}_{2} \mathrm{~S}_{2} \mathrm{O}_{3}$ (10 $\mathrm{mL}$ ) and stirred at room temperature for 15 minutes. The aqueous and organic layers were separated. The aqueous layer was extracted with dichloromethane (3 x $10 \mathrm{~mL})$. 
The organic extracts were combined and washed with saturated aqueous $\mathrm{NaHCO}_{3}(10$ $\mathrm{mL}$ ). The organic extract was dried with anhydrous magnesium sulfate and concentrated. Flash chromatography (2:1 hexane/ethyl acetate) provided 175 as a colourless oil $(0.11 \mathrm{~g}, 0.26 \mathrm{mmol}, 93 \%) . \mathrm{R}_{f} 0.23$ (2:1 hexane/ethyl acetate). ${ }^{1} \mathrm{H}$ NMR $\left(500 \mathrm{MHz}, \mathrm{CDCl}_{3}\right) \delta 9.55(\mathrm{~s}, 1 \mathrm{H}), 7.28(\mathrm{~d}, J=8.5 \mathrm{~Hz}, 2 \mathrm{H}), 6.87(\mathrm{~d}, J=2.1 \mathrm{~Hz}, 8.5$ $\mathrm{Hz}, 2 \mathrm{H}), 5.81(\mathrm{~m}, 1 \mathrm{H}), 5.64(\mathrm{~d}, J=9.3 \mathrm{~Hz}, 1 \mathrm{H}), 4.69$ (d, $J=11.4 \mathrm{~Hz}, 1 \mathrm{H}), 4.39$ (d, $J=$ $11.5 \mathrm{~Hz}, 2 \mathrm{H}), 4.36(\mathrm{~d}, J=11.2 \mathrm{~Hz}, 1 \mathrm{H}), 4.01(\mathrm{~d}, J=4.7 \mathrm{~Hz}, 1 \mathrm{H}), 3.80(\mathrm{~s}, 3 \mathrm{H}), 3.77$ (s, 3H), $3.69(\mathrm{~m}, 1 \mathrm{H}), 3.42(\mathrm{~s}, 3 \mathrm{H}), 2.11(\mathrm{~m}, 1 \mathrm{H}), 1.84(\mathrm{~m}, 2 \mathrm{H}), 1.48(\mathrm{~m}, 1 \mathrm{H}), 1.06(\mathrm{~s}$, $3 \mathrm{H}), 1.02(\mathrm{~s}, 3 \mathrm{H}) .{ }^{13} \mathrm{C} \mathrm{NMR}\left(500 \mathrm{MHz}, \mathrm{CDCl}_{3}\right) \delta 206.22,171.57,159.58,129.98$, 129.90, 129.37, 123.87, 113.92, 78.48, 78.04, 77.03, 72.50, 70.86, 70.03, 59.47, $55.42,52.07,49.22,34.59,25.08,19.41,16.63 .^{100}$

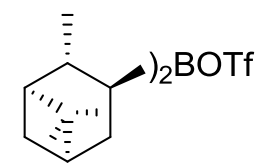

\section{(+)-B-Diisopinocamphenyl trifluoromethanesulfonate (176)}

To a solution of (-)- $\alpha$-pinene $(15.00 \mathrm{~mL}, 12.83 \mathrm{~g}, 94.14 \mathrm{mmol})$ in tetrahydrofuran $(12.00 \mathrm{~mL})$ at room temperature was added dropwise borane dimethyl sulfide complex $(3.80 \mathrm{~mL}, 3.04 \mathrm{~g}, 40.07 \mathrm{mmol})$. The reaction mixture was cooled to $18{ }^{\circ} \mathrm{C}$ and a white solid settled out overnight. The solvent was removed and the white solid was rinsed with anhydrous diethyl ether $(3 \times 15 \mathrm{~mL})$, then dried under vacuum. The white solid was suspended in anhydrous hexane $(13.00 \mathrm{~mL})$ and cooled to $0{ }^{\circ} \mathrm{C}$. Freshly distilled trifluoromethanesulfonic acid $(3.30 \mathrm{~mL}, 5.60 \mathrm{~g}, 37.29 \mathrm{mmol})$ was added dropwise and reaction mixture returned to room temperature. The reaction mixture was stirred until no white solid remained. Stirring was stopped and reaction mixture separated into two layers. The upper yellow coloured layer was used for formation of 177. Assumed 176 was formed in $60 \%$ yield, as a $1.9 \mathrm{M}$ solution in hexane. ${ }^{100,108}$

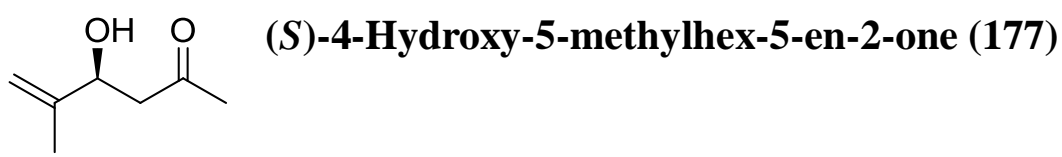

To a solution of $176(1.9 \mathrm{M}$ in hexane, $20.00 \mathrm{~mL}, 38.00 \mathrm{mmol})$ in dichloromethane $(11.00 \mathrm{~mL})$ at $-78{ }^{\circ} \mathrm{C}$, was added $N, N$-diisopropylethylamine $(7.50$ $\mathrm{mL}, 5.57 \mathrm{~g}, 43.06 \mathrm{mmol})$. The reaction mixture turned colourless and freshly distilled acetone $(1.30 \mathrm{~mL}, 1.03 \mathrm{~g}, 17.70 \mathrm{mmol})$ was added dropwise. The reaction mixture was stirred at $-78{ }^{\circ} \mathrm{C}$ for 2 hours. Freshly distilled methacrolein $(2.80 \mathrm{~mL}, 2.38 \mathrm{~g}$, 
33.96 mmol) was added dropwise and the reaction mixture cooled to $-18{ }^{\circ} \mathrm{C}$ overnight. The reaction was quenched with $0.5 \mathrm{M}$ sodium phosfate buffer $(\mathrm{pH} 7.0,30$ $\mathrm{mL}$ ) and returned to room temperature. The aqueous and organic layers were separated. The aqueous layer was extracted with dichloromethane $(3 \times 30 \mathrm{~mL})$. The organic extracts were combined and concentrated. The yellow slurry was dissolved in methanol (25 mL), 0.5 M sodium phosfate buffer $(\mathrm{pH} 7.0,25 \mathrm{~mL})$, and 30\% hydrogen peroxide $(20 \mathrm{~mL})$. The solution was stirred at room temperature for 2 hours. The solution was added into distilled water $(30 \mathrm{~mL})$ and extracted with dichloromethane $(3 \times 30 \mathrm{~mL})$. The organic extracts were combined and washed with saturated aqueous brine $(30 \mathrm{~mL})$. The organic extract was dried with anhydrous magnesium sulfate and concentrated. Gradient flash chromatography (10:1 to 5:1 hexane/ethyl acetate) provided 177 as a colourless oil (2.01 g, $15.68 \mathrm{mmol}, 89 \%)$. $\mathrm{R}_{f} 0.20$ (2:1 hexane/ethyl acetate). $[\alpha]_{\mathrm{D}}^{23}-37\left(\mathrm{C} 0.9 \mathrm{CHCl}_{3}\right) .{ }^{1} \mathrm{H} \mathrm{NMR}\left(500 \mathrm{MHz}, \mathrm{CDCl}_{3}\right) \delta 5.02(\mathrm{~s}, 1 \mathrm{H}), 4.87$ (s, 1H), $4.51(\mathrm{~m}, 1 \mathrm{H}), 2.91(\mathrm{~d}, J=3.2 \mathrm{~Hz}, 2 \mathrm{H}), 2.68(\mathrm{~d}, J=6.1 \mathrm{~Hz}, 3 \mathrm{H}) 1.75(\mathrm{~s}$, $3 \mathrm{H}){ }^{100,108}$

\section{$\mathrm{OH} \quad( \pm)$-2-Ethylbut-3-en-1-ol (178)}

To a solution of 2,5-dihydrofuran $(3.70 \mathrm{~mL}, 3.43 \mathrm{~g}, 48.94 \mathrm{mmol})$ in tetrahydrofuran $(15.00 \mathrm{~mL})$ at $0{ }^{\circ} \mathrm{C}$, was added dropwise ethylmagnesium chloride $(2.0 \mathrm{M}$ in tetrahydrofuran, $26.00 \mathrm{~mL}, 52.00 \mathrm{mmol}$ ). The reaction mixture was returned to room temperature and bis(cyclopentadienyl)zirconium(IV) dichloride (0.40 g, $1.37 \mathrm{mmol})$ was added. The reaction mixture was stirred at room temperature overnight. The reaction was quenched with distilled water $(50 \mathrm{~mL})$. The aqueous and organic layers were separated. The aqueous layer was extracted with dichloromethane (3 x $50 \mathrm{~mL})$. The organic extracts were combined and washed with saturated aqueous brine $(2 \times 20$ $\mathrm{mL})$. The organic extract was dried with anhydrous magnesium sulfate and concentrated. Vacuum distillation $\left(5 \mathrm{mmHg}, 60{ }^{\circ} \mathrm{C}\right)$ provided 178 as a colourless oil (2.60 g, $25.96 \mathrm{mmol}, 53 \%) . \mathrm{R}_{f} 0.62$ (2:1 hexane/ethyl acetate). ${ }^{1} \mathrm{H}$ NMR (500 MHz, $\left.\mathrm{CDCl}_{3}\right) \delta 5.58(\mathrm{~m}, 1 \mathrm{H}), 5.21(\mathrm{~m}, 2 \mathrm{H}), 3.74(\mathrm{~m}, 1 \mathrm{H}), 3.41(\mathrm{~m}, 1 \mathrm{H}), 2.14(\mathrm{~m}, 1 \mathrm{H}), 1.46$ (m, 1H), $1.39(\mathrm{~m}, 1 \mathrm{H}), 1.28(\mathrm{~m}, 1 \mathrm{H}), 0.90(\mathrm{t}, J=7.6 \mathrm{~Hz}, 3 \mathrm{H}){ }^{100}$ 


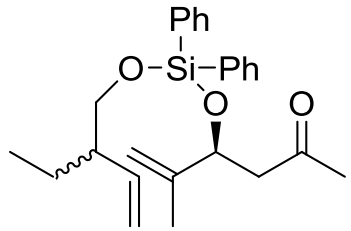

(S)-4-([\{R\}-2-Ethylbut-3-enyloxy $]$ diphenylsilyloxy)-5-

methylhex-5-en-2-one (179)

To a solution of freshly distilled dichlorodiphenylsilane $(2.50$ $\mathrm{mL}, 3.01 \mathrm{~g}, 11.89 \mathrm{mmol})$ in dichloromethane $(62.00 \mathrm{~mL})$ at $0{ }^{\circ} \mathrm{C}$, was added triethylamine ( $1.60 \mathrm{~mL}, 1.16 \mathrm{~g}, 11.48 \mathrm{mmol})$. A solution of $\mathbf{1 7 8}(1.07 \mathrm{~g}, 10.68 \mathrm{mmol})$ in dichloromethane $(16.00 \mathrm{~mL})$ was added to the reaction mixture. The reaction mixture was warmed to $50{ }^{\circ} \mathrm{C}$ and refluxed for 20 hours. The reaction mixture was returned to room temperature and then cooled to $0{ }^{\circ} \mathrm{C}$. Triethylamine $(5.00 \mathrm{~mL}, 3.63$ $\mathrm{g}, 35.87 \mathrm{mmol}$ ) was added to the reaction mixture followed with a solution of $\mathbf{1 7 7}$ $(2.00 \mathrm{~g}, 15.60 \mathrm{mmol})$ in dichloromethane $(9.50 \mathrm{~mL})$. The reaction mixture was returned to room temperature and stirred for 2 days. The reaction was quenched with saturated aqueous $\mathrm{NaHCO}_{3}(50 \mathrm{~mL})$. The aqueous and organic layers were separated. The aqueous layer was extracted with dichloromethane $(3 \times 50 \mathrm{~mL})$. The organic extracts were combined and washed with saturated aqueous brine $(2 \times 50 \mathrm{~mL})$. The organic extract was dried with anhydrous magnesium sulfate and concentrated. Flash chromatography (20:1 hexane/ethyl acetate) provided $\mathbf{1 7 9}$ as a colourless oil (1.64 g, $4.01 \mathrm{mmol}, 38 \%) . \mathrm{R}_{f} 0.31$ (10:1 hexane/ethyl acetate). ${ }^{1} \mathrm{H}$ NMR (500 MHz, $\left.\mathrm{CDCl}_{3}\right) \delta$ $7.62(\mathrm{~d}, J=7.8 \mathrm{~Hz}, 4 \mathrm{H}), 7.44-7.33(\mathrm{~m}, 6 \mathrm{H}), 5.63(\mathrm{~m}, 1 \mathrm{H}), 5.06(\mathrm{~m}, 2 \mathrm{H}), 5.06(\mathrm{~s}, 1 \mathrm{H})$, $4.77(\mathrm{~s}, 1 \mathrm{H}), 4.76(\mathrm{~m}, 1 \mathrm{H}), 3.64(\mathrm{~d}, J=6.3 \mathrm{~Hz}, 2 \mathrm{H}), 2.78(\mathrm{dd}, J=7.6 \mathrm{~Hz}, 14.9 \mathrm{~Hz}$, 1H), 2.55 (dd, $J=5.1 \mathrm{~Hz}, 14.9 \mathrm{~Hz}, 1 \mathrm{H}), 2.13(\mathrm{~m}, 1 \mathrm{H}), 2.07$ (s, 3H), 1.70 (s, 3H), 1.57 $(\mathrm{m}, 1 \mathrm{H}), 1.26(\mathrm{~m}, 1 \mathrm{H}), 0.85(\mathrm{t}, J=7.5 \mathrm{~Hz}, 3 \mathrm{H}) \cdot{ }^{13} \mathrm{C}$ NMR $\left(500 \mathrm{MHz}, \mathrm{CDCl}_{3}\right) \delta$ 206.74, 145.58, 140.10, 140.06, 135.21, 135.20, 134.92, 132.88, 132.80, 130.42, $130.37,127.88,127.81,115.90,112.42,112.40,73.41,66.37,66.36,50.47,48.03$, $48.02,31.04,30.22,23.67,17.53,17.52,11.62 .^{100}$

Side product:

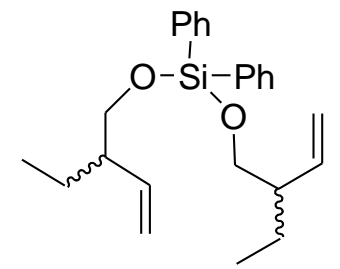

Bis(2-ethylbut-3-enyloxy)diphenylsilane (203)

Flash chromatography (20:1 hexane/ethyl acetate) provided 203 as a colourless oil $(0.01 \mathrm{~g}, 0.03 \mathrm{mmol}, 3 \%) . \mathrm{R}_{f} 0.88$ (20:1 hexane/ethyl acetate). ${ }^{1} \mathrm{H} \mathrm{NMR}\left(500 \mathrm{MHz}, \mathrm{CDCl}_{3}\right) \delta 7.65(\mathrm{~d}, J=7.8 \mathrm{~Hz}, 4 \mathrm{H}), 7.44$ $7.35(\mathrm{~m}, 6 \mathrm{H}), 5.65(\mathrm{~m}, 2 \mathrm{H}), 5.07(\mathrm{~s}, 2 \mathrm{H}), 5.05(\mathrm{~d}, J=3.9 \mathrm{~Hz}, 2 \mathrm{H}), 3.69(\mathrm{~d}, J=6.4 \mathrm{~Hz}$, 4H), $2.17(\mathrm{~m}, 2 \mathrm{H}), 1.60(\mathrm{~m}, 2 \mathrm{H}), 1.28(\mathrm{~m}, 2 \mathrm{H}), 0.86(\mathrm{t}, J=7.5 \mathrm{~Hz}, 3 \mathrm{H})$. 


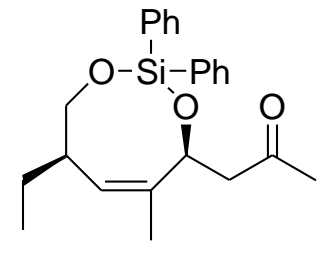

([4S,7R,Z]-7-Ethyl-5-methyl-2,2-diphenyl-7,8-dihydro-4H-

1,3,2-dioxasilocin-4-yl)propan-2-one (180)

Method 1:

A solution of Grubbs' $2^{\text {nd }}$ generation catalyst $(0.02 \mathrm{~g}, 0.02 \mathrm{mmol})$ in dichloromethane $(4.00 \mathrm{~mL})$ was refluxed at $50{ }^{\circ} \mathrm{C}$. A solution of $179(0.11 \mathrm{~g}, 0.27 \mathrm{mmol})$ in dichloromethane $(42.00 \mathrm{~mL})$ was then added at a constant rate of $1.5 \mathrm{~mL} /$ hour over 24 hours. The reaction mixture was stirred for another 24 hours after addition of the diene solution was completed. The reaction mixture was returned to room temperature and concentrated. Flash chromatography (20:1 hexane/ethyl acetate) provided $\mathbf{1 8 0}$ as a white solid (0.03 g, $0.08 \mathrm{mmol}, 30 \%)$.

\section{Method 2:}

A solution of $179(0.30 \mathrm{~g}, 0.73 \mathrm{mmol})$ in dichloromethane $(124.00 \mathrm{~mL})$ was refluxed at $50{ }^{\circ} \mathrm{C}$. A solution of Grubbs' $2^{\text {nd }}$ generation catalyst $(0.07 \mathrm{~g}, 0.08 \mathrm{mmol})$ in dichloromethane $(13.00 \mathrm{~mL})$ was then added as follows; $1 \mathrm{~mL}$ was added initially, then $2 \mathrm{~mL}$ every hour over 6 hours. The reaction mixture was stirred and refluxed overnight after addition of the catalyst solution was completed. The reaction mixture was returned to room temperature and concentrated. Flash chromatography (20:1 hexane/ethyl acetate) provided 180 as a white solid (0.09 g, $0.24 \mathrm{mmol}, 33 \%)$.

$\mathrm{R}_{f} 0.38$ (5:1 hexane/ethyl acetate). $[\alpha]_{\mathrm{D}}^{23}+24\left(\mathrm{C} 3.8, \mathrm{CHCl}_{3}\right) . \mathrm{HRMS}: \mathrm{m} / \mathrm{z}$ $\mathrm{C}_{23} \mathrm{H}_{28} \mathrm{O}_{3} \mathrm{SiNa}^{+}[\mathrm{M}+\mathrm{Na}]^{+}$calcd 403.1705, found 403.1712. ${ }^{1} \mathrm{H}$ NMR (500 MHz, $\left.\mathrm{CDCl}_{3}\right) \delta 7.58(\mathrm{~m}, 4 \mathrm{H}), 7.36(\mathrm{~m}, 6 \mathrm{H}), 5.39(\mathrm{dd}, J=4.7 \mathrm{~Hz}, 9.1 \mathrm{~Hz}, 1 \mathrm{H}), 5.05(\mathrm{dd}, J=$ $1.4 \mathrm{~Hz}, 8.9 \mathrm{~Hz}, 1 \mathrm{H}), 4.08(\mathrm{dd}, J=3.2 \mathrm{~Hz}, 10.6 \mathrm{~Hz}, 1 \mathrm{H}), 3.59(\mathrm{t}, J=10.6 \mathrm{~Hz}, 1 \mathrm{H})$, $3.05(\mathrm{dd}, J=9.1 \mathrm{~Hz}, 15.2 \mathrm{~Hz}, 1 \mathrm{H}), 2.73(\mathrm{~m}, 1 \mathrm{H}), 2.60(\mathrm{dd}, J=4.6 \mathrm{~Hz}, 15.5 \mathrm{~Hz}, 1 \mathrm{H})$, $2.22(\mathrm{~s}, 3 \mathrm{H}), 1.70(\mathrm{~s}, 3 \mathrm{H}), 1.33(\mathrm{~m}, 1 \mathrm{H}), 1.17(\mathrm{~m}, 1 \mathrm{H}), 0.88(\mathrm{t}, J=7.5 \mathrm{~Hz}, 3 \mathrm{H}) .{ }^{13} \mathrm{C}$ NMR (500 MHz, $\left.\mathrm{CDCl}_{3}\right) \delta 207.56,207.13,138.61,134.60,134.43,134.07,130.12$, $130.07,127.93,127.83,70.05,67.64,48.36,42.60,31.20,31.08,24.79,19.25$, 12.07. ${ }^{100}$ 
Side product:

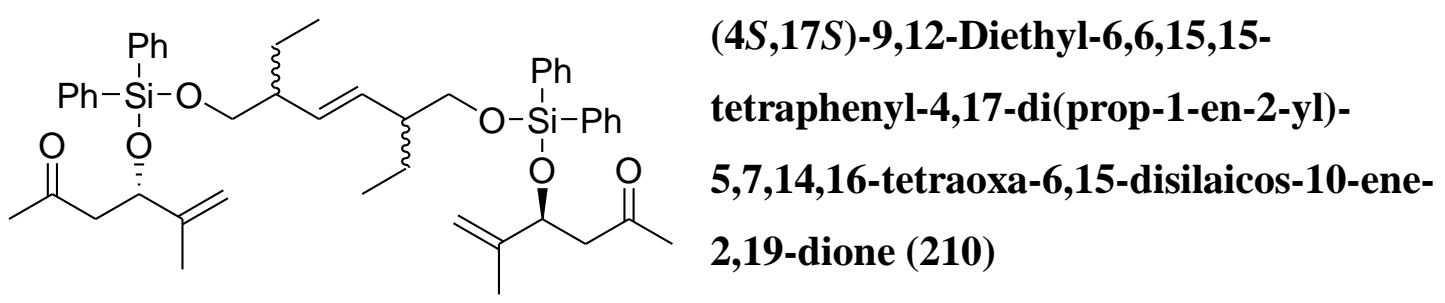

Flash chromatography (20:1 hexane/ethyl acetate) provided $\mathbf{2 1 0}$ as a colourless oil $(0.03 \mathrm{~g}, 0.04 \mathrm{mmol}, 13 \%) . \quad \mathrm{R}_{f} 0.28$ (5:1 hexane/ethyl acetate). HRMS: $\mathrm{m} / \mathrm{z}$ $\mathrm{C}_{48} \mathrm{H}_{60} \mathrm{O}_{6} \mathrm{Si}_{2} \mathrm{Na}^{+}[\mathrm{M}+\mathrm{Na}]^{+}$calcd 811.3826, found 811.3833. ${ }^{1} \mathrm{H}$ NMR (500 MHz, $\left.\mathrm{CDCl}_{3}\right) \delta 7.60(\mathrm{~m}, 8 \mathrm{H}), 7.40(\mathrm{~m}, 4 \mathrm{H}), 7.32(\mathrm{~m}, 8 \mathrm{H}), 5.21(\mathrm{dd}, J=2.5,5.2 \mathrm{~Hz}, 2 \mathrm{H})$, $4.88(\mathrm{~d}, J=8.0 \mathrm{~Hz}, 2 \mathrm{H}), 4.74(\mathrm{~m}, 4 \mathrm{H}), 3.59(\mathrm{~m}, 4 \mathrm{H}), 2.76(\mathrm{~m}, 2 \mathrm{H}), 2.54(\mathrm{~m}, 2 \mathrm{H}), 2.07$ (bs, 2H), $2.04(\mathrm{~d}, J=12.0 \mathrm{~Hz}, 6 \mathrm{H}), 1.68(\mathrm{~d}, J=7.8 \mathrm{~Hz}, 6 \mathrm{H}), 1.62(\mathrm{~m}, 2 \mathrm{H}), 1.21$ (m, 2H), $0.82(\mathrm{~m}, 6 \mathrm{H}) .{ }^{13} \mathrm{C}$ NMR $\left(500 \mathrm{MHz}, \mathrm{CDCl}_{3}\right) \delta 206.69,145.56,139.34,135.19$, 132.72, 127.86, 112.28, 73.41, 66.67, 50.44, 47.10, 31.00, 24.09, 17.52, 11.72.<smiles>C=C(C)[C@H](CC(C)=O)O[Si](OC[C@H](/C=C/c1ccccc1)CC)(c1ccccc1)c1ccccc1</smiles>

\section{$(S, E)-4-([2-E t h y l-4-p h e n y l b u t-3-$} enyloxy]diphenylsilyloxy)-5-methylhex-5-en-2-one (212)

Flash chromatography (20:1 hexane/ethyl acetate) provided 212 as a colourless oil $(3.45 \mathrm{mg}, 0.01 \mathrm{mmol}, 6 \%) . \mathrm{R}_{f} 0.49$ (5:1 hexane/ethyl acetate). ${ }^{1} \mathrm{H}$ NMR $\left(500 \mathrm{MHz}, \mathrm{CDCl}_{3}\right) \delta 7.63(\mathrm{~m}, 4 \mathrm{H}), 7.36(\mathrm{~m}, 10 \mathrm{H}), 7.19$ (t, $J=7.2$ $\mathrm{Hz}, 1 \mathrm{H}), 6.40$ (d, $J=15.8 \mathrm{~Hz}, 1 \mathrm{H}), 6.02(\mathrm{dd}, J=8.7 \mathrm{~Hz}, 16.0 \mathrm{~Hz}, 1 \mathrm{H}), 4.89$ (d, $J=7.9$ $\mathrm{Hz}, 1 \mathrm{H}), 4.77(\mathrm{~m}, 2 \mathrm{H}), 3.72(\mathrm{~d}, J=6.1 \mathrm{~Hz}, 2 \mathrm{H}), 2.78(\mathrm{~m}, 1 \mathrm{H}), 2.54(\mathrm{~m}, 1 \mathrm{H}), 2.32(\mathrm{~m}$, $1 \mathrm{H}), 2.03(\mathrm{~d}, J=13.2 \mathrm{~Hz}, 3 \mathrm{H}), 1.69(\mathrm{~d}, J=6.9 \mathrm{~Hz}, 3 \mathrm{H}), 1.62(\mathrm{dd}, J=6.6 \mathrm{~Hz}, 22.0 \mathrm{~Hz}$, $1 \mathrm{H}), 1.39(\mathrm{~m}, 1 \mathrm{H}), 0.88(\mathrm{t}, J=7.7 \mathrm{~Hz}, 3 \mathrm{H}) .{ }^{13} \mathrm{C} \mathrm{NMR}\left(500 \mathrm{MHz}, \mathrm{CDCl}_{3}\right) \delta 206.73$, 145.56, 137.86, 135.21, 132.17, 131.29, 130.36, 128.58, 127.86, 127.06, 126.14, $112.40,73.45,66.55,50.45,47.48,30.99,24.18,17.48,11.83$.

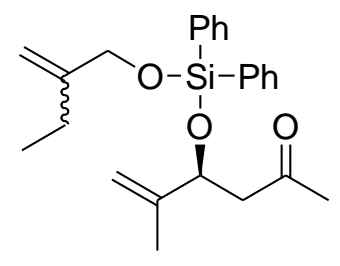

(S)-5-Methyl-4-([2-methylenebutoxy]diphenylsilyloxy)hex-5en-2-one (215)

Flash chromatography (20:1 hexane/ethyl acetate) provided 215 
as a colourless oil $(3.45 \mathrm{mg}, 0.01 \mathrm{mmol}, 6 \%) . \mathrm{R}_{f} 0.49$ (5:1 hexane/ethyl acetate). ${ }^{1} \mathrm{H}$ NMR (500 MHz, $\left.\mathrm{CDCl}_{3}\right) \delta 7.63(\mathrm{~m}, 4 \mathrm{H}), 7.36(\mathrm{~m}, 6 \mathrm{H}), 5.11(\mathrm{~s}, 1 \mathrm{H}), 4.89(\mathrm{~d}, J=7.9$ $\mathrm{Hz}, 1 \mathrm{H}), 4.84$ (s, 1H), 4.77 (m, 2H), 4.19 (s, 2H), 2.78 (m, 1H), 2.54 (m, 1H), 2.03 (d, $J=13.2 \mathrm{~Hz}, 3 \mathrm{H}), 2.03(\mathrm{~m}, 2 \mathrm{H}), 1.69(\mathrm{~d}, J=6.9 \mathrm{~Hz}, 3 \mathrm{H}), 1.01(\mathrm{t}, J=7.4 \mathrm{~Hz}, 3 \mathrm{H}) .{ }^{13} \mathrm{C}$ NMR (500 MHz, $\left.\mathrm{CDCl}_{3}\right) \delta$ 206.73, 149.49, 145.56, 135.21, 132.17, 130.36, 127.86, 112.40, 107.81, 73.45, 65.90, 50.45, 30.99, 25.56, 17.48, 12.27 .

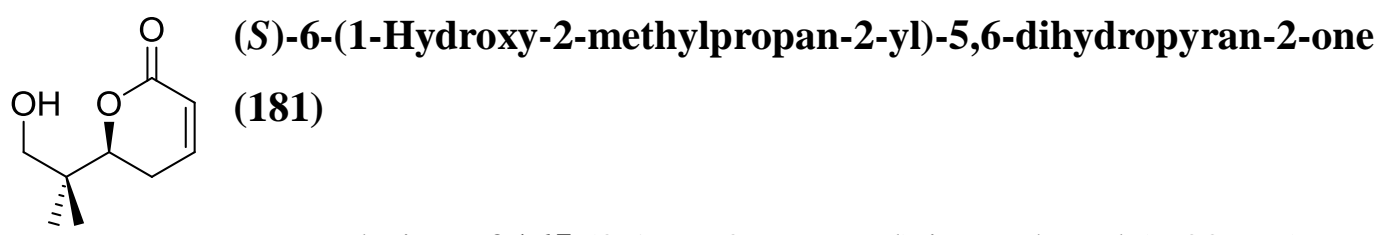

To a solution of $165(0.19 \mathrm{~g}, 0.67 \mathrm{mmol})$ in methanol $(7.00 \mathrm{~mL})$ at room temperature was added, dropwise, $36 \%$ aqueous hydrochloric acid solution $(0.10 \mathrm{~mL})$. The reaction mixture was stirred for 30 minutes. The reaction was quenched with saturated aqueous $\mathrm{NaHCO}_{3}(10 \mathrm{~mL})$. The reaction mixture was extracted with dichloromethane $(3 \times 15 \mathrm{~mL})$. The organic extracts were combined and dried with anhydrous magnesium sulfate, then concentrated. Gradient flash chromatography (3:1 to $1: 1$ hexane/ethyl acetate) provided 181 as a colourless oil $(0.06 \mathrm{~g}, 0.35 \mathrm{mmol}$, $52 \%) . \mathrm{R}_{f} 0.03$ (3:1 hexane/ethyl acetate). IR ( $\left.\mathrm{KBr}, \mathrm{cm}^{-1}\right) v_{\max } 3476.0,2921.0,1701.0$, 1388.0, 1265.0, 1038.0, 914.0, 818.9, 748.7. $[\alpha]_{\mathrm{D}}^{23}-81\left(\mathrm{C} 0.6, \mathrm{CHCl}_{3}\right) . \mathrm{HRMS}: m / z$ $\mathrm{C}_{9} \mathrm{H}_{14} \mathrm{O}_{3} \mathrm{Na}^{+}[\mathrm{M}+\mathrm{Na}]^{+}$calcd 193.0841, found 193.0836. ${ }^{1} \mathrm{H} \mathrm{NMR}\left(500 \mathrm{MHz}, \mathrm{CDCl}_{3}\right)$ $\delta 6.94(\mathrm{~m}, 1 \mathrm{H}), 6.02(\mathrm{~d}, J=9.5 \mathrm{~Hz}, 1 \mathrm{H}), 4.42(\mathrm{dd}, J=3.6 \mathrm{~Hz}, 13.8 \mathrm{~Hz}, 1 \mathrm{H}), 3.66(\mathrm{~d}, J$ $=10.7 \mathrm{~Hz}, 1 \mathrm{H}), 3.45(\mathrm{~d}, J=10.9 \mathrm{~Hz}, 1 \mathrm{H}), 2.46(\mathrm{~m}, 1 \mathrm{H}), 2.31(\mathrm{~m}, 1 \mathrm{H}), 1.00(\mathrm{~s}, 3 \mathrm{H})$, 0.97 (s, 3H). ${ }^{13} \mathrm{C}$ NMR (500 MHz, $\left.\mathrm{CDCl}_{3}\right) \delta 145.57,121.27,81.99$, 69.09, 38.57, $24.60,21.04,19.59$.<smiles>C[C@@H](C=O)C1CC=CC(=O)O1</smiles>

(S)-2-Methyl-2-(6-oxo-3,6-dihydro-2H-pyran-2-yl)propanal (182)

To a solution of $181(0.06 \mathrm{~g}, 0.35 \mathrm{mmol})$ in dichloromethane $(5.20 \mathrm{~mL})$ at room temperature, was added (bisacetoxyiodo)benzene $(0.23 \mathrm{~g}, 0.71$ $\mathrm{mmol})$ and TEMPO (7.00 $\mathrm{mg}, 0.04 \mathrm{mmol})$. The reaction mixture was stirred for 5.5 hours at room temperature. The reaction was quenched with saturated aqueous $\mathrm{Na}_{2} \mathrm{~S}_{2} \mathrm{O}_{3}(10 \mathrm{~mL})$ and stirred at room temperature for 15 minutes. The aqueous and organic layers were separated. The aqueous layer was extracted with dichloromethane 
( $3 \times 10 \mathrm{~mL}$ ). The organic extracts were combined and washed with saturated aqueous $\mathrm{NaHCO}_{3}(10 \mathrm{~mL})$. The organic extract was dried with anhydrous magnesium sulfate and concentrated. Flash chromatography (2:1 hexane/ethyl acetate) provided $\mathbf{1 8 2}$ as a colourless oil (0.04 g, $0.24 \mathrm{mmol}, 69 \%) . \mathrm{R}_{f} 0.35$ (1:1 hexane/ethyl acetate). ${ }^{1} \mathrm{H}$ NMR $\left(500 \mathrm{MHz}, \mathrm{CDCl}_{3}\right) \delta 9.63(\mathrm{~s}, 1 \mathrm{H}), 6.93(\mathrm{~m}, 1 \mathrm{H}), 6.05$ (ddd, $J=1.0 \mathrm{~Hz}, 3.0 \mathrm{~Hz}, 10.0$ $\mathrm{Hz}, 1 \mathrm{H}), 4.58$ (dd, J = 4.7 Hz, $11.9 \mathrm{~Hz}, 1 \mathrm{H}), 2.38$ (m, 2H), 1.23 (s, 3H), 1.19 (s, 3H). ${ }^{13} \mathrm{C}$ NMR $\left(500 \mathrm{MHz}, \mathrm{CDCl}_{3}\right) \delta 203.77,145.16,121.46,80.87,48.924,24.76,18.58$, 18.13<smiles>C=C(C)C[C@H](O)[C@@H](C)CO[R5](F)(F)F</smiles>

\section{1-(tert-Butyldimethylsilyloxy)-2,2,5-trimethylhex-5-en-3-ol} (183)

To a solution of $161(0.13 \mathrm{~g}, 0.60 \mathrm{mmol})$ in tetrahydrofuran $(6.00 \mathrm{~mL})$ at room temperature, was added 3-bromo-2-methylpropene $(0.07 \mathrm{~mL}, 0.09 \mathrm{~g}, 0.89 \mathrm{mmol})$ followed with zinc powder $(0.09 \mathrm{~g}, 1.38 \mathrm{mmol})$. The reaction mixture was stirred and heated at $65{ }^{\circ} \mathrm{C}$ for 20 minutes. Tetrahydrofuran was then distilled off the reaction mixture. The residue was returned to room temperature and dissolved in diethyl ether $(20 \mathrm{~mL})$. The reaction mixture was quenched with saturated aqueous $\mathrm{NH}_{4} \mathrm{Cl}(3 \mathrm{~mL})$ and the precipitate was filtered off. The aqueous and organic layers were separated. The organic layer was washed with saturated aqueous $\mathrm{NH}_{4} \mathrm{Cl}(3 \times 10 \mathrm{~mL})$. The organic extract was dried with anhydrous magnesium sulfate and concentrated. Flash chromatography (20:1 hexane/ethyl acetate) provided $\mathbf{1 8 3}$ as a colourless oil (0.04 g, $0.15 \mathrm{mmol}, 25 \%) . \mathrm{R}_{f} 0.53$ (5:1 hexane/ethyl acetate). ${ }^{1} \mathrm{H}$ NMR (500 MHz, $\left.\mathrm{CDCl}_{3}\right) \delta$ 4.85 (s, 1H), $4.81(\mathrm{~s}, 1 \mathrm{H}), 3.65$ (d, $J=10.7 \mathrm{~Hz}, 1 \mathrm{H}), 3.48$ (d, J=3.9 Hz, 2H), 2.19 (d, $J=14.6 \mathrm{~Hz}, 1 \mathrm{H}), 2.07$ (dd, $J=10.5 \mathrm{~Hz}, 13.7 \mathrm{~Hz}, 1 \mathrm{H}), 1.79$ (s, 3H), 0.91 (s, 3H), 0.90 $(\mathrm{s}, 9 \mathrm{H}), 0.85(\mathrm{~s}, 3 \mathrm{H}), 0.06(\mathrm{~s}, 6 \mathrm{H}) .{ }^{13} \mathrm{C} \mathrm{NMR}\left(500 \mathrm{MHz}, \mathrm{CDCl}_{3}\right) \delta$ 143.99, 112.69, $75.55,72.75,40.60,38.61,25.99,22.45,22.14,19.28,18.32,-5.49,-5.52$.

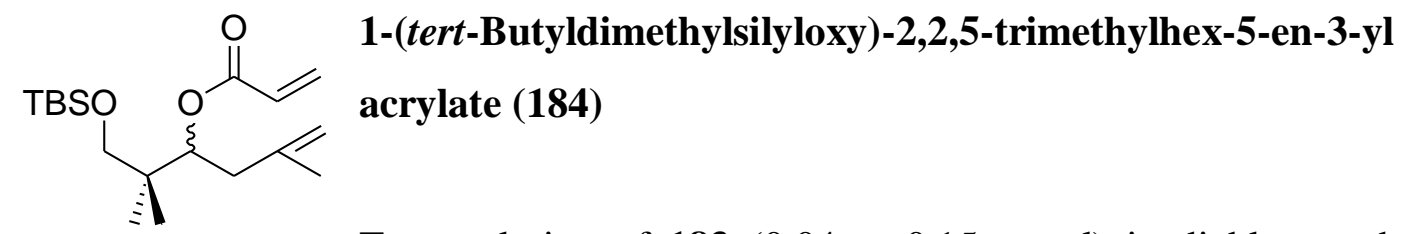

To a solution of $\mathbf{1 8 3}(0.04 \mathrm{~g}, 0.15 \mathrm{mmol})$ in dichloromethane $(0.80 \mathrm{~mL})$ at $0{ }^{\circ} \mathrm{C}$, was added $N, N$-diisopropylethylamine $(0.07 \mathrm{~mL}, 0.05 \mathrm{~g}, 0.40$ mmol), followed with acryloyl chloride $(0.03 \mathrm{~mL}, 0.03 \mathrm{~g}, 0.37 \mathrm{mmol})$. The reaction 
mixture was returned to room temperature and stirred overnight. The reaction was quenched with saturated aqueous $\mathrm{NH}_{4} \mathrm{Cl}(5 \mathrm{~mL})$. The aqueous and organic layers were separated. The aqueous layer was extracted with dichloromethane (3 x $10 \mathrm{~mL})$. The organic extracts were combined and washed with saturated aqueous brine (10 $\mathrm{mL})$. The organic extract was dried with anhydrous magnesium sulfate and concentrated. Flash chromatography (20:1 hexane/ethyl acetate) provided $\mathbf{1 8 4}$ as a colourless oil (0.03 g, $0.09 \mathrm{mmol}, 60 \%) . \mathrm{R}_{f} 0.57$ (10:1 hexane/ethyl acetate). ${ }^{1} \mathrm{H}$ NMR $\left(500 \mathrm{MHz}, \mathrm{CDCl}_{3}\right) \delta 6.35(\mathrm{dd}, J=1.5 \mathrm{~Hz}, 17.3 \mathrm{~Hz}, 1 \mathrm{H}), 6.08(\mathrm{dd}, J=10.5 \mathrm{~Hz}, 17.3$ $\mathrm{Hz}, 1 \mathrm{H}), 5.77$ (dd, $J=1.5 \mathrm{~Hz}, 10.5 \mathrm{~Hz}, 1 \mathrm{H}), 5.21(\mathrm{dd}, J=3.2 \mathrm{~Hz}, 10.0 \mathrm{~Hz}, 1 \mathrm{H}), 4.70$ $(\mathrm{s}, 1 \mathrm{H}), 4.66\left(\mathrm{~s}, 1 \mathrm{H}, \mathrm{H}_{2} \mathrm{C}-\mathrm{C}\left(\mathrm{CH}_{3}\right)=\mathrm{CH}_{2}\right), 3.34(\mathrm{dd}, J=9.6 \mathrm{~Hz}, 33.2 \mathrm{~Hz}, 2 \mathrm{H}), 2.25(\mathrm{~m}$, 2H), 1.76 (s, 3H), $0.92(\mathrm{~s}, 3 \mathrm{H}), 0.90(\mathrm{~s}, 9 \mathrm{H}), 0.88(\mathrm{~s}, 3 \mathrm{H}), 0.02(\mathrm{~s}, 6 \mathrm{H}) .{ }^{13} \mathrm{C}$ NMR $(500$ $\left.\mathrm{MHz}, \mathrm{CDCl}_{3}\right) \delta 165.75,142.67,130.11,129.04,113.33,75.43,69.47,39.70,38.75$, $25.99,22.25,21.48,20.46,18.37,18.36,-5.48,-5.49$.

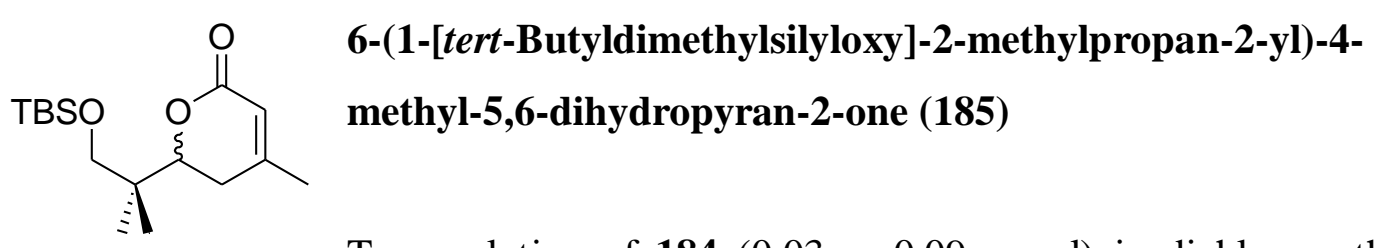

To a solution of $184(0.03 \mathrm{~g}, 0.09 \mathrm{mmol})$ in dichloromethane $(9.00 \mathrm{~mL})$ at room temperature, was added Grubbs' $2^{\text {nd }}$ generation catalyst $(4.00 \mathrm{mg}$, $4.71 \mu \mathrm{mol})$. The reaction mixture was refluxed at $50{ }^{\circ} \mathrm{C}$ for 6 hours. The reaction mixture was then returned to room temperature and concentrated. Flash chromatography (20:1 hexane/ethyl acetate) provided 185 as a colourless oil (0.02 g, $0.07 \mathrm{mmol}, 78 \%) . \mathrm{R}_{f} 0.14$ (10:1 hexane/ethyl acetate). ${ }^{1} \mathrm{H}$ NMR $\left(500 \mathrm{MHz}, \mathrm{CDCl}_{3}\right) \delta$ 5.79 (bs, 1H), 4.30 (dd, $J=3.5 \mathrm{~Hz}, 13.2 \mathrm{~Hz}, 1 \mathrm{H}), 3.53(\mathrm{~d}, J=9.7 \mathrm{~Hz}, 1 \mathrm{H}), 3.36$ (d, $J$ = 9.7 Hz, 1H), $2.45(\mathrm{~m}, 1 \mathrm{H}), 2.09(\mathrm{dd}, J=3.5 \mathrm{~Hz}, 17.9 \mathrm{~Hz}, 1 \mathrm{H}), 1.98$ (s, 3H), 0.97 (s, $3 \mathrm{H}), 0.91(\mathrm{~s}, 3 \mathrm{H}), 0.87$ (s, 9H), $0.03(\mathrm{~s}, 6 \mathrm{H}) .{ }^{13} \mathrm{C} \mathrm{NMR}\left(500 \mathrm{MHz}, \mathrm{CDCl}_{3}\right) \delta 165.85$, $157.95,116.47,80.81,68.68,38.72$, 29.97, 25.98, 23.30, 20.66, 20.13, 18.35, -5.40, 5.46 .

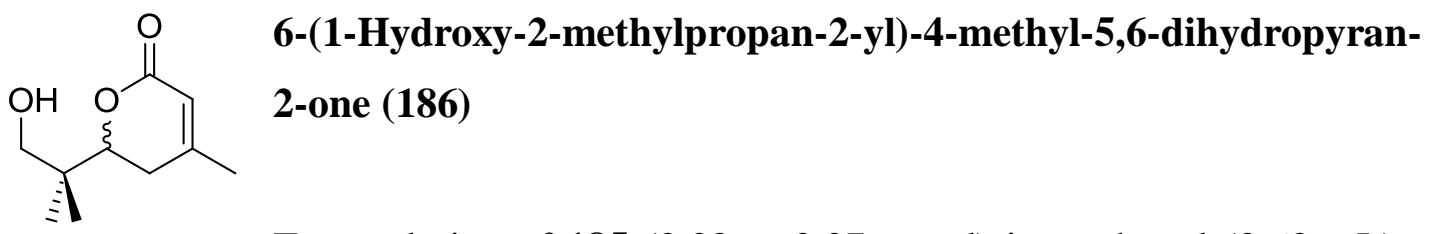

To a solution of $185(0.02 \mathrm{~g}, 0.07 \mathrm{mmol})$ in methanol $(0.60 \mathrm{~mL})$ at room temperature was added, dropwise, $36 \%$ aqueous hydrochloric acid solution 
$(0.01 \mathrm{~mL})$. The reaction mixture was stirred for 30 minutes. The reaction was quenched with saturated aqueous $\mathrm{NaHCO}_{3}(1 \mathrm{~mL})$. The reaction mixture was extracted with dichloromethane $(3 \times 5 \mathrm{~mL})$. The organic extracts were combined and dried with anhydrous magnesium sulfate, then concentrated. Flash chromatography (2:1 hexane/ethyl acetate) provided 186 as a colourless oil $(6.90 \mathrm{mg}, 0.04 \mathrm{mmol}$, $57 \%) . \mathrm{R}_{f} 0.14$ (1:1 hexane/ethyl acetate). IR ( $\left.\mathrm{KBr}, \mathrm{cm}^{-1}\right) v_{\max } 3480.0,2962.0,1695.0$, 1389.0, 1263.0, 1047.0, 757.3. $[\alpha]_{\mathrm{D}}^{23}-73\left(\mathrm{C} 0.1, \mathrm{CHCl}_{3}\right)$. HRMS: $m / z \mathrm{C}_{10} \mathrm{H}_{16} \mathrm{O}_{3} \mathrm{Na}^{+}$ $[\mathrm{M}+\mathrm{Na}]^{+}$calcd 207.0997, found 207.0992. ${ }^{1} \mathrm{H} \mathrm{NMR}\left(500 \mathrm{MHz}, \mathrm{CDCl}_{3}\right) \delta 5.80(\mathrm{bs}$, $1 \mathrm{H}), 4.36(\mathrm{dd}, J=3.4 \mathrm{~Hz}, 13.2 \mathrm{~Hz}, 1 \mathrm{H}), 3.66(\mathrm{~d}, J=10.8 \mathrm{~Hz}, 1 \mathrm{H}), 3.44(\mathrm{~d}, J=11.0$ Hz, 1H), 2.46 (m, 1H), 2.13 (dd, $J=3.6 \mathrm{~Hz}, 17.7 \mathrm{~Hz}, 1 \mathrm{H}), 2.00$ (s, 3H), 0.99 (s, 3H), 0.96 (s, 3H). ${ }^{13} \mathrm{C}$ NMR (500 MHz, $\left.\mathrm{CDCl}_{3}\right) \delta$ 165.57, 158.12, 116.37, 81.33, 69.20, $38.47,29.86,23.33,21.07,19.58$.

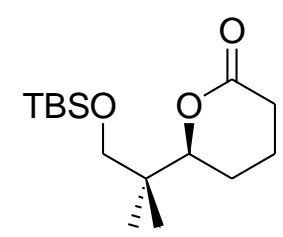

\section{(S)-6-(1-(tert-Butyldimethylsilyloxy)-2-methylpropan-2-yl)-} tetrahydropyran-2-one (187)

To platinum(IV) oxide $(1.80 \mathrm{mg}, 7.93 \mu \mathrm{mol})$ was added a solution of $165(0.02 \mathrm{~g}, 0.07 \mathrm{mmol})$ in ethyl acetate $(2.20 \mathrm{~mL})$ at room temperature. The reaction vessel was purged with hydrogen gas and the reaction mixture was stirred for 4 hours at room temperature. The reaction mixture was filtered through a pad of celite and washed with ethyl acetate. The collected filtrate was concentrated to provide $\mathbf{1 8 7}$ as a colourless oil (17.00 $\mathrm{mg}, 0.05 \mathrm{mmol}, 71 \%)$ and was used without further purification. $\mathrm{R}_{f} 0.27$ (10:1 hexane/ethyl acetate). ${ }^{1} \mathrm{H}$ NMR $\left(500 \mathrm{MHz}, \mathrm{CDCl}_{3}\right) \delta 4.25$ $(\mathrm{dd}, J=2.9 \mathrm{~Hz}, 12.0 \mathrm{~Hz}, 1 \mathrm{H}), 3.51(\mathrm{~d}, J=9.8 \mathrm{~Hz}, 1 \mathrm{H}), 3.32(\mathrm{~d}, J=9.7 \mathrm{~Hz}, 1 \mathrm{H}), 2.35$ (m, 1H), $1.97(\mathrm{~m}, 1 \mathrm{H}), 1.97(\mathrm{~m}, 3 \mathrm{H}), 1.57(\mathrm{~m}, 1 \mathrm{H}), 0.93(\mathrm{~s}, 3 \mathrm{H}), 0.88(\mathrm{~s}, 9 \mathrm{H}), 0.87$ (s, $3 \mathrm{H}), 0.03(\mathrm{~s}, 6 \mathrm{H}) .^{95}$

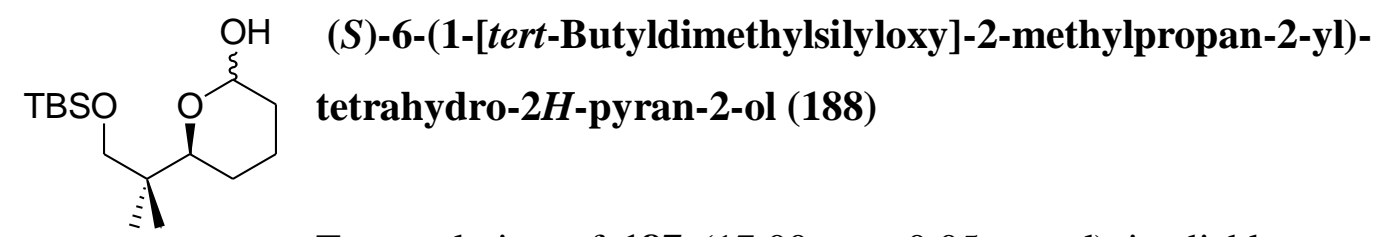

To a solution of $187(17.00 \mathrm{mg}, 0.05 \mathrm{mmol})$ in dichloromethane $(0.84 \mathrm{~mL})$ at $-23{ }^{\circ} \mathrm{C}$, was added diisobutylaluminium hydride $(1.0 \mathrm{M}$ in toluene, 0.07 $\mathrm{mL}, 0.07 \mathrm{mmol}$ ) and the reaction mixture was stirred for 45 minutes. The reaction was 
quenched with methanol $(0.5 \mathrm{~mL})$ and returned to room temperature. A saturated aqueous solution of Rochelle's salt $(5 \mathrm{~mL})$ was added to the reaction mixture. The aqueous and organic layers were separated. The aqueous layer was extracted with dichloromethane $(3 \times 5 \mathrm{~mL})$. The organic extracts were combined and dried with anhydrous magnesium sulfate. Removal of solvent provided $\mathbf{1 8 8}$ as a yellow slurry and was used without further purification. $\mathrm{R}_{f} 0.42$ (10:1 hexane/ethyl acetate). ${ }^{1} \mathrm{H}$ NMR (500 MHz, $\left.\mathrm{CDCl}_{3}\right) \delta 4.67(\mathrm{~m}, 1 \mathrm{H}), 3.85(\mathrm{dd}, J=2.0 \mathrm{~Hz}, 11.7 \mathrm{~Hz}, 1 \mathrm{H}), 3.47$ (d, $J=9.3 \mathrm{~Hz}, 1 \mathrm{H}), 3.26(\mathrm{~d}, J=9.3 \mathrm{~Hz}, 1 \mathrm{H}), 2.64(\mathrm{bs}, 1 \mathrm{H}), 1.90-1.18(\mathrm{~m}, 6 \mathrm{H}), 0.89$ (s, $9 \mathrm{H}), 0.87(\mathrm{~s}, 3 \mathrm{H}), 0.83(\mathrm{~s}, 3 \mathrm{H}), 0.02(\mathrm{~s}, 6 \mathrm{H}){ }^{106}$<smiles>CC(=O)O[C@H]1CCC[C@@H]([C@@H](C)CO[R15](F)(F)F)O1</smiles>

(S)-6-(1-[tert-Butyldimethylsilyloxy]-2-methylpropan-2-yl)tetrahydro-2H-pyran-2-yl acetate (189)

To a solution of $\mathbf{1 8 8}$ (assumed to be $0.05 \mathrm{mmol}$ ) in dichloromethane $(0.50 \mathrm{~mL})$ at room temperature, was added triethylamine $(0.02 \mathrm{~mL}$, $14.52 \mathrm{mg}, 0.14 \mathrm{mmol})$. Acetic anhydride $(0.01 \mathrm{~mL}, 0.01 \mathrm{~g}, 0.11 \mathrm{mmol})$ was added to the reaction mixture, followed with $N, N$-dimethyl-4-aminopyridine $(3.00 \mathrm{mg}, 24.55$ $\mu \mathrm{mol})$. The reaction mixture was stirred overnight at room temperature. The reaction mixture was diluted with dichloromethane $(10 \mathrm{~mL})$ and extracted with saturated aqueous $\mathrm{KHSO}_{4}(5 \mathrm{~mL})$, followed with saturated aqueous $\mathrm{NaHCO}_{3}(5 \mathrm{~mL})$ and saturated aqueous brine $(5 \mathrm{~mL})$. The organic layer was dried with anhydrous magnesium sulfate. Removal of solvent provided 189 as a yellow oil and was used without further purification. $\mathrm{R}_{f} 0.76$ (10:1 hexane/ethyl acetate). ${ }^{1} \mathrm{H}$ NMR (500 MHz, $\left.\mathrm{CDCl}_{3}\right) \delta 5.58(\mathrm{dd}, J=2.1 \mathrm{~Hz}, 9.7 \mathrm{~Hz}, 1 \mathrm{H}), 3.40(\mathrm{~m}, 1 \mathrm{H}), 3.31(\mathrm{~m}, 1 \mathrm{H}), 2.09(\mathrm{~s}, 3 \mathrm{H})$, $1.91(\mathrm{~m}, 1 \mathrm{H}), 1.77(\mathrm{~m}, 1 \mathrm{H}), 1.67(\mathrm{~m}, 1 \mathrm{H}), 1.55(\mathrm{~m}, 1 \mathrm{H}), 1.39(\mathrm{~m}, 1 \mathrm{H}), 1.27(\mathrm{~m}, 1 \mathrm{H})$, $0.89(\mathrm{~s}, 6 \mathrm{H}), 0.88(\mathrm{~s}, 9 \mathrm{H}), 0.01(\mathrm{~s}, 6 \mathrm{H})$.

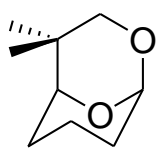

\section{4,4-Dimethyl-2,9-dioxa-bicyclo[3.3.1]nonane (226)}

To a solution of 189 (assumed to be $0.05 \mathrm{mmol}$ ) in acetonitrile $(0.40 \mathrm{~mL})$ at room temperature was added freshly distilled vinyloxy-trimethylsilane $(0.01 \mathrm{~mL}$, $7.79 \mathrm{mg}, 0.70 \mathrm{mmol}$ ), followed with freshly distilled boron trifluoride diethyl etherate $(0.50 \mu \mathrm{L}, 0.58 \mathrm{mg}, 4.09 \mu \mathrm{mol})$. The reaction mixture was stirred for 3.5 hours at room temperature. The reaction was quenched with saturated aqueous $\mathrm{NaHCO}_{3}(5 \mathrm{~mL})$. The 
aqueous and organic layers were separated. The aqueous layer was extracted with dichloromethane $(3 \times 10 \mathrm{~mL})$. The organic extracts were combined and dried with anhydrous magnesium sulfate, then concentrated to provided $\mathbf{2 2 6}$ as a crude product (9.00 mg, $0.06 \mathrm{mmol}, 26 \%) . \mathrm{R}_{f} 0.24$ (10:1 hexane/ethyl acetate). ${ }^{1} \mathrm{H}$ NMR (500 MHz, $\left.\mathrm{CDCl}_{3}\right) \delta 5.30(\mathrm{~s}, 1 \mathrm{H}), 4.05(\mathrm{~m}, 1 \mathrm{H}), 3.53-3.32(\mathrm{~m}, 2 \mathrm{H}), 2.05-1.25(\mathrm{~m}, 6 \mathrm{H}), 0.92(\mathrm{~s}$, $3 \mathrm{H}), 0.88(\mathrm{~s}, 3 \mathrm{H})$.

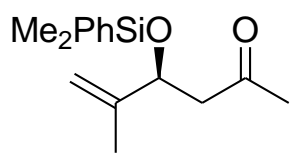

(S)-4-(Dimethyl[phenyl]silyloxy)-5-methylhex-5-en-2-one (190)

To a solution of $177(0.11 \mathrm{~g}, 0.86 \mathrm{~mol})$ in $N, N$-dimethylformamide $(0.30 \mathrm{~mL})$ at $0 \quad{ }^{\circ} \mathrm{C}$, was added imidazole $(0.12 \mathrm{~g}, \quad 1.76 \mathrm{mmol})$ and chloro(dimethyl)phenylsilane $(0.16 \mathrm{~mL}, 0.16 \mathrm{~g}, 0.95 \mathrm{mmol})$. The reaction mixture was returned to room temperature and stirred overnight. The reaction was diluted with diethyl ether $(5 \mathrm{~mL})$ and extracted with saturated aqueous $\mathrm{NaHCO}_{3}(3 \times 3 \mathrm{~mL})$, followed with distilled water $(2 \times 3 \mathrm{~mL})$. The organic extract was dried with anhydrous magnesium sulfate and concentrated. Flash chromatography (5:1 hexane/ethyl acetate) provided 190 as a colourless oil $(0.16 \mathrm{~g}, 0.61 \mathrm{mmol}, 71 \%) . \mathrm{R}_{f}$ 0.33 (5:1 hexane/ethyl acetate). IR $\left(\mathrm{KBr}, \mathrm{cm}^{-1}\right) v_{\max } 3418.0,2960.0,1717.0,1429.0$, 897.3, 833.4. $[\alpha]_{\text {D }}^{23}-26\left(\mathrm{C} 0.2, \mathrm{CHCl}_{3}\right)$. HRMS: $m / z \mathrm{C}_{15} \mathrm{H}_{22} \mathrm{O}_{2} \mathrm{SiNa}^{+}[\mathrm{M}+\mathrm{Na}]^{+}$calcd 285.1287, found 285.1291. ${ }^{1} \mathrm{H}$ NMR $\left(500 \mathrm{MHz}, \mathrm{CDCl}_{3}\right) \delta 7.55(\mathrm{dd}, J=1.6 \mathrm{~Hz}, 7.5$ $\mathrm{Hz}, 2 \mathrm{H}), 7.37$ (m, 3H), 4.91 (s, 1H), 4.77 (s, 1H), 4.57 (dd, J=4.1 Hz, 8.65 Hz, 1H), $2.74(\mathrm{dd}, J=8.8 \mathrm{~Hz}, 14.9 \mathrm{~Hz}, 1 \mathrm{H}), 2.42(\mathrm{dd}, J=3.8 \mathrm{~Hz}, 15.0 \mathrm{~Hz}, 1 \mathrm{H}), 2.10$ (s, 3H) $1.67(\mathrm{~s}, 3 \mathrm{H}), 0.36$ (s, 3H), 0.35 (s, 3H). $\left.{ }^{13} \mathrm{C} \mathrm{NMR} \mathrm{(500} \mathrm{MHz,} \mathrm{CDCl}_{3}\right) \delta$ 207.45, $146.49,137.84,133.67,129.73,127.86,111.79$, 73.60, 50.38, 31.55, 17.53, -1.18, 1.48 .

\section{Representative procedure for 1,5-anti aldol reaction:}

To a solution of ketone $\mathbf{1 8 0}$ (1.5 equivalent) in anhydrous diethyl ether $(10 \mathrm{~mL} / \mathrm{mmol})$ at $-78{ }^{\circ} \mathrm{C}$, was added triethylamine (4.0 equivalent), followed by dibutylboryl trifluoromethanesulfonate (1.0 $\mathrm{M}$ in dichloromethane, 2.0 equivalent). The reaction mixture was stirred for 45 minutes and a solution of aldehyde (1.0 equivalent) in anhydrous diethyl ether $(5 \mathrm{~mL} / \mathrm{mmol})$ was added. The reaction mixture was warmed 
to $-18{ }^{\circ} \mathrm{C}$ and reacted overnight. Silica gel was added, the reaction mixture was warmed to $0{ }^{\circ} \mathrm{C}$ and stirred for 45 minutes. The reaction mixture was filtered and rinsed with diethyl ether. The solvent was removed under reduced pressure and the residue was purified by gradient flash chromatography.

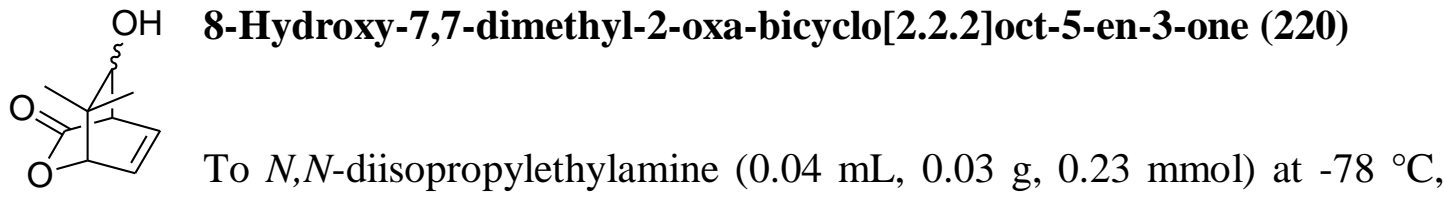
was added dibutylboryl trifluoromethanesulfonate $(1.0 \mathrm{M}$ in dichloromethane, 0.48 $\mathrm{mL}, 0.48 \mathrm{mmol})$. The reaction mixture was stirred for 45 minutes and a solution of $182(0.02 \mathrm{~g}, 0.12 \mathrm{mmol})$ in anhydrous diethyl ether $(1.20 \mathrm{~mL})$ was added. The reaction mixture was warmed to $-18{ }^{\circ} \mathrm{C}$ and reacted overnight. Silica gel was added, the reaction mixture was warmed to $0{ }^{\circ} \mathrm{C}$ and stirred for 45 minutes. The reaction mixture was filtered and rinsed with diethyl ether $(3 \times 5 \mathrm{~mL})$ and the solvent removed under reduced pressure. Gradient flash chromatography (2:1 hexane/ethyl acetate to neat ethyl acetate) provided 220 as a colourless oil (3.00 mg, $0.02 \mathrm{mmol}, 17 \%) . \mathbf{R}_{f}$ 0.19 (1:1 hexane/ethyl acetate). ${ }^{1} \mathrm{H}$ NMR $\left(500 \mathrm{MHz}, \mathrm{CDCl}_{3}\right) \delta 6.68(\mathrm{~m}, 1 \mathrm{H}), 6.51(\mathrm{~m}$, $1 \mathrm{H}), 6.40(\mathrm{~m}, 2 \mathrm{H}), 4.63(\mathrm{~m}, 2 \mathrm{H}), 3.85(\mathrm{~s}, 1 \mathrm{H}), 3.72(\mathrm{~m}, 1 \mathrm{H}), 3.65(\mathrm{~s}, 1 \mathrm{H}), 3.54(\mathrm{~m}$, $1 \mathrm{H}), 1.21(\mathrm{~s}, 3 \mathrm{H}), 1.20(\mathrm{~s}, 3 \mathrm{H}), 1.03(\mathrm{~s}, 3 \mathrm{H}), 0.97(\mathrm{~s}, 3 \mathrm{H}),{ }^{13} \mathrm{C}$ NMR $(500 \mathrm{MHz}$, $\left.\mathrm{CDCl}_{3}\right) \delta 172.00,172.00,133.63,133.43,128.53,129.02,83.37,82.91,73.95,72.86$, $51.35,50.69,39.65,41.97,28.65,26.97,21.13,21.58$.<smiles>CC(=O)C[C@H](O)[C@@H](C)[C@H]1CC=CC(=O)O1</smiles>

\section{(S)-6-(3-Hydroxy-2-methyl-5-oxohexan-2-yl)-5,6-} dihydropyran-2-one (221)

To $N, N$-diisopropylethylamine $(0.04 \mathrm{~mL}, 0.03 \mathrm{~g}, 0.23 \mathrm{mmol})$ at $78{ }^{\circ} \mathrm{C}$, was added dibutylboryl trifluoromethanesulfonate (1.0 $\mathrm{M}$ in dichloromethane, $0.24 \mathrm{~mL}, 0.24 \mathrm{mmol})$. The reaction mixture was stirred for 45 minutes and a solution of $182(0.02 \mathrm{~g}, 0.12 \mathrm{mmol})$ in anhydrous diethyl ether $(1.20 \mathrm{~mL})$ was added. The reaction mixture was warmed to $-18{ }^{\circ} \mathrm{C}$ and reacted overnight. Silica gel was added, the reaction mixture was warmed to $0{ }^{\circ} \mathrm{C}$ and stirred for 45 minutes. The reaction mixture was filtered and rinsed with diethyl ether $(3 \times 5 \mathrm{~mL})$ and the solvent removed under reduced pressure. Gradient flash chromatography (2:1 hexane/ethyl acetate to 
neat ethyl acetate) provided 221 as a colourless oil ( $0.01 \mathrm{~g}, 0.03 \mathrm{mmol}, 26 \%)$. Rf 0.09 (1:1 hexane/ethyl acetate). HRMS: $m / z \mathrm{C}_{12} \mathrm{H}_{18} \mathrm{O}_{4} \mathrm{Na}^{+}\left[\mathrm{M}^{+} \mathrm{Na}\right]^{+}$calcd 249.1103, found 249.1106. ${ }^{1} \mathrm{H}$ NMR $\left(500 \mathrm{MHz}, \mathrm{CDCl}_{3}\right) \delta 6.92(\mathrm{~m}, 2 \mathrm{H}), 6.01(\mathrm{~m}, 2 \mathrm{H}), 4.65(\mathrm{dd}, J=$ $3.7 \mathrm{~Hz}, 12.5 \mathrm{~Hz}, 1 \mathrm{H}), 4.50(\mathrm{dd}, J=6.5 \mathrm{~Hz}, 10.0 \mathrm{~Hz}, 1 \mathrm{H}), 4.28(\mathrm{dd}, J=2.0 \mathrm{~Hz}, 10.2$ $\mathrm{Hz}, 1 \mathrm{H}), 3.97(\mathrm{dd}, J=2.0 \mathrm{~Hz}, 9.9 \mathrm{~Hz}, 1 \mathrm{H}), 2.65(\mathrm{~m}, 4 \mathrm{H}), 2.44(\mathrm{~m}, 4 \mathrm{H}), 2.22(\mathrm{~m}, 6 \mathrm{H})$, $1.06(\mathrm{~s}, 3 \mathrm{H}), 0.94(\mathrm{~s}, 6 \mathrm{H}), 0.89$ (s, 3H). ${ }^{13} \mathrm{C} \mathrm{NMR}(500 \mathrm{MHz}, \mathrm{CDCl} 3) \delta 210.86$, 210.00, 164.90, 164.66, 146.09, 145.90, 121.33, 121.19, 81.93, 80.85, 71.59, 69.85, 44.93, 44.75, 40.31, 40.20, 31.09, 31.04, 24.72, 24.68, 20.15, 18.94, 18.48, 17.97.

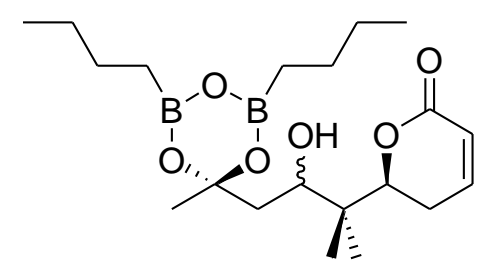

\section{(S)-6-(4-[2,4-Dibutyl-6-methyl-1,3,5,2,4-}

trioxadiborinan-6-yl]-3-hydroxy-2-methylbutan-2yl)-5,6-dihydropyran-2-one (222)

To $N, N$-diisopropylethylamine $(0.04 \mathrm{~mL}, 0.03 \mathrm{~g}, 0.23 \mathrm{mmol})$ at $-78{ }^{\circ} \mathrm{C}$, was added dibutylboryl trifluoromethanesulfonate $(1.0 \mathrm{M}$ in dichloromethane, $0.24 \mathrm{~mL}, 0.24$ $\mathrm{mmol})$. The reaction mixture was stirred for 45 minutes and a solution of $\mathbf{1 8 2}(0.02 \mathrm{~g}$, $0.12 \mathrm{mmol})$ in anhydrous diethyl ether $(1.20 \mathrm{~mL})$ was added. The reaction mixture was warmed to $-18{ }^{\circ} \mathrm{C}$ and reacted overnight. Silica gel was added, the reaction mixture was warmed to $0{ }^{\circ} \mathrm{C}$ and stirred for 45 minutes. The reaction mixture was filtered and rinsed with diethyl ether $(3 \times 5 \mathrm{~mL})$ and the solvent removed under reduced pressure. Gradient flash chromatography (2:1 hexane/ethyl acetate to neat ethyl acetate) provided 222 as a colourless oil (2.00 mg, $5.07 \mu \mathrm{mol}, 4 \%) . \mathrm{R}_{f} 0.33$ (1:1 hexane/ethyl acetate). HRMS: $m / z, \mathrm{C}_{20} \mathrm{H}_{36} \mathrm{O}_{6} \mathrm{~B}_{2} \mathrm{Na}^{+}\left[\mathrm{M}^{+} \mathrm{Na}\right]^{+}$calcd 418.1889 , found 417.1893. ${ }^{1} \mathrm{H}$ NMR (500 MHz, $\left.\mathrm{CDCl}_{3}\right) \delta 6.94(\mathrm{~m}, 1 \mathrm{H}), 6.04(\mathrm{~d}, J=9.8 \mathrm{~Hz}, 1 \mathrm{H}), 4.48$ $(\mathrm{dd}, J=3.6 \mathrm{~Hz}, 12.8 \mathrm{~Hz}, 1 \mathrm{H}), 4.33(\mathrm{dd}, J=2.7 \mathrm{~Hz}, 11.8 \mathrm{~Hz}, 1 \mathrm{H}), 1.86(\mathrm{dd}, J=2.8 \mathrm{~Hz}$, $13.5 \mathrm{~Hz}, 1 \mathrm{H}), 1.72$ (dd, $J=12.3 \mathrm{~Hz}, 13.4 \mathrm{~Hz}, 1 \mathrm{H}), 1.28(\mathrm{~m}, 8 \mathrm{H}), 3.49$ (bs, 3H), 2.53 $(\mathrm{m}, 1 \mathrm{H}), 2.43(\mathrm{~m}, 1 \mathrm{H}), 1.05(\mathrm{~s}, 3 \mathrm{H}), 0.96(\mathrm{~s}, 3 \mathrm{H}), 0.86(\mathrm{t}, J=7.1 \mathrm{~Hz}, 6 \mathrm{H}), 0.69$ (t, $J=$ $7.3 \mathrm{~Hz}, 4 \mathrm{H}) .{ }^{13} \mathrm{C} \mathrm{NMR}\left(500 \mathrm{MHz}, \mathrm{CDCl}_{3}\right) \delta 164.87,145.93,121.15,91.45,82.16$, $70.00,39.95,37.65,26.06,25.21,24.69,19.36,18.14,14.01,13.88$. 


\section{References}

1. Faguet, G. B. The War on Cancer: An Anatomy of Failure, A Blueprint for the Future; Springer, 2005.

2. Kachroo, S.; Etzel, C. J. European Journal of Cancer Care 2009, 18, 18-21.

3. Rehman, M. U.; Buttar, Q. M.; Khawaja, M. I. et al. Asian Pacific J. Cancer Prev. 2009, 10, 719-720.

4. Mann, J. The Elusive Magic Bullet: The Search for the Perfect Drug; Oxford University Press, 1999.

5. McAfee, A. J.; McSorley, E. M.; Cuskelly, G. J. et al. Meat Science 2010, 84, $1-13$.

6. Jemal, A.; Thun, M. J.; Ries, L. A. G. et al. J. Natl. Cancer Inst. 2008, 100, 1672-1694.

7. Karim-Kos, H. E.; de Vries, E.; Soerjomataram I. et al. Eur. J. Cancer 2008, $44,1345-1389$.

8. King, R. J. B.; Robins, M. W. Cancer Biology, $3^{\text {rd }}$ ed.; Pearson Education Limited, 2006.

9. Chemin, I; Zoulim, F. Cancer Letters 2009, 286, 52-59.

10. Greaves, M. Cancer: The Evolutionary Legacy; Oxford University Press, 2000.

11. Newman, D. J.; Cragg, G. M. J. Nat. Prod. 2004, 67, 1216-1238.

12. Cragg, G. M.; Grothaus, P. G.; Newman, D. J. Chem. Rev. 2009, 109, 30123043.

13. Kluza, J.; Arimondo, P. B.; Bailly, C. et al. In Cancer Drug Design and Discovery; Neidle, S. Ed.; Elsevier Inc, 2008, pp 173-197.

14. Kristensen, L. S.; Nielsen, H. M.; Hansen, L. L. Eur. J. Pharmacol. 2009, 625, 131-142.

15. Cheever, M. A. Immunological Reviews 2008, 222, 357-368.

16. Raven, P. H.; Johnson, G. B. Biology, $6^{\text {th }}$ ed.; McGraw-Hill, 2002.

17. Russell, P. J. Genetics, $5^{\text {th }}$ ed.; The Benjamin/Cummings Publishing Company Inc, 1998.

18. Wade, R. H.; Hyman, A. A. Current Opinion in Cell Biology 1997, 9, 12-17.

19. Sept, D. Current Biology 2007, 17, R764-R766. 
20. Waterman-Storer, C. M. Salmon, E. D. Current Biology 1997, 7, R369-R372.

21. Cole, N. B.; Lippincott-Schwartz, J. Current Opinion in Cell Biology 1995, 7, $55-64$.

22. Kingston, D. G. I. J. Nat. Prod. 2009, 72, 507-515.

23. Arnal, I.; Wade, R. H. Current Biology 1995, 5, 900-908.

24. Jordan, M. A; Wilson, L. Nature Reviews 2004, 4, 253-265.

25. Wani, M. C.; Taylor, H. L.; Wall, M. E. et al. J. Am. Chem. Soc. 1971, 93, 2325-2327.

26. Schiff, P.B.; Fant, J.; Horwitz, S. B. Nature 1979, 277, 665-667.

27. Holton, R. A.; Somoza, C.; Kim, H-B. et al. J. Am. Chem. Soc. 1994, 116, 1597-1598.

28. Holton, R. A.; Somoza, C.; Kim, H-B. et al. J. Am. Chem. Soc. 1994, 116, 1599-1600.

29. Geunard, D.; Gueritte-Voegelein, F.; Potier, P. Acc. Chem. Res. 1993, 26, $160-$ 167.

30. Höfle, G.; Bedorf, N.; Steinmetz, H. et al. Angew. Chem. Int. Ed. Engl. 1996, $35,1567-1569$.

31. Gallagher Jr., B. M. Curr. Med. Chem. 1997, 14, 2959-2967.

32. Zhan, W.; Jiang, Y.; Brodie, P. J. et al. Org. Lett. 2008, 10, 1565-1568.

33. Chen, K.; Huzil, J. T.; Freedan, H. et al. Journal of Molecular Graphics and Modelling 2008, 27, 497-505.

34. Zhou, J.; Ginnakakou, P. Curr. Med. Chem. - Anti-Cancer Agents 2005, 5, 6571.

35. Pettit, G. R.; Singh, S. B.; Hamel, E. et al. Experientia 1989, 45, $209-211$.

36. Gunasekera, S. P.; Gunasekera, M.; Longley, R. E. et al. J. Org. Chem. 1990, $55,4912-4915$.

37. Molinski, T. F.; Dalisay, D. S.; Lievens, S. L. et al. Nature Review: Drug Discovery 2009, 8, 69-85.

38. Mayer, A. M. S.; Gustafson, K. R. Eur. J. Cancer 2008, 44, 2357-2387.

39. Uemura, D.; Takahashi, K.; Yamamoto, T. et al. J. Am. Chem. Soc. 1985, 107, 4796-4798.

40. Tanaka, J.; Higa, T. Tetrahedron Lett. 1996, 37, 5535-5538.

41. Field, J. J.; Singh, A. J.; Kanakkanthara, A. et al. J. Med. Chem. 2009, 52, 7328-7332. 
42. West, L. M.; Northcote, P. T. J. Org. Chem. 2000, 65, 445-449.

43. Hood, K. A.; West, L. M.; Rouwé, B. et al. Cancer Res. 2002, 62, 3356-3360.

44. Singh, A. J; Xu, C-X.; Xu, X. et al. J. Org. Chem. 2010, 75, 2-10.

45. Gulab, S. A. An Aldol Approach towards the Synthesis of Peloruside A and Analogues Thereof. Ph.D. Thesis, Victoria University of Wellington, New Zealand, 2007.

46. Gaitanos, T. N; Buey, R. M.; Díaz, J. F. et al. Cancer Res. 2004, 64, 50635067.

47. Hamel, E.; Day, B. W.; Miller, J. H. et al. Mol. Pharmacol. 2006, 70, 15551564.

48. Wilmes, A.; Bargh, K.; Kelly, C. et al. Molecular Pharmaceutics 2006, 4, 269-280.

49. Page, M. J.; Northcote, P. T.; Webb, V. L. et al. Aquaculture 2005, 250, 256269.

50. Page, M.; West, L.; Northcote, P. et al. J. Chem. Ecol. 2005, 31, 1161-1174.

51. Liao, X.; Wu, Y.; De Brabander, J. K. Angew. Chem. Int. Ed. 2003, 42, 16481652.

52. Jin, M.; Taylor, R. E. Org. Lett. 2005, 7, 1303-1305.

53. Ghosh, A. K.; Xu, X.; Kim, J-H et al. Org. Lett. 2008, 10, 1001-1004.

54. Evans, D.A.; Welch, D. S.; Speed, A. W. H. et al. J. Am. Chem. Soc. 2009, 131, 3840-3841.

55. Floreancig, P. E. Angew. Chem. Int. Ed. 2009, 48, 7736-7739.

56. Yeung, K-S.; Paterson, I. Chem. Rev. 2005, 105, 4237-4313.

57. Smith III, A. B.; Cox, J. M.; Furuichi, N. et al. Org. Lett. 2008, 10, 5501-5504.

58. Wullschleger, C. W.; Gertsch, J.; Altmann, K-H. Org. Lett. 2010, 12, 11201123.

59. Xu, Z.; Johannes, C. W.; Houri, A. F. et al. J. Am. Chem. Soc. 1997, 119, $10302-10316$.

60. Jin, M.; Taylor, R. E. Org. Lett. 2003, 5, 4959-4961.

61. Ghosh, A. K.; Kim, J-H. Tetrahedron Lett. 2003, 44, 7659-7661.

62. Ihara, M.; Katsumata, A.; Setsu, F. et al. J. Org. Chem. 1996, 61, 677-684.

63. Quinoa, E.; Kakou, Y.; Crew, P. J. Org. Chem. 1988, 53, 3642-3644.

64. Corley, D. G.; Herb, R.; Moore, R. E. et al. J. Org. Chem. 1988, 53, 36443646. 
65. Cutignano, A.; Bruno, I.; Bifulco, G. et al. Eur. J. Org. Chem. 2001, 4, 775778.

66. Tanaka, J.; Higa, T.; Bernardinelli, G. et al. Chem. Lett. 1996, 25, 255-256.

67. Mulzer, J.; Öhler, E. Chem. Rev. 2003, 103, 3753-3786.

68. Gollner, A.; Altmann, K-H.; Gertsch, J. et al. Chem. Eur. J. 2009, 15, 59795997.

69. Mooberry, S. L; Tien, G.; Hernandez, A. H. et al. Cancer Res. 1999, 59, 653660.

70. Paterson, I.; Menche, D.; Håkansson, A. E. et al. Bioorg. Med. Chem. Lett. 2005, 15, 2243-2247.

71. Ghosh, A. K.; Wang, Y. J. Am. Chem. Soc. 2000, 122, 11027-11028.

72. Ghosh, A. K.; Wang, Y. Tetrahedron Lett. 2001, 42, 3399-3401.

73. Ghosh, A.K.; Wang, T.; Kim, J. T. J. Org. Chem. 2001, 66, 8973-8982.

74. Mulzer, J.; Öhler, E. Angew. Chem. Int. Ed. 2001, 40, 3842-3846.

75. Enev, V. S.; Kaehlig, H.; Mulzer, J. J. Am. Chem. Soc. 2001, 123, 1076410765 .

76. Mulzer, J.; Öhler, E.; Enev, V. S. et al. Adv. Synth. Catal. 2002, 344, 573-584.

77. Mulzer, J.; Hanbauer, M. Tetrahedron Lett. 2002, 43, 3381-3383.

78. Nelson, S. G.; Cheung, W. S.; Kassick, A. J. et al. J. Am. Chem. Soc. 2002, $124,13654-13655$.

79. Pitts, M. R.; Mulzer, J. Tetrahedron Lett. 2002, 43, 8471-8473.

80. Ahmed, A.; Hoegenauer, E. K.; Enev, V. S. et al. J. Org. Chem. 2003, 68, 3026-3042.

81. Paterson, I.; De Savi, C.; Tudge, M. Org. Lett. 2001, 3, 3149-3152.

82. Wender, P. A.; Hegde, S. G.; Hubbard, R. D. et al. J. Am. Chem. Soc. 2002, $124,4956-4957$.

83. Williams, D. R.; Mi. L.; Mullins, R. J. et al. Tetrahedron Lett. 2002, 43, 48414844.

84. Crimmins, M. T.; Stanton, M. G.; Allwein, S. P. J. Am. Chem. Soc. 2002, 124, 5958-5959.

85. Uenishi, J.; Ohmi, M. Angew. Chem. Int. Ed. 2005, 44, 2756-2760.

86. Trost, B. M.; Amans, D.; Seganish, W. M. et al. J. Am. Chem. Soc. 2009, 131, 17087-17089. 
87. Ahmed, A.; Hoegenauer, E. K.; Enev, V. S. et al. J. Org. Chem. 2003, 68, 3026-3042.

88. Wender, P. A.; Hegde, S. G.; Hubbard, R. D. et al. Org. Lett. 2003, 5, 35073509.

89. Mooberry, S. L.; Randall-Hlubek, D. A.; Leal, R. M. et al. Proc. Natl. Acad. Sci. U.S.A. 2004, 101, 8803-8808.

90. Mooberry, S. L.; Hilinski, M. K.; Clark, E. A. et al. Molecular Pharmaceutics 2008, 5, 829-838.

91. Gollner, A.; Altmann, K-H.; Gertsch, J. et al. Tetrahedron Lett. 2009, 50, 5790-5792.

92. Pineda, O.; Farràs, J.; Maccari, L. et al. Bioorg. Med. Chem. Lett. 2004, 14, 4825-4829.

93. Huzil, J. T.; Chik, J. K.; Slysz, G. W. et al. J. Mol. Bio. 2008, 378, 1016-1030.

94. Jiménez-Barbero, J.; Canales, A.; Northcote, P. T. et al. J. Am. Chem. Soc. 2006, $128,8757-8765$.

95. Ferrié, L.; Boulard, L.; Pradaux, F. et al. J. Org. Chem. 2008, 73, 1864-1880.

96. Kolb, H. C.; VanNieuwenhze, M. S.; Sharpless, K. B. Chem. Rev. 1994, 94, 2483-2547.

97. Zanardi, F.; Battistini, L.; Nespi, M. et al. Tetrahedron: Assymmetry 1996, 7, 1167-1180.

98. Khalaf, J. K.; Datta, A. J. Org. Chem. 2005, 70, 6937-6940.

99. Jadhav, P. K.; Bhat, K. S.; Perumal, P. T. et al. J. Org. Chem. 1986, 51, 432439.

100. Turner, E. M. Design and Synthesis of Hybrid Peloruside A - Laulimalide Analogues. Ph.D. Thesis, Victoria University of Wellington, New Zealand, 2007.

101. Casey, E. M.; Teesdale-Spittle, P.; Harvey, J. E. Tetrahedron Lett. 2008, 49, 7021-7023.

102. Stocker, B. L.; Teesdale-Spittle, P.; Hoberg, J. O. Eur. J. Org. Chem. 2004, 2, 330-336.

103. Gage, J. R.; Evans, D. A. Organic Syntheses, Coll. 1993, 8, 339-342.

104. Brown, H.C.; Bhat, K.S.; Randad, R.S. (1987) Am. Chem. Soc. 1987, 52, 3701-3704.

105. Dale, J.A.; Mosher, H.S. J. Am. Chem. Soc. 1972, 95, 512-518. 
106. Dias, L. C.; Meira P. R. R. J. Org. Chem. 2005, 70, 4762-4773.

107. Ward, D. E.; Rhee, C. K. Tetrahedron Lett. 1991, 32, 7165-7166.

108. Paterson, I.; Goodman, J. M.; Lister, M. A. et al. Tetrahedron 1990, 46, 46634684.

109. Morken, J. P.; Didiuk, M. T., Hoveyda, A. H. J. Am. Chem. Soc. 1993, 115, 6997-6998.

110. Visser, M. S.; Heron, N. M.; Didiuk, M. T. et al. J. Am. Chem. Soc. 1996, 118, 4291-4298.

111. Hanessian, S.; Giroux, S., Larsson, A. Org. Lett. 2006, 8, 5481-5484.

112. Courchay, F. C.; Baughmann, T. W.; Wagener, K. B. J. Organomet. Chem. 2006, 691, 585-594.

113. Kanomata, N.; Maruyama, S.; Tomono, K. et al. Tetrahedron Lett. 2003, 44, 3599-3603.

114. Mojtahedi, M. M.; Akbarzadeh, E.; Sharifi, R. et al. Org. Lett. 2007, 9, 27912793.

115. Abaee, M. S.; Sharifi, R.; Mojtahedi, M. M. Org. Lett. 2005, 7, 5893-5895.

116. Cannizzaro, S. Justus Liebigs Annalen der Chemie 1953, 88, 129-130.

117. Posner, G. H.; Dai, H.; Afarinkia, K. et al. J. Org. Chem. 1993, 58, 7209-7215.

118. Posner, G. H.; Nelson, T. D.; Kinter, C. M. et al. Tetrahedron Lett. 1991, 32, 5295-5298.

119. Taschner, M. J.; Peddada, L. J. Chem. Soc., Chem. Commun. 1992, 19, 13841385 .

120. Kobayashi, Y.; Tan, C-H.; Kishi. Y. Helv. Chim. Acta 2000, 83, 2562-2570.

121. Northcote, P. Personal communication, 2010.

122. Anteunis, M.; Swaelens, G.; Gelan, J. Tetrahedron 1971, 27, 1917-1929.

123. Aiguade, J.; Hao, J.; Forsyth, C. J. Org. Lett. 2001, 3, 979-982.

124. Astashko, D. A.; Kulinkovich, O. G.; Tyvorskii, V. I. Russ. J. Org. Chem. 2006, 42, 719-723.

125. Hoberg, J.O.; Cousins, G. S. Chem. Soc. Rev. 2000, 29, 165-174.

126. Batchelor, R. A. Ring Expansions of Cyclopropanated Carbohydrates. Ph.D. Thesis, Victoria University of Wellington, New Zealand, 2008. 